\title{
DNA barcoding reveals unprecedented diversity in Dancing Frogs of India (Micrixalidae, Micrixalus): a taxonomic revision with description of 14 new species
}

\author{
S. D. Biju ${ }^{1, *}$, Sonali Garg1, K. V. Gururaja ${ }^{2}$, Yogesh Shouche ${ }^{3}$ and Sandeep A. Walujkar ${ }^{3}$ \\ ${ }^{1}$ Systematics Lab, Department of Environmental Studies, University of Delhi, Delhi 110 007, India \\ ${ }^{2}$ Centre for Infrastructure, Sustainable Transportation and Urban Planning, \\ Indian Institute of Science, Bangalore 560 012, India \\ ${ }^{3}$ Microbial Culture Collection, National Center for Cell Science, NCCS Complex, \\ Pune University Campus, Ganeshkhind, Pune 411 007, India \\ Accepted April 26, 2014
}

\begin{abstract}
In this study, we investigate species level diversity in the monotypic frog family Micrixalidae, which is endemic to the Western Ghats of Peninsular India. Attempting the first near-complete taxon sampling of Indian dancing frogs from the entire Western Ghats, we use 138 tissue samples collected from 70 localities over the last 12 years for DNA barcoding. Our results of multiple mitochondrial gene (16S and COI) barcoding reveal unexpectedly high species level diversity in the genus Micrixalus. Based on molecular and morphological evidence, we herein describe 14 new species, leading to a more than two-fold increase in the number of known species in this ancient lineage. Additionally, certain taxonomic uncertainties about the status of previously known taxa in this genus are resolved. Micrixalus narainensis and M. swamianus are considered as junior subjective synonyms of $M$. kottigeharensis, whereas $M$. herrei is resurrected from synonymy of $M$. fuscus and confirmed as a valid species. Taxonomic accounts of three species- $M$. elegans, M. silvaticus and $M$. thampii - are provided for the first time after their original descriptions. For nomenclatural stability, M. fuscus, M. saxicola and M. silvaticus are lectotypified, and M. elegans and $M$. kottigeharensis are neotypified. Detailed descriptions, morphological and genetic comparisons, illustrations, data on distribution, and natural history are provided for all species. We also provide the first osteological description of M. fuscus, the type species of the genus Micrixalus, and we report foot-flagging behaviour in a total eight species, including two for which it has been studied previously. Overall, our results highlight the underestimation of true diversity in several amphibian groups of the Western Ghats, suggesting that spatial patterns of amphibian richness and endemism in this region need to be further reexamined.
\end{abstract}

Keywords: Western Ghats, biodiversity, endemic family, ancient lineage, taxonomy, systematics, footflagging, osteology

\section{INTRODUCTION}

The Western Ghats is one of the major centers of global biodiversity, remarkable for its diverse flora and fauna as well as their origin and patterns of evolution (Biju and Bossuyt, 2003; Bossuyt and Milinkovitch, 2001; Bossuyt et al., 2004; Briggs, 2003; Mittermeier et al., 2004; Roelants et al., 2004; Van Bocxlaer et al., 2012). The Western Ghats primarily consists of a long north-south orientated mountain chain, extending from Gujarat in the north $\left(21.00^{\circ} \mathrm{N}\right)$ to the southern tip of Peninsular India in Tamil Nadu $\left(08.25^{\circ} \mathrm{N}\right)$ and covering a distance of approximately $1,600 \mathrm{~km}$. Its historical isolation from neighbouring regions and consistent history of humid tropical to subtropical climate has resulted in ideal conditions for amphibian speciation and a high level of generic and familial endemism (Biju and Bossuyt, 2003, 2009; Biju et al., 2008, 2009, 2011; Bossuyt et al.,
2004; Roelants et al., 2004).

One of the Western Ghats endemic monotypic family, Micrixalidae Dubois, Ohler and Biju, 2001, was only recently recognised as an ancient group of frogs that diversified from the superfamily Ranidae during the Upper-Cretaceous or Palaeocene period (Roelants et al., 2004). This ancient lineage of small-sized (SVL 13-35 mm) frogs currently has only 11 valid species (Frost et al., 2006). The genus Micrixalus, commonly known as 'Tropical frogs' (Frank and Ramus, 1995), comprises of species that usually occur in splash zones of fast flowing perennial hill streams for which some are even called 'Torrent frogs' (Das and Dutta, 1998). However, most notable is that some of the species exhibit the remarkable behaviour of foot-flagging (Gururaja, 2010; Krishna and Krishna, 2006; Reddy et al., 2002; Vasudevan, 2001) akin to 'dancing', and for this

*Corresponding author's email: sdbiju@es.du.ac.in 
unique behaviour we propose the common name 'Indian dancing frogs' for this genus.

Micrixalidae, currently contains only one genus, Micrixalus Boulenger, 1888 that was created to accommodate five species; four that were originally described in Rhacophorid genera, Ixalus: Ixalus fuscus Boulenger, 1882 (= Micrixalus fuscus), Ixalus opisthorhodus Günther, 1869 "1868" (= Micrixalus opisthorhodus), Ixalus silvaticus Boulenger, 1882 (= Micrixalus silvaticus); Polypedates?: Polypedates? saxicola Jerdon, 1854 "1853" (= Micrixalus saxicola), and one species, Ixalus sarasinorum Müller, 1887 (= Pseudophilautus sarasinorum) later returned back to Rhacophoridae (Boulenger, 1888; Dubois, 1987 "1986"). After these colonial descriptions, there was a lean period of species discovery from the Western Ghats (Fig. 1), following which, Rao (1937) described four new species in this group, and additional three were described after Indian independence (Pillai, 1978, 1981; Pillai and Pattabiraman, 1990). However, no new species have been discovered in this genus over the last nearly 25 years - the period during which maximum new species were described in Indian herpetology, including a near doubling of the number of amphibian species known from the Western Ghats (Fig. 1).

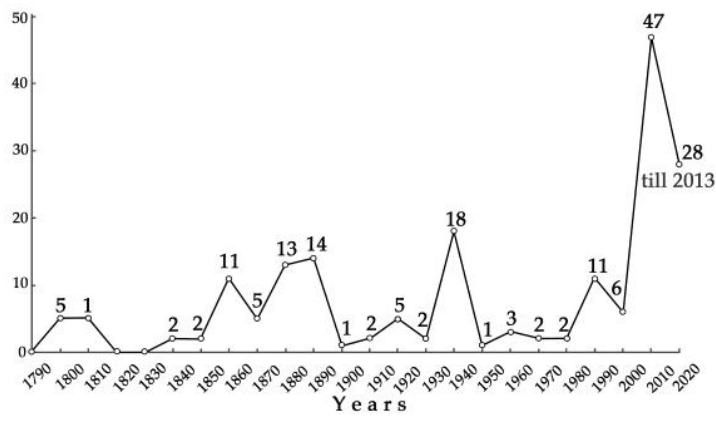

Figure 1. Trend of amphibian species descriptions from the Western Ghats. Numbers of new species shown on the curve at intervals of ten years (up to 2013) are based on Frost, 2014 and AmphibiaWeb, 2014.

Taxonomic placement of species in the genus Micrixalus remained confusing for a long time, mostly due to some superficial morphological similarities with other groups (e.g., dilated finger and toe tips, and webbed feet in 'Philautus') and lack of proper morphological examination of these small-sized frogs. Some of the species, originally described in the Rhacophorid genus Philautus, were transferred to Micrixalus recently (Bossuyt and Dubois, 2001), and subsequently Micrixalidae was proposed as a distinct family (Dubois et al.,
2001). Roelants et al. (2004) provided the first evidence for ancient origin of this family along with showing Ranixalidae and Nyctibatrachidae as its closest relatives, and further discussed the evolutionary significance of these endemic lineages.

However, members of the genus Micrixalus gained the attention of researchers for their unique ecological and behavioural adaptations. Studies have reported habitat features (Reddy et al., 2002), foot-flagging (Krishna and Krishna, 2006; Malhotra and Davis, 1991; Vasudevan, 2001) and reproductive behaviour (Gururaja, 2010) in Micrixalus species, and a few have specifically dealt with visual and acoustic communication in these frogs (Preininger et al., 2013a, 2013b, 2013c). However, all of these studies concentrated only on two species, M. fuscus and M. 'saxicola', and there is no information available for other species in the genus. Furthermore, though Micrixalus is among the more widely distributed and well-studied genera of the Western Ghats, extensive surveys to understand species diversity in this ancient and endemic lineage have never been attempted.

Growing interest in the taxonomy and systematics of Indian amphibians within the herpetological community has been accentuated by the knowledge that species diversity on this ancient subcontinent remains poorly understood (Biju, 2001). Though there is a rapidly increasing number of scientific papers and books published every year on the subject, most involve checklists (e.g., Daniels, 2005; Dinesh et al., 2009; Gururaja, 2012; Krishnamurthy and Sakunthala, 1993; Purushotham and Tapley, 2011) and sightings of species (e.g., Aravind, 2002; Dinesh et al., 2010; Gururaja et al., 2007; Reddy et al., 2001), and only a minority specifically deal with resolving the problematic taxonomic and systematic issues plaguing many taxa in India (e.g., Abraham et al., 2013; Biju and Bossuyt, 2009; Biju et al., 2008, 2009, 2011; Kuramoto et al., 2007). For many species, only the historical and often vague original descriptions exist, with type specimens long lost, destroyed or in some cases never deposited in a museum collection (Biju and Bossuyt, 2009; Biju et al., 2011; Bossuyt and Dubois, 2001; Dubois, 1984, 1987 “1986”). Without such essential basic reference specimens to define a species, subsequent descriptions of specimens from localities other than the type localities in various literature have resulted in the 

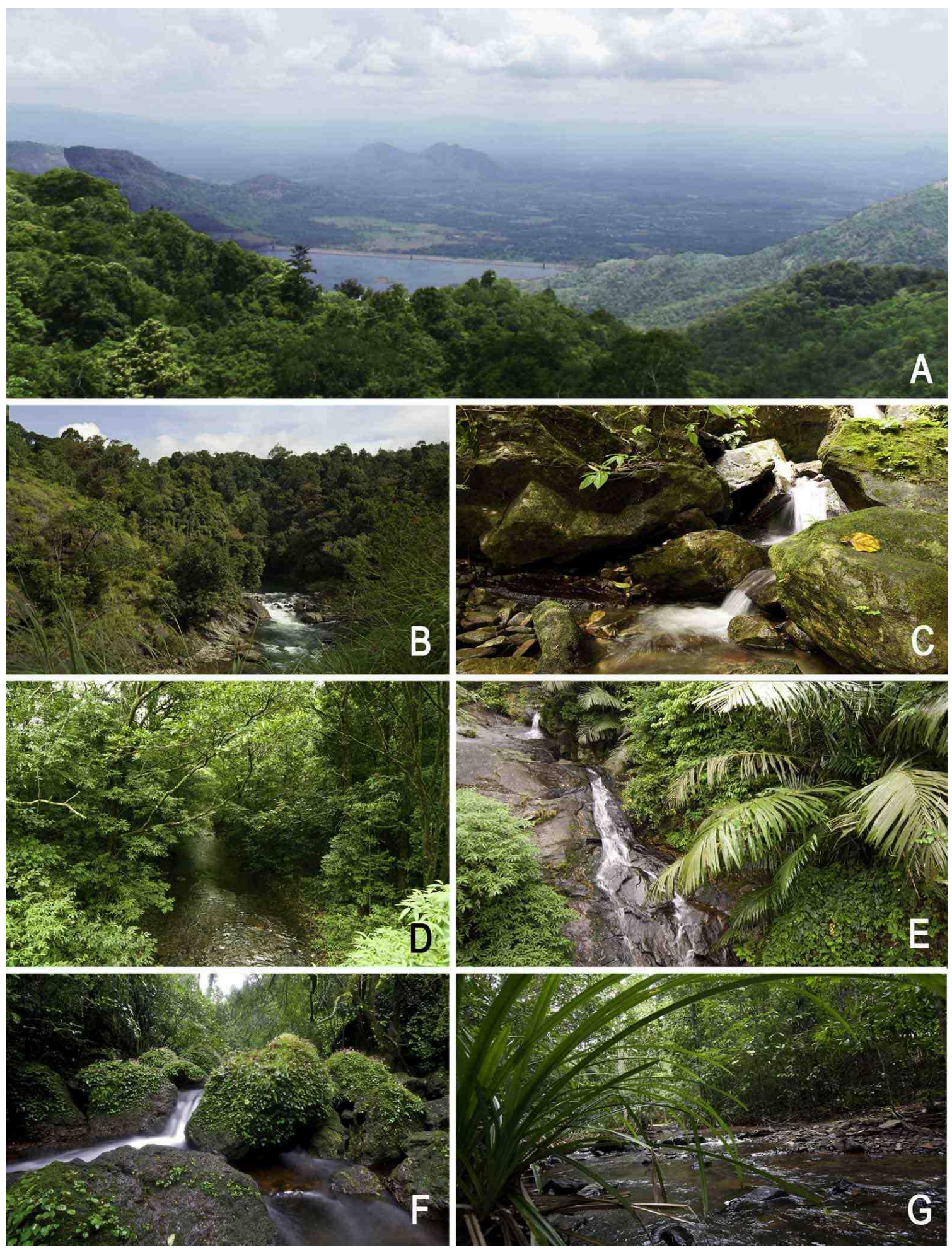

Figure 2. A. The Palghat Gap - approximately $30 \mathrm{~km}$ wide area with elevations below $100 \mathrm{~m}$ a.s.l., forming a major discontinuity in the Western Ghats; B-G. typical habitats of Micrixalus species in the Western Ghats: B. fast flowing stream inside a wet evergreen forest, Silent valley National Park, C. small stream in a secondary forest, Aralam Wildlife Sanctuary, D. slow-flowing rivulet in the forests of Siruvani, E. hill stream inside a shola forest, Eravikulam National Park, F. high altitude forest stream in Amboli, G. Myristica swamp forest at Kathlekan. 
propagation of character misconceptions for several obscure and cryptic species. These errors lead increasingly to the misidentification of extralimital populations in texts, often giving the perception that these species are more widespread than they actually are (e.g., Biju and Bossuyt, 2009; Biju et al., 2011; Mahony et al., 2011).

Considering the current state of knowledge and taxonomic history of Micrixalus species, almost half of which are categorized as Data Deficient (IUCN, 2013) and have ambiguous or historically defined distributional extents, a comprehensive study has long been pending not only for taxonomic stability of many of the species but also to understand the true diversity in this unique group of frogs. In this study, we investigate the level of species diversity in Micrixalidae using the DNA barcoding approach, which has emerged as a potential tool for identification and discovery of amphibian species (e.g., Fouquet et al., 2007; Funk et al., 2011; Vences et al., 2005a, 2005b; Vieites et al., 2009). We integrate evidence from multiple gene barcoding along with morphological study of historical and new collections to delineate species boundaries, identify unknown taxa, and to understand patterns of species distribution in this endemic lineage.

\section{MATERIALS AND METHODS}

Field Survey and Specimen Collection. Extensive field surveys were conducted through out the Western Ghats from 2001-2012 and we sampled a total of 87 Micrixalus populations from 70 localities. Typical habitats of Micrixalus species range from wet evergreen forests, high altitude shola forests, Myristica swamps to secondary forests. The study sites were usually closed canopy perennial forest streams (Fig. 2). Adult specimens were mostly collected during the day, either by locating calling males or through opportunistic surveys. Special emphasis was laid on photography of live animals with minimal disturbance in the wild, and with a few exceptions in captivity. Animals were euthanized using Tricaine methanesulphonate and a portion of tissue sample was taken from the thigh muscle or liver, preserved in $95 \%$ ethanol and stored at $20^{\circ} \mathrm{C}$ in the Systematics Lab, University of Delhi (SDBDU) for molecular analysis. Specimens were fixed in $4 \%$ formalin and preserved in $70 \%$ ethanol. GPS coordinates of sampling localities were recorded in the field and maps were prepared using QGIS (http://www.qgis.org). Details of collection localities and species recorded at the respective sites are provided in Table 1 , and the geographical ranges of species in the present study are shown in Figure 3.

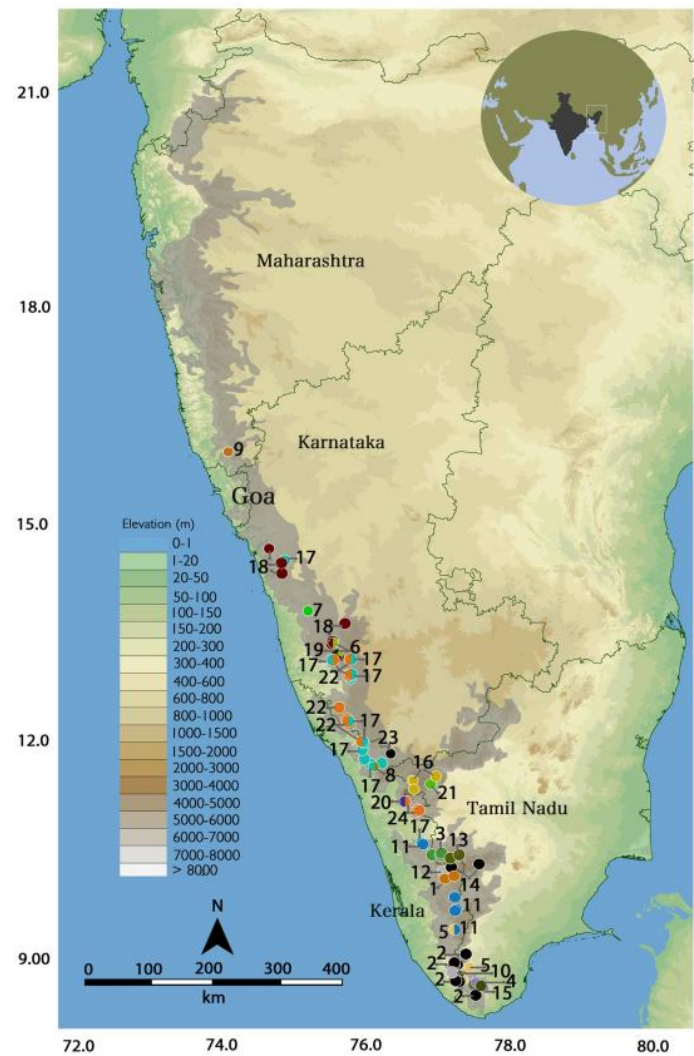

Figure 3. Distribution of 24 Micrixalus species in the Western Ghats, India. Species numbers are cross-referenced in Figure 7A. The Western Ghats are shown in grey.

Reproductive Behaviour. Observations of the breeding behaviour were made during the years 2001 to 2012. Opportunistic surveys were conducted through out the year, in three broad phases: monsoon (June-September), postmonsoon (October-November) and dry period (December-May). Our searches were mostly conducted during daytime and focused on torrential as well as cascading sections of streams. Breeding behaviour observations were made applying the focal animal approach (Martin and Bateson, 1986). Foot-flagging behaviour was recorded by direct observation of males. In cases where foot-flagging was not directly observed, we presumed the occurrence of a suite of characters, i.e. flashy white coloration on dorsal surface of foot, degree of webbing and torrent waters as habitat preference, to be indirect inference of footflagging. All observations were made without disturbing the animals, with exception in cases where animals were collected and preserved after the observation period. 
DNA Extraction, PCR, and Sequencing. Whole genomic DNA was extracted from ethanolpreserved muscle or liver tissue using standard extraction protocol (Sambrook et al., 1989) or Qiagen $^{\odot}$ DNeasy tissue kit following manufacturer's protocol. Two mitochondrial gene fragments, $16 \mathrm{~S}$ rRNA $(\approx 540 \mathrm{bp})$ and COI $(\approx 650$ bp), were PCR-amplified and cycle sequenced on both strands using ABI 3730 automated DNA sequencer (Applied Biosystems). Primers used in the study follow Simon et al. (1994) and Che et al. (2012). Sequences were checked and assembled in ChromasPro v1.34 (Technelysium Pty Ltd.); MEGA 5.0 (Tamura et al., 2011) was used to create alignment by ClustalW, edit and manually optimize the dataset. Sequences were deposited in the GenBank under accession numbers KJ711257-KJ711526 (Table 2).

DNA Barcoding Analysis. Separate datasets were created for both the barcoding genes (16S and COI) using MEGA 5.0 (Tamura et al., 2011). A total of 138 sequences of $16 \mathrm{~S}$ (535 characters) and 132 sequences of COI (611 characters) were used in the study for two independent barcoding analyses. Neighbor Joining (NJ) trees were constructed using the Kimura 2-parameter (K2P) distance model as implemented in PAUP* 4.0b10 (Swofford, 2002), with Nyctibatrachus species as the out group taxa (Roelants et al., 2004). PAUP* $4.0 \mathrm{~b} 10$ (Swofford, 2002) was used to compute intra and interspecific uncorrected pairwise distances and data matrices were constructed for total 3970 pairwise comparisons from both $16 \mathrm{~S}$ and COI sequences. Interspecific pairwise sequence comparisons were made between genetically related species, based on grouping of species in individual $\mathrm{NJ}$ trees. Intra and interspecific genetic distance values are provided in Tables 3 and 4, respectively. Frequency of maximum intraspecific and minimum interspecific genetic divergence values were plotted to understand the barcode gap and identify threshold values for species delineation by the $16 \mathrm{~S}$ and COI markers.

Morphology and Recognition of New Species. In our study, we identified candidate species by integrating morphological data with molecular evidences from multiple gene barcoding. These were compared with available types, other museum specimens and new collections from across the geographic range of Micrixalus. For species whose types have been lost/destroyed, new specimens were collected from the type locality. All illustrations of dorsal and lateral sides of head, ventral sides of hand and feet were made using the stereomicroscope Camera Lucida (Nikon SMZ
1500). Sex and maturity were determined by examining gonads through a small lateral or ventral incision and only adult animals were used for morphological analysis, species comparisons and type series. In cases where identity of subadult specimens was confirmed through molecular data, we included the collection localities in the distribution (Table 1).

Measurements and associated terminology follow Biju et al. (2011); the webbing formulas follow Savage and Heyer (1967) as modified by Myers and Duellman (1982). The amount of webbing relative to subarticular tubercles is described by numbering the tubercles $1-3$, starting from the toe discs. The term shank is used here to refer to the part of the leg containing the tibia, and thigh is used for the part containing the femur. Measurements of all specimens were taken by SDB using a digital slide-caliper, or a binocular microscope with a micrometre ocular, to the nearest $0.1 \mathrm{~mm}$. All measurements and photographs were taken for the left side of the specimen, except when a character was damaged, in which case the measurement was taken on the right side. Measurements of fingers and toes were taken from the base (joint to the next digit) of each digit to the tip (including disc). All measurements provided in the taxonomy section are in millimetres. Range, average and standard deviation of the 'comparison' section without mentioning the sex are for males. Abbreviations: SVL (snout-vent length), HW (head width, at angle of jaws), HL (head length, from rear of mandible to tip of snout), MN (distance from rear of mandible to nostril), MFE (distance from rear of mandible to anterior orbital border), $\mathrm{MBE}$ (distance from rear of mandible to posterior orbital border), SL (snout length, from tip of snout to anterior orbital border), EL (eye length, horizontal distance between bony orbital borders), IUE (inter upper eyelid width, shortest distance between upper eyelids), UEW (maximum upper eyelid width), IFE (internal front of eyes, shortest distance between anterior orbital borders), IBE (internal back of eyes, shortest distance between posterior orbital borders), FAL (forearm length, from flexed elbow to base of outer palmar tubercle), HAL (hand length, from base of outer palmar tubercle to tip of third finger), FD $_{\text {III }}$ (disc width of finger III), $\mathrm{FW}_{\text {III }}$ (width of finger III, measured at the base of disc), $\mathrm{F}_{\mathrm{III}} \mathrm{L}$ (length of finger III), $\mathrm{T}_{\text {III }} \mathrm{L}$ (length of toe III), SHL (shank length), TL (thigh length), FOL (foot length, from base of inner metatarsal tubercle to tip of fourth toe), TFOL (distance from heel to tip of fourth toe). 
Taxonomic Grouping. For morphological comparisons, the present study grouped species in the genus Micrixalus based on their morphological similarities. We identified five groups: (1) Micrixalus elegans group (Micrixalus candidus sp. nov., M. elegans, Micrixalus kurichiyari sp. nov., Micrixalus niluvasei sp. nov., Micrixalus sairandhri sp. nov., Micrixalus spelunca sp. nov. and Micrixalus uttaraghati sp. nov.); (2) Micrixalus fuscus group (Micrixalus adonis sp. nov., M. fuscus, M. herrei, Micrixalus mallani sp. nov., Micrixalus nelliyampathi sp. nov. and Micrixalus kodayari sp. nov.); (3) Micrixalus nudis group (M. gadgili, M. nudis, Micrixalus sali sp. nov. and M. thampii); (4) Micrixalus saxicola group (M. kottigeharensis, M. saxicola and Micrixalus specca sp. nov.); and (5) Micrixalus silvaticus group (Micrixalus frigidus sp. nov., Micrixalus nigraventris sp. nov., M. phyllophilus and $M$. silvaticus). Degree of webbing, presence or absence of dorsolateral folds, snout shape and dorsal markings (observed both in life and preservation), were found to be intraspecifically stable diagnostic characters for distinguishing species in the genus. A special effort was made to represent new species through photographs of live specimens, in order to provide a better understanding of body coloration and markings in life, and thus also aid their identification in field. The following characters are common to all species of Micrixalus examined, and are consequently not repeated in the descriptions: Finger and toes with dermal fringes, and discs dilated with dorsoterminal grooves; pupil oval; webbing absent on hand; pineal ocellus, vomerine teeth and ridge absent.

Osteology. An adult specimen of Micrixalus fuscus was cleared and double-stained using Alizarin Red S and Alcian blue; procedures follow Taylor and Dyke (1985). Osteological description of cranial and postcranial characters was provided following terminologies that of Duellman and Trueb (1986). Photographs were taken either using a digital camera or captured with the aid of a QImaging camera mounted on Nikon SMZ 1500 stereomicroscope. The specimen was scored for presence of bones within one day after the staining process. We noted the presence and absence of sixteen skull bones, including exoccipital, frontoparietals, nasal, parasphenoid, prootics, pterygoids, sphenethmoid, septomaxilla, squamosal, vomer, angulosplenial, dentary, mentomeckelians, maxilla, premaxilla and quadratojugal. Along with bones constructing the axial skeleton, pectoral girdle, fore limb, pelvic girdle and the hind limb were observed.
Abbreviations. For museums and frequently used terms, abbreviations are as follows: BNHS (Bombay Natural History Society, Bombay, India), SDBDU (S. D. Biju collection at University of Delhi, Delhi, India), NHM (The Natural History Museum, London, United Kingdom, formerly British Museum Natural History), BMNH (The British Museum Natural History, London, United Kingdom), ZSIC (Zoological Survey of India, Kolkata, India), SRSZSI (South Regional station, Zoological Survey of India, Chennai, India), SDB (S. D. Biju), SG (Sonali Garg), KVG (K. V. Gururaja), RS (Robin Suyesh), GS (Gargi Sircar). In the 'Material studied' section and 'Table 5' the following abbreviations after specimen numbers refer to: HT (holotype), PT (paratype), LT (lectotype), NT (neotype), PL (paralectotype), RS (referred specimen) and TT (topotype). In figure legends: (m) refers to male, (f) refers to female. In 'Table 1 ' and species distribution sections abbreviations refer to: NP (National Park), WLS (Wildlife Sanctuary), TR (Tiger Reserve), PA (Protected Area), $\mathrm{m}$ asl (meters above sea level).

\section{RESULTS}

ReProductive BeHAViour. Males were mostly observed calling from surface of wet rocks emerging from streams, usually near small waterfalls and rapids. The present study documents foot-flagging behaviour in Micrixalus elegans, M. fuscus, M. herrei, M. kottigeharensis, Micrixalus nelliyampathi sp. nov., Micrixalus niluvasei sp. nov., M. saxicola, Micrixalus specca sp. nov. and Micrixalus uttaraghati sp. nov. (Figs $4,5)$. Calling males in these species were found close to flowing waters, with their noticeable flashy white vocal sacs. Along with calling, males occasionally tapped their foot and thigh, followed by stretching of the entire hind limb away from body and waving their fully stretched foot. In cases of male-male combats, kicking the intruder by foot was also observed in $M$. elegans, $M$. fuscus, M. herrei, M. kottigeharensis, Micrixalus nelliyampathi sp. nov., M. saxicola and Micrixalus specca sp. nov. Similar observations have been reported for M. fuscus (Vasudevan, 2001) and $M$. 'saxicola' (Krishna and Krishna, 2006; Gururaja, 2010). Furthermore, Gururaja (2010) reported the reproductive behaviour in $M$. 'saxicola'. In this study, we made observations of different Micrixalus species and found this unique reproductive behaviour (Figs 5,6) in five species (to be published elsewhere). Direct observation of foot-flagging was made in nine species 

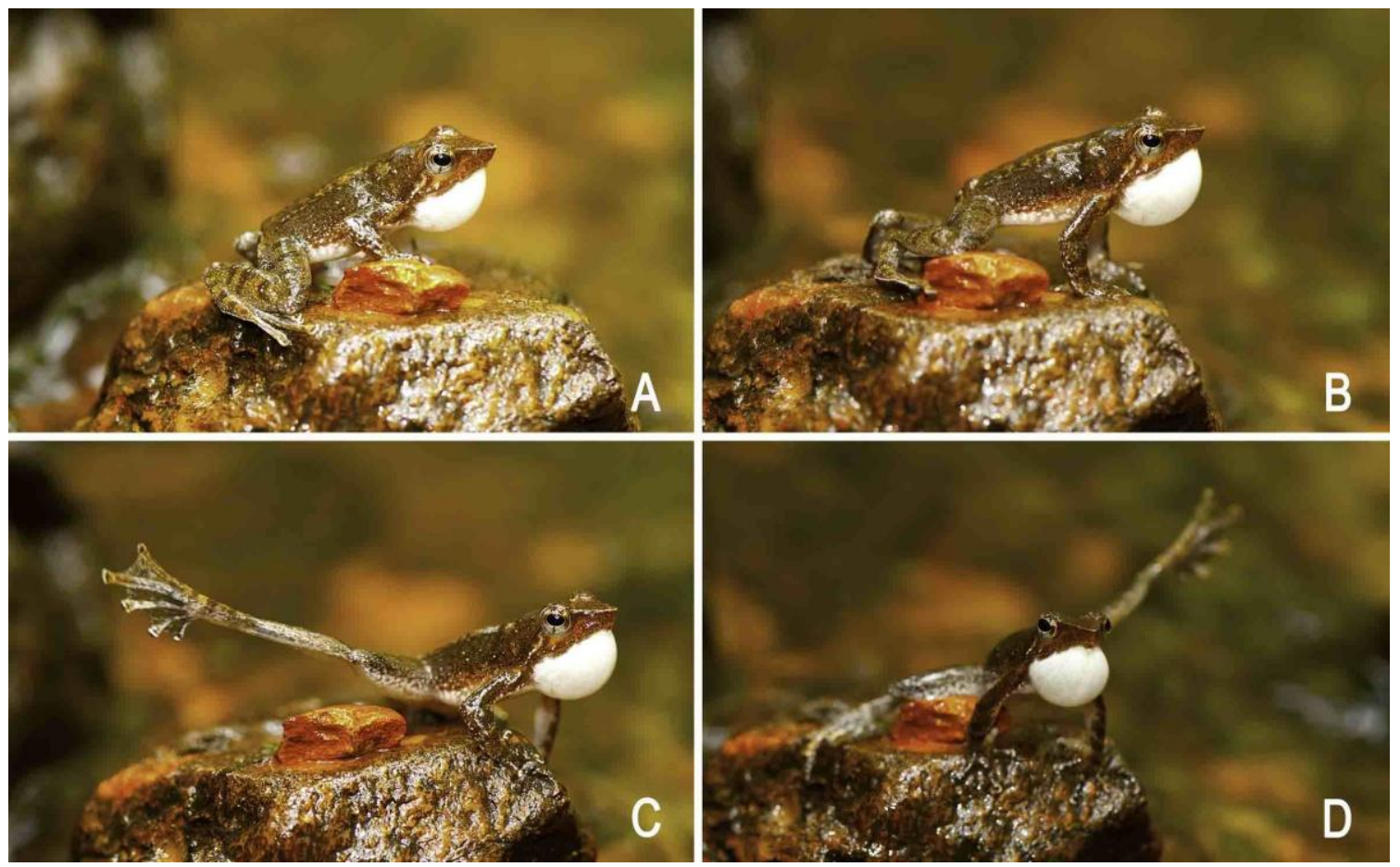

Figure 4. 'Foot-flagging' behaviour in a male of Micrixalus kottigeharensis, observed at Kathlekan in Karnataka state: A. calling and foot tapping, B. posture just before raising the hind limb, C. foot-flagging with the right foot, D. foot-flagging with the left foot. Photos: SDB.

(mentioned above), while in the cases of Micrixalus adonis sp. nov., Micrixalus candidus sp. nov., Micrixalus kodayari sp. nov., Micrixalus kurichiyari sp. nov., Micrixalus mallani sp. nov., Micrixalus sairandhri sp. nov. and M. thampii, presence of flashy coloration on dorsal surface of foot in combination with degree of webbing and habitat preference, were considered as indirect evidence of foot-flagging. Though males of many of the above species were seen actively calling during the monsoon period (June-August), footflagging and breeding were mostly recorded during the late (September) or post-monsoon period (October-November). The reason for this could be the need for shallow waters for breeding, egg-laying and development of tadpoles.

Our study did not observe foot-flagging in Micrixalus sali sp. nov., while the presence of this behaviour could not be known in Micrixalus frigidus sp. nov., M. gadgili, Micrixalus nigraventris sp. nov., $M$. nudis, $M$. phyllophilus, M. silvaticus and Micrixalus spelunca sp. nov. In general, species in which foot-flagging was not observed, the webbing on foot was reduced (fourth toe webbing did not extend beyond the second subarticular tubercle on either side) compared to the foot-flagging species. We also found the latter to be associated with flowing water in streams, while the former occurred on the sides of streams or in leaf litter. On one occasion we observed an egg clutch of M. gadgili (identity confirmed through DNA) under wet leaf litter away from flowing water. These observations probably indicate that within the genus Micrixalus, reproductive behaviour and ovipostion sites could vary depending on the habitat preference of species, and therefore require further investigation at species level. It would also be interesting to undertake studies to confirm the presence and absence of foot-flagging behaviour in all Micrixalus species. This can provide insights into origin of the foot-flagging behaviour, which could have evolved multiple times in this ancient lineage.

DNA BARCODING. Neighbor Joining (NJ) trees for $16 \mathrm{~S}$ (Fig. 7A) and COI (Fig. 8A) produced identical grouping of taxa, corresponding to 24 morphologically confirmed species. The clade relationships varied to a certain extent in both the trees. However, since the NJ analyses were performed only for delineation of species and their geographical ranges, both our trees were successful in reproducing clades that correspond to nine known Micrixalus species: $M$. elegans, $M$. fuscus, M. gadgili, M. kottigeharensis, M. nudis, M. phyllophilus, M. saxicola, M. silvaticus and $M$. thampii; one species, $M$. herrei, currently considered as synonym; and another 14 
representing potential new species (Figs 7A, 8A). Species could be discriminated at threshold values of minimum $3 \%$ for $16 \mathrm{~S}$ and $6.5 \%$ for COI, while the mean thresholds were above $3.9 \%(16 \mathrm{~S})$ and $7 \%$ (COI) for all the species identified as new in this study. The maximum intraspecific and minimum interspecific genetic distances were overlapping at divergence values that included different species in $16 \mathrm{~S}$ and COI, respectively (Figs 7B, 8B; Tables 3, 4). Three known species (M. elegans, M. nudis and M. thampii) were found to be genetically cryptic. Few other species, $M$. fuscus, M. herrei, M. kottigeharensis and $M$. saxicola showed high intraspecific variations and could possibly be complexes of cryptic species. Though previous studies have discussed differential ability of $16 \mathrm{~S}$ and COI to distinguish candidate species (e.g., Vences et al., 2005b; Xia et al., 2012), a critical examination of datasets available for both the barcoding markers in our study allowed us to define threshold values for delineation of new species. These values were also in agreement with earlier amphibian studies (e.g., Fouquet et al., 2007; Smith et al., 2008). We exercised caution while interpreting our results in the case of Micrixalus candidus sp. nov., Micrixalus frigidus sp. nov., Micrixalus kodayari sp. nov., Micrixalus kurichiyari sp. nov., Micrixalus sali sp. nov., M. silvaticus, Micrixalus specca sp. nov. and Micrixalus uttaraghati sp. nov., where there were few samples for calculating intraspecific divergences. However, not only did the above clades show high interspecific divergence from genetically related species, but also possessed distinct morphological characters. Therefore, our results do not raise doubts on their validity as genetically and morphologically distinct species, and further suggest that these could probably have restricted distribution ranges.

\section{MorPhological RECOGNITION OF SPECIES. In} this study, we identified 24 Micrixalus species based on detailed morphological comparison of available types, original descriptions, museum specimens and new collections, along with molecular evidences from multiple gene barcoding. Our study included specimens for 11

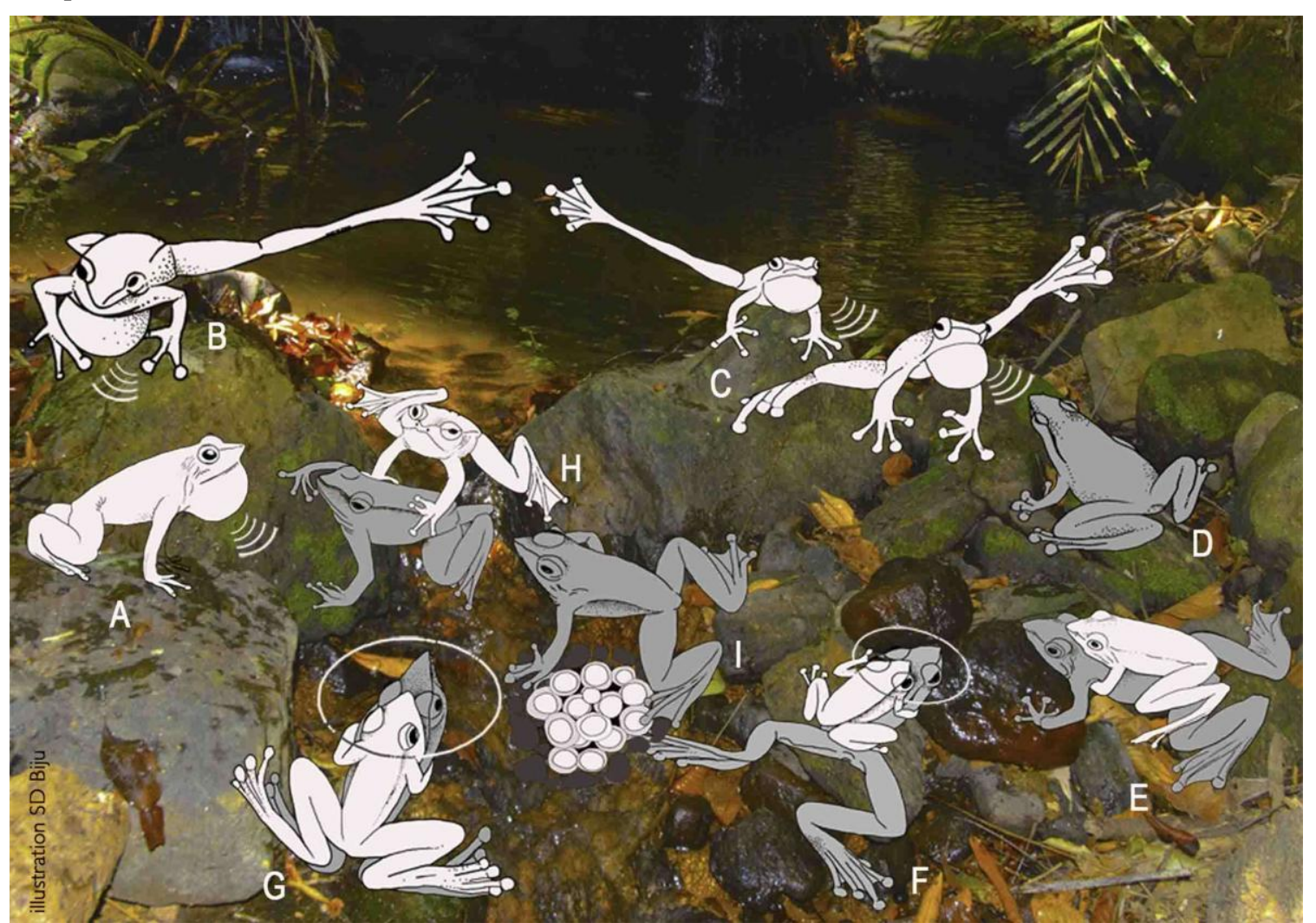

Figure 5. Schematic illustration of breeding behaviour in Micrixalus: A. male calling and foot tapping, B. male foot flagging with simultaneous calling, C. male kicking another intruding male, D. female approaching a calling male, E. male and female in amplexus, moving inside the water, F. amplected pair with their heads emerging out of water, and female digging a cavity on the stream bed with the help of hindlimbs, G. female releasing eggs inside the cavity, H. male detaching from the female, I. female covering the eggs with sand and gravel using hindlimbs. In the illustration, male is shown in light grey, and female in dark grey. 
known Micrixalus species (Frost et al., 2006), including three previously considered as 'lost', one species currently in synonymy (Inger et al., 1985 "1984"), and several unidentified populations. Our results confirm the presence of 14 unnamed species in this genus, in addition to taxonomic revision of the available 12 names. Micrixalus herrei Myers, 1942 is considered as a valid species and removed from synonymy of $M$. fuscus (Boulenger, 1882). Two species, $M$. narainensis (Rao, 1937) and M. swamianus (Rao, 1937) are considered as junior subjective synonyms of M. kottigeharensis (Rao, 1937). Micrixalus fuscus, M. saxicola and M. silvaticus are lectotypified, and $M$. elegans and $M$. kottigeharensis are neotypified, for taxonomic

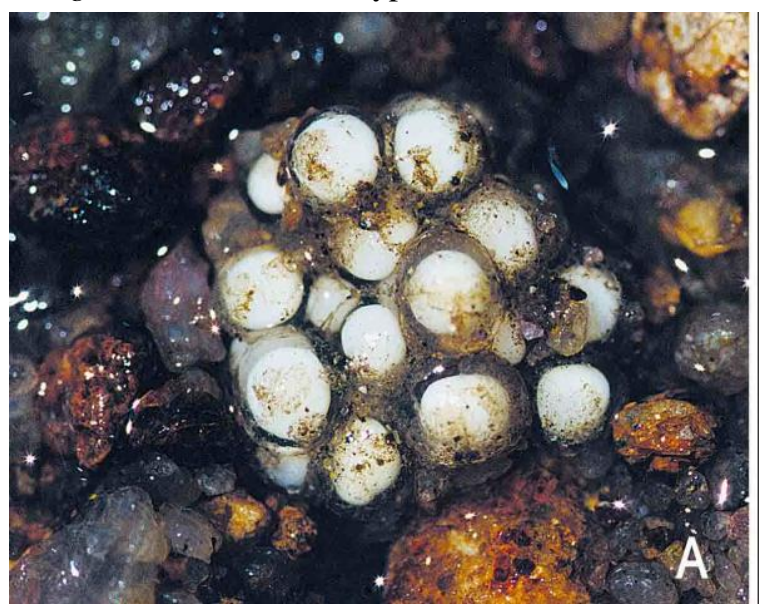

stability. Fourteen new species are herein described as: Micrixalus adonis sp. nov., Micrixalus candidus sp. nov., Micrixalus frigidus sp. nov., Micrixalus kodayari sp. nov., Micrixalus kurichiyari sp. nov., Micrixalus mallani sp. nov., Micrixalus nelliyampathi sp. nov., Micrixalus nigraventris sp. nov., Micrixalus niluvasei sp. nov., Micrixalus sairandhri sp. nov., Micrixalus sali sp. nov., Micrixalus specca sp. nov., Micrixalus spelunca sp. nov. and Micrixalus uttaraghati sp. nov. The first-ever comprehensive taxonomic revision of all members of the endemic frog family Micrixalidae is provided, with detailed species accounts and descriptions in the 'Taxonomy' section.

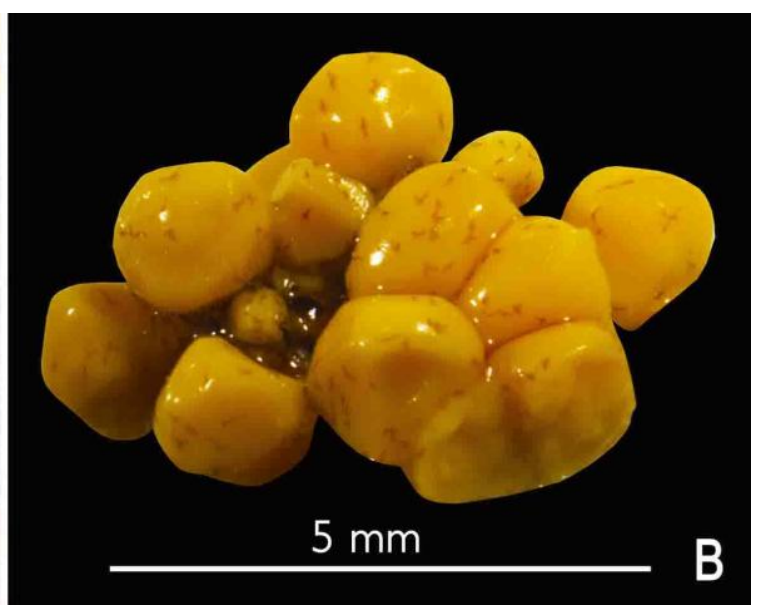

Figure 6. Eggs of Micrixalus herrei: A. an egg clutch at the oviposition site (inside a cavity), observed by removal of gravel after five minutes of egg laying, B. eggs from a preserved specimen (BNHS 5680), with minute brown markings.

ENDEMISM AND SPECIES DiSTRIBUTION. Several studies have highlighted the uniqueness of flora and fauna along the Western Ghats (Biju and Bossuyt, 2003; Bossuyt and Milinkovitch, 2001; Bossuyt et al., 2004; Roelants et al., 2004; Van Bocxlaer et al., 2009) but not many have focused on understanding the role of geographic discontinuities or gaps along the Western Ghats, in influencing patterns of species distribution and diversification in amphibians of this region. Van Bocxlaer et al. (2012) first discussed patterns of endemism that were most likely caused by restricted dispersal across the three major gaps in the Western Ghats (Figs 7C-D), observed in their study of another Western Ghats endemic genus Nyctibatrachus. Our findings corroborate similar patterns in the genus Micrixalus. Most species showed restricted distribution with respect to either the Palghat, Shencottah or Goa gap; three species (M. fuscus, Micirixalus kodayari sp. nov. and Micrixalus sali sp. nov.) were only found south of Shencottah gap, along a stretch that forms southern limits of the Western Ghats; six species (Micrixalus adonis sp. nov., Micrixalus frigidus sp. nov., M. gadgili, Micrixalus nelliyampathi sp. nov., Micrixalus nigraventris sp. nov. and $M$. silvaticus) were found between the Shencottah and Palghat gap; 12 species (Micrixalus candidus sp. nov., M. elegans, M. kottigeharensis, Micrixalus kurichiyari sp. nov., Micrixalus niluvasei sp. nov., M. nudis, M. phyllophilus, M. saxicola, Micrixalus sairandhri sp. nov., Micrixalus specca sp. nov., Micrixalus spelunca sp. nov. and $M$. thampii) between the Palghat and Goa gap; and one species (Micrixalus uttaraghati sp. nov.) crossed the Goa gap and formed the northern most distribution limit of this genus. Micrixalus mallani sp. nov. was the only species that was found on both sides of the Shencottah gap, but not beyond the Palghat gap, while $M$. herrei also occurred at low elevations of Shencottah along with its distribution south of the gap (Figs 3, 7A-E, 8A). While studies have cited the Palghat gap as a barrier promoting distinct patterns of distribution 
in diverse amphibian genera (Bossuyt et al., 2004; Van Bocxlaer et al., 2012), the role of Palghat, Shencottah and Goa gaps in case of peculiar dispersal and speciation of Micrixalus remains to be investigated. The state-wise occurrence of known and newly described Micrixalus species, was found to be maximum in Kerala which had the highest number of species in both categories (eight known, eight new), followed by Karnataka (three known, three new), Tamil Nadu (three known, six new) and Maharashtra (one new) (Fig. $8 \mathrm{C})$.

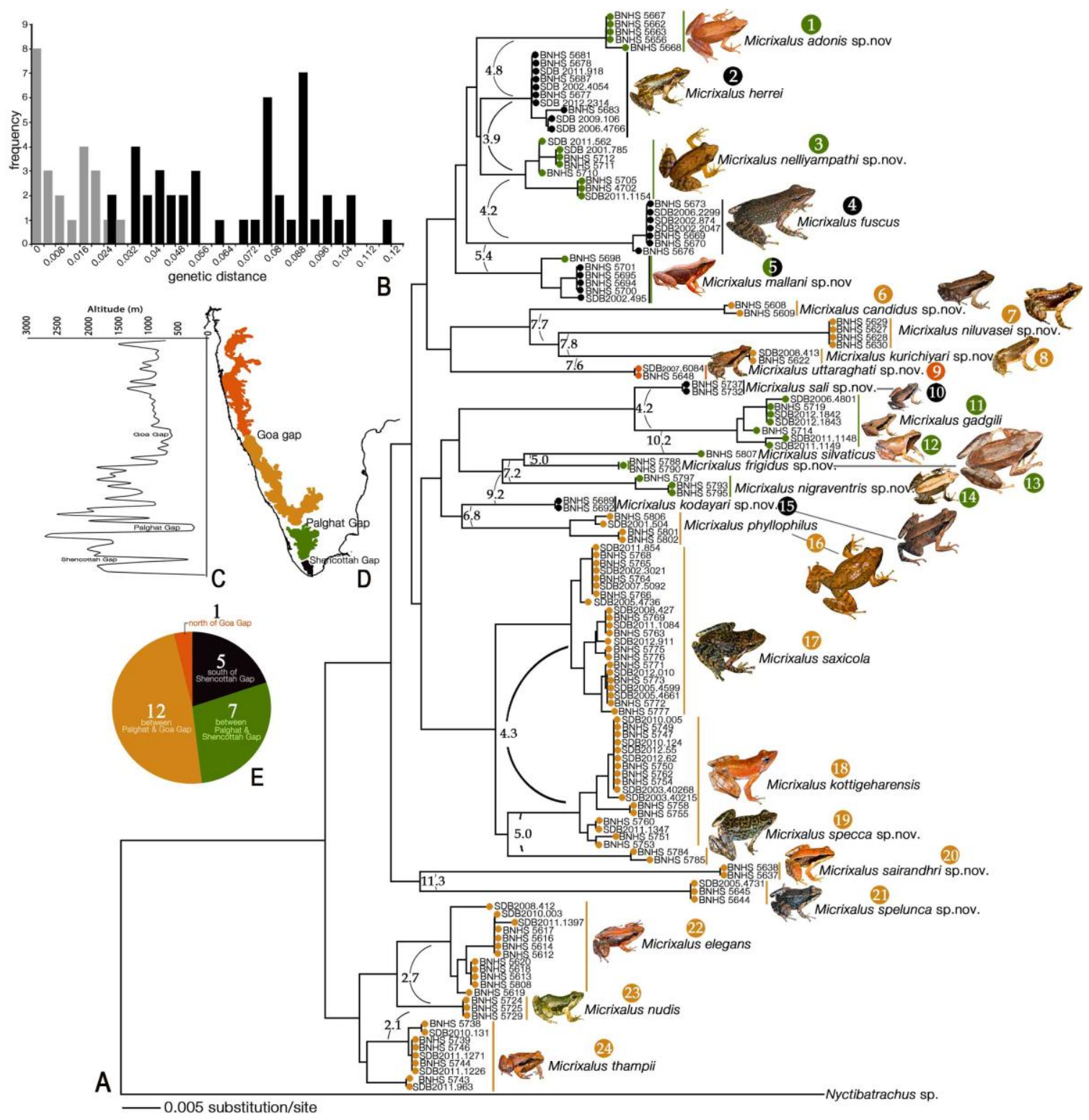

Figure 7. A. NJ tree based on K2P distances for 16S rRNA gene sequences of 137 samples, belonging to 24 Micrixalus species from the Western Ghats. Voucher numbers are cross-referenced in Table 2; clades representing species are numbered (1-24) from top to bottom; colour of terminal nodes indicate distribution of species based on regions shown in Figure 7D; and number towards internal nodes of the tree represents mean interspecific genetic distance (in percent) between the species, B. intra (grey) and interspecific (black) uncorrected pairwise genetic distances for $16 \mathrm{~S}$, C. elevational profile of the Western Ghats (adapted from Ramesh et al., 1997 and Robin et al., 2010), D. the Western Ghats showing four broad regions divided by three major elevational discontinouties, E. number of species occuring in four regions of the Western Ghats. 


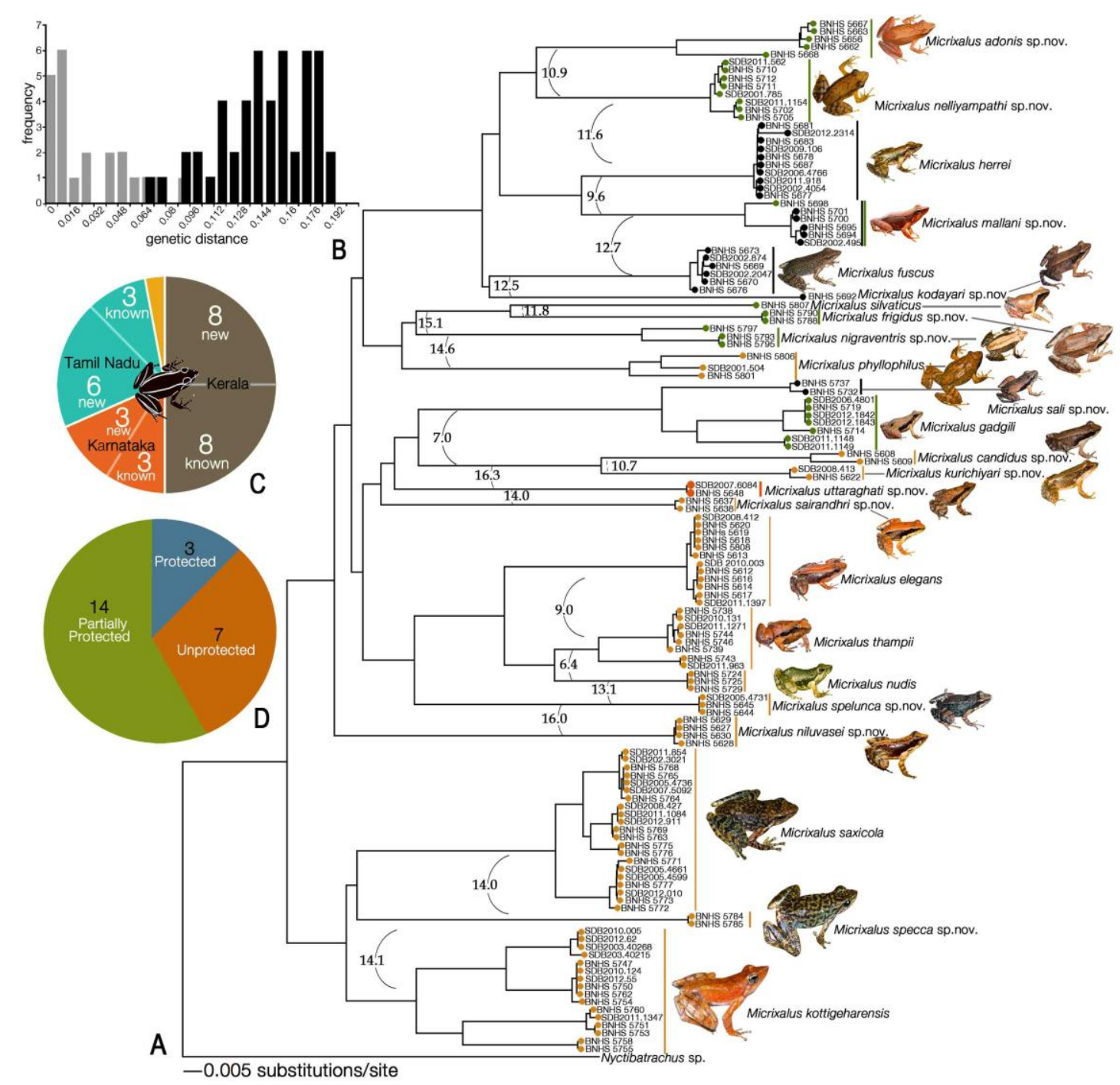

Figure 8. A. NJ tree based on K2P distances for COI gene sequences of 131 samples, belonging to 24 Micrixalus species from the Western Ghats. Voucher numbers are cross-referenced in Table 2; colour of terminal nodes indicate distribution of species based on regions shown in Fig. 7D, B. intra (grey) and interspecific (black) uncorrected pairwise genetic distances for COI, C. number of previously known and new species found in four states of the Western Ghats, D. number of species occuring inside and outside Protected Areas. Species only found inside protected areas (blue); species found outside protected areas (red); species with one or more populations inside protected or undisturbed forest areas (green).

CONSERVATION IMPLiCATION. Our study also made an attempt to understand the occurance of species in protected areas of the Western Ghats (Fig. 8D). We demonstrate that seven species (nearly 30\%), Micrixalus adonis sp. nov., Micrixalus candidus sp. nov., Micrixalus niluvasei sp. nov., M. silvaticus, Micrixalus specca sp. nov., Micrixalus spelunca sp. nov. and Micrixalus uttaraghati sp. nov., are found only in regions outside protected areas; while in the case of 14 species (58\%), M. elegans, M. fuscus, M. gadgili, M. herrei, Micrixalus kodayari sp. nov., $M$. kottigeharensis, Micrixalus kurichiyari sp. nov., Micrixalus mallani sp. nov., Micrixalus nelliyampathi sp. nov., Micrixalus nigraventris sp. nov., M. phyllophilus, Micrixalus sali sp. nov., $M$. saxicola and $M$. thampii, at least one or more populations are either inside a protected area or undisturbed forest in close vicinity of a protected area. Three species, Micrixalus frigidus sp. nov, M. nudis and Micrixalus sairandhri sp. nov., are currently reported only from protected areas. Further studies are required to understand population status and threats in case of all the species. More importantly, considering the revised state of knowledge with respect to diversity and distribution of species in the family Micrixalidae, our results present a strong need to revisit conservation status of all the recognized species. 


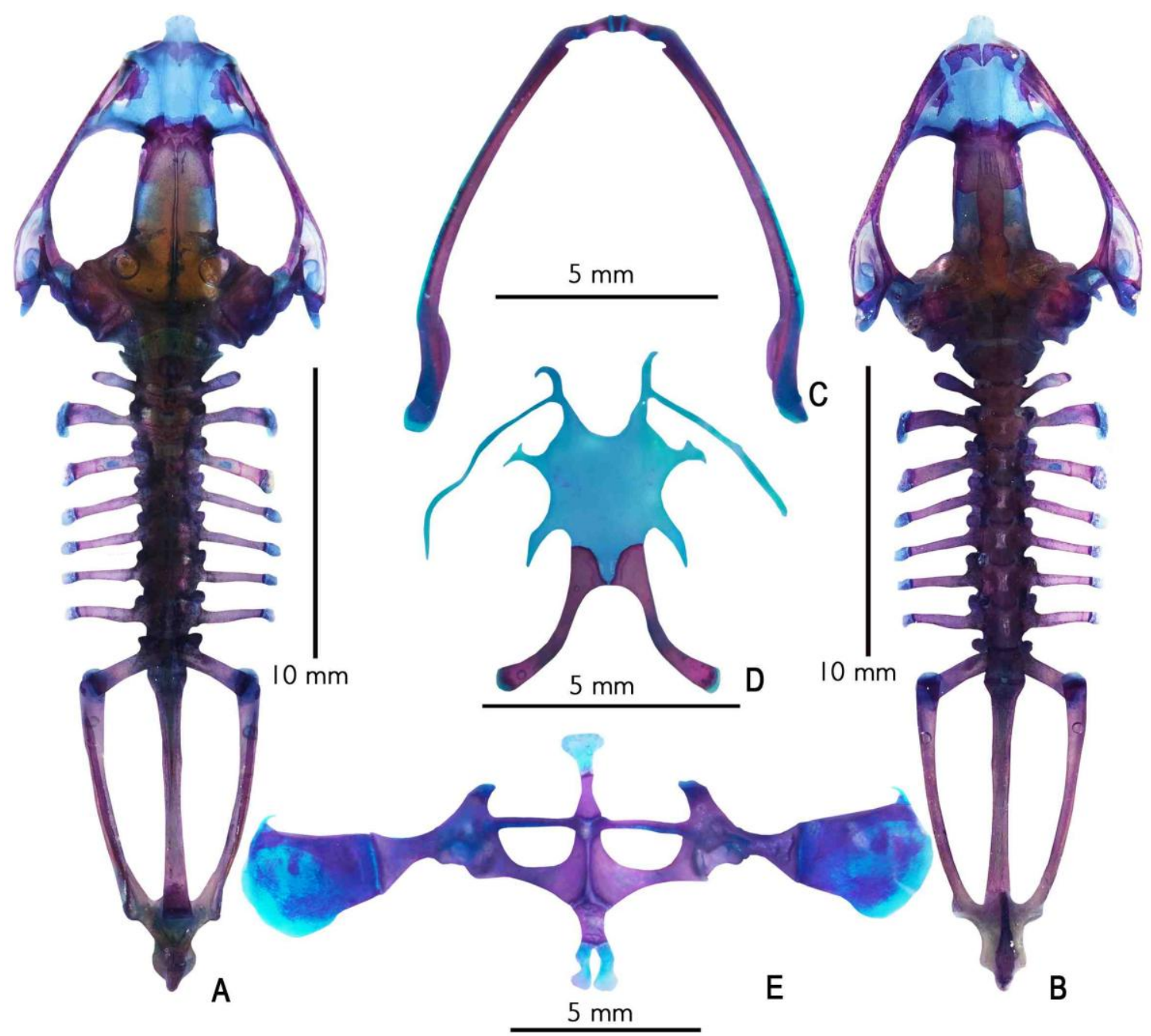

Figure 9. Skull, vertebral column, hyobranchial skeleton and pelvic girdle of Micrixalus fuscus (SDBDU 2006.2296): A. skull, vertebral column (dorsal view), B. skull, vertebral column (ventral view), C. mandible (dorsal view), D. hyobranchial skeleton (ventral view), E. pectoral girdle (ventral view).

OSTEOLOGY. The following osteological description of type species of the genus Micrixalus (M. fuscus) is based on a cleared-and-double stained adult male specimen (SDBDU 2006.2296, SVL = $27.9 \mathrm{~mm})$, collected by SDB from Kakkachi, Tirunelveli dist., Tamil Nadu, on 28 May 2006.

Cranium. Skull is narrower anteriorly, at the orbital region, and widest posteriorly at the otic region. Neurocranium. The sphenethmoid, paired exoccipitals and prootics form the neurocranium of M. fuscus. Sphenethmoid is an unpaired bone, constructing the anterior portion of the brain case and also the medial and posterior walls of the nasal capsules. It is visible between the frontoparietals and nasals when observed dorsally, and between parasphenoid and vomers when viewed ventrally. Prootics are paired bones and the posterolateral ossifications of these bones give rise to auditory capsules. Exoccipitals fused with the prootics form the auditory capsules, and also form the posterior end of the neurocranium by bordering the foramen magnum. Medially the exoccipitals are separated from one another. Auditory apparatus. The stapes (also known as the pars media plectra) and the footplate of the stapes (pars interna plectra) are ossified. The operculum remains oval and cartilaginous. Dermal investing bones. Dorsal bones encompass nasals and frontoparietals. Nasals are paired, triangular shaped bones, roofing the nasal capsule. These are formed anterior to the Sphenethmoid. They do not articulate with the maxilla and are separated from one another. Paired frontoparietals are long and slender, cover the frontoparietal fenestra. These bones are separated by a narrow gap. They are fused with the prootics posteriorly. Ventral bones of the cranium are denoted by 
vomers, palatines, parasphenoid and pterygoids. Paired vomers form the floor of the nasal capsules and part of the palate. Vomerine teeth are absent. T-shaped azygous parasphenoid invests the ventral side of the neurocranium. Posterolateral alae cover the auditory capsules laterally. Parasphenoid extends up to the vomerines, but does not fuse with them. Palatines are paired bones and are present as a transverse slim ridge. They are connected laterally with the maxillae. Pterygoid being a triradiate bone has an inverted $\mathrm{Y}$ shape. The anterior arm connects with the maxilla, and the lateral arms connect to the auditory capsules and the quadrate. Lateral bones investing the cranium are squamosals. They are paired, triradiate bones. Ventral arm extends along the quadrate. Otic (posterior) ramus fuses with the prootics. Zygomatic (anterior) ramus extends towards the maxilla, but does not fuse with it. Otic ramus is shorter compared to the other two arms of the squamosals (Figs 9A-B).

Maxillary arcade. Upper jaw consists of premaxilla, maxilla and quadratojugals. Premaxillae are paired bones composed of three parts: alary process, pars dentalis and pars palatina. Pars dentalis houses 8-9 teeth in each premaxilla. Paired maxilla made of pars facialis, palatina and dentalis, are dentate. Pars dentalis bears 23-25 teeth on each bone. Quadratojugals are paired bones. The anterior parts of each bone invest the posterior and external surface of maxilla and ventrally fuse with the pars articulates of the quadrate (Figs 9A-B).

Mandible. Angulosplenial, dentary and mentomeckelians give rise to the lower jaw. They are edentate paired bones. Mentomeckelians are seen in the anterior part, separated from each other by a narrow space. Dentaries invest the anterior margin of the meckel's cartilage and the paired angulosplenials occupy more than half of the meckel's cartilage along its posterior margin. Dentaries fuse with angulosplenials at their proximal ends (Fig. 9C).

Hyoid apparatus. Hyoid plate (central corpus) is completely cartilaginous. The width is narrower than the antero-posterior medial length. Posteromedial processes are ossified. Cartilaginous anterolateral and posterolateral processes are present having pointed ends. Posterolateral processes are short compared to the ossified posteromedial processes. Cornua, arising anterolaterally from the hyoid plate, extends posterolaterally and articulates with the auditory capsules (Fig. 9D).

Pectoral girdle. Scapula is expanded and articulates with the cartilaginous base of the suprascapula, which takes the form of a blade. Anterior margin of the suprascapula is ossified, denoting the cleithrum. Zonal components of the pectoral girdle, which include clavicles (formed on the anterior margin of the procoraccoid cartilage), coracoids (bone deposition occurring on anterior and posterior margins of the coracoid cartilage) and cartilaginous arc, were observed in the stained $M$. fuscus specimen. The pre-zonal and post-zonal elements, omosternum and sternum respectively showed ossifications starting from the point of attachment to the cartilaginous arc (Fig. 9E).

Fore limb. Humerus, being the proximal element of the forelimb is attached to the pectoral girdle via the articular surface, glenoid fossa. Radio-ulna is present by fusion of radius and ulna. Manus consists of five ossified carpals, radiale, ulnare, carpal 2, carpals 3-5, centrale and central. Prepollex is ossified. Relative lengths of the metacarpals are IV $>$ III $>\mathrm{V}>$ II. The phalangeal formula is 2-2-3-3. Distal phalanges are forked (Figs 10A-E).

Pelvic girdle. It is made up of ilium, ischium and pubis. The ilium articulates with the ventral surface of the sacral diapophysis. Posterior half of the acetabulum is denoted by the ischium. Ventral to the acetabulum, cartilaginous pubis is apparent.

Hind limb. Femur that articulates with the pelvic girdle, and tibiofibula that articulates anteriorly with the femur, are fully ossified. Fibulare and tibiale articulating anteriorly with the tibiofibula are fused medially at their proximal and distal ends. Two tarsal elements, tarsal 1 and tarsal 2-3 were ossified. The prehallux was observed as cartilaginous element with a bony base. The relative lengths of the Metatarsals are IV> V> III > II $>$ I. The phalangeal formula is 2-2-3-4-3, and the distal phalanges were fork-shaped (Figs 10F-J).

Axial skeleton. The presacral region consists of eight presacral vertebrae. Atlas being the most anterior vertebra lacks transverse processes. A pair of atlantal cotyles is seen. The transverse processes of presacral II have an anterolateral orientation, whereas transverse processes III-VIII have a posterolateral orientation. The specialized vertebra, sacrum is positioned in between the presacrals anteriorly, and coccyx posteriorly. Vertebrae starting from II-VIII have prezygapophyses and postzygapophyses on each neural arch. The sacrum has only a pair of prezygapophyses. Sacral diapophyses are formed by the expansions of the sacrum. The last element of the vertebral column, the rod-like coccyx, can be seen between the shafts of ila. 


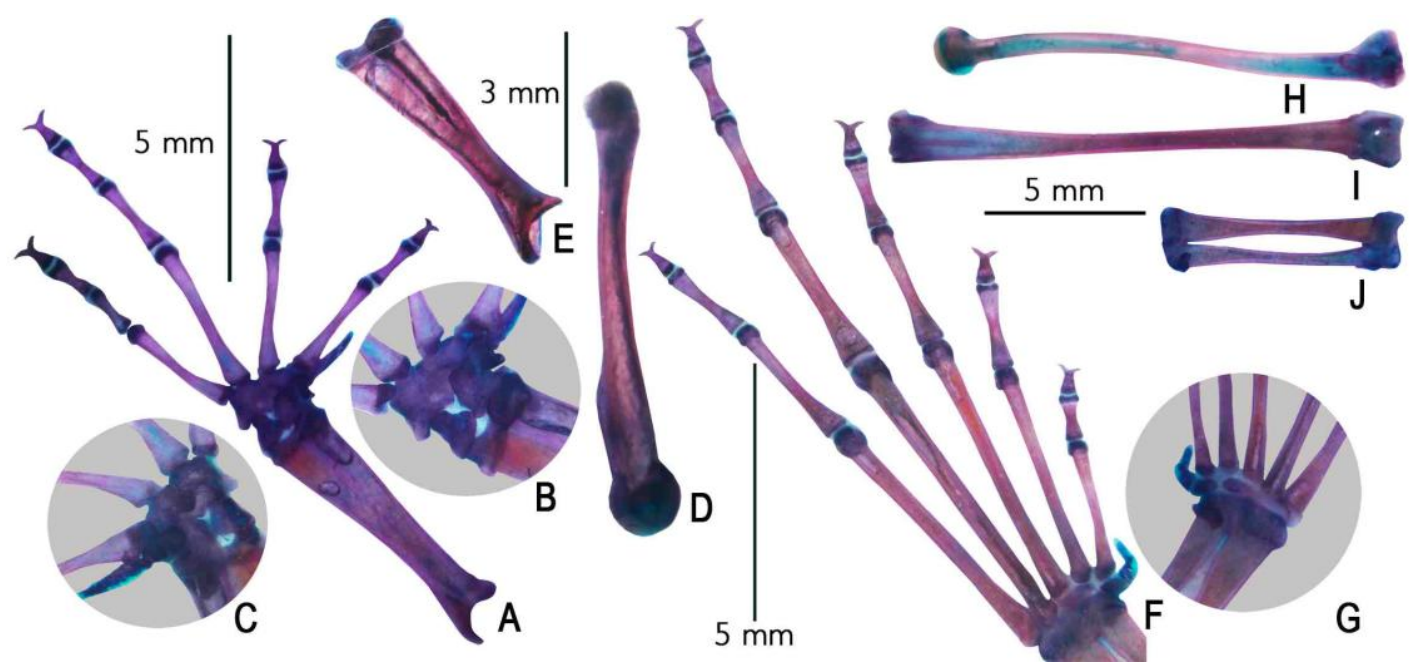

Figure 10. Anterior appendicular skeleton and posterior extremity of Micrixalus fuscus (SDBDU 2006.2296). A. left hand (dorsal view), B. left hand showing six different types of carpals (dorsal view), C. left hand showing the six different types of carpals (ventral view), D. left humerus (medial view), E. left radio-ulna (medial view), F. left foot (dorsal view), G. left foot revealing two tarsal elements (ventral view), H. left femur (medial view), I. left tibiafibula (medial view), J. left fibulare and tibiale (medial view).

\section{TAXONOMY}

Family: Micrixalidae Dubois, Ohler \& Biju, 2001 Type genus: Micrixalus Boulenger, 1888

Type species: Micrixalus fuscus Boulenger, 1882 Common name: Indian Dancing Frogs

Etymology. The name Micrixalus is composed of two words, 'Micro' which is derived from the Greek "mīkrós" meaning small, and the word "ixalus" which is often used as a suffix in rhacophorid generic names.

Diagnosis. Small-sized frogs with an elongated appearance, male SVL 13-29 mm, female SVL 15-34 mm; presence or absence of dorsolateral skin folds; pupil oval; shagreened to sparsely granular skin; tympanum small or faintly visible externally; vomerine teeth absent; tongue emarginated posteriorly with or without lingual papillae; tip of fingers and toes with discs, with distinct dorsoterminal grooves; webbing absent on fingers; webbing present on toes; posterior parts of thigh usually with a yellow or yellowish-brown longitudinal stripe extending towards the knee, in life.

Distribution. This family is endemic to the Western Ghats mountain range of Peninsular India. The distribution range extends from Kirippara $\left(08.42^{\circ} \mathrm{N}, \quad 77.42^{\circ} \mathrm{E}\right)$, Kanyakumari district, Tamil Nadu state in the south to Amboli $\left(15.95^{\circ} \mathrm{N}, \quad 74.00^{\circ} \mathrm{E}\right), \quad$ Sindhudurg district, Maharashtra state in the north (Fig. 3).

Taxonomic groups. Based on morphological similarities between members of the genus Micrixalus, the present study identified five major groups: Micrixalus elegans group, Micrixalus fuscus group, Micrixalus nudis group, Micrixalus saxicola group and Micrixalus silvaticus group. Taxonomic accounts of all the species are provided group-wise and each species is morphologically compared only with closely related members within its group.

\section{Micrixalus elegans group}

Members. Micrixalus candidus sp. nov., Micrixalus elegans, Micrixalus kurichiyari sp. nov., Micrixalus niluvasei sp. nov., Micrixalus sairandhri sp. nov., Micrixalus spelunca sp. nov. and Micrixalus uttaraghati sp. nov.

This group can be distinguished from other Micrixalus groups by the combination of following morphological characters: small adult size (male, SVL 11-21 mm; female, SVL 17-23 $\mathrm{mm}$ ); dorsolateral folds weakly developed or absent; fourth toe webbing extends beyond the second subarticular tubercle on either side; absence of outer metatarsal tubercles; presence of a white streak that extends from margins of the lower jaw, up to the posterior corner of upper arm insertion or beyond (except in Micrixalus uttaraghati sp. nov.); lateral sides of head (snout and tympanic area) distinctly lighter in colour compared to the flank (Fig. 11).

\section{Micrixalus candidus sp. nov. White-Cheeked Dancing Frog} (Figs 3, 11A, 12; Tables 1-5)

Holotype. BNHS 5608, an adult male, Kemmanagundi, Chikmagalur dist., Karanataka state, India, collected by SDB and team, 30 June 2010. 
Paratypes. Karnataka: Chikmagalur dist., Kottigehara, BNHS 5609-BNHS 5611 (three males), collected by SDB and team, 17 November 2010.

Comparison. Micrixalus candidus could be confused with $M$. elegans, $M$. kurichiyari, $M$. niluvasei, $M$. sairandhri, $M$. spelunca and $M$. uttaraghati. However, M. candidus differs from $M$. elegans by its nostril closer to tip of snout than eye, EN $1.2 \pm 0.2 \mathrm{~mm}$, NS $0.9 \pm 0.1 \mathrm{~mm}, N=4$ (vs. as close to tip of snout as to eye, EN $1.0 \pm 0.1$ $\mathrm{mm}$, NS $1.0 \pm 0.2 \mathrm{~mm}, N=5$ ), anterior part of flank brown (vs. dark brownish-black), dorsum light grey to light brown (vs. reddish brown); differs from $M$. kurichiyari by its snout rounded in dorsal view (vs. subelliptical), snout rounded in lateral view (vs. acute), nostril closer to tip of snout than eye, EN $1.2 \pm 0.2 \mathrm{~mm}$, NS $0.9 \pm 0.1$ $\mathrm{mm}, N=4$ (vs. as close to tip of snout as to eye, EN $1.4 \pm 0.1 \mathrm{~mm}$, NS $1.4 \pm 0.1 \mathrm{~mm}, N=6$ ), fourth toe webbing just below the first subarticular tubercle on either side (vs. just beyond the second subarticular tubercle on either side); differs from $M$. niluvasei by its snout rounded in dorsal view (vs. subovoid), snout rounded in lateral view (vs. acute); differs from $M$. sairandhri by its nostril closer to tip of snout than eye, EN $1.2 \pm 0.2 \mathrm{~mm}$, NS $0.9 \pm 0.1 \mathrm{~mm}, N=4$ (vs. as close to tip of snout as to eye, EN $1.3 \pm 0.2 \mathrm{~mm}$, NS $1.3 \pm 0.1$ $\mathrm{mm}, N=6$ ); interorbital space wider than upper eyelid, IUE $1.5 \pm 0.1 \mathrm{~mm}$, UEW $1.0 \pm 0.1 \mathrm{~mm}, N$ $=4$ (vs. equal, IUE $1.5 \pm 0.1 \mathrm{~mm}$, UEW $1.5 \pm 0.1$ $\mathrm{mm}, N=6$ ), snout rounded in lateral view (vs. acute), fourth toe webbing up to the first subarticular tubercle on either side (vs. just beyond the second subarticular tubercle on either side); differs from $M$. spelunca by its snout rounded in dorsal view (vs. subovoid), snout rounded in lateral view (vs. acute), head longer than its wide, HW $5.4 \pm 0.6 \mathrm{~mm}$, HL $6.1 \pm 0.9, N$ $=4$ (vs. equal, HW $5.6 \pm 0.2 \mathrm{~mm}$, HL $5.6 \pm 0.2, N$ $=6$ ), shank longer to foot length, SHL $8.6 \pm 1.1$ $\mathrm{mm}$, FOL $7.8 \pm 0.4 \mathrm{~mm}, N=4$ (vs. equal, SHL 8.4 $\pm 0.2 \mathrm{~mm}$, FOL $8.4 \pm 0.3 \mathrm{~mm}, N=6$ ), anterior part of flank brown, in life (vs. bluish-black or brownish-black with light brown reticulations); differs from $M$. uttaraghati by its snout rounded in lateral view (vs. acute), fourth toe webbing below the first subarticular tubercle on either side (vs. up to the disc on either side), dorsal skin shagreened (vs. spinular), dermal fringe along toe $\mathrm{V}$ from tip of toe to heel weakly developed, without glandular projections and spinules in males (vs. dermal fringe along toe $\mathrm{V}$ from tip of toe to heel well developed, with glandular projections ending with sharp spinules in males).

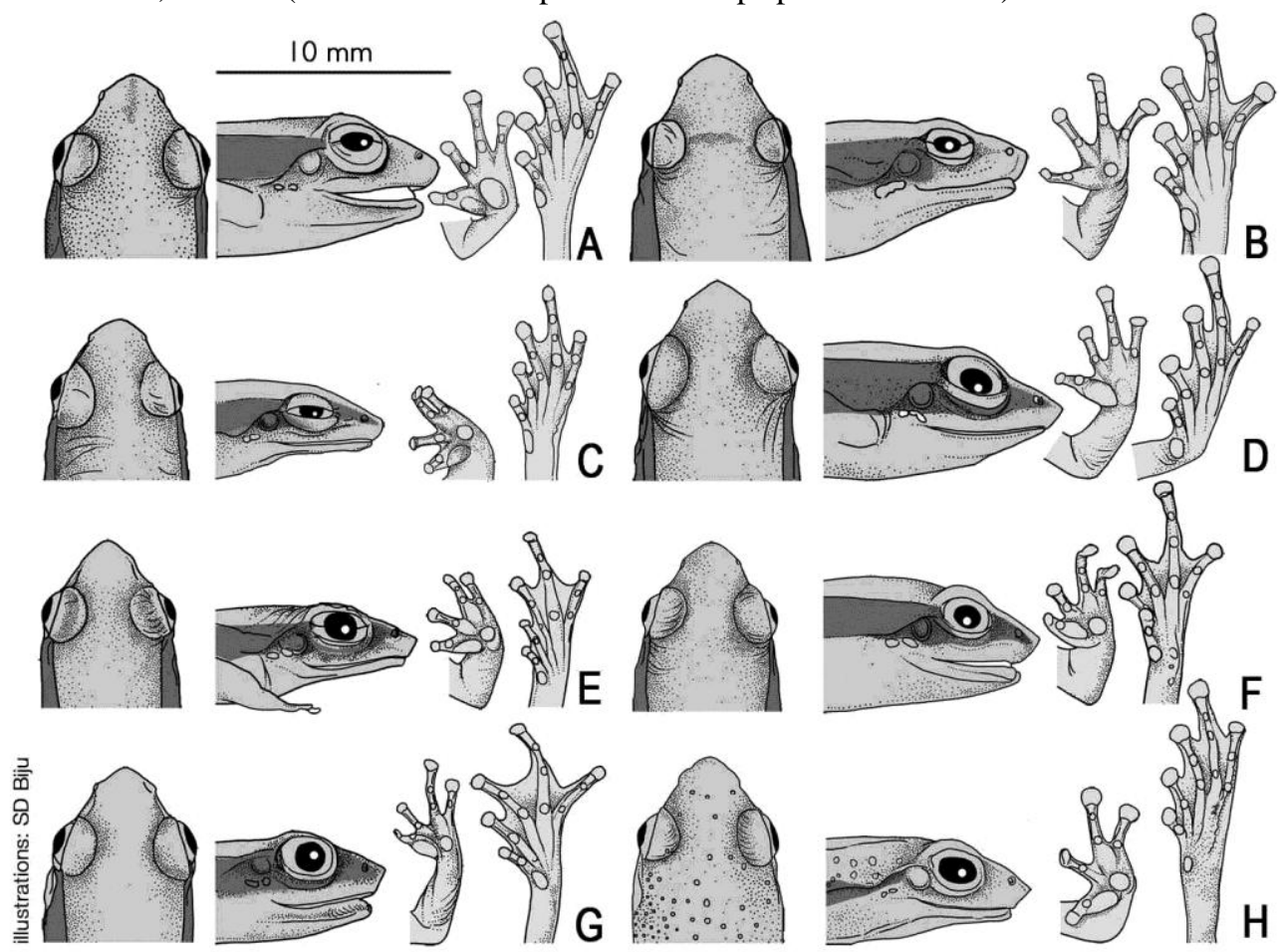

Figure 11. From left to right, dorsal view of head, lateral view of head, ventral view of hand and ventral view of foot of Micrixalus elegans group: A. Micrixalus candidus sp. nov. (HT, BNHS 5608, m), B. M. elegans (NT, BNHS 5808, f), C. M. elegans (RS, BNHS 5613, m), D. Micrixalus kurichiyari sp. nov. (HT, BNHS 5621, m), E. Micrixalus niluvasei sp. nov. (HT, BNHS 5627, m), F. Micrixalus sairandhri sp. nov. (HT, BNHS 5633, m), G. Micrixalus spelunca sp. nov. (HT, BNHS 5640, m), H. Micrixalus uttaraghati sp. nov. (HT, BNHS 5647, m). 
Micrixalus candidus could not be confused with three other species (M. kottigeharensis, $M$. narainensis and $M$. swamianus) described from its type locality, Kottigehara. However, in order to avoid any confusion, we compare the new species with the later three species. Micrixalus candidus differs from $M$. kottigeharensis, $M$. narainensis and $M$. swamianus by its snout rounded in dorsal view (vs. pointed), snout rounded in lateral view (vs. acute), tongue without lingual papilla (vs. with lingual papilla) and presence of a white streak extending from margins of the lower jaw, up to the posterior corner of upper arm insertion or beyond (vs. absent).

Description of holotype (measurements in mm). Adult male (SVL 20.2); head small (HW 6.2, HL 7.1), longer than wide, flat above; snout rounded in dorsal and lateral view, its length (SL 3.1) longer than horizontal diameter of eye (EL 2.5); loreal region vertical, rounded canthus rostralis; interorbital space flat, wider (IUE 1.5) than upper eyelid (UEW 1.0) and shorter than internarial distance (IN 1.8); distance between back of eye (IBE 5.2) 1.5 times the distance between front of eye (IFE 3.4); nostril oval, closer to tip of snout (NS 1.1) than eye (EN 1.4); tympanum (TYD 0.6) $24 \%$ of eye diameter (EL 2.5); tongue moderately large, emarginate, without median lingual papillae; supratympanic fold that extends from posterior corner of eye to near the shoulder, weakly developed. Forelimbs (FAL 3.7) shorter than hand length (HAL 5.0); finger discs moderately wide compared to finger width (fd1 0.6, fw1 0.3; fd2 0.6, fw2 0.3; fd3 0.7, fw3 0.3; fd4 0.6, fw4 0.3); subarticular tubercles weakly developed, oval, single, all present. Thigh length (TL 9.7) equal to shank (SHL 9.7), and longer than foot (FOL 8.2); toe discs wide compared to toe width (td1 0.6, tw1 $0.2 ; \operatorname{td} 20.7$, tw2 $0.2 ; \operatorname{td} 3$ 0.9, tw3 0.4; td4 0.9, tw4 0.3; td5 0.7, tw5 0.3); webbing present: I1 $-1 \frac{3}{4} \mathrm{III} 1-2 \mathrm{III} 1-2^{+} \mathrm{IV} 2^{+}-1{ }^{1} / 4 \mathrm{~V}$; subarticular tubercles weakly developed, oval, all present; inner metatarsal tubercles distinct and moderately short; outer metatarsal tubercles absent.

Skin of snout, between eyes, upper eyelids and posterior part of back shagreened; dorsolateral folds that extend from the posterior corner of the eye to the entire body length on both sides, weakly developed; dorsal parts of forelimb shagreened; thigh, tibia and tarsus shagreened; ventral surfaces of throat, chest and abdomen smooth; posterior parts of thigh shagreened.

Colour in preservation. Dorsum light grey with irregular light brown spots; a brown band connecting the eyes; anterior parts of flank dark brown; tympanic area brownish-black; forelimbs, dorsal surfaces of thigh, tibia and feet greyishbrown with dark brown cross-bands, posterior parts of thigh light grey with dark grey reticulations; throat, chest and belly light grey with minute black spots; tibia and feet greyishbrown, webbing blackish-grey.

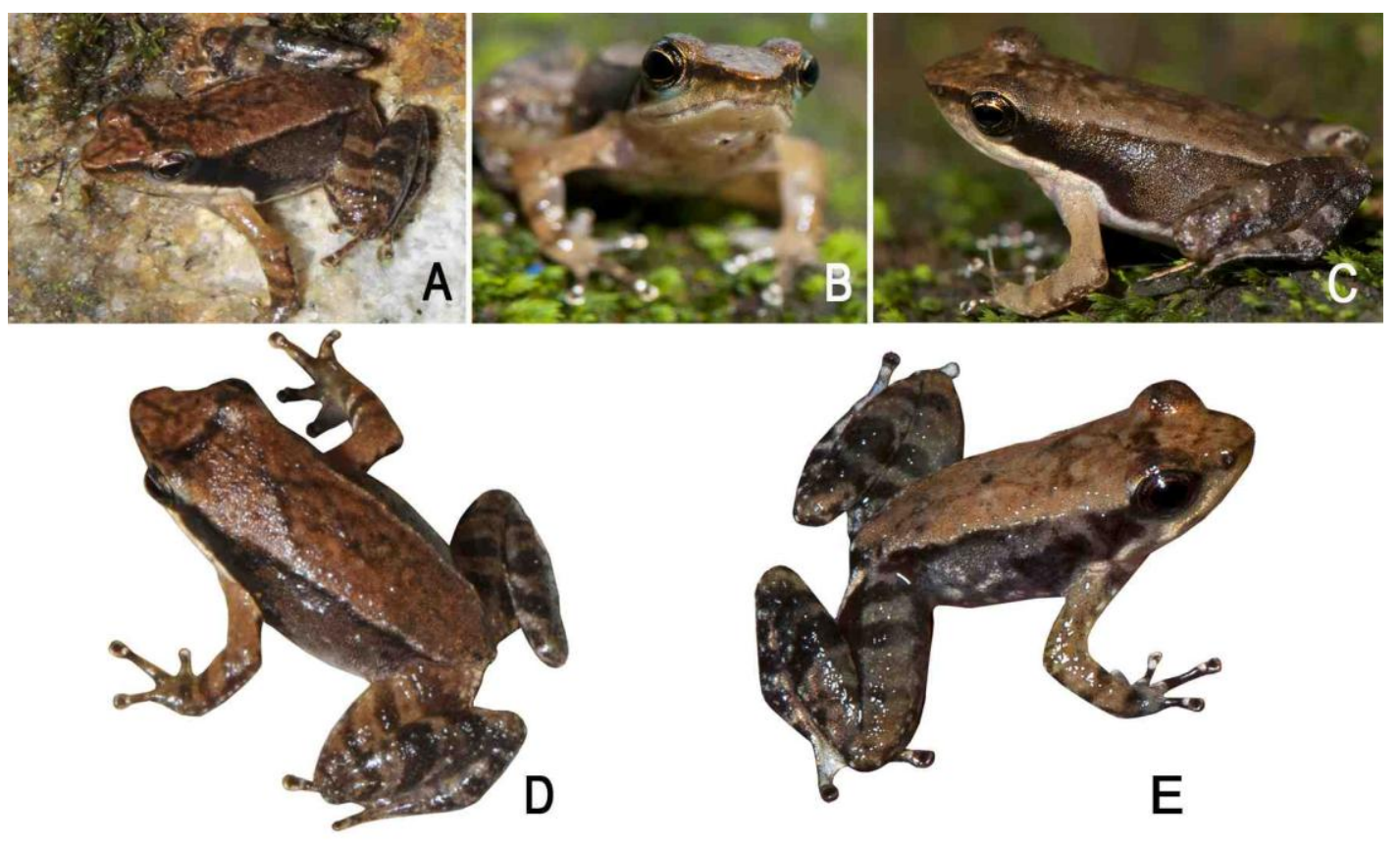

Figure 12. Micrixalus candidus sp. nov. in life: A. dorsolateral view (HT, BNHS 5608, m); B. front view (PT, BNHS 5611, m); C. dorsolateral view (PT, BNHS 5609, m); D. dorsal view (HT, BNHS 5608, m); E. dorsolateral view (PT, BNHS 5610, m). Photos: SDB. 
Colour in life. Dorsum uniform light brown; tympanum and surrounding areas light brown; iris light brown with reddish tinge; anterior parts of flank brown, posterior parts of flank light greyishbrown; groin light grey with minute black spots; dorsal surface of limbs light brown with dark brown cross-bands; throat, chest and belly greyish-white.

Variations. See Table 5 for morphometric characters of four adult males. For colour variations see Figure 12.

Secondary sexual characters. Male: Single prominent oval-shaped nuptial pad on finger I present, cream-coloured; single gular pouch while calling.

Etymology. The species epithet is a noun in apposition, therefore invariable, derived from the Latin word 'candidus' meaning white, referring to the prominent white streak on sides of the head, in this species.

Distribution. Micrixalus candidus is known only from the state of Karnataka, with its distribution restricted between the Palghat gap and Goa gap in the Western Ghats. The present study found this species in Kemmanagundi and Kottigehara (Chikmagalur dist.) (Fig. 3, Table 1).

Habitat and natural history. The preferred habitat of this species is flowing streams covered with forest canopy. The male specimens were found actively calling and collected between 10:00-16:00 h.

\section{Micrixalus elegans (Rao, 1937) Elegant Dancing Frog \\ (Figs 3,11B-C, 13; Tables 1-5)}

Original name and description. Philautus elegans Rao, 1937. On some new forms of Batrachia from S. India. Proceedings of Indian Academy Science (B) 6: 407. Neotype. By present designation, BNHS 5808, an adult female (SVL $21.0 \mathrm{~mm}$ ), collected by SDB, 12 September 2012 . Neotype locality. Kempholay, Hassan dist., Karnataka state. Current status of specific name. Valid name, as Micrixalus elegans (Rao, 1937) (Bossuyt and Dubois, 2001).

Referred specimens. Karnataka: Hassan dist., Kempholay, BNHS 5612, an adult male, collected by SDB, 30 July 2002, BNHS 5613, an adult male, collected by SDB, 12 September 2012; Maranhalli, Sakleshpur, BNHS 5614-BNHS 5615, two adult males, and BNHS 5616, an adult female, collected by SDB and Systematics lab team, 1 October 2012; Kodagu dist., Bhagamandala, BNHS 5617, an adult female, collected by SDB, 28 June 2012; Yavakapady, Coorg, BNHS 5618, an adult male, BNHS 5619BNHS 5620, two adult females, collected by SDB and Systematics lab team, 4 October 2012.
Other material studied. Karnataka: Dakshina Kannada dist., Charmadi Ghats, SDBDU 2011.1397, collected by SDB and Systematics lab team, 23 October 2011; Hassan dist., Kempholay, SDBDU 2010.003, collected by SDB and Systematics lab team, 16 November 2010; Kerala: Kannur dist., Meenmutty, Aralam, SDBDU 2008.412, collected by SDB, 5 June 2008.

Comments. Rao (1937) described Philautus elegans from "Kempholey, Hassan" based on a sole specimen ("SVL $23.0 \mathrm{~mm}$ "). Bossuyt and Dubois (2001) transferred this taxon to the genus Micrixalus. However, since the original namebearing type of this nominal species is unknown and probably lost (Dubois 1987; SDB personal observation), the status interpretation of its name has to rely on the original description (Rao, 1937). For nomenclatural stability, designation of a neotype for Micrixalus elegans is necessary. Our new collections from the type locality (Kempholay) are comparable with a few characters stated in the original description of Philautus elegans: "SVL $23.0 \mathrm{~mm}$ ", "crimson above" and "sides of body commencing from behind the eyes black". In order to stabilize this name, we herein designate a neotype for Philautus elegans (= Micrixalus elegans) Rao, 1937.

Comparison. Micrixalus elegans could be confused with $M$. candidus, $M$. kurichiyari, $M$. niluvasei, $M$. sairandhri, $M$. spelunca and $M$. uttaraghati. However, M. elegans differs from $M$. kurichiyari by its snout rounded in dorsal view (vs. subelliptical), snout rounded in lateral view (vs. acute), fourth toe webbing extending up to the first subarticular tubercle on either side (vs. just beyond the second subarticular tubercle on either side); differs from $M$. niluvasei by its snout rounded in dorsal view (vs. subovoid), snout rounded in lateral view (vs. acute), nostril as close to eye as to tip of snout, male, EN $1.0 \pm 0.1 \mathrm{~mm}$, NS $1.0 \pm 0.1 \mathrm{~mm}, N=6$, female, EN $1.3 \pm 0.2$ $\mathrm{mm}$, NS $1.3 \pm 0.2 \mathrm{~mm}, N=5$ (vs. closer to tip of snout than eye, male, EN $1.0 \pm 0.1 \mathrm{~mm}$, NS $0.5 \pm$ $0.1 \mathrm{~mm}, N=2$, female, EN $1.8 \pm 0.1 \mathrm{~mm}$, NS 1.1 $\pm 0.1 \mathrm{~mm}, N=4$ ); differs from $M$. sairandhri by its snout rounded in lateral view (vs. acute), interorbital space wider than upper eyelid, male, IUE $1.7 \pm 0.1 \mathrm{~mm}$, UEW $1.0 \pm 0.2 \mathrm{~mm}, N=6$, female, IUE $2.3 \pm 0.3 \mathrm{~mm}$, UEW $1.2 \pm 0.2 \mathrm{~mm}, N$ $=5$ (vs. equal, male, IUE $1.5 \pm 0.1 \mathrm{~mm}$, UEW 1.5 $\pm 0.1 \mathrm{~mm}, N=6$, female, IUE $2.1 \mathrm{~mm}$, UEW 2.0 $\mathrm{mm}, N=1$ ), shank equal to thigh length, male, SHL $7.9 \pm 0.5 \mathrm{~mm}$, TL $7.9 \pm 0.5 \mathrm{~mm}, N=6$, female, SHL $10.3 \pm 0.4 \mathrm{~mm}$, TL $10.3 \pm 0.7 \mathrm{~mm}, N$ $=5$ (vs. shorter, SHL $9.4 \pm 0.3 \mathrm{~mm}$, TL $10.1 \pm 0.3$ $\mathrm{mm}, N=6$, female, SHL $11.5 \mathrm{~mm}$, TL $12.3 \mathrm{~mm}$, $N=1$ ); differs from $M$. spelunca by its snout 


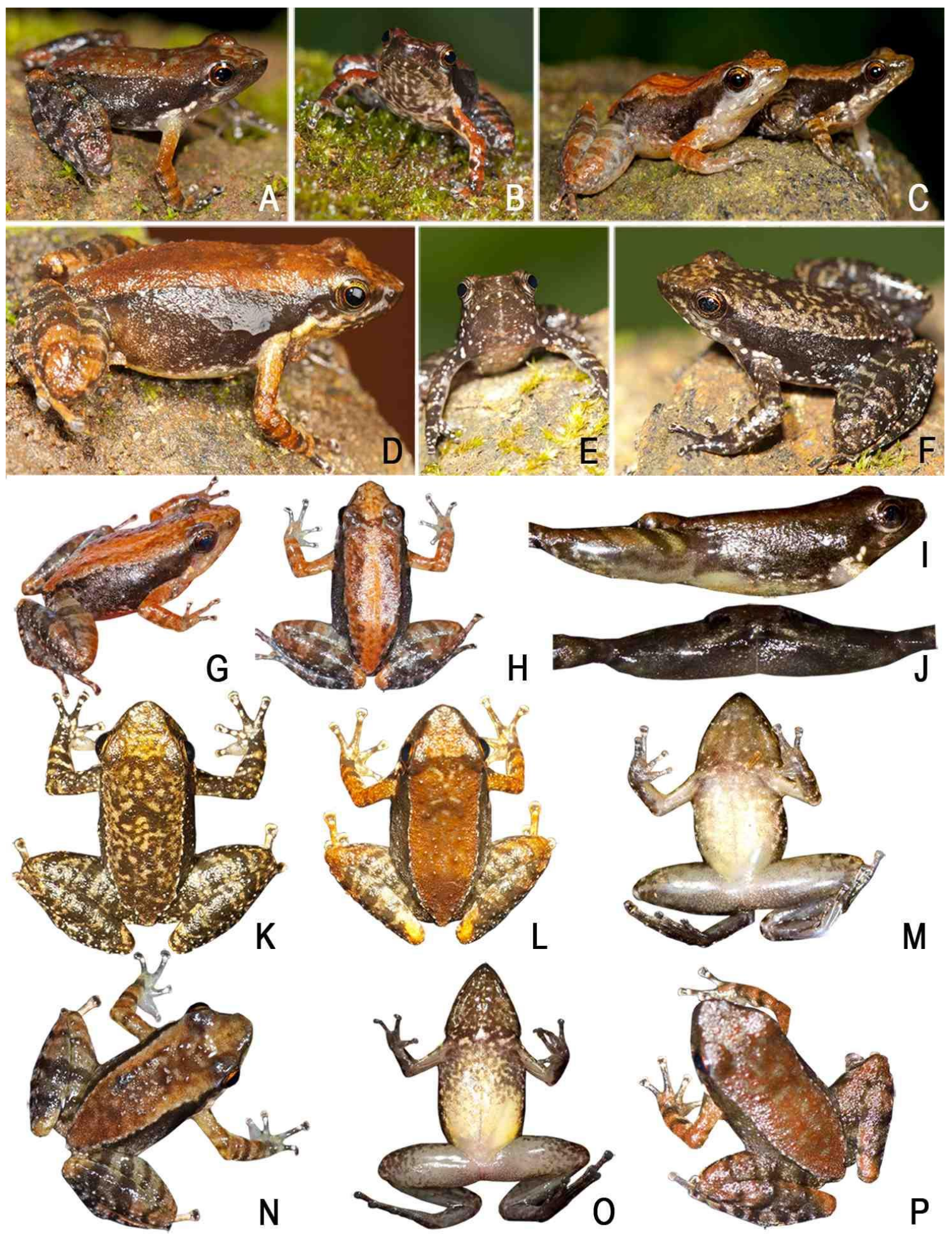

Figure 13. Micrixalus elegans in life: A. dorsolateral view, B. front view (NT, BNHS 5808, f); C. dorsolateral view (RS, BNHS 5616, f, on left; RS, BNHS 5614, m, on right); D. dorsolateral view (RS 2118, f); E. front view, F. dorsolateral view (RS, BNHS 5613, m); G. dorsolateral view, H. dorsal view (RS, BNHS 5614, m); I. lateral view of thigh and groin, J. posterior side of thighs (NT, BNHS 5808, f); K. dorsal view (RS, BNHS 5613, m); L. dorsal view, M. ventral view (RS, BNHS 5619, f); N. dorsal view, O. ventral view (RS, SDB2012.2235, m); P. dorsal view (RS, BNHS 5618, m). Photos: SDB.

rounded in dorsal view (vs. subovoid), snout rounded in lateral view (vs. acute), head longer than wide, male, HW $4.9 \pm 0.3 \mathrm{~mm}$, HL $5.2 \pm 0.3$, $N=6$, female, HW $6.0 \pm 0.5 \mathrm{~mm}$, HL $6.5 \pm 0.4, N$ 
= 5 (vs. equal, male, HW $5.6 \pm 0.2 \mathrm{~mm}$, HL $5.6 \pm$ $0.2, N=6$, female, HW $6.3 \mathrm{~mm}$, HL 6.4, $N=1$ ), shank longer than foot length, male, SHL $7.9 \pm 0.5$ $\mathrm{mm}$, FOL $6.9 \pm 0.4 \mathrm{~mm}, N=6$, female, SHL 10.3 $\pm 0.4 \mathrm{~mm}$, FOL $8.5 \pm 0.6 \mathrm{~mm}, N=5$ (vs. equal, SHL $8.4 \pm 0.2 \mathrm{~mm}$, FOL $8.4 \pm 0.3 \mathrm{~mm}, N=6$, female, SHL $9.1 \mathrm{~mm}$, FOL $9.1 \mathrm{~mm}, N=1$ ); differs from $M$. uttaraghati by its snout rounded in lateral view (vs. acute), fourth toe webbing below the first subarticular tubercle on either side (vs. up to the disc on either side), colour of flanks blackishbrown, and darker compared to the dorsal colour both in life and preservation (vs. flank colour similar to dorsum, with a dark brownish-black streak from behind the eye to near the groin, on either side).

For differences with Micrixalus candidus see 'Comparison' of that species.

Description of neotype (all measurements in $\mathrm{mm}$ ). Adult female (SVL 21.0); head small (HW 6.4, HL 7.0), longer than wide, flat above; snout rounded in dorsal and lateral view, its length (SL $3.5)$ longer than horizontal diameter of eye (EL 2.4); loreal region vertical with rounded canthus rostralis; interorbital space flat, wider (IUE 2.7) than upper eyelid (UEW 1.2); distance between back of eye (IBE 5.4) 1.4 times the distance between front of eye (IFE 3.8); nostril oval, closer to eye (EN 1.6) than tip of snout (NS 2.5); tympanum (TYD 0.8 ) $33 \%$ of eye diameter (EL 2.4); tongue moderately large, emarginate, without lingual papilla; supratympanic fold that extends from posterior corner of eye to near the shoulder, weakly developed. Forelimbs (FAL 4.2) shorter than hand length (HAL 5.6); finger discs moderately wide compared to finger width (fd1 0.5, fw1 0.2; fd2 0.6, fw2 0.3; fd3 0.7, fw3 0.3; fd4 0.7, fw4 0.2); subarticular tubercles well developed, oval, single, all present; prepollex weakly developed; round palmar tubercles present. Thigh length (TL 10.6) subequal to shank (SHL 10.5), and longer than foot (FOL 8.0); toe discs wide compared to toe width (td1 0.6 , tw1 $0.3 ; \mathrm{td} 20.8, \mathrm{tw} 20.3 ; \mathrm{td} 30.9$, tw3 0.3; td4 1.0, tw4 0.4 ; td5 0.9, tw5 0.4); webbing present: I1$1 \frac{1}{2} \mathrm{II} 1-2 \mathrm{III} 1-2^{+} \mathrm{IV} 2^{+}-1 \mathrm{~V}$; subarticular tubercles weakly developed, oval, all present; inner metatarsal tubercles distinct and moderately short; outer metatarsal tubercle absent.

Skin of snout, between eyes and upper eyelids shagreened; dorsolateral folds that extend from the posterior corner of the eye to the entire body length on both sides, weakly developed; thigh, tibia and tarsus shagreened; ventral surfaces of throat, chest and abdomen smooth; posterior parts of thigh shagreened to sparsely granular.

Colour in preservation. Dorsum blackishbrown; a white streak starting just behind the tympanum, continuing over the arm and ending at posterior corner of the shoulder; lateral sides of head (snout and tympanic area) distinctly dark grey; flanks dark blackish-brown; forelimbs, dorsal surfaces of thigh, tibia and feet light brown with dark brown cross-bands, posterior parts of thigh grey with dark grey reticulations; throat, chest and belly light brown with light grey reticulations. Colour in life. Dorsum uniform reddish-brown with scattered yellowish-grey spots; lateral sides of head (snout and tympanic area) distinctly dark blackish-brown; iris light brown with reddish tinge; flanks blackish-brown; groin greyish-brown; dorsal surface of limbs reddish-brown with dark brown cross-bands; throat and margins of throat and chest greyishbrownish with light yellowish-grey reticulations; belly light yellowish-grey; thigh and shank grey with light brown spots; foot brownish-black.

Variations. See Table 5 for morphometric characters of six adult males and five adult females. For colour variations see Figure 13.

Secondary sexual characters. Male (SDB 2002.1085): Single prominent oval-shaped nuptial pad on finger I present, cream-coloured. Female (SDB 2012.2245): ova yellowish-white with minute black spots (diameter 1.3-1.5 $\mathrm{mm}, N=$ 20).

Distribution. Micrixalus elegans is known only from the states of Kerala and Karnataka, with its distribution restricted between the Palghat gap and Goa gap in the Western Ghats. The present study found this species only at Aralam (Kannur dist.) in Kerala, and at Kempholay, Sakleshpur (Hassan dist.), Yavakapady and Bhagamandala (Kodagu dist.) in Karnataka (Fig. 3, Table 1).

Habitat and natural history. The preferred habitat of this species is damp leaf litter on the banks of fast flowing forest streams. In the present study specimens were collected between 10:0016:00 h.

\section{Micrixalus kurichiyari sp. nov. Kurichiyar Dancing Frog \\ (Figs 3, 11D, 14; Tables 1-5)}

Holotype. BNHS 5621, an adult male, Kurichiyarmala, Wayanad dist., Kerala state, India, collected by SDB and SG, 5 June 2012.

Paratypes. Kerala: Wayanad dist., Kurichiyarmala, BNHS 5622-BNHS 5626, five adult males, collected along with holotype.

Other material studied. Kerala: Wayanad dist., Kurichiyarmala, SDBDU 2008.413, collected by SDB, 5 June 2008.

Comparison. Micrixalus kurichiyari could be confused with $M$. candidus, M. elegans, $M$. niluvasei, M. sairandhri, M. spelunca and $M$. uttaraghati, However, M. kurichiyari differs from 
M. niluvasei by its snout subelliptical in dorsal view (vs. subovoid), nostril as close to eye as to tip of snout, EN $1.4 \pm 0.1 \mathrm{~mm}$, NS $1.4 \pm 0.1 \mathrm{~mm}$, $N=6$ (vs. closer to tip of snout as to eye, EN $1.0 \pm$ $0.1 \mathrm{~mm}$, NS $0.5 \pm 0.1 \mathrm{~mm}, N=2$ ), fourth toe webbing just beyond the second subarticular tubercle on either side (vs. extending up to the first subarticular tubercle on either side); differs from $M$. sairandhri by its snout subelliptical in dorsal view (vs. rounded), fourth toe webbing just beyond the second subarticular tubercle on either side (vs. well beyond second subarticular tubercle on either side), interorbital space wider than upper eyelid, IUE $2.2 \pm 0.1 \mathrm{~mm}$, UEW $1.4 \pm 0.1 \mathrm{~mm}, N$ $=6$ (vs. equal, IUE $1.5 \pm 0.1 \mathrm{~mm}$, UEW $1.5 \pm 0.1$ $\mathrm{mm}, N=6$ ), thigh subequal to foot length, male TL $9.2 \pm 0.1 \mathrm{~mm}$, FOL $9.3 \pm 0.3 \mathrm{~mm}, N=6$ (vs. longer, TL $10.1 \pm 0.3 \mathrm{~mm}$, FOL $8.9 \pm 0.2 \mathrm{~mm}, N=$
6); differs from $M$. spelunca by its snout subelliptical in dorsal view (vs. subovoid), head longer than its wide, male, HW $6.0 \pm 0.1 \mathrm{~mm}$, HL $7.3 \pm 0.2, N=6$ (vs. equal, male, HW $5.6 \pm 0.2$ $\mathrm{mm}$, HL $5.6 \pm 0.2, N=6$ ), thigh subequal to foot length, male TL $9.2 \pm 0.1 \mathrm{~mm}$, FOL $9.3 \pm 0.3 \mathrm{~mm}$, $N=6$ (vs. longer, TL $9.4 \pm 0.3 \mathrm{~mm}$, FOL $8.4 \pm 0.3$ $\mathrm{mm}, N=6$ ); differs from $M$. uttaraghati by its snout subelliptical in dorsal view (vs. rounded), fourth toe webbing just beyond the second subarticular tubercle on either side (vs. up to the disc on either side), dermal fringe along toe $\mathrm{V}$ smooth in males (vs. dermal fringe along toe $\mathrm{V}$ well developed from tip of toe to heel, with glandular projections ending with sharp spinules in males).

For differences with Micrixalus candidus, and M. elegans see 'Comparison' of those species.
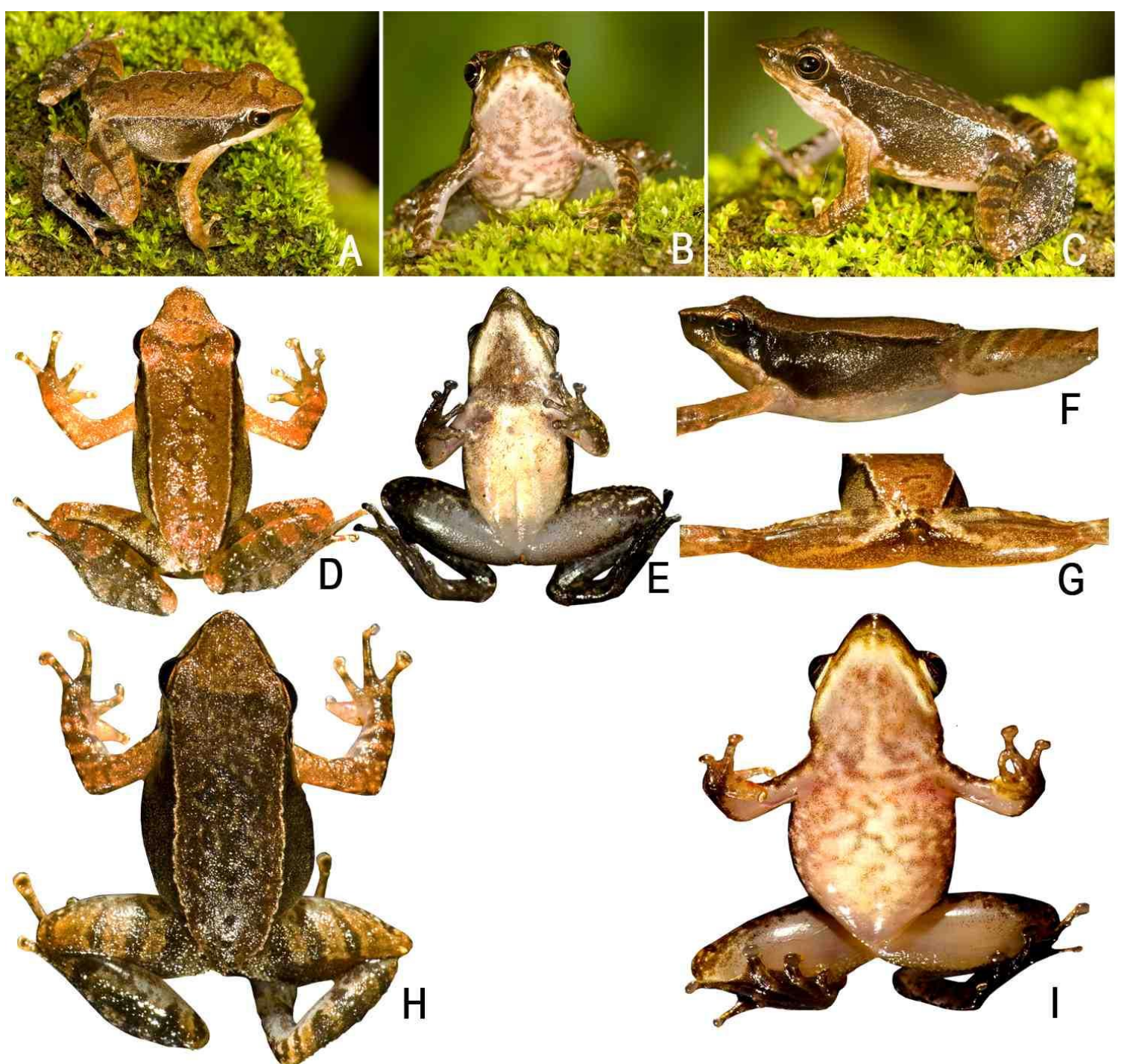

Figure 14. Micrixalus kurichiyari sp. nov. in life: A. dorsolateral view, B. front view (HT, BNHS 5621, m); C. dorsolateral view (PT, BNHS 5622, m); D. dorsal view, E. ventral view, F. lateral view of thigh and groin, G. posterior side of thighs (HT, BNHS 5621, m); H. dorsal view, I. ventral view (PT, BNHS 5622, m). Photos: SDB. 
Description of holotype (measurements in $\mathrm{mm}$ ). Adult male (SVL 18.6); head small (HW 6.1, HL 7.3), longer than wide, flat above; snout subelliptical in dorsal view, acute in lateral view, its length (SL 3.2) longer than horizontal diameter of eye (EL 2.6); loreal region vertical, rounded canthus rostralis; interorbital space flat, wider (IUE 2.3) than upper eyelid (UEW 1.5) and subequal to internarial distance (IN 2.4); distance between back of eye (IBE 5.3) 1.8 times the distance between front of eye (IFE 3.0); nostril oval, as close to eye (EN 1.5) as to tip of snout (NS 1.5); tympanum (TYD 1.0) $38 \%$ of eye diameter (EL 2.6); tongue moderately large, emarginate, without median lingual papillae; supratympanic fold that extends from posterior corner of eye to near the shoulder, weakly developed. Forelimbs (FAL 4.0) shorter than hand length (HAL 5.0); finger discs moderately wide compared to finger width (fd1 0.5 , fw 10.3 ; fd2 0.5, fw2 0.2; fd3 0.7, fw3 0.3; fd4 0.7, fw4 0.3); subarticular tubercles weakly developed, oval, single, all present. Thigh length (TL 9.1) shorter to shank (SHL 9.8), and subequal to foot (FOL 9.2); toe discs wide compared to toe width (td1 0.6 , tw1 $0.3 ; \operatorname{td} 20.8, \operatorname{tw} 20.3 ; \operatorname{td} 30.8, \operatorname{tw} 30.3 ; \operatorname{td} 40.8, \operatorname{tw} 4$ 0.3 ; td5 0.7, tw5 0.3); webbing present: I113/4II1-2III1-2-IV2--1V; subarticular tubercles rather well developed, oval, all present; inner metatarsal tubercles distinct and moderately short; outer metatarsal tubercles absent.

Skin of snout, between eyes, upper eyelids and posterior part of back shagreened to sparsely granular; dorsolateral folds that extend from the posterior corner of the eye to the entire body length on both sides, weakly developed; flanks shagreened to sparsely granular; dorsal parts of forelimb, thigh, tibia and tarsus shagreened to sparsely granular; ventral surfaces of throat, chest and abdomen smooth; posterior parts of thigh shagreened.

Colour in preservation. Dorsum brown with irregular light grey spots; flanks dark brown; tympanic area brownish-black; forelimbs, dorsal surfaces of thigh, tibia and foot greyish-brown with dark brown cross-bands, posterior parts of thigh light grey with dark grey reticulations; throat, chest and belly light grey with minute black spots; tibia and feet greyish-brown; webbing blackish-grey. Colour in life. Dorsum uniform brown; tympanum and surrounding areas dark brown; iris light brown with reddish tinge; anterior parts of flank brownish-black, posterior parts of flanks light greyish-brown; groin light yellow; dorsal surface of limbs light brown with dark brown cross-bands; throat and margins of throat, chest and belly greyish-white; ventral surface of thighs dark grey; foot blackish-grey.
Variations. See Table 5 for morphometric characters of six adult males and for colour variations see Figure 14.

Secondary sexual characters. Male: Single prominent, oval-shaped nuptial pad on finger I present, cream-coloured; single gular pouch while calling.

Etymology. The species is named after 'Kurichiyar', where the type series was collected. The species name kurichiyari is a noun in the genitive case.

Distribution. Micrixalus kurichiyari is known only from its type locality Kurichiyarmala (Wayanad dist., Kerala state), which lies north of Palghat gap in the Western Ghats (Fig. 3, Table 1).

Habitat and natural history. The preferred habitat of this species is flowing streams covered with forest canopy. A few male specimens were found calling and collected between 11:00-16:00 h.

\section{Micrixalus niluvasei sp. nov. Niluvase Dancing Frog (Figs 3,11E, 15; Tables 1-5)}

Holotype. BNHS 5627, an adult male, Niluvase, Shimoga dist., Karnataka state, India, collected by KVG, GS and Sameer Ali, 29 September 2012.

Paratypes. Karnataka: Shimoga dist., Niluvase, BNHS 5628, an adult male, BNHS 5629- BNHS 5632, four adult females, collected along with holotype.

Comments. This species was identified as Micrixalus fuscus by Gururaja et al. (2007).

Comparison. Micrixalus niluvasei could be confused with $M$. candidus, M. elegans, $M$. kurichiyari, M. sairandhri, M. spelunca and $M$. uttaraghati. However, M. niluvasei differs from M. sairandhri by its snout subovoid in dorsal view (vs. rounded), fourth toe webbing up to first subarticular tubercle on either side (vs. extending beyond the second subarticular tubercle on either side), interorbital space wider than upper eyelid, male, IUE $1.9 \pm 0.0 \mathrm{~mm}$, UEW $1.2 \pm 0.0 \mathrm{~mm}, N=$ 2 , female, IUE $2.0 \pm 0.3 \mathrm{~mm}$, UEW $1.2 \pm 0.1 \mathrm{~mm}$, $N=4$ (vs. equal, male, IUE $1.5 \pm 0.1 \mathrm{~mm}$, UEW $1.5 \pm 0.1 \mathrm{~mm}, N=6$, female, IUE $2.1 \mathrm{~mm}$, UEW $2.0 \mathrm{~mm}, N=1$ ), thigh equal to shank length, male, TL $8.8 \pm 0.1 \mathrm{~mm}$, SHL $8.8 \pm 0.1 \mathrm{~mm}, N=2$, female, TL $10.3 \pm 0.3 \mathrm{~mm}$, SHL $10.3 \pm 0.3 \mathrm{~mm}, N$ $=4$ (vs. longer, TL $10.1 \pm 0.3 \mathrm{~mm}$, SHL $9.4 \pm 0.3$ $\mathrm{mm}, N=6$, female, TL $12.3 \mathrm{~mm}$, SHL $11.5 \mathrm{~mm}, N$ $=1$ ); differs from $M$. spelunca by its thigh equal to shank length, male, TL $8.8 \pm 0.1 \mathrm{~mm}$, SHL $8.8 \pm$ $0.1 \mathrm{~mm}, N=2$, female, TL $10.3 \pm 0.3 \mathrm{~mm}$, SHL $10.3 \pm 0.3 \mathrm{~mm}, N=4$ (vs. longer, TL $9.4 \pm 0.3$ mm, SHL $8.4 \pm 0.2 \mathrm{~mm}, N=6$, female, TL 10.5 $\mathrm{mm}$, SHL $9.1 \mathrm{~mm}, N=1$ ), shank longer than foot length, male, SHL $8.8 \pm 0.1 \mathrm{~mm}$, FOL $7.0 \pm 0.1$ 
$\mathrm{mm}, N=2$, female, SHL $10.3 \pm 0.3 \mathrm{~mm}$, FOL 9.0 $\pm 0.4 \mathrm{~mm}, N=4$ (vs. equal, male, SHL $8.4 \pm 0.2$ $\mathrm{mm}$, FOL $8.4 \pm 0.3 \mathrm{~mm}, N=6$, female, SHL 9.1 $\mathrm{mm}$, FOL $9.1 \mathrm{~mm}, N=1$ ); differs from $M$. uttaraghati by its snout subovoid in dorsal view (vs. rounded), fourth toe webbing extending up to first subarticular tubercle on either side (vs. up to the disc on either side), dermal fringe along toe $\mathrm{V}$ smooth (vs. dermal fringe along toe $\mathrm{V}$ well developed from tip of toe to heel, with glandular projections ending with sharp spinules in males).

For differences with Micrixalus candidus, $M$. elegans and M. kurichiyari, see 'Comparison' of those species.

Description of holotype (measurements in mm). Adult male (SVL 15.5), head small (HW 4.9, subovoid in dorsal view, acute in lateral view, its length (SL 1.8) longer than horizontal diameter of eye (EL 1.2); loreal region vertical, rounded canthus rostralis; interorbital space flat, wider (IUE 1.8) than upper eyelid (UEW 1.2) and equal to internarial distance (IN 1.8); distance between back of eye (IBE 4.7) 1.6 times the distance between front of eye (IFE 2.9); nostril oval, closer to tip of snout (NS 0.5) than eye (EN 0.9); tympanum (TYD 0.4 ) $33 \%$ of eye diameter (EL 1.2); tongue moderately large, emarginate, without median lingual papillae; supratympanic fold that extends from posterior corner of eye to near the shoulder, weakly developed. Forelimbs (FAL 2.9) shorter than hand length (HAL 3.6); finger discs moderately wide compared to finger width
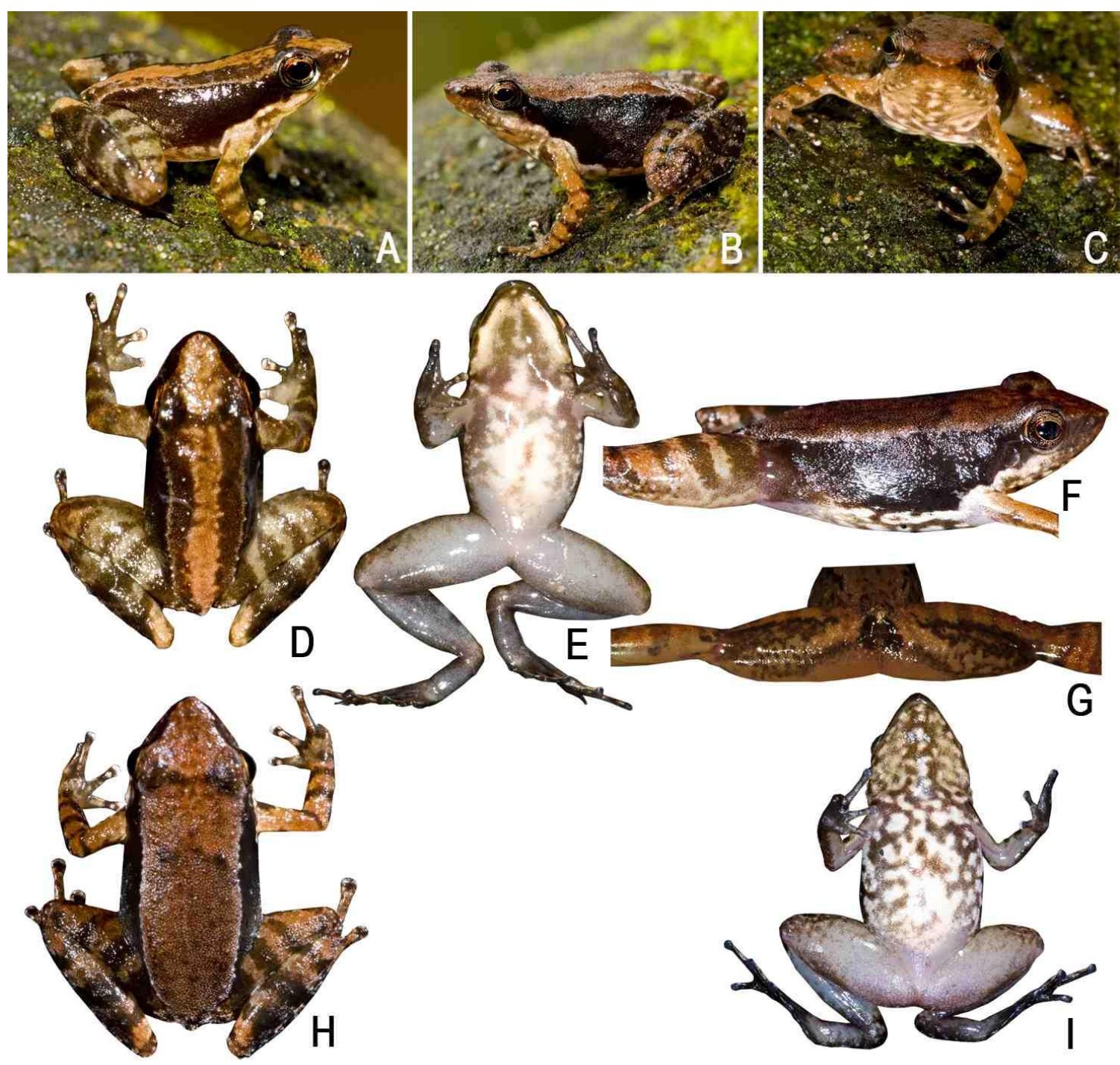

\section{,}


(fd1 0.3, fw1 0.2; fd2 0.4, fw2 0.2; fd3 0.6, fw3 0.3 ; fd4 0.5, fw4 0.3); subarticular tubercles weakly developed, oval, single, all present. Thigh length subequal (TL 8.8) to shank (SHL 8.7), and longer than foot (FOL 6.9); toe discs wide compared to toe width $(\operatorname{td} 10.4, \operatorname{tw} 10.2 ; \operatorname{td} 20.5$, tw2 0.2; td3 0.6, tw3 0.2; td4 0.6, tw4 0.2; td5 0.5, tw5 0.2); webbing present: I1-2-II1-2III1-2IV2$1 \mathrm{~V}$; subarticular tubercles weakly developed, oval, all present; inner metatarsal tubercles distinct and moderately short; outer metatarsal tubercles absent.

Skin of snout, between eyes, upper eyelids and posterior part of back shagreened; dorsolateral folds that extend from the posterior corner of the eye to the entire body length on both sides, weakly developed; dorsal parts of forelimb shagreened; thigh, tibia and tarsus shagreened; ventral surfaces of throat, chest and abdomen smooth; posterior parts of thigh shagreened.

Colour in preservation. Dorsum brown with a broad light orangish-brown band from the tip of snout to vent, a brown band connecting the eyes; flanks dark brown; tympanic area brownishblack; forelimbs, dorsal surfaces of thigh, tibia and feet greyish-brown with dark brown cross-bands, posterior parts of thigh light brown with dark greyish-brown reticulations; throat, chest and belly light grey with minute black spots; tibia and feet greyish-brown; webbing blackish-grey. Colour in life. Dorsum uniform dark brown with a broad light brown band from the tip of snout to vent; tympanum and surrounding areas dark brown; iris light brown with reddish tinge; anterior parts of flank brownish-black, posterior parts of flank light greyish-brown; groin light brown; dorsal surface of limbs greyish-brown with dark brown cross-bands; throat and margins of throat, chest and belly dark grey; thighs light grey; foot blackish-grey.

Variations. See Table 5 for morphometric characters of two adult males and four adult females. For colour variations see Figure 15.

Secondary sexual characters. Male: Single prominent oval-shaped nuptial pad on finger I present, cream-coloured; single gular pouch while calling. Female (BNHS 5629): ova yellowishwhite with minute black spots (diameter 0.8-1.0 mm, $N=10$ ).

Etymology. The species is named after Niluvase, where the type series was collected. The species name niluvasei is a noun in the genitive case.

Distribution. Micrixalus niluvasei is known only from its type locality Niluvase (Shimoga dist., Karanataka state), which lies north of Palghat gap in the Western Ghats (Fig. 3, Table 1).

Habitat and natural history. The preferred habitat of this species is moist leaf litter or rock surfaces in streams covered with forest canopy. The male specimens were found actively calling and'foot-flagging'. Collections were made between 13:00-16:00 h.

\section{Micrixalus sairandhri sp. nov. Sairandhri Dancing Frog \\ (Figs 3, 11F, 16; Tables 1-5)}

Holotype. BNHS 5633, an adult male, Sairandhri, Silent Valley, Palakkad dist., Kerala state, India, collected by SDB and SG, 19 September 2011.

Paratypes. Kerala: Palakkad dist., Sairandhri, Silent Valley, BNHS 5634-BNHS 5638, five adult males, and BNHS 5639, an adult female, collected along with holotype.

Comparison. Micrixalus sairandhri could be confused with $M$. candidus, M. elegans, $M$. kurichiyari, M. niluvasei, $M$. spelunca and $M$. uttaraghati. However, M. sairandhri differs from $M$. spelunca by its snout rounded in dorsal view (vs. subovoid), head longer than its wide, HW 5.7 $\pm 0.2 \mathrm{~mm}$, HL $6.6 \pm 0.2, N=6$, (vs. equal, HW 5.6 $\pm 0.2 \mathrm{~mm}$, HL $5.6 \pm 0.2, N=6$ ), interorbital space equal to upper eyelid, IUE $1.5 \pm 0.1 \mathrm{~mm}$, UEW $1.5 \pm 0.1 \mathrm{~mm}, N=6$, (vs. longer, IUE $2.0 \pm 0.2$ $\mathrm{mm}$, UEW $1.2 \pm 0.1 \mathrm{~mm}, N=6$ ), shank longer than foot length, SHL $9.4 \pm 0.3 \mathrm{~mm}$, FOL $8.9 \pm$ $0.2 \mathrm{~mm}, N=6$ (vs. equal, SHL $8.4 \pm 0.2 \mathrm{~mm}$, FOL $8.4 \pm 0.3 \mathrm{~mm}, N=6$,); differs from $M$. uttaraghati by its interorbital space equal to upper eyelid, IUE $1.5 \pm 0.1 \mathrm{~mm}$, UEW $1.5 \pm 0.1 \mathrm{~mm}, N=6$, (vs. longer, IUE $1.9 \pm 0.1 \mathrm{~mm}$, UEW $1.2 \pm 0.1 \mathrm{~mm}, N$ $=7$ ), fourth toe webbing beyond the second subarticular tubercle on either side (vs. fourth toe webbing up to the disc on either side), dermal fringe along toe $\mathrm{V}$ smooth in males (vs. dermal fringe along toe $\mathrm{V}$ well developed from tip of toe to heel, with glandular projections ending with sharp spinules in males).

For differences with Micrixalus candidus, $M$. elegans, M. kurichiyari and M. niluvasei see 'Comparison' of those species.

Description of holotype (measurements in $\mathrm{mm}$ ). Adult male (SVL 17.8); head small (HW 5.5, HL 6.8), longer than wide, flat above; snout round in dorsal view, acute in lateral view, its length (SL 2.9) longer than horizontal diameter of eye (EL 2.4); loreal region vertical, rounded canthus rostralis; interorbital space flat, subequal (IUE 1.6) to upper eyelid (UEW 1.5) and shorter than internarial distance (IN 1.8); distance between back of eye (IBE 4.9) 1.5 times the distance between front of eye (IFE 3.2); nostril oval, nearly as close to eye (EN 1.5) as to tip of snout (NS 1.4); tympanum (TYD 0.6) $50 \%$ of eye diameter (EL 1.2); tongue moderately large, emarginate, without median lingual papillae; supratympanic 
fold that extends from posterior corner of eye to near the shoulder, weakly developed. Forelimbs (FAL 3.8) shorter than hand length (HAL 4.9); finger discs moderately wide compared to finger width (fd1 0.5, fw1 0.3; fd2 0.6, fw2 0.3; fd3 0.7, fw3 0.3; fd4 0.6, fw4 0.3); subarticular tubercles weakly developed, oval, single, all present. Thigh length (TL 10.3) longer than shank (SHL 9.8), and foot (FOL 8.7); toe discs wide compared to toe width (td1 0.6, tw1 0.3; td2 0.7 , tw2 0.3; td3 0.8, tw3 0.3; td4 0.8, tw4 0.3; td5 0.7, tw5 0.3); webbing present: I1-2-II1-2III $1^{+}-2 \frac{1}{2} \mathrm{IV}_{2} \frac{1}{2} 2_{-}$ $1 \frac{1}{5} \mathrm{~V}$; subarticular tubercles weakly developed, oval, all present; inner metatarsal tubercles distinct and moderately short; outer metatarsal tubercles absent.

Skin of snout, between eyes, upper eyelids and posterior part of back shagreened to sparsely granular; dorsolateral folds that extend from the posterior corner of the eye to the entire body length on both sides, weakly developed; flanks sparsely granular; dorsal parts of forelimb shagreened; thigh, tibia and tarsus shagreened to sparsely granular; ventral surfaces of throat, chest and abdomen smooth; posterior parts of thigh shagreened.

Colour in preservation. Dorsum light brown with irregular grey spots, a brown band connecting the eyes; flanks dark brown; tympanic area brownish-black; forelimbs, dorsal surfaces of thigh, tibia and feet greyish-brown with dark brown cross-bands; throat, chest and belly light grey with minute black spots; tibia and feet greyish-brown, margins light blackish-brown; webbing blackish-grey. Colour in life. Dorsum uniform reddish-brown; tympanum and surrounding areas blackish-brown; iris light brown

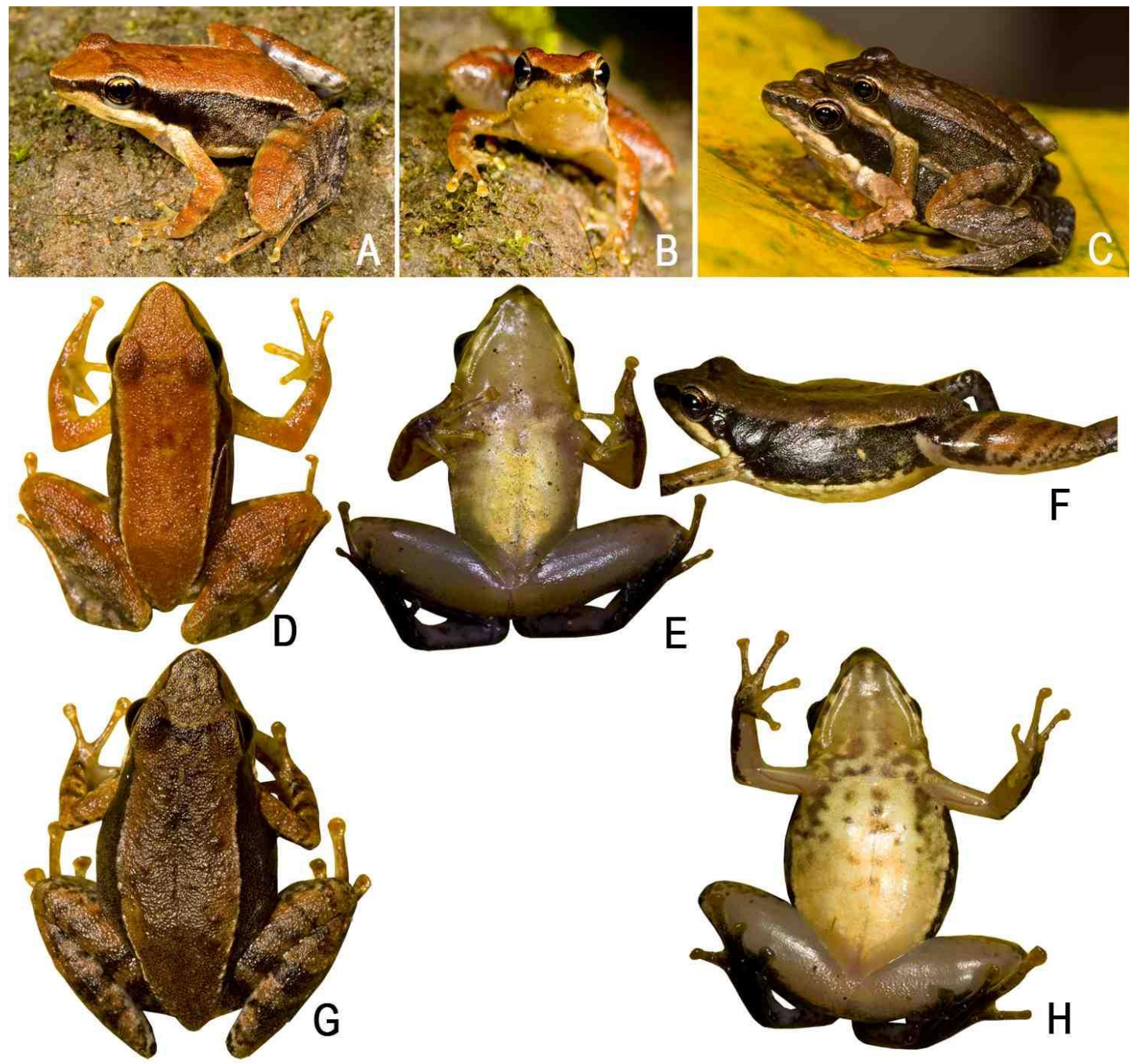

Figure 16. Micrixalus sairandhri sp. nov. in life: A. dorsolateral view, B. front view (HT, BNHS 5633, m); C. amplected pair (PT, BNHS 5638, m; PT, BNHS 5639, f); D. dorsal view, E. ventral view, F. lateral view of thigh and groin (HT, BNHS 5633, m); G. dorsal view, H. ventral view (PT, BNHS 5639, f). Photos: SDB. 
with reddish tinge; anterior parts of flank brownish-black, posterior parts of flank light blackish-brown; groin light blackish-brown; dorsal surfaces of limbs reddish-brown with light brown cross-bands; throat and margins of throat, chest and belly dark grey; thighs blackish-brown; foot blackish-grey.

Variations. See Table 5 for morphometric characters of six males and a female. For colour variations see Figure 16.

Secondary sexual characters. Male: Single prominent oval-shaped nuptial pad on finger I present, cream-coloured; single gular pouch while calling. Female (BNHS 5639): ova creamy white with minute black spots (diameter $0.9-1.2 \mathrm{~mm}, N$ $=20$ ).

Etymology. The species is named after Sairandhri, where the type series was collected. The specific name is a noun in apposition to the generic name and therefore invariable.

Distribution. Micrixalus sairandhri is known only from its type locality Sairandhri, Silent Valley (Palakkad dist., Kerala state), which lies north of Palghat gap in the Western Ghats (Fig. 3, Table 1).

Habitat and natural history. The preferred habitat of this species is damp leaf liiter or rock surfaces close to forest streams. BNHS 5638BNHS 5639, were observed in amplexus on the surface of a wet rock close to fast flowing water. Specimens were collected between 09:00-12:00 h.

\section{Micrixalus spelunca sp. nov. Cave Dancing Frog \\ (Figs 3, 11G, 17; Tables 1-5)}

Holotype. BNHS 5640, an adult male, Coonoor, Nilgiris dist., Tamil Nadu state, India, collected by SDB, SG and RS, 21 August 2012.

Paratypes. Tamil Nadu: Nilgiris dist. Coonoor, BNHS 5641-BNHS 5643, three adult males, BNHS 5644, an adult female, collected along with holotype, BNHS 5645-BNHS 5646, two adult males, collected by SDB and SG, 9 June 2012.

Other material studied. Tamil Nadu: Nilgiris dist., Coonoor, SDBDU 2005.4731, collected by SDB, 12 October 2005.

Comparison. Micrixalus spelunca could be confused with $M$. candidus, $M$. elegans, $M$. kurichiyari, M. niluvasei, M. sairandhri and $M$. uttaraghati. However, M. spelunca differs from M. uttaraghati by its snout subovoid in dorsal view (vs. rounded), fourth toe webbing not extending beyond the first subarticular tubercle on either side (vs. up to the disc on either side), dermal fringe along toe $\mathrm{V}$ smooth in males (vs. dermal fringe along toe $\mathrm{V}$ well developed from tip of toe to heel, with glandular projections ending with sharp spinules), dorsum shagreened (vs. prominently spinular).

For differences with Micrixalus candidus, $M$. elegans, M. kurichiyari, M. niluvasei and $M$. sairandhri see 'Comparison' of those species.

Description of holotype (measurements in $\mathrm{mm}$ ). Adult male (SVL 17.2), head small (HW 5.9, HL 5.9), as long as wide, flat above; snout subovoid in dorsal view, acute in lateral view, its length (SL 2.6) longer than horizontal diameter of eye (EL 2.1); loreal region vertical, rounded canthus rostralis; interorbital space flat, wider (IUE 2.3) than upper eyelid (UEW 1.3) and shorter than internarial distance (IN 2.1); distance between back of eye (IBE 5.1) 1.4 times the distance between front of eye (IFE 3.6); nostril oval, closer to tip of snout (NS 1.1) than eye (EN 1.4); tympanum obscure externally; tongue moderately large, emarginate, without median lingual papillae; supratympanic fold absent. Forelimbs (FAL 3.5) shorter than hand length (HAL 4.5); finger discs moderately wide compared to finger width (fd1 0.4 , fw1 0.2 ; fd2 0.5, fw2 0.2; fd3 0.6, fw3 0.2; fd4 0.6, fw4 0.2); subarticular tubercles weakly developed, oval, single, all present. Thigh longer (TL 9.5) than shank (SHL 8.5), and foot (FOL 8.5); toe discs wide compared to toe width (td1 $0.5, \operatorname{tw} 10.3 ; \operatorname{td} 2$ 0.6, tw2 0.2; td3 0.7, tw3 0.2; td4 0.7, tw4 0.2; td5 0.5 , tw5 0.2); webbing present: I1-2-II1-2III1$2^{1 / 5} \mathrm{IV} 2^{4} / 5-1 \frac{1}{5} \mathrm{~V}$; subarticular tubercles weakly developed, oval, all present; inner metatarsal tubercles distinct and moderately short; outer metatarsal tubercles absent.

Skin of snout, between eyes, upper eyelids and posterior part of back shagreened; dorsolateral folds that extend from the posterior corner of the eye to the entire body length on both sides, weakly developed; flanks shagreened; dorsal parts of forelimb, thigh, tibia and tarsus shagreened; ventral surfaces of throat, chest and abdomen smooth; posterior parts of thigh shagreened.

Colour in preservation. Dorsum dark grey with irregular light grey spots; flanks dark brown with light grey reticulations; tympanic area brownish-black; forelimbs, dorsal surfaces of thigh, tibia and feet light grey with light brown cross-bands; webbing blackish-grey. Colour in life. Dorsum uniform dark brown with light brown reticulations; tympanum and surrounding areas blackish-brown; iris light brown with reddish tinge; anterior parts of flank bluish-black with light brown reticulations, posterior parts of flank light brown; groin light reddish-brown; dorsal surface of limbs greyish-brown with dark brown cross-bands; throat and margins of throat and chest light reddish-brown; belly yellowish-brown 

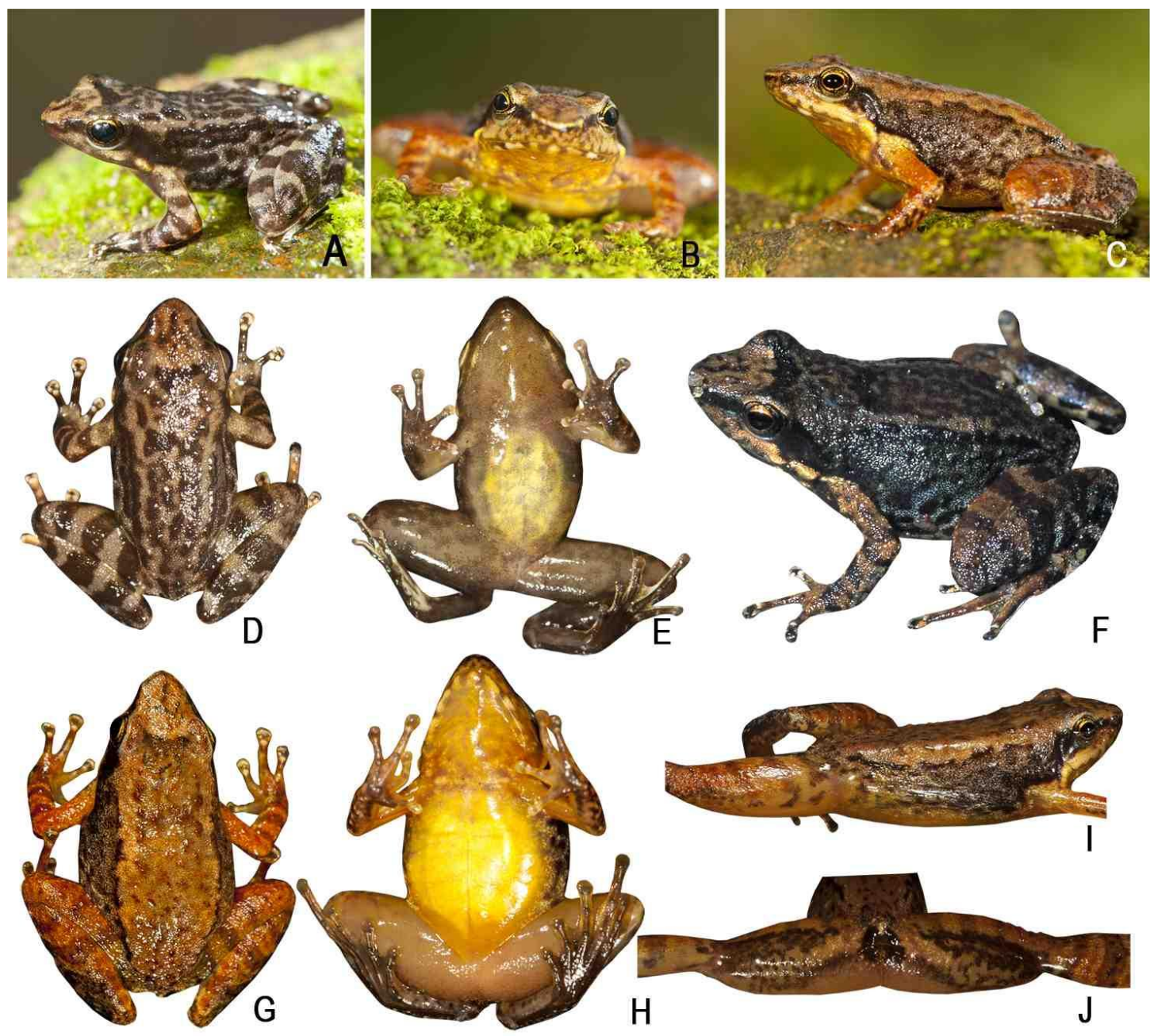

Figure 17. Micrixalus spelunca sp. nov. in life: A. dorsolateral view (HT, BNHS 5640, m); B. front view, C. dorsolateral view (PT, BNHS 5644, f); D. dorsal view, E. ventral view (HT, BNHS 5640, m); F. dorsolateral view (not preserved); G. dorsal view, H. ventral view, I. lateral view of thigh and groin, J. posterior side of thigh (PT, BNHS 5644, f). Photos: SDB.

with scattered light grey spots; thigh light grey; foot blackish-grey.

Variations. See Table 5 for morphometric characters of six adult males and an adult female. For colour variations see Figure 17.

Secondary sexual characters. Male: Single prominent oval-shaped nuptial pad on finger I present, cream-coloured; single gular pouch while calling. Female (BNHS 5644): ova creamy white with minute black spots (diameter $0.9-1.2 \mathrm{~mm}, \mathrm{~N}$ $=10$ ).

Etymology. The species epithet is a noun in apposition, therefore invariable, derived from the Latin word 'spelunca' meaning cave, referring to the damp cave habitat where the type series was collected.

Distribution. Micrixalus spelunca is known only from its type locality Coonoor (Nilgiris dist., Tamil Nadu state), which lies north of Palghat gap in the Western Ghats (Fig. 3, Table 1).

Habitat and natural history. The present study found this species is inside a damp cave with a shallow stream of water flowing underneath. The collection site was located in a secondary forest. Male specimens were found actively calling and collections were made between 12:00-16:00 $\mathrm{h}$.

\section{Micrixalus uttaraghati sp. nov. \\ Northern Dancing Frog}

(Figs 3, 11H, 18; Tables 1-5)

Holotype. BNHS 5647, an adult male, Amboli, Sindhudurg dist., Maharashtra state, India, collected by SDB and SG, 21 October 2012.

Paratypes. Maharashtra: Sindhudurg dist., Amboli, BNHS 5648- BNHS 5653, six adult males, and BNHS 5654, an adult female, collected along with holotype. 
Other material studied. Maharashtra: Sindhudurg dist., Amboli, SDBDU 2007.6084, collected SDB, 21 March 2007.

Comparison. Micrixalus uttaraghati could not be confused with other members of the Micrixalus elegans group due to its toe webbing extending up to the disc on all digits, prominently spinular dorsum and dermal fringe along toe $\mathrm{V}$ well developed from tip of toe to heel, with glandular projections ending with sharp spinules in males.

For more specific differences with Micrixalus candidus, M. elegans, M. kurichiyari, M. niluvasei, M. sairandhri and $M$. spelunca see 'Comparison' of those species.

Description of holotype (measurements in mm). Adult male (SVL 17.4); head small (HW 5.8, HL 6.2), longer than wide, flat above; snout rounded in dorsal view, acute in lateral view, its length (SL 2.6) longer than horizontal diameter of eye (EL 1.8); loreal region vertical, rounded canthus rostralis; interorbital space flat, wider (IUE 2.1) than upper eyelid (UEW 1.2) and shorter than internarial distance (IN 1.9); distance between back of eye (IBE 5.0) 1.4 times the distance between front of eye (IFE 3.4); nostril oval, closer to eye (EN 1.1) than tip of snout (NS 1.5); tympanum (TYD 0.8) 44\% of eye diameter (EL 1.8); tongue moderately large, emarginate, without median lingual papillae; supratympanic fold that extends from posterior corner of eye to near the shoulder, weakly developed. Forelimbs (FAL 2.7) shorter than hand length (HAL 4.7); finger discs moderately wide compared to finger width (fd1 0.5, fw1 0.3; fd2 0.6, fw2 0.2; fd3 0.8, fw3 0.2; fd4 0.8, fw4 0.3); subarticular tubercles weakly developed, oval, single, all present. Thigh longer (TL 10.2) than shank (SHL 9.7), and foot (FOL 8.0); toe discs wide compared to toe width (td1 0.6, tw1 0.3; td2 0.6, tw2 0.3; td3 0.7, tw30.3; td4 0.8 , tw4 $0.3 ;$ td5 0.6 , tw5 0.3 ); webbing present: I1-1II1-1III1-1IV1-1V; subarticular
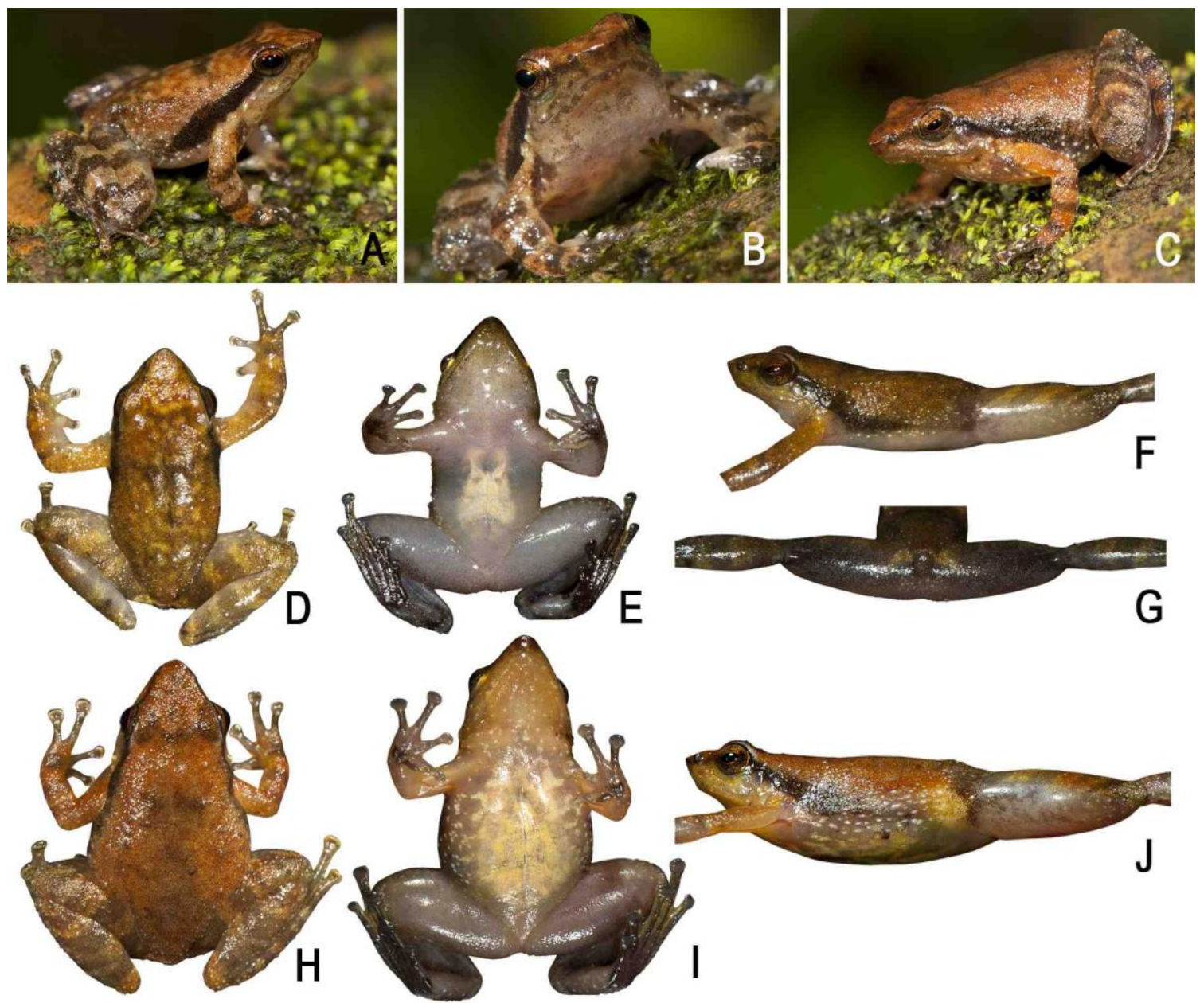

Figure 18. Micrixalus uttaraghati sp. nov. in life: A. dorsolateral view, B. frontal view (HT, BNHS 5647, m); C. dorsolateral view (PT, BNHS 5654, f); D. dorsal view, E. ventral view, F. lateral view of thigh and groin, G. posterior side of thighs (HT, BNHS 5647, m); H. dorsal view, I. ventral view, J. lateral view of thigh and groin (PT, BNHS 5654, f ). Photos: SDB. 
tubercles weakly developed, oval, all present; inner metatarsal tubercles distinct and moderately short; outer metatarsal tubercles absent.

Skin of snout, between eyes, upper eyelids and posterior part of back shagreened with prominent spinular projections; dorsolateral folds that extend from the posterior corner of the eye to the entire body length on both sides, weakly developed; flanks prominently spinular; dorsal parts of forelimb shagreened and sparsely spinular; thigh, tibia and tarsus shagreened with scattered granular projections; dermal fringe along toe $\mathrm{V}$ well developed from tip of toe to heel, with glandular projections ending with sharp spinules in males; ventral surfaces of throat, chest and abdomen smooth, posterior parts of thigh shagreened.

Colour in preservation. Dorsum dark grey with irregular light grey patches; anterior parts of flank light brown; tympanic area brownish-black; forelimbs, dorsal surfaces of thigh and tibia light grey with dark grey cross-bands; feet grey with dark brown cross-bands; posterior parts of thigh light grey with dark grey reticulations; throat, chest and belly light grey with minute black spots; ventral surfaces of tibia and feet light grey with black spots; webbing light brownish-grey. Colour in life. Dorsum uniform brownish-grey with grey patches; tympanum and surrounding areas dark brown; iris light brown with reddish tinge; presence of a dark brownish-black streak that extends from the posterior corner of eye up to near the groin on either side; anterior parts of flank brown, posterior parts of flank light brown; groin light grey; dorsal surface of limbs light brown with blackish-brown cross-bands; throat, chest and belly dark grey; thighs light grey; foot blackishgrey.

Variations. See Table 5 for morphometric characters of seven adult males and an adult female. For colour variations see Figure 18.

Secondary sexual characters. Male: Single prominent oval-shaped nuptial pad on finger I present, cream-coloured; single gular pouch while calling. Female (BNHS 5654): ova creamy white with minute black spots (diameter $0.7-0.9 \mathrm{~mm}, N$ $=10$ ).

Etymology. The species epithet is derived from two Sanskrit words- 'uttara' meaning north and 'ghat' meaning mountains - referring to this species forming the extreme limit of Micrixalus distribution in the Western Ghats. The species name uttaraghati is a noun in the genitive case.

Distribution. Micrixalus uttaraghati is known only from its type locality Amboli (Sindhudurg dist., Maharashtra state), which lies north of Goa gap in the Western Ghats (Fig. 3, Table 1).
Habitat and natural history. The preferred habitat of this species is flowing streams covered with forest canopy. The majority of male specimens were found actively calling and 'footflagging'. A few calling males were observed inside rock crevices in splashy zones of the stream. Collections were made between 10:0014:00 h.

\section{Micrixalus fuscus group}

Members. Micrixalus adonis sp. nov., Micrixalus fuscus, Micrixalus herrei, Micrixalus kodayari sp. nov., Micrixalus mallani sp. nov. and Micrixalus nelliyampathi sp. nov.

This group can be distinguished from other Micrixalus groups by the combination of following morphological characters: small adult size (male, SVL 16-29 mm; female, SVL 24-33 $\mathrm{mm}$ ), body slender; dorsolateral folds present; two to four circular glands that start just behind the tympanum and extend towards the posterior axis of mandibles; dorsum with inverted V-shaped glandular ridge on the anterior half; lateral sides of head (snout and tympanic area) lighter in colour than upper parts of flank; distribution restricted to regions south of Palghat gap in the Western Ghats (Fig. 19).

\section{Micrixalus adonis sp. nov. Beautiful Dancing Frog}

(Figs 3, 19A, 20; Tables 1-5)

Holotype. BNHS 5655, an adult male, Sevenmallay, Munnar, Idukki dist., Kerala state, India, collected by SDB and Systematics lab team, 20 September 2011.

Paratypes. Kerala: Idukki dist., Sevenmallay, BNHS 5656, an adult male, collected by SDB, 15 March 2002; Kadalar estate, Munnar, BNHS 5657-BNHS 5661, five adult males, and BNHS 5662-BNHS 5665, four adult females, collected by SDB and Systematics lab team, 23 September 2011; Letchmi estate, Munnar, BNHS 5666, an adult male, and BNHS 5667, an adult female, collected by SDB and Systematics lab team, 20 September 2011; Thekkady, BNHS 5668, an adult female, collected by SDB, 8 June 2006.

Comparison. Micrixalus adonis could be confused with M. fuscus, M. herrei, M. kodayari, $M$. mallani and $M$. nelliyampathi. However, $M$. adonis differs from M. fuscus, M. kodayari, $M$. mallani and $M$. nelliyampathi by its head rounded in lateral view (vs. acute in $M$. fuscus, M. kodayari and $M$. nelliyampathi; nearly acute in M. mallani); differs from $M$. fuscus, $M$. herrei, M. kodayari and M. mallani by its snout subovoid in dorsal view (vs. pointed in $M$. fuscus and $M$. herrei; 
subelliptical in $M$. kodayari and $M$. mallani). More specifically differs from $M$. kodayari and $M$. mallani by its fourth toe webbing extending up to the first subarticular tubercle on the outside (vs. below the second subarticular in both species); differs from $M$. herrei and $M$. nelliyampathi by its third toe webbing at the base of first subarticular tubercle (vs. extending above the first subarticular tubercle in both species); and differs from $M$. fuscus by its fourth toe webbing extending up to the first subarticular tubercle on the outside side (vs. upto the disc). Furthermore, M. adonis differs from $M$. herrei by its larger snout-vent size, male, SVL 21.1-24.1 mm, $N=8$, female, SVL 26.5$30.1 \mathrm{~mm}, N=6$ (vs. smaller, $M$. herrei, male, SVL 16.7-19.4 mm, $N=9$, female, SVL 24.8-26.6 $\mathrm{mm}, N=3$ ); differs from $M$. fuscus by its smaller snout-vent size, male, SVL 21.1-24.1 mm, $N=8$, female, SVL 26.5-30.1 mm, $N=6$ (vs. larger, $M$. fuscus, male, SVL 27.9-28.8 mm, $N=3$, female, SVL 30.1-33.1 mm, $N=8$ ); differs from $M$. herrei, M. kodayari and M. mallani by its shank longer than thigh length, male, SHL $12.4 \pm 0.4$ $\mathrm{mm}$, TL $11.4 \pm 0.5 \mathrm{~mm}, N=8$, female, SHL 15.1 $\pm 0.5 \mathrm{~mm}$, TL $13.2 \pm 0.3 \mathrm{~mm}, N=6$ (vs. subequal in $M$. herrei, male, SHL $10.1 \pm 0.4 \mathrm{~mm}$, TL $10.0 \pm$ $0.4 \mathrm{~mm}, N=9$, female, SHL $13.5 \pm 0.6 \mathrm{~mm}$, TL $13.4 \pm 0.6 \mathrm{~mm}, N=3$; subequal in $M$. kodayari, male, SHL $10.3 \pm 0.9 \mathrm{~mm}$, TL $10.2 \pm 1.0 \mathrm{~mm}, N=$
2, female, SHL $13.0 \pm 0.2 \mathrm{~mm}$, TL $13.0 \pm 0.1 \mathrm{~mm}$, $N=3$; equal in $M$. mallani, male, SHL $10.5 \pm 0.3$ $\mathrm{mm}$, TL $10.5 \pm 0.2 \mathrm{~mm}, N=4$, female, SHL 13.7 $\pm 0.5 \mathrm{~mm}$, TL $13.7 \pm 0.6 \mathrm{~mm}, N=4$ ); differs from $M$. nelliyampathi by its thigh longer than foot length, male, TL $11.4 \pm 0.5 \mathrm{~mm}$, FOL $10.3 \pm 0.3$ $\mathrm{mm}, N=8$; female, TL $13.2 \pm 0.3 \mathrm{~mm}$, FOL 11.7 $\pm 0.4 \mathrm{~mm}, N=6$ (vs. subequal, $M$. nelliyampathi, male, TL $10.7 \pm 0.9 \mathrm{~mm}$, FOL $10.6 \pm 0.9 \mathrm{~mm}, N=$ 7, female, TL $12.7 \pm 0.6 \mathrm{~mm}$, FOL $12.7 \pm 0.5 \mathrm{~mm}$, $N=5)$.

Description of holotype (measurements in $\mathrm{mm}$ ). Adult male (SVL 22.6); head small (HW 6.7, HL 8.0), longer than wide, flat above; snout subovoid in dorsal view, rounded in lateral view, its length (SL 3.8) longer than horizontal diameter of eye (EL 2.8); loreal region vertical and concave with rounded canthus rostralis; interorbital space flat, wider (IUE 2.3) than upper eyelid (UEW 1.8), and equal to internarial distance (IN 2.3); distance between back of eye (IBE 6.1) 1.6 times the distance between front of eye (IFE 3.7); nostril oval, closer to eye (EN 1.4) than tip of snout (NS 1.7); tympanum (TYD 1.0) 36\% of eye diameter (EL 2.8); tongue moderately large, emarginate, without lingual papilla; supratympanic fold that extends from posterior corner of eye to near the shoulder, weakly developed. Forelimbs (FAL 4.7) shorter than hand length (HAL 5.8);

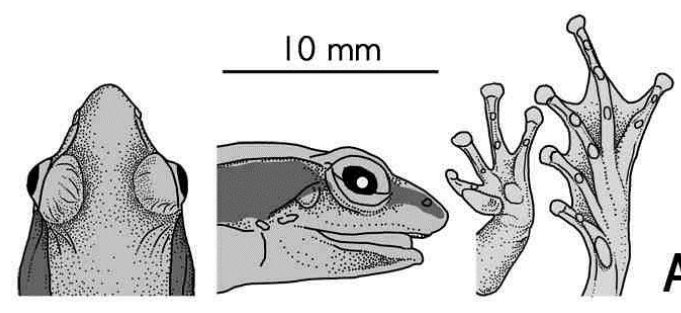

A
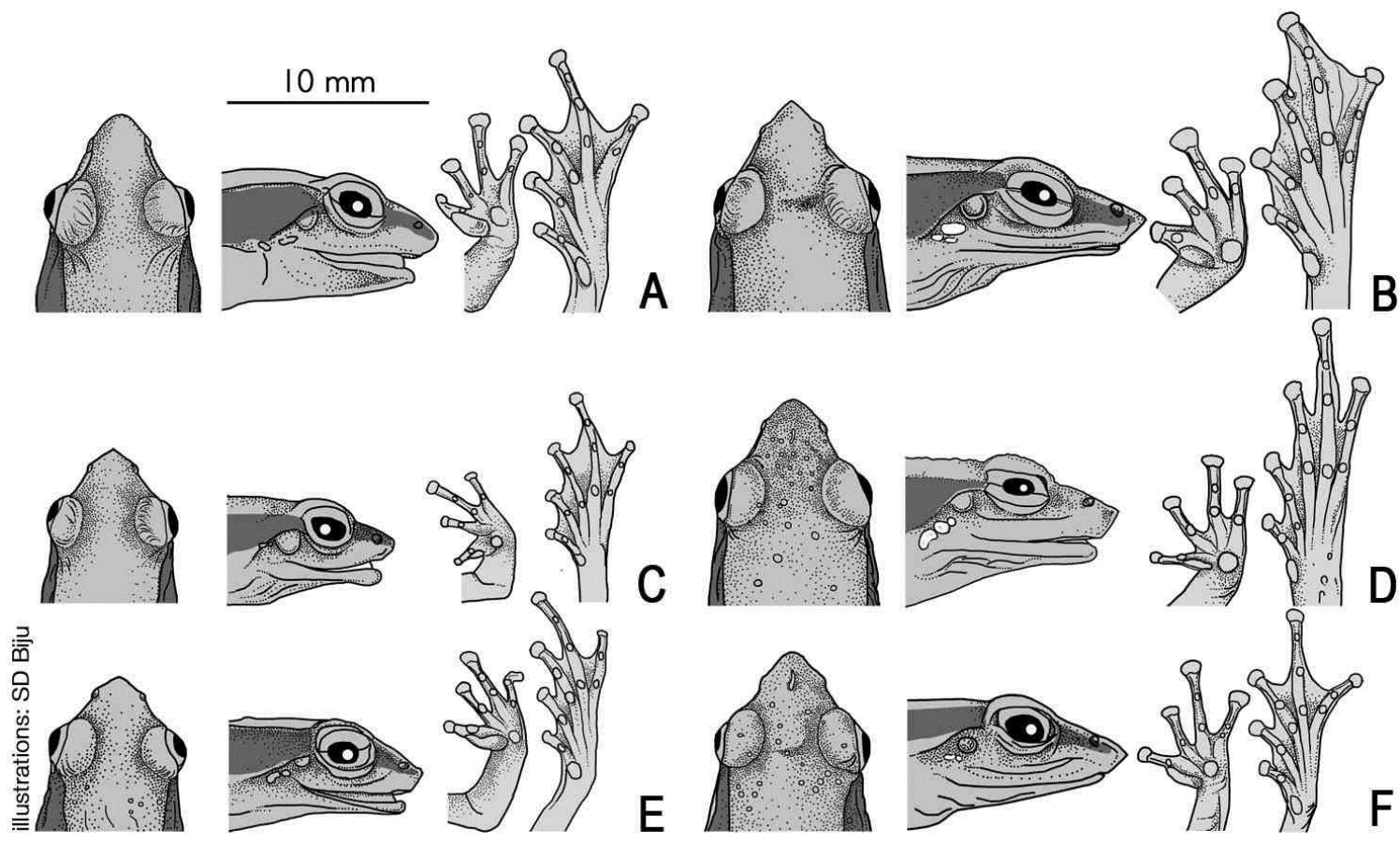

Figure 19. From left to right, dorsal view of head, lateral view of head, ventral view of hand and ventral view of foot of Micrixalus fuscus group: A. Micrixalus adonis sp. nov. (HT, BNHS 5655, m); B. M. fuscus (LT, NHM 74.4.29.258, f); C. M. herrei (TT, BNHS 5677, m); D. Micrixalus kodayari sp. nov. (HT, BNHS 5689, f); E. Micrixalus mallani sp. nov. (HT, BNHS 5694, m); F. Micrixalus nelliyampathi sp. nov. (HT, BNHS 5702, m). 

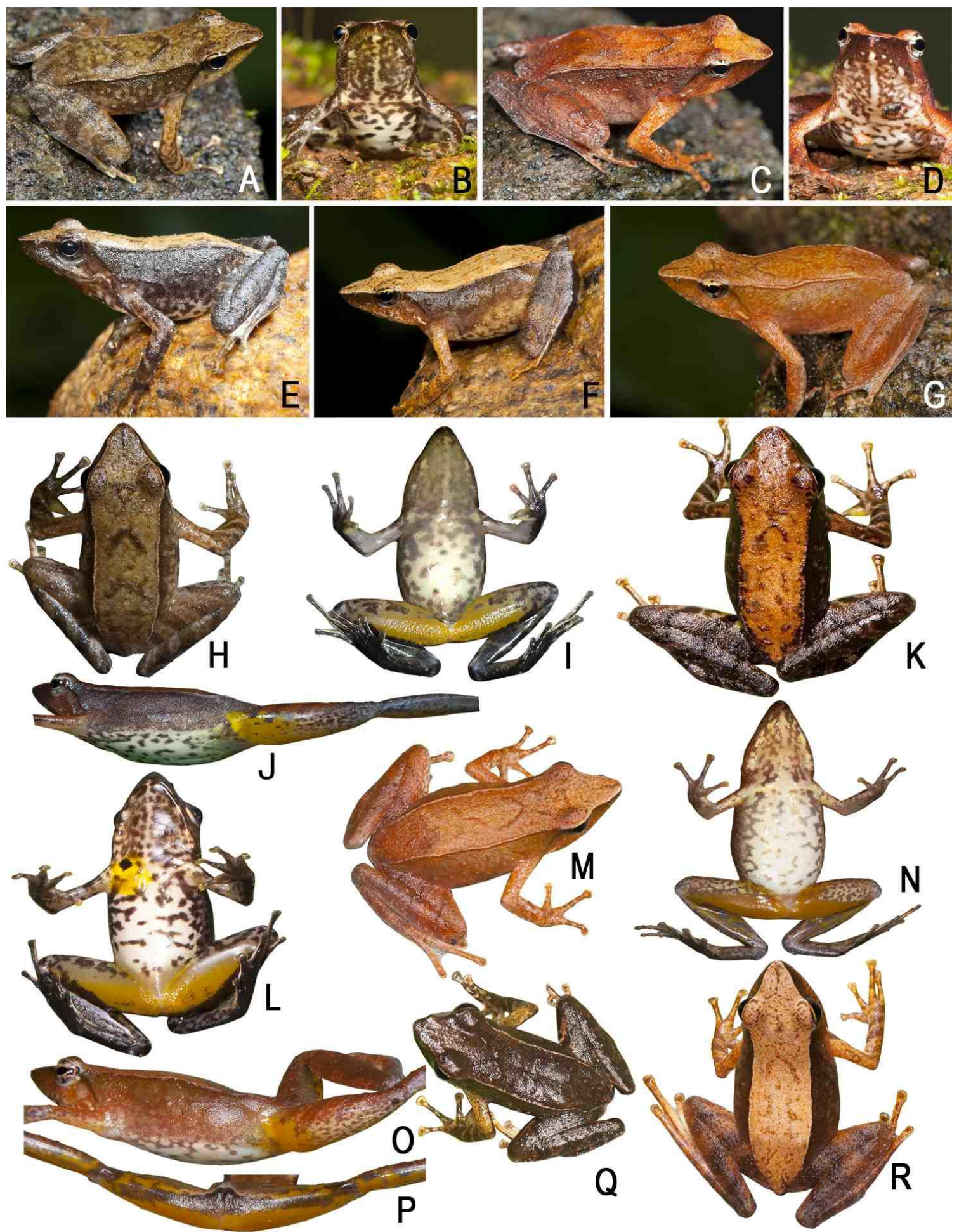
finger discs moderately wide compared to finger width (fd1 0.5, fw1 0.2; fd2 0.7, fw2 0.2; fd3 0.8, fw3 0.3; fd4 0.8, fw4 0.3); subarticular tubercles weakly developed, oval, single, all present. Thigh length (TL 11.5) shorter than shank (SHL 12.3), and longer than foot (FOL 10.2); toe discs wide compared to toe width $(\operatorname{td} 10.6, \operatorname{tw} 10.2 ; \operatorname{td} 20.8$, tw2 0.3; td3 0.9, tw3 0.2; td4 0.9, tw4 0.3; td5 0.7, tw5 0.2); webbing present: I1- $1 \frac{1}{2}$ III-2III12IV2-1V; subarticular tubercles weakly developed, oval, all present; inner metatarsal tubercles distinct and moderately short; outer metatarsal tubercles rounded, rather prominent.

Skin of snout, between eyes and upper eyelids shagreened to finely glandular; posterior part of back shagreened to sparsely granular; dorsolateral folds that extend from the posterior corner of the eye to the entire body length on both sides, well developed; dorsal parts of forelimb shagreened; thigh, tibia and tarsus with weakly developed glandular projections; ventral surface of throat, chest and abdomen smooth; posterior parts of thigh shagreened to sparsely granular.

Colour in preservation. Dorsum greyishbrown; lower flanks dark grey with black speckles; dorsolateral folds light grey; forelimbs, dorsal surfaces of thigh, tibia and feet light greyish-brown with dark brown cross-bands, ventral surfaces of thigh light grey with scattered dark grey spots, tibia and feet brownish-black, posterior parts of thigh light grey with dark greyish-brown reticulations; webbing blackishgrey; throat, chest and belly greyish-white with black reticulations. Colour in life. Dorsum uniform greyish-brown with black specks; tympanum and surrounding areas light brown; iris light brown with reddish tinge; flanks light yellowish-grey with light grey reticulations; groin yellow with light spots; dorsal surface of limbs greyish-brown with light brown cross-bands; throat and margins of throat, chest and belly greyish-white with prominent brownish reticulations.

Variations. See Table 5 for morphometric characters of eight adult males and six adult females. For colour variations see Figure 20.

Secondary sexual characters. Male: Single prominent oval-shaped nuptial pad on finger I present, cream-coloured; single gular pouch while calling. Female (BNHS 5662): ova creamy white with minute black spots (diameter $1.0-1.5 \mathrm{~mm}, N$ $=20$ ).

Etymology. The species name adonis refers to the mythic character Adonis, a demigod of beauty and desire in Greek mythology. The name reflects the vividly rich and contrasting colouration observed on this species. The specific name is an invariable noun in the nominative singular standing in apposition to the generic name.

Distribution. Micrixalus adonis is known only from the Western Ghats state of Kerala, with its distribution restricted between the Palghat gap and Shencottah gap. The present study found this species in Sevenmallay; Letchmi estate, Munnar; Kadalar estate, Munnar; and Thekkady in Idukki district (Fig. 3, Table 1).

Habitat and natural history. The preferred habitat of this species was streams covered with forest canopy at Sevenmallay, Letchmi estate and Thekkady. Collections from Kadalar estate were predominately from streams near cardamom plantations. BNHS 5657 and BNHS 5660 were collected from leaf litter close to forest streams, while all other collections were from boulders emerging from streams. Micrixalus adonis was found to be relatively abundant at all the collection localities. The majority of male specimens were found actively calling and collected between 08:00-18:00 h.

\section{Micrixalus fuscus (Boulenger, 1882) Kalakkad Dancing Frog \\ (Figs 3, 19B, 21A-B, 22; Tables 1-5)}

Original name and description. Ixalus fuscus Boulenger, 1882. Catalogue of the Batrachia Salientia s. Ecaudata in the Collection of the British Museum, ed. 2: $96 . \quad$ Lectotype. NHM 74.4.29.258, an adult female, SVL $32.1 \mathrm{~mm}$, by present designation. Type locality. "Travancore". Current status of specific name. Valid name, as Micrixalus fuscus (Boulenger, 1882).

Referred specimens. Tamil Nadu: Tirunelveli dist., Kakkachi, BNHS 5669-BNHS 5670, SDBDU 2006.2296, three adult males, collected by SDB, 28 May 2006, and BNHS 5671-BNHS 5672, two adult females, collected by SDB, 31 August 2002; Sengaltheri, BNHS 5673-BNHS 5674, two adult females, collected by SDB, 15 August 2003; Kerala: Thiruvananthapuram dist., Athirimala, BNHS 5675, an adult female, collected by SDB, 8 Augsut 2002; Pandipath, BNHS 5676, an adult female, collected by SDB and Systematics lab team, 21 September 2012; Paralectotype, "Travancore", NHM 74.4.29.259, an adult female, collected by Beddome.

Other material studied. Tamil Nadu: Tirunelveli dist., Kakkachi, SDBDU 2002.2047, collected by SDB, 31 August 2002, Kakkachi, SDBDU 2006.2299, collected by SDB, 28 May 2006; Sengaltheri, SDBDU 2002.874, collected by SDB, 12 January 2002.

Comments. Boulenger (1882) described this species based on several specimens from six localities: "Travancore", NHM 74.4.29.258-265, 
eight specimens (five females and three males); "Torocata", NHM 74.4.29.1401-4, four specimens (three females and a male); "Anamallays", NHM 14.4.29.1506-8, three male specimens; "Sevagherry", NHM 74.4.29.1459-68, eight specimens (three females and five males); "Malabar", NHM 74.4.29.927-930, four specimens according to the NHM catalogue but a total of six specimens (three females and three male) found in the jar; and "N. Canara", NHM 72.4.17.256, three male specimens. We examined all the available syntypes at NHM (without individual specimen numbers) and found them to be heterogeneous in identity, composing of at least four different Micrixalus species. Since collection localities of these historical specimens are mentioned as broad colonial regions (Biju, 2001), it was difficult for us to provide accurate identification of specimens in the syntype series. However, we find NHM 74.4.29.258-265 (from "Travancore") and NHM 74.4.29.1459-64 (from "Sevagherry") to be comparable with the original description and accompanying illustration. More specifically, specimens from "Travancore" agree with the original description in their snout-vent size ("from snout to vent 32 millim"), snout shape ("snout pointed") and toe webbing ("toes entirely webbed"). Therefore, in order to avoid any possible doubt or confusion, we hereby designate NHM 74.4.29.258 (from “Travancore", SVL 32.1 $\mathrm{mm}$ ) as lectotype of Micrixalus fuscus (Figs 21AB).

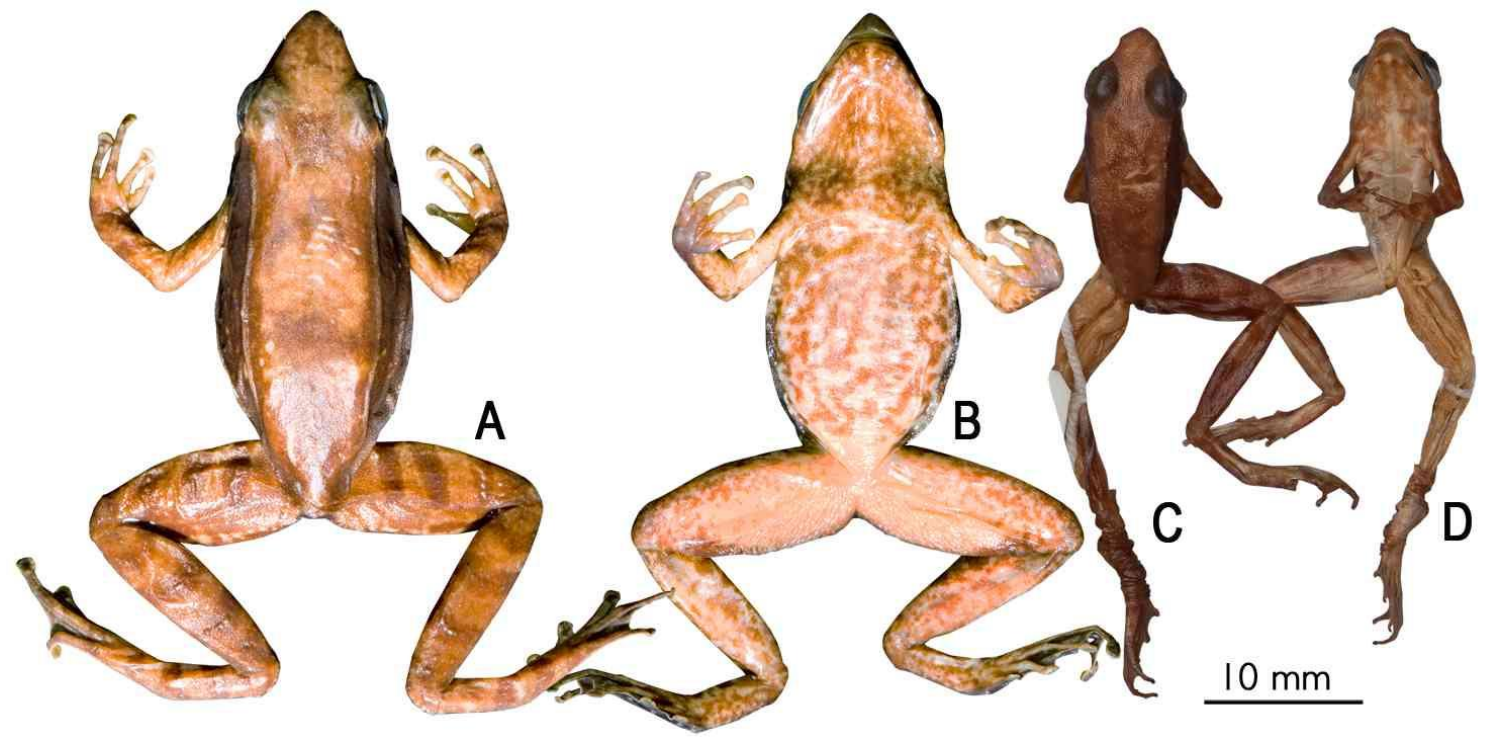

Figure 21. A-B. Lectotype of Ixalus fuscus Boulenger, 1882 (NHM 74.4.29.258, f), from "Travancore": A. dorsal view, B. ventral view; C-D. Holotype of Micrixalus herrei Myers, 1942 (CAS-SU 7265, m), from "Kallar": C. dorsal view, D. ventral view.

Comparison. Micrixalus fuscus could not be confused with any of the allied taxa within Micrixalus fuscus group due its larger snout-vent adult size, male, SVL 27.9-28.8 $\mathrm{mm}, N=3$, female, SVL 30.0-33.1 mm, $N=8$ (vs. smaller in M. adonis: male, SVL 21.1-24.1 mm, $N=8$, female, SVL 26.5-30.1 mm, $N=6$; $M$. herrei: male, SVL 16.7-19.4 mm, $N=9$, female, SVL 24.8-26.6 mm, $N=3$; M. kodayari: male, SVL 17.7-18.7 mm, $N=2$, female, SVL 24.6-25.6 $\mathrm{mm}, N=3$; M. mallani: male, SVL $19.5-22.4 \mathrm{~mm}$, $N=4$, female, SVL 25.1-27.7 mm, $N=4$; and $M$. nelliyampathi: male, SVL 21.3-23.7 $\mathrm{mm}, N=7$, female, SVL 25.6-29.5 mm, $N=5$ ), presence of median lingual papillae on tongue (vs. absent in all other species) and webbing between toes extending up to the tip of the disc on all toes (vs. well below the disc on either side of toe IV in all other species). More specifically, differs from $M$. adonis, M. herrei, and M. mallani by its head acute in lateral view (vs. rounded in all three species); differs from $M$. kodayari and $M$. nelliyampathi by its head pointed in dorsal view (vs. subelliptical in $M$. kodayari; subovoid in $M$. nelliyampathi).

Description of lectotype (measurements in mm). Adult female (SVL 32.1); head small (HW 8.3, HL 10.5) longer than wide, flat above; snout pointed in dorsal view, acute in lateral view, its length (SL 5.1) longer than horizontal diameter of eye (EL 3.5); loreal region vertical with sharp canthus rostralis; interorbital space flat, wider (IUE 2.7) than upper eyelid (UEW 2.5), and narrower than internarial distance (IN 3.8); distance between back of eye (IBE 10.1) 1.3 times the distance between front of eye (IFE 7.9); nostril oval, nearly as close to eye (EN 2.1) as to tip of 
snout (NS 2.2); tympanum (TYD 1.2) $34 \%$ of eye diameter (EL 3.5); tongue moderately large, emarginate, with median lingual papillae; supratympanic fold that extends from posterior corner of eye to near the shoulder, weakly developed. Forelimbs (FAL 5.2) shorter than hand length (HAL 7.9); finger discs moderately wide compared to finger width (fd1 1.0, fw1 0.4; fd2 1.2, fw2 0.4; fd3 1.5, fw3 0.4; fd4 1.3, fw4 0.3); subarticular tubercles weakly developed, oval, single, all present. Thigh length (TL 14.9) shorter than shank (SHL 16.0), and longer than foot (FOL
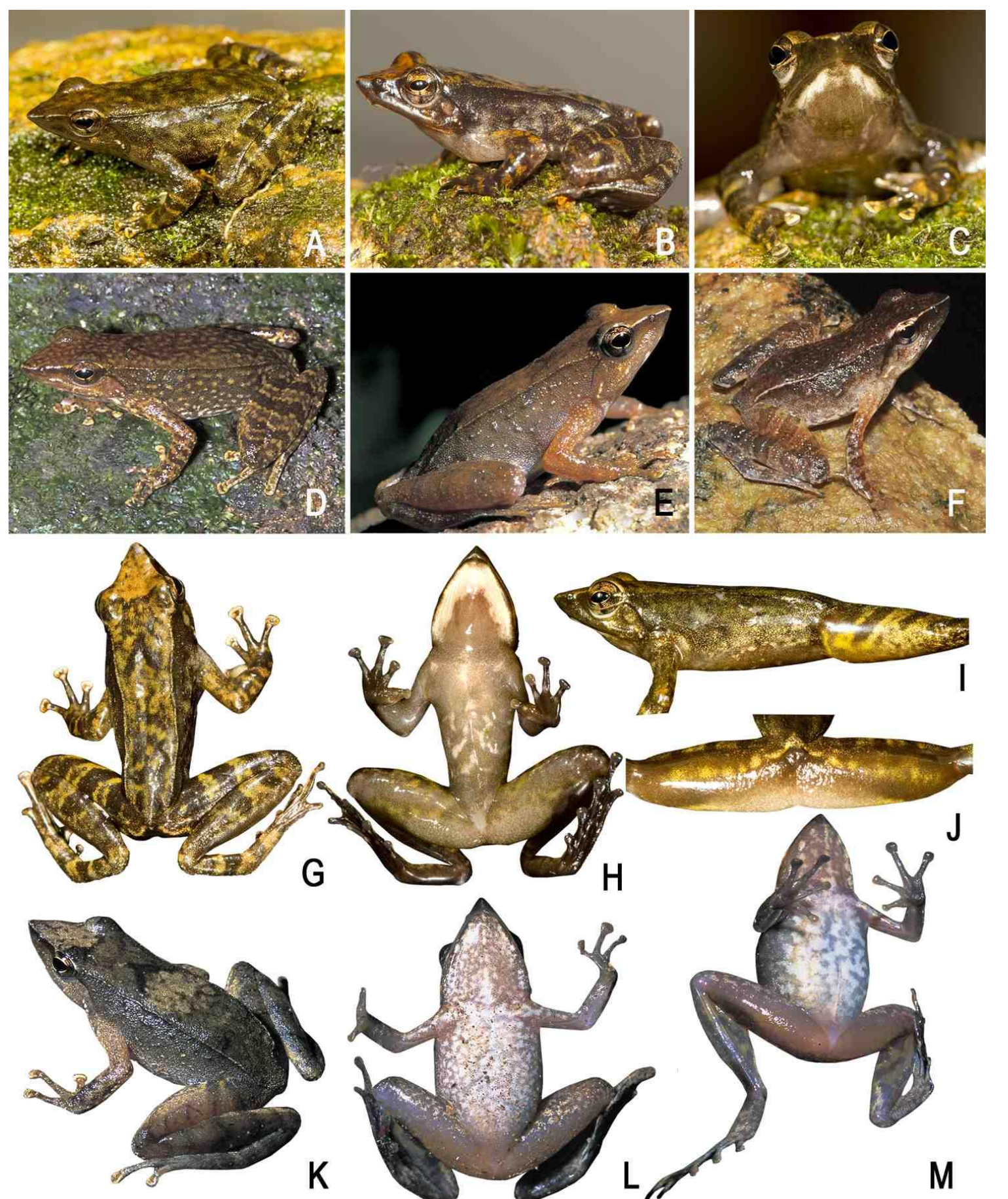
13.6); toe discs wide compared to toe width (td1 0.9, tw1 0.3; td2 1.4, tw2 0.3; td3 1.4, tw3 0.3; td4 1.6, tw4 0.4; td5 1.2, tw5 0.4); webbing complete: I0-0II0-0III0-0IV0-0V; subarticular tubercles weakly developed, oval, all present; inner metatarsal tubercles distinct and moderately short; outer metatarsal tubercles rounded, rather prominent.

Skin of snout, between eyes and upper eyelids shagreened to sparsely granular; posterior part of back shagreened; dorsolateral folds that extend from the posterior corner of the eye to the entire body length on both sides; a faintly developed inverted V-shaped glandular projection on the middle of dorsum; dorsal parts of forelimb shagreened; thigh, tibia and tarsus shagreened with weakly developed granular projections; shanks shagreened with prominent glandular projections; ventral surfaces of throat, chest and abdomen smooth; posterior parts of thigh shagreened to sparsely granular.

Colour in preservation. Dorsum light reddish-brown with faint light grey reticulations; lower flanks dark grey; tympanic area light grey; dorsolateral folds light greyish-brown; forelimbs, dorsal surfaces of thigh, tibia and feet light greyish-brown with faint brown cross-bands, posterior parts of thigh light grey with dark greyish-brown reticulations; throat, chest and belly, ventral parts of thigh and tibia greyish-white with black reticulations; webbing blackish-grey. Colour in life (BNHS 5674, female). Dorsum uniform dark grey with black specks; tympanum and surrounding areas light grey; iris light brown with reddish tinge; flanks light greenish-grey; groin light grey; dorsal surface of limbs greyishbrown with light brown cross-bands; throat and margins of throat, chest and belly greyish-white with prominent light brown reticulations.

Variations. See Table 5 for morphometric characters of three adult males and eight adult females. For colour variations see Figure 22.

Secondary sexual characters. Male (BNHS 5669): Single prominent oval-shaped nuptial pad on finger I present, cream-coloured; single gular pouch while calling, white patch on lower jaw. Female (NHM 74.4.29.258): ova creamy white with minute black spots (diameter 1.2-1.6 mm, $N$ $=20$ ).

Distribution. Micrixalus fuscus is known only from the Western Ghats state of Kerala and Tamil Nadu, with its distribution restricted to south of Shencottah gap. The present study found this species in Kakkachi and Sengaltheri (Tirunelveli dist.) in Tamil Nadu state, and Athirimala and Pandipath (Thiruvananthapuram dist.) in Kerala state (Fig. 3, Table 1). It is possible that Beddome collected the type series from
Kalakkad-Mundanthurai or Pandipath area, since many of Beddome's plant collections from "Travancore" mentioned these locality names (Biju, 2001).

Habitat and natural history. The preferred habitat of this species is fast flowing streams covered with forest canopy. Micrixalus fuscus was found to be relatively abundant at all the collection localities. The majority of male specimens were found actively calling and 'footflagging'. Collections were made between 07:00 16:00 h.

Micrixalus herrei Myers, 1942

Kallar Dancing Frog

(Figs 3, 19C, 21C-D, 23; Tables 1-5)

Original name and description. Micrixalus herrei Myers, 1942. A new frog of the genus Micrixalus from Travancore, Proceedings of the Biological Society of Washington, 55: 71-74. Holotype. CAS-SU 7265, an adult male, by original designation. Type locality. "Kallar, 30 miles northeast of Trivandrum, Travancore, South India", Thiruvananthapuram (= Trivandrum) dist., Kerala state. Current status of specific name. Valid name, as Micrixalus herrei Myers, 1942.

Referred specimens. Kerala: Thiruvananthapuram dist., Kallar, BNHS 5677BNHS 5678, two adult males, collected by SDB, 24 May 2006; Chathankod, BNHS 5679, an adult male, and BNHS 5680, an adult female, collected by SDB, 20 July 2002, BNHS 5681-BNHS 5682, two adult males, and BNHS 5683, an adult female, collected by SDB and Systematics lab team, 11 September 2011, BNHS 5684, an adult male, collected by SDB and SG, 31 May 2012; Ponmudi, BNHS 5685, an adult male, collected by SDB, 20 March 2001; Kollam dist., Kovachal, BNHS 5686, an adult male, collected by SDB and Systematics lab team, 15 September 2011; Tamil Nadu: Kanyakumari dist., Glenback estate, Kiriparai, BNHS 5687, an adult male, collected by SDB, 19 November 2008; Tirunelveli dist., Puthericharium, BNHS 5688, an adult female, collected by SDB, 17 November 2002.

Other material studied. Kerala: Thiruvananthapuram dist., Attayar, SDBDU 2012.2314, collected by SDB, 1 June 2012; Chathankod, SDBDU 2006.4766, collected by SDB, 23 May 2006, SDBDU 2009.106, collected by SDB and Systematics lab team, 20 July 2009; Kollam dist., Kovachal, SDBDU 2011.918, collected by SDB and Systematics lab team, 15 September 2011; Tamil Nadu: Tirunelveli dist., Puthericharium, SDBDU 2002.4054, collected by SDB, 17 November 2002.

Comments. Inger et al. (1985 “1984”) proposed synonymy of Micrixalus herrei with 
Micrixalus fuscus, and subsequently Dutta (1997) and Dinesh et al. (2009) did not consider it as a valid species. We studied both the taxa and find $M$. herrei to be morphologically dissimilar from M. fuscus, the most conspicuous difference being the webbing between its toes that does not extend up to the tip of the disc on either side of toe IV (vs. extends up to the tip of the disc on all toes) and head rounded in lateral view (vs. acute). For detailed comparison see $M$. fuscus. Furthermore, our study finds $M$. herrei to differ from $M$. fuscus by considerable mean genetic divergence of $5.6 \%$ for $16 \mathrm{~S}$ and $12.6 \%$ for COI. The molecular and morphological differences allow us to remove the former from synonymy of $M$. fuscus.

Myers (1942) described Micrixalus herrei based on a sole specimen that is currently present in the California Academy of Sciences, Herpetological collection. However, the original publication does not provide a description of the holotype (museum number CAS-SU 7265) apart from a few basic measurements including the snout-vent size (SVL $17.5 \mathrm{~mm}$ ). Though we could not physically study the type specimen, we studied photographs of the holotype (Figs 21C-D), and new collections from the type locality (Kallar) that correspond to the snout-vent size of the holotype. A detailed description of the topotype is provided below.

Comparison. Micrixalus herrei could be confused with M. adonis, M. fuscus, M. kodayari, M. mallani and M. nelliyampathi. However, $M$. herrei differs from $M$. adonis, M. fuscus, $M$. mallani and $M$. nelliyampathi by its smaller snoutvent size, male, SVL 16.7-19.4 mm, $N=9$, female, SVL 24.8-26.6 mm, $N=3$ (vs. M. adonis: male, SVL 21.1-24.1 mm, $N=8$, female, SVL 26.5-30.1 mm, $N=6$; M. fuscus: male, SVL 27.9-
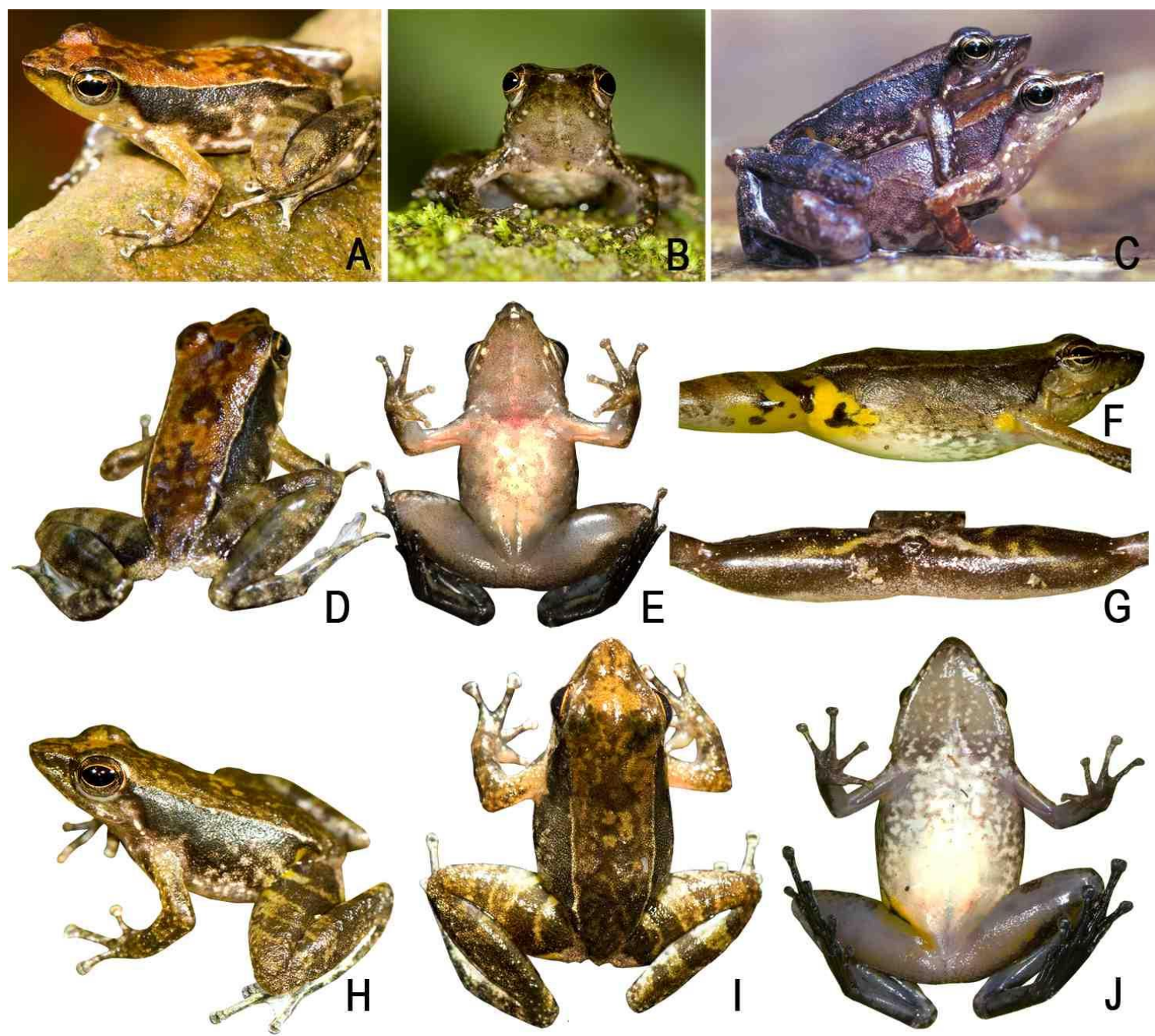

Figure 23. Micrixalus herrei in life: A. dorsolateral view, B. front view (TT, BNHS 5677, m); C. dorsolateral view, amplected pair (RS, BNHS 5679, m, and RS, BNHS 5680, f); D. dorsal view, E. ventral view, F. lateral view of thigh and groin, G. posterior side of thighs (TT, BNHS 5677, m); H. dorsolateral view (RS, BNHS 5687, m); I. dorsal view, J. ventral view (RS, BNHS 5681, m). Photos: SDB. 
$28.8 \mathrm{~mm}, N=3$, female, SVL $30.0-33.1 \mathrm{~mm}, N=$ 8; M. mallani: male, SVL 19.5-22.4 mm, $N=4$, female, SVL 25.1-27.7 $\mathrm{mm}, \quad N=4 ; M$. nelliyampathi: male, SVL 21.3-23.7 mm, $N=7$, female, SVL 25.6-29.5 mm, $N=5$ ). More specifically, M. herrei differs from M. kodayari, $M$. mallani and $M$. nelliyampathi by its snout pointed in dorsal view (vs. subelliptical in $M$. kodayari and $M$. mallani; subovoid in $M$. nelliyampathi) and rounded in lateral view (vs. nearly acute in $M$. mallani; acute in $M$. kodayari and $M$. nelliyampathi).

For more differences with Micrixalus adonis and M. fuscus see 'Comparison' of those species.

Description of topotype (measurements in mm). Adult male (SVL 17.7); head small, as long as its width (HW 6.0, HL 6.0), flat above; snout pointed in dorsal view, rounded in lateral view, its length (SL 2.8) longer than horizontal diameter of eye (EL 2.3); loreal region vertical with rounded canthus rostralis; interorbital space flat, wider (IUE 1.7) than upper eyelid (UEW 1.3) and narrower than internarial distance (IN 2.2); distance between back of eye (IBE 5.1) 1.4 times the distance between front of eye (IFE 3.6); nostril oval, subequal to eye (EN 1.2) and tip of snout (NS 1.1); tympanum (TYD 0.9) $39 \%$ of eye diameter (EL 2.3); tongue moderately large, emarginate, without median lingual papillae; supratympanic fold that extends from posterior corner of eye to near the shoulder, weakly developed. Forelimbs (FAL 3.6) shorter than hand length (HAL 4.8); finger discs moderately wide compared to finger width (fd1 0.4 , fw1 0.2 ; fd2 0.6, fw2 0.3; fd3 0.7, fw3 0.3; fd4 0.7, fw4 0.3); subarticular tubercles weakly developed, oval, single, all present. Thigh length (TL 10.4) subequal to shank (SHL 10.5), and longer than foot (FOL 8.9); toe discs wide compared to toe width (td1 0.6, tw1 0.3; td2 0.7, tw2 0.3; td3 0.7, tw3 0.3; td4 0.9, tw4 0.3; td5 0.8, tw5 0.3); webbing present: I1- $1 \frac{1}{2} \mathrm{II} 1-2^{-} \mathrm{III} 1-2 \mathrm{IV} 2-1 \mathrm{~V}$; subarticular tubercles weakly developed, oval, all present; inner metatarsal tubercles distinct and moderately short; outer metatarsal tubercles rounded, rather prominent.

Skin of snout, between eyes and upper eyelids, and posterior part of back shagreened to sparsely granular; dorsolateral folds that extend from the posterior corner of the eye to the entire body length on both sides, well developed; lateral side of head shagreened; dorsal parts of forelimb, thigh, tibia and tarsus shagreened; weakly developed inverted V-shaped glandular projection on the middle of dorsum; ventral surface of throat, chest and abdomen smooth; posterior parts of thigh shagreened.
Colour in preservation. Dorsum light brown; lower flanks greyish-brown; tympanic area light grey; dorsolateral folds light greyish-brown; forelimbs, dorsal surfaces of thigh, tibia and feet greyish-brown with brown cross-bands, posterior parts of thigh light grey with dark greyish-brown reticulations; throat, chest and belly, ventral parts of thigh and tibia greyish-white; webbing blackish-grey. Colour in life. Dorsum reddishorange with irregular light brown patches; tympanum and surrounding areas dark grey; iris light brown with reddish tinge; flanks light grey; groin light yellow with brown patches; dorsal surface of limbs light brown with dark brown cross-bands; throat and margins of throat, chest and belly greyish-white with scattered light greyish-yellow reticulations on belly.

Variations. See Table 5 for morphometric characters of nine adult males and three adult females. For colour variations see Figure 23.

Secondary sexual characters. Male (BNHS 5677): Single prominent oval-shaped nuptial pad on finger I present, cream-coloured; single gular pouch while calling. Female (BNHS 5680): ova creamy white with minute black spots, (diameter 0.7-1.0 mm, $N=20$ ).

Distribution. Micrixalus herrei is known only from the Western Ghats states of Kerala and Tamil Nadu, with its distribution restricted to south of Shencottah gap. The present study found this species in Attayar, Chathankod, Kallar and Ponmudi (Thiruvananthapuram dist.) and Kovachal (Kollam dist.) in Kerala state, and Kiriparai (Kanyakumari dist.) and Puthericharium (Tirunelveli dist.) in Tamil Nadu state (Fig. 3, Table 1).

Habitat and natural history. The preferred habitat of this species is fast flowing streams and rivulets in primary and secondary forests. Micrixalus herrei was found to be relatively abundant at all the collection localities. The majority of male specimens were found actively calling and 'foot-flagging'. Collections were made between 10:00-15:00 h.

\section{Micrixalus kodayari sp. nov. Kodayar Dancing Frog \\ (Figs 3, 19D, 24; Tables 1-5)}

Holotype. BNHS 5689, an adult female, Kodayar, Tirunelveli dist., Tamil Nadu state, India, collected by SDB, 16 November 2008.

Paratypes. Tamil Nadu: Tirunelveli dist., Kodayar, BNHS 5690, an adult male, collected by SDB, 31 August 2002, BNHS 5691, an adult male, collected by SDB, 26 November 2002; Kakkachi, SDB BNHS 5692-BNHS 5693, two adult females, collected by SDB, 25 November 2002.

Comparison. Micrixalus kodayari could be 
confused with $M$. adonis, $M$. fuscus, $M$. herrei, $M$. mallani and $M$. nelliyampathi. However, $M$. kodayari differs from $M$. mallani by its head acute in lateral view (vs. nearly acute) and $M$. nelliyampathi by its head subelliptical in dorsal view (vs. subovoid). Furthermore, M. kodayari differs from $M$. nelliyampathi by its shank subequal to thigh length, male, SHL $10.3 \pm 0.9$ $\mathrm{mm}$, TL $10.2 \pm 1.0 \mathrm{~mm}, N=2$, female, SHL 13.0 $\pm 0.2 \mathrm{~mm}$, TL $13.0 \pm 0.1 \mathrm{~mm}, N=3$ (vs. longer, male, SHL $12.0 \pm 0.6 \mathrm{~mm}$, TL $10.7 \pm 0.9 \mathrm{~mm}, N=$ 7, female, SHL $14.8 \pm 0.4 \mathrm{~mm}$, TL $12.7 \pm 0.6 \mathrm{~mm}$, $N=5$ ).

For more differences with Micrixalus adonis, $M$. fuscus and M. herrei see 'Comparison' of those species.

Description of holotype (measurements in $\mathrm{mm}$ ). Adult male (SVL 24.6); head small (HW 8.0, HL 8.8), longer than wide, flat above; snout subelliptical in dorsal view, acute in lateral view, its length (SL 3.6) longer than horizontal diameter of eye (EL 2.3); loreal region acute and concave with rounded canthus rostralis; interorbital space flat, subequal (IUE 2.0) to upper eyelid (UEW

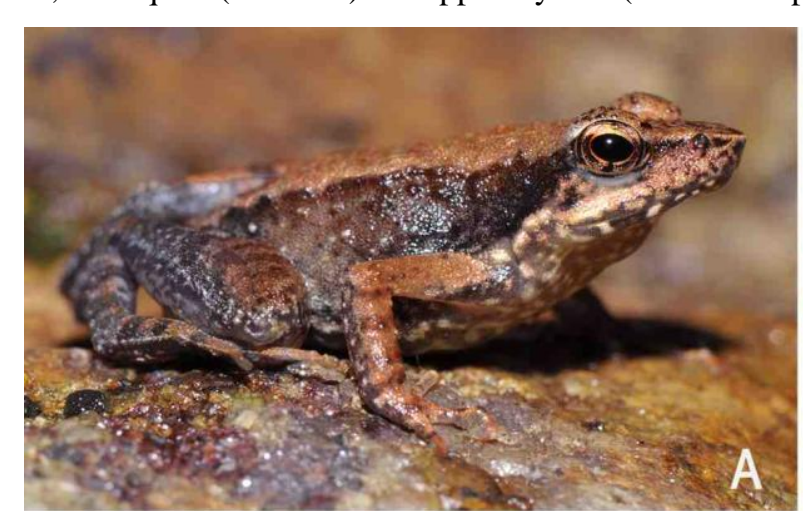

1.9) and narrower than internarial distance (IN 2.6); distance between back of eye (IBE 6.9) 1.8 times the distance between front of eye (IFE 3.8); nostril oval, as close to eye (EN 1.6) as to tip of snout (NS 1.7); tympanum (TYD 0.9) 39\% of eye diameter (EL 2.3); tongue moderately large, emarginate, without median lingual papillae; supratympanic fold that extends from posterior corner of eye to near the shoulder, well developed. Forelimbs (FAL 4.9) shorter than hand length (HAL 6.1); finger discs moderately wide compared to finger width (fd1 0.5 , fw1 0.2 ; fd2 0.6, fw2 0.3; fd3 1.0, fw3 0.3; fd4 0.8, fw4 0.3); subarticular tubercles well developed, oval, single, all present. Thigh length (TL 12.9) equal to shank (SHL 12.9), and longer than foot (FOL 11.2); toe discs wide compared to toe width (td1 0.6, tw1 0.3; td2 0.9, tw2 0.3; td3 1.0, tw3 0.3; td4 1.0, tw4 0.3 ; td5 0.8, tw5 0.3); webbing present: I1-2II1$2 \frac{1}{3} \mathrm{IIII} 1-2^{2} /{ }_{3} \mathrm{IV} 3-1 \frac{1}{5} \mathrm{~V} ; \quad$ subarticular tubercles weakly developed, oval, all present; inner metatarsal tubercles distinct and moderately short; outer metatarsal tubercles rounded, rather prominent.
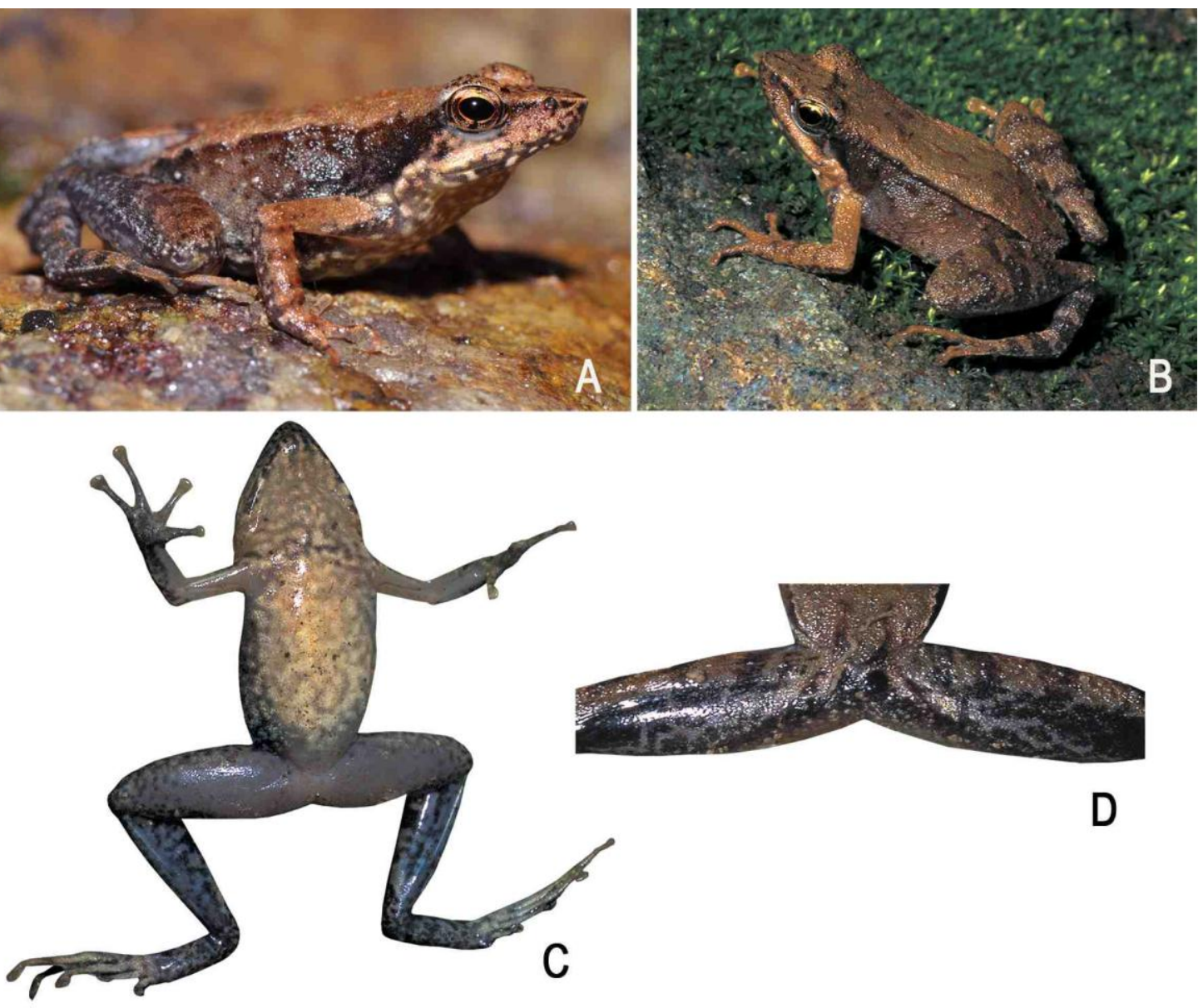

Figure 24. Micrixalus kodayari sp. nov. in life: A. dorsolateral view (HT, BNHS 5689, f); B. dorsolateral view, C. ventral view, D. posterior side of thighs (PT, BNHS 5692, f). Photos: SDB.

Skin of snout, between eyes and upper eyelids shagreened with prominently glandular 
projections; posterior part of back shagreened with sparsely glandular projections; dorsolateral folds that extend from the posterior corner of the eye to the entire body length on both sides, well developed; dorsal part of forelimbs shagreened to sparsely granular; thigh, tibia and tarsus shagreened with glandular projections and scattered glandular warts; weakly developed inverted V-shaped glandular projection on the middle of dorsum; ventral surfaces of throat, chest and abdomen smooth; posterior parts of thigh shagreened to sparsely granular.

Colour in preservation. Dorsum uniform light greyish-brown; anterior part of flanks light brown with dark grey speckles; tympanic area dark brown; forelimbs, dorsal surfaces of thigh, tibia and feet light greyish-brown with dark brown cross-bands, posterior parts of thigh dark brownish-grey with light greyish-brown reticulations; throat, chest and belly light grey with prominent black reticulations; ventral parts of thigh light grey with scattered dark spots, tibia and feet brownish-black with grey reticulations; groin light brown with brown reticulations; webbing light grey with minute black spots. Colour in life. Dorsum uniform greyish-brown with metallic tinge; tympanum and surrounding areas light brown; iris light brown with reddish tinge; anterior parts of flank dark blackish-brown, posterior parts of flank light greyish-brown; groin light grey with minute black spots; dorsal surface of limbs greyish-brown with light brown cross-bands; posterior parts of thigh greyish-blue with light black reticulations; throat and margins of throat, chest and belly greyish-white with prominent grey reticulations; thigh light grey, shank and feet bluish-grey; webbing dark greyish-black.

Variations. See Table 5 for morphometric characters of an adult male and three adult females. For colour variations see Figure 24.

Secondary sexual characters. Female (BNHS 5689): ova creamy white with black reticulations (diameter $0.9-1.1 \mathrm{~mm}, N=20$ ).

Etymology. The species is named after Kodayar, where the holotype was collected. The specific name is a noun in apposition to the generic name and therefore invariable.

Distribution. Micrixalus kodayari is known only from the Western Ghats state of Tamil Nadu, with its distribution restricted to the south of Shencottah gap. The present study found this species in Kodayar and Kakkachi, (Tirunelveli dist.) (Fig. 3, Table 1).

Habitat and natural history. The preferred habitat of this species is shallow waters on the sides of flowing streams covered with forest canopy. Micrixalus kodayari was found to be rare at both the collection localities. Specimens were collected between 10:00-17:00 h.

\author{
Micrixalus mallani sp. nov. \\ Mallan's Dancing Frog \\ (Figs 3, 19E, 25; Tables 1-5)
}

Holotype. BNHS 5694, an adult male, Pandimotta, Shendurney WLS, Kollam dist., Kerala state, India, collected by SDB and Systematics lab team, 13 September 2011.

Paratypes. Kerala: Kollam dist., Pandimotta, BNHS 5695, an adult female, collected along with the holotype; Pathanamthitta dist., Sabarimala, BNHS 5696-BNHS 5698, three adult males, collected by SDB, 11 June 2006; Thiruvananthapuram dist., Athirimala, BNHS 5699-BNHS 5700, two adult females, collected by SDB, 13 March 2003; Ponkalappara, BNHS 5701, an adult female, collected by SDB, 23 December 2007.

Other material studied. Kerala: Thiruvananthapuram dist., Athirimala, SDBDU 2002.495, collected by SDB, 9 June 2002.

Comparison. Micrixalus mallani could be confused with $M$. adonis, $M$. fuscus, $M$. herrei, $M$. kodayari and $M$. nelliyampathi. However, $M$. mallani differs from $M$. nelliyampathi by its snout subelliptical in dorsal view (vs. subovoid) and its shank equal to thigh length, male, SHL $10.5 \pm 0.3$ $\mathrm{mm}$, TL $10.5 \pm 0.2 \mathrm{~mm}, N=4$, female, SHL 13.7 $\pm 0.5 \mathrm{~mm}$, TL $13.7 \pm 0.6 \mathrm{~mm}, N=4$ (vs. longer than thigh, male, SHL $12.0 \pm 0.6 \mathrm{~mm}$, TL $10.7 \pm$ $0.9 \mathrm{~mm}, N=7$, female, SHL $14.8 \pm 0.4 \mathrm{~mm}$, TL $12.7 \pm 0.6 \mathrm{~mm}, N=5$ ).

For differences with Micrixalus adonis, $M$. fuscus, $M$. herrei and $M$. kodayari see 'Comparison' of those species.

Description of holotype (measurements in mm). Adult male (SVL 19.5); head small (HW 6.1, HL 7.2), longer than wide, flat above; snout subelliptical in dorsal view, nearly acute in lateral view, its length (SL 3.1) longer than horizontal diameter of eye (EL 2.3); loreal region vertical with rounded canthus rostralis; interorbital space flat, wider (IUE 1.7) than upper eyelid (UEW 1.2) and narrower than internarial distance (IN 2.4); distance between back of eye (IBE 5.8) 1.5 times the distance between front of eye (IFE 4.0); nostril oval, closer to eye (EN 1.1) than tip of snout (NS 1.3); tympanum (TYD 0.9) 39\% of eye diameter (EL 2.3); tongue moderately large, emarginate, without median lingual papillae; supratympanic fold that extends from posterior corner of eye to near the shoulder, weakly developed. Forelimbs (FAL 3.8) shorter than hand length (HAL 5.1); finger discs moderately wide compared to finger width (fd1 0.7, fw1 0.3; fd2 0.8, fw2 0.3; fd3 0.9, fw3 0.2; fd4 0.9, fw4 0.2); subarticular tubercles weakly developed, oval, single, all present. Thigh 
length (TL 10.5) longer than shank (SHL 10.1), and longer than foot (FOL 9.2); toe discs wide compared to toe width $(\operatorname{td} 10.6, \operatorname{tw} 10.3 ; \operatorname{td} 20.9$, tw2 0.3; td3 0.9, tw3 0.3; td4 0.9, tw4 0.3; td5 0.6, tw5 0.2); webbing present: I1- $1 \frac{1}{2} \mathrm{II} 1-2 \mathrm{III} 1-$ 3IV3-1V; subarticular tubercles weakly developed, oval, all present; inner metatarsal tubercles distinct and moderately short; outer metatarsal tubercles rounded, rather prominent.
Skin of snout, between eyes and upper eyelids shagreened to finely granular; posterior part of back shagreened to sparsely granular; dorsolateral folds that extend from the posterior corner of the eye to the entire body length on both sides, well developed; thigh, tibia and tarsus shagreened with weakly developed glandular projections; an inverted V-shaped glandular projection on the middle of dorsum; dorsal parts

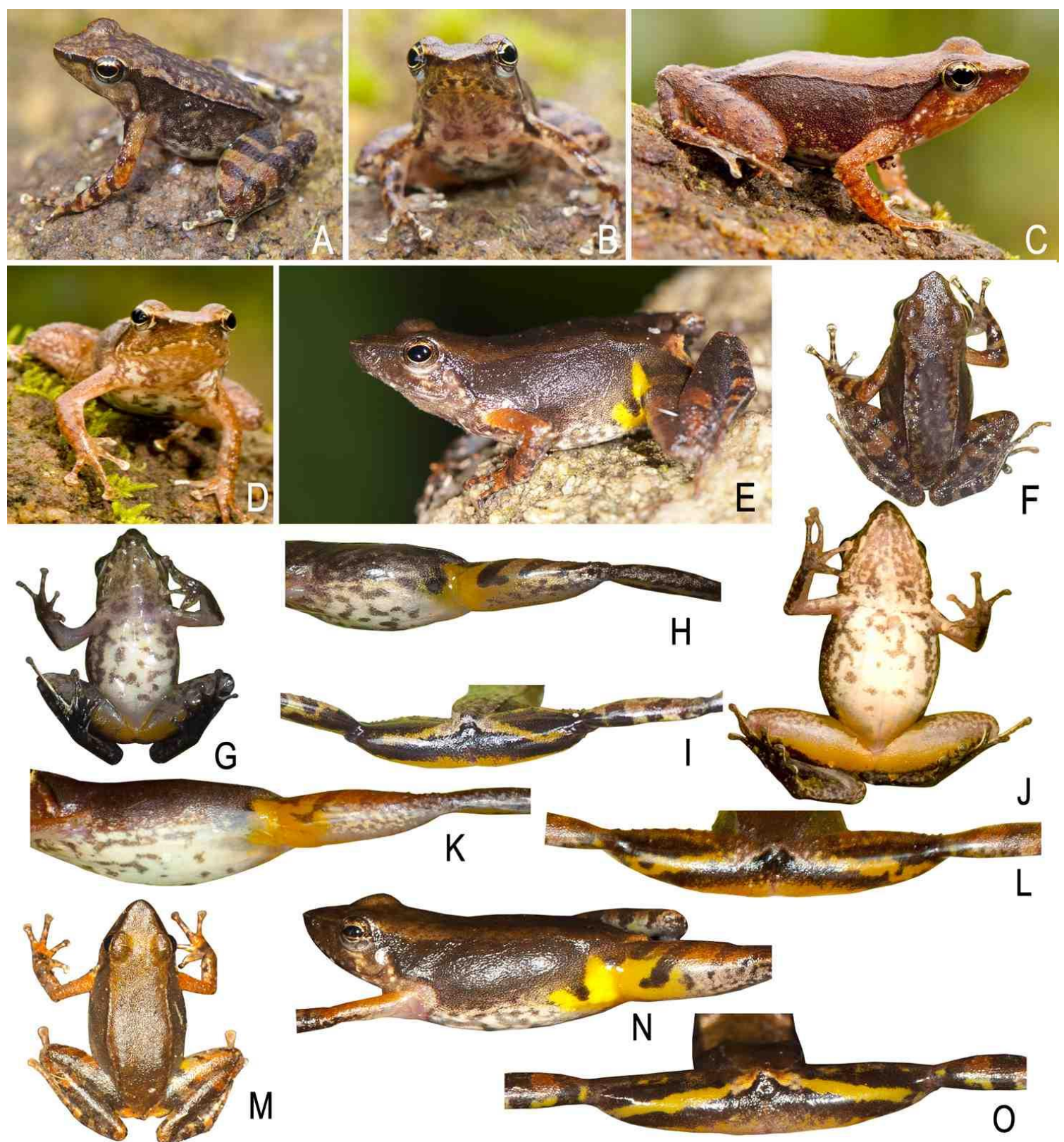

Figure 25. Micrixalus mallani sp. nov. in life: A. dorsolateral view, B. front view (HT, BNHS 5694, m); C. dorsolateral view, D. front view (PT, BNHS 5695, f); E. dorsolateral view (PT, BNHS 5700, f); F. dorsal view, G. ventral view, H. lateral view of thigh and groin, I. posterior side of thighs (HT, BNHS 5694, m); J. ventral view, K. lateral view of thigh and groin, L. posterior side of thigh (PT, BNHS 5695, f); M. dorsal view, N. lateral view of thigh and groin, O. posterior side of thighs (PT, BNHS 5700, f). Photos: SDB. forelimb shagreened; ventral surface of throat, chest and abdomen smooth; posterior parts of

thigh shagreened to sparsely granular.

Colour in preservation. Dorsum brown 
with light grey reticulations; posterior parts of flank grey with dark grey speckles; tympanic area grey; dorsolateral folds light brown; forelimbs, dorsal surfaces of thigh, tibia and feet light greyish-brown with dark brown cross-bands; throat, chest and belly greyish-white with grey reticulations; ventral parts of thigh light grey with scattered dark spots, tibia and feet brownish-black; webbing blackish-grey. Colour in life. Dorsum uniform greyish-brown with light grey specks; iris light brown with reddish tinge; flanks light brownish-grey with brown reticulations; groin yellow with light grey spots; dorsal surface of limbs greyish-brown with light brown crossbands; throat and margins of throat, chest and belly grey with prominent brownish-grey reticulations; ventral surface of thighs light orange.

Variations. See Table 5 for morphometric characters of four adult males and four adult females. For colour variations see Figure 25.

Secondary sexual characters. Male: Single prominent oval-shaped nuptial pad on finger I present, cream-coloured; single gular pouch while calling. Female (BNHS 5695): ova creamy white with black spots or reticulations (diameter 0.8-1.0 $\mathrm{mm}, N=20$ ).

Etymology. This species is named after Mr. Mallan Kani, in appreciation of his tremendous support and companionship to SDB in field, since 1998. The species name mallani is a noun in the genitive case.

Distribution. Micrixalus mallani is known only from the Western Ghats state of Kerala, with its distribution restricted to the south of Palghat gap. The present study found this species in Pandimotta (Kollam dist.), Sabarimala (Pathanamthitta dist.), Athirimala and Ponkalapara (Thiruvananthapuram dist.) (Fig. 3, Table 1).

Habitat and natural history. The preferred habitat of this species is streams covered with forest canopy. The majority of male specimens were found actively calling and 'foot-flagging'. Collections were made between 09:00-17:00 h.

\section{Micrixalus nelliyampathi sp. nov. Nelliyampathi Dancing Frog (Figs 3, 19F, 26; Tables 1-5)}

Holotype. BNHS 5702, an adult male, Kesavapara, Nelliyampathy, Palakkad dist., Kerala state, India, collected by SDB and Systematics lab team, 14 October 2011.

Paratypes. Kerala: Palakkad dist., Kesavapara, Nelliyampathy, BNHS 5703-BNHS 5704, two adult males, and BNHS 5705-BNHS 5706, two adult females, collected along with holotype; Poopara, BNHS 5707, an adult male, collected by SDB and Systematics lab team, 13 August 2011; Tamil Nadu: Coimbatore dist., Andiparai shola, BNHS 5708-BNHS 5709, two adult males, and BNHS 5710, an adult female, collected by SDB, 15 August 2002, BNHS 5711, an adult male, collected by SDB, 8 January 2004; Grass hills, BNHS 5712-BNHS 5713, two adult females, collected by SDB, 12 July 2005.

Other material studied. Kerala: Palakkad dist., Kesavapara, Nelliyampathy, SDBDU 2011.1154, collected along with holotype; Poopara, SDBDU 2011.562, collected by SDB and Systematics lab team, 13 August 2011; Tamil Nadu: Coimbatore dist., Puthuthottam, SDBDU 2001.785, collected by SDB, 28 July 2001.

Comparison. Micrixalus nelliyampathi could be confused with $M$. adonis, $M$. fuscus, $M$. herrei, M. kodayari and $M$. mallani. For differences with Micrixalus adonis, M. fuscus, $M$. herrei, M. kodayari and M. mallani see 'Comparison' of those species.

Description of holotype (measurements in $m m$ ). Adult male (SVL 23.7); head small (HW 7.2, HL 8.4), longer than wide, flat above; snout subovoid in dorsal view, acute in lateral view, its length (SL 4.1) longer than horizontal diameter of eye (EL 3.0); loreal region vertical and concave with rounded canthus rostralis; interorbital space flat, wider (IUE 2.1) than upper eyelid (UEW 1.8) and narrower than internarial distance (IN 2.6); distance between back of eye (IBE 6.3) 1.7 times the distance between front of eye (IFE 3.8); nostril oval, closer to eye (EN 1.3) than tip of snout (NS 1.7); tympanum (TYD 0.8) $27 \%$ of eye diameter (EL 3.0); tongue moderately large, emarginate, without median lingual papillae; supratympanic fold that extends from posterior corner of eye to near the shoulder, weakly developed. Forelimbs (FAL 5.1) shorter than hand length (HAL 6.2); finger discs moderately wide compared to finger width (fd1 0.7, fw1 0.3; fd2 0.7, fw2 0.3; fd3 1.0, fw3 0.3; fd4 0.9, fw4 0.3); subarticular tubercles weakly developed, oval, single, all present. Thigh length (TL 11.9) shorter than shank (SHL 12.1), and subequal to foot (FOL 11.8); toe discs wide compared to toe width (td1 0.6 , tw1 $0.2 ;$ td2 0.9 , tw2 $0.3 ; \operatorname{td} 30.9$, tw3 0.3; td4 0.9, tw4 0.3; td5 0.9, tw5 0.3); webbing present: I1- $1 \frac{1}{2} / 2 \mathrm{II} 1-2^{-} \mathrm{III} 1-$ 2IV2-1V; subarticular tubercles weakly developed, oval, all present; inner metatarsal tubercles distinct and moderately short; outer metatarsal tubercles rounded, rather prominent.

Skin of snout, between eyes and upper eyelids, posterior part of back shagreened to sparsely granular; dorsolateral folds that extend 


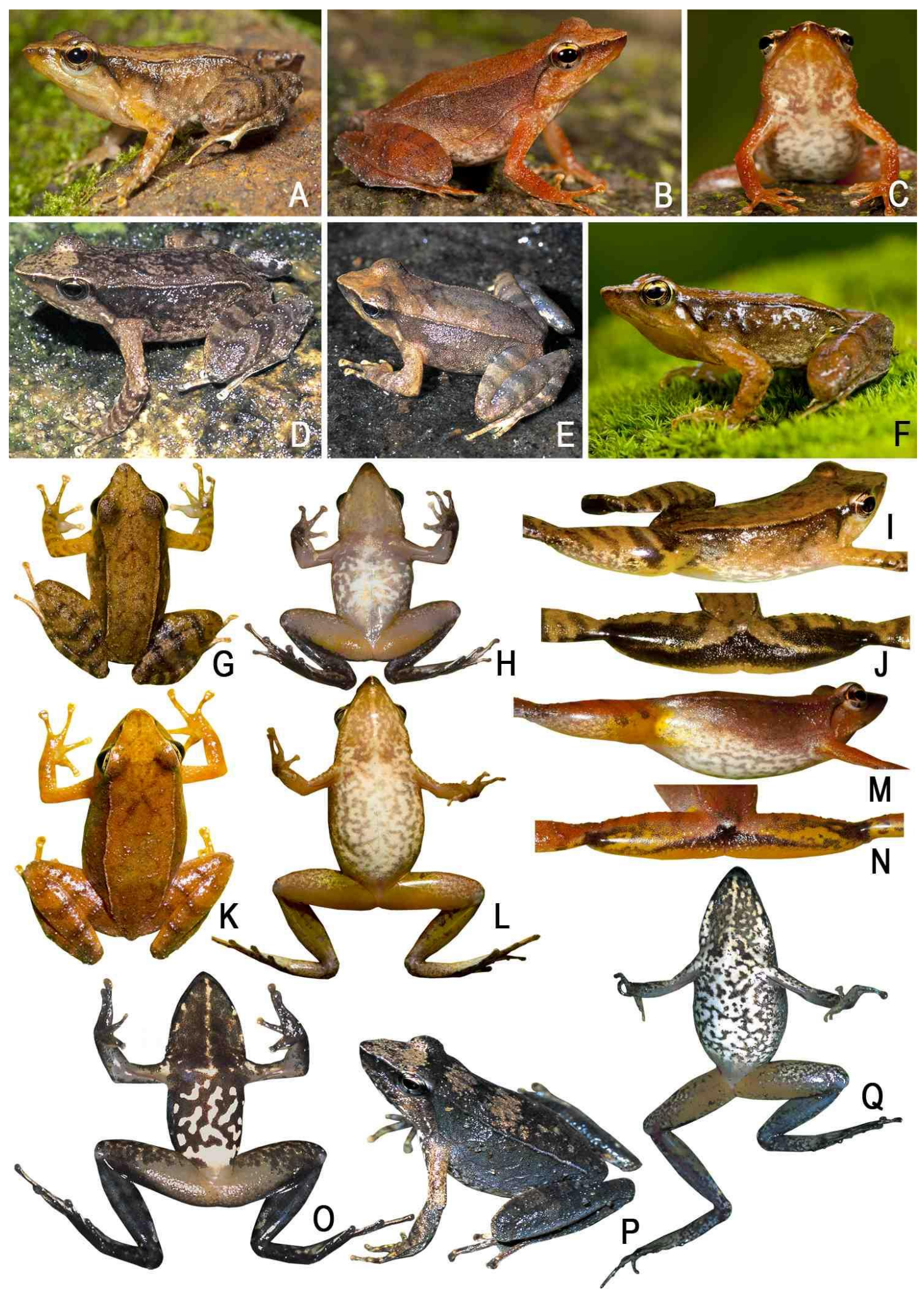

Figure 26. Micrixalus nelliyampathi sp. nov. in life: A. dorsolateral view (HT, BNHS 5702, m); B. dorsolateral view, C. front view (PT, BNHS 5705, f); D. dorsolateral view (PT, BNHS 5711, m); E. dorsolateral view (PT, BNHS 5708, m); F. dorsolateral view (PT, BNHS 5707, m); G. dorsal view, H. ventral view, I. lateral view of thigh and groin, J. posterior side of thighs (HT, BNHS 5702, m); K. dorsal view, L. ventral view, M. lateral view of thigh and groin, N. posterior side of thighs (PT, BNHS 5705, f); O. ventral view (PT, BNHS 5711, m); P. dorsolateral view, Q. ventral view (PT, BNHS 5712, f). Photos: SDB. 
from the posterior corner of the eye to the entire body length on both sides, well developed; dorsal part of forelimbs shagreened to sparsely granular; thigh, tibia and tarsus with weakly developed glandular projections; an inverted V-shaped glandular projection on the middle of dorsum; ventral surface of throat, chest and abdomen smooth; posterior parts of thigh shagreened to sparsely granular.

Colour in preservation. Dorsum light grey; flanks brown with dark grey speckles; tympanic area light grey; dorsolateral folds light grey; forelimbs, dorsal surfaces of thigh, tibia and feet light greyish-brown with dark brown cross-bands, posterior parts of thigh dark brown with greyishbrown reticulations; throat, chest and belly greyish-white with black reticulations; ventral parts of thigh light grey with scattered dark spots, tibia and feet brownish-black; webbing blackishgrey. Colour in life. Dorsum uniform greyishbrown with minute brown spots; flanks light yellowish-grey with brown spots; tympanum and surrounding areas light brownish-grey; iris light brown with minute reddish tinge; groin light yellow with light brown spots; posterior parts of thigh dark brownish-black; dorsal surface of limbs yellowish-brown with brown cross-bands; throat, chest and belly greyish-white with prominent white reticulations.

Variations. See Table 5 for morphometric characters of seven adult males and five adult females. For colour variations see Figure 26.

Secondary sexual characters. Male: Single prominent oval-shaped nuptial pad on finger I present, cream-coloured; single gular pouch while calling. Female (BNHS 5705): ova creamy white with black spots (diameter 1.0-1.3 $\mathrm{mm}, N=20$ ).

Etymology. The species is named after Nelliyampathi, where the holotype was collected. The specific name is a noun in apposition to the generic name and therefore invariable.

Distribution. Micrixalus nelliyampathi is known from the Western Ghats states of Kerala and Tamil Nadu, with its distribution restricted between the Palghat gap and Shencottah gap. The present study found this species in Kesavapara and Poopara (Palakkad dist.) in Kerala state, and Andiparai shola, Grass hills and Puthuthottam (Coimbatore dist.) in Tamil Nadu state (Fig. 3, Table 1).

Habitat and natural history. The preferred habitat of this species is fast flowing streams covered with forest canopy at Kesavapara, Poopara and Grass hills. However the collections from Andiparai shola were predominantly from streams near plantations. Micrixalus nelliyampathi was found to be relatively abundant at all the collection localities. The majority of male specimens were found actively calling and 'footflagging'. Collections were made between 10:0017:00 h.

\section{Micrixalus nudis group}

Members. Micrixalus gadgili, Micrixalus nudis, Micrixalus sali sp. nov. and Micrixalus thampii

This group can be distinguished from other Micrixalus groups by the combination of following morphological characters: small adult size (male, SVL 13.0-17.0 mm; female, SVL 17.0-22.0 $\mathrm{mm}$ ); absence or presence of dorsolateral folds; fourth toe webbing does not extend beyond the second subarticular tubercle on either side; presence of outer metatarsal tubercle; absence of glands behind the tympanum or near posterior axis of the mandibles; and presence of a dark brownish-black band that extends from posterior corner of the eye up to the groin, where it ends in to a thin line. It is also one of the more widely distributed Micrixalus groups that is found on both sides of the Palghat gap and Shencottah gap in the Western Ghats, but with individual species having narrow geographical ranges (Fig. 27).

\section{Micrixalus gadgili Pillai and Pattabiraman, 1990 \\ Gadgil's Dancing Frog}

(Figs 3, 27A, 28, 29; Tables 1-5)

Original name and description. Micrixalus gadgili Pillai and Pattabiraman, 1990. Amphibians from Sabagiri forest, Western Ghats, Kerala, including a new species of Micrixalus. Records of the Zoological Survey of India 86: 386-388. Holotype. ZSI-SRS VA/780 according to Chanda et al., 2001 "2000". Type locality. "Dynamite House, Pamba, Sabarigiri, S. India". Current status of specific name. Valid name, as Micrixalus gadgili Pillai and Pattabiraman, 1990.

\section{Referred Specimens. Kerala:}

Pathanamthitta dist., Sabarimala, BNHS 5714, an adult male, collected by SDB, 9 June 2006; Gavi, BNHS 5715, an adult male, and BNHS 5716, an adult female, collected by SDB, 10 June 2006; Idukki dist., Thekkady, BNHS 5717-BNHS 5718, two adult males, collected by SDB, 8 June 2006, BNHS 5719, an adult male, collected by SDB and SG, 28 January 2012; Palakkad dist., Kesavapara, Nelliyampathy, BNHS 5720-BNHS 5722, three adult males, collected by SDB and Systematics lab team, 14 October 2011.

Other material studied. Kerala: Idukki dist., Thekkady, SDBDU 2006.4801, collected by SDB, 8 June 2006, SDBDU 2012.1842-1843, collected by SDB and SG, 28 January 2012; Palakkad dist., Kesavapara, Nelliyampathy, 


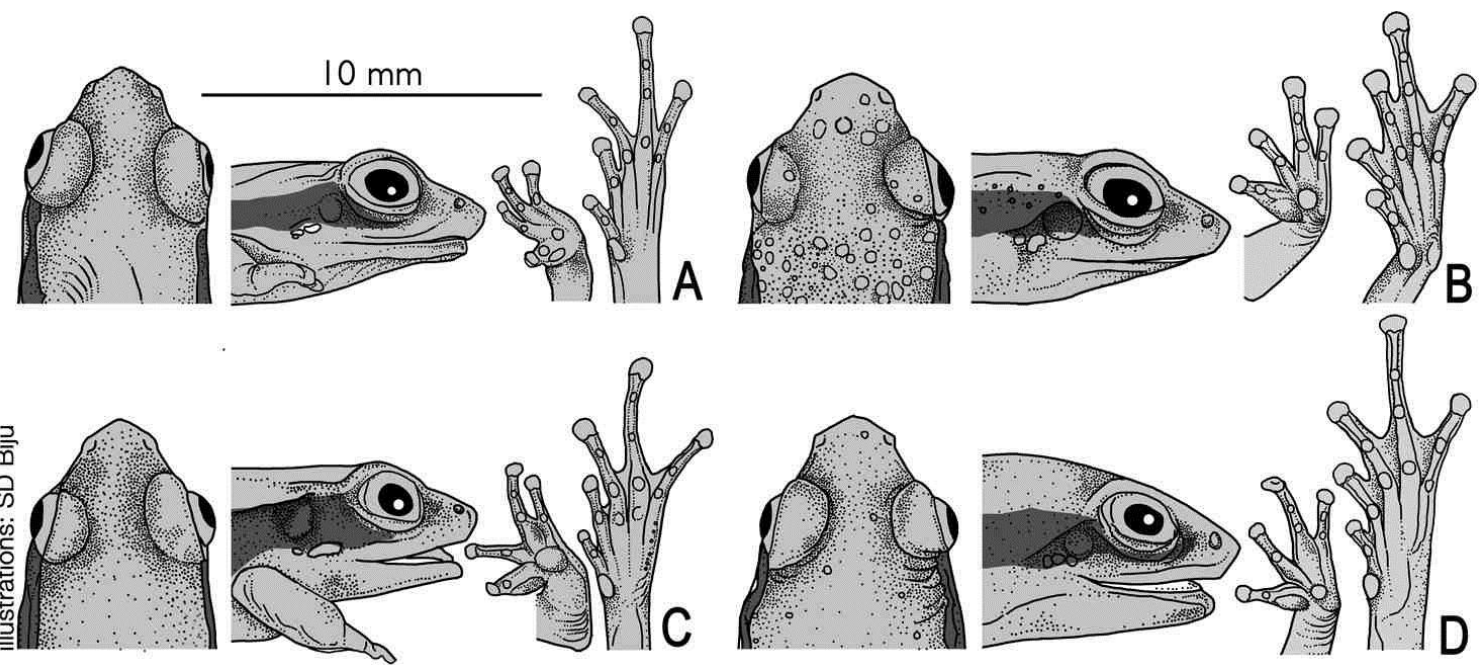

Figure 27. From left to right, dorsal view of head, lateral view of head, ventral view of hand and ventral view of foot of Micrixalus nudis group: A. M. gadgili (RS, BNHS 5715, m); B. M. nudis (RS, BNHS 5725, m); C. Micrixalus sali sp. nov. (HT, BNHS 5731, m); D. M. thampii (RS, BNHS 5742, m).

SDBDU 2011.1148-1149, collected by SDB and Systematics lab team, 15 October 2011.

Comments. Pillai and Pattabiraman (1990) described this species based on seven specimens (the holotype along with six paratypes). However, the original description does not cite any specimen numbers. Chanda et al. (2001 "2000") stated ZSI/SRS Chennai VA/780 to be the holotype (Fig. 28) and ZSI/SRS Chennai VA/781 (unregistered) as paratypes. We studied the type series in ZSI/SRS, and found four specimens (one male and three females), including the holotype. SDB first studied the holotype in 2002, and later in 2011 found it severely damaged.

Comparison. Micrixalus gadgili could be confused with $M$. nudis, M. sali and M. thampii. However, M. gadgili differs from $M$. nudis and $M$. thampii by its first toe webbing basal on the inside (vs. extending up to base of the disc, in both species) and nostril closer to eye than tip of snout, male, EN $0.8 \pm 0.1 \mathrm{~mm}$, NS $1.3 \pm 0.1 \mathrm{~mm}, N=8$, female, EN $1.2 \pm 0.1 \mathrm{~mm}$, NS $1.6 \pm 0.1 \mathrm{~mm}, N=2$ (vs. closer to tip of snout than eye in $M$. nudis: male, EN $1.5 \pm 0.1 \mathrm{~mm}$, NS $1.0 \pm 0.1 \mathrm{~mm}, N=5$, female, EN $1.7 \pm 0.1 \mathrm{~mm}$, NS $1.2 \pm 0.0 \mathrm{~mm}, N=$ 3 ; as close to eye as to tip of snout in M. thampii: male, EN $1.1 \pm 0.2 \mathrm{~mm}$, NS $1.1 \pm 0.1 \mathrm{~mm}, N=6$, female, EN $1.4 \pm 0.2 \mathrm{~mm}$, NS $1.3 \pm 0.1 \mathrm{~mm}, N=$ $3)$; differs from $M$. sali by its larger adult size, male, SVL 15.1-16.2 mm, $N=8$, female, SVL 17.0-18.2 mm, $N=2$ (vs. small, male, SVL 13.8$14.9 \mathrm{~mm}, N=6$, female, SVL $16.2 \mathrm{~mm}, N=1$ ), second toe webbing extending beyond the subarticular tubercle on the outside (vs. basal) and nostril closer to eye than tip of snout, male, EN $0.8 \pm 0.1 \mathrm{~mm}$, NS $1.3 \pm 0.1 \mathrm{~mm}, N=8$, female,
EN $1.2 \pm 0.1 \mathrm{~mm}$, NS $1.6 \pm 0.1 \mathrm{~mm}, N=2$ (vs. as close to eye as to tip of snout, male, EN $1.1 \pm 0.1$ $\mathrm{mm}$, NS $1.1 \pm 0.1 \mathrm{~mm}, N=6$, female, EN $1.3 \mathrm{~mm}$, NS $1.3 \mathrm{~mm}, N=1$ ).

Description of holotype. A general description was published by Pillai and Pattabiraman (1990).

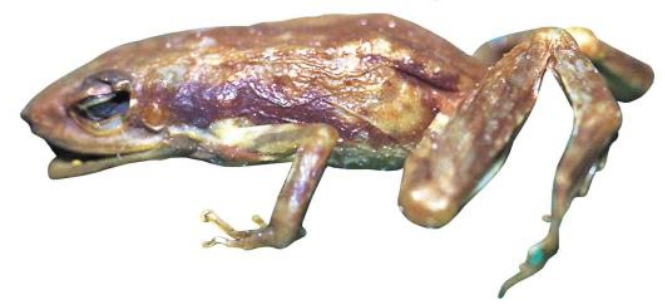

Figure 28. Holotype of Micrixalus gadgili (ZSISRS VA/780, f).

Distribution. Micrixalus gadgili is known only from the Western Ghats state of Kerala, with its distribution restricted between the Palghat and Shencottah gap. The present study found this species in Sabarimala, Gavi (Pathanamthitta dist.), Thekkady (Idukki dist.) and Kesavapara (Palakkad dist.) (Fig. 3, Table 1).

Habitat and natural history. The preferred habitat of this species is mostly damp leaf litter on the sides of streams covered with forest canopy. The majority of male specimens were found actively calling and collected between 12:0016:00 h. 


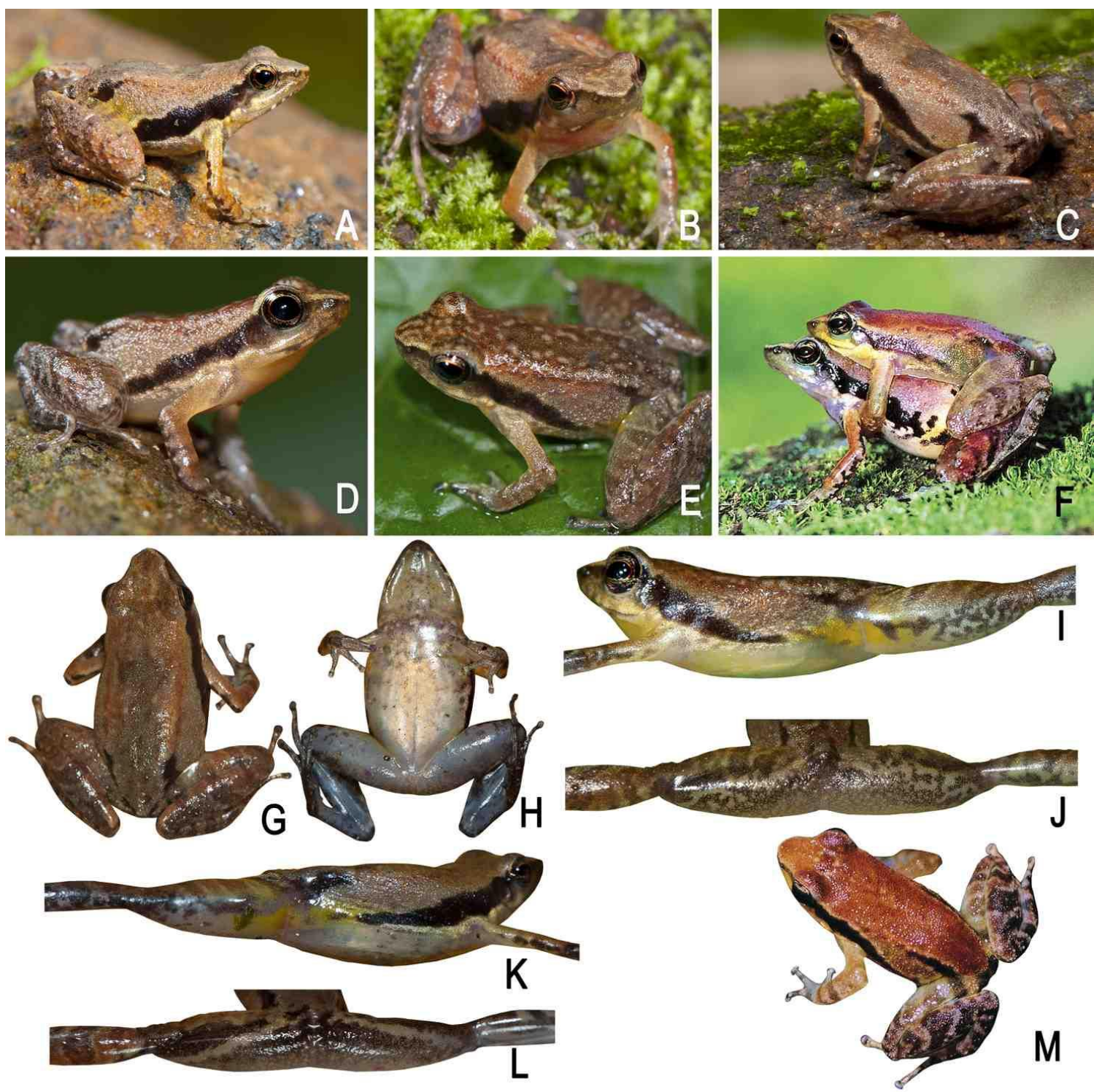

Figure 29. Micrixalus gadgili in life: A. dorsolateral view, B. front view, C. dorsolateral view (RS, BNHS 5722, m); D. dorsolateral view, E. dorsolateral view (RS, BNHS 5719, m); F. amplected pair (RS, BNHS 5715, m, and BNHS 5716, f); G. dorsal view, H. ventral view, I. lateral view of thigh and groin, J. posterior side of thighs (RS, BNHS 5722, m); K. lateral view of thigh and groin, L. posterior side of thighs (RS, BNHS 5719, m); M. dorsal view (RS, BNHS 5715, m). Photos: SDB.

\section{Micrixalus nudis Pillai, 1978 \\ Naked Dancing Frog}

(Figs 3, 27B, 30, 31; Tables 1-5)

Original name and description. Micrixalus nudis Pillai, 1978. A new frog of the genus Micrixalus Boul. from Wynad, S. India. Proceedings of the Indian Academy of Sciences, Section B 87: 173. Holotype. ZSI-SRS VA/771, an adult female, according to Chanda et al., 2001 "2000". Type locality. "forest brook, $8 \mathrm{~km}$ north of Forest Rest House, Chedleth, Kurichiat Reserve Forest", Wayanad dist., Kerala state. Current status of specific name. Valid name, as Micrixalus nudis Pillai, 1978.
Referred specimens. Kerala: Wayanad dist., Chethalayam falls, Kurichiat, BNHS 5723, an adult male, and BNHS 5724, an adult female, collected by SDB, 20 September 2002, BNHS 5725-BNHS 5728, four adult males, and BNHS 5729-BNHS 5730, two adult females, collected by SDB and SG, 6 June 2012.

Comments. This species has been reported from Ponmudi (Inger et al., 1984), Siruvani (Biju et al., 2004) and Nagarahole (Aravind, 2002). However, the populations from Ponmudi belong to a different species, described herein as a new species (Micrixalus sali), whereas population from Siruvani and surrounding regions belong to Micrixalus thampii. 


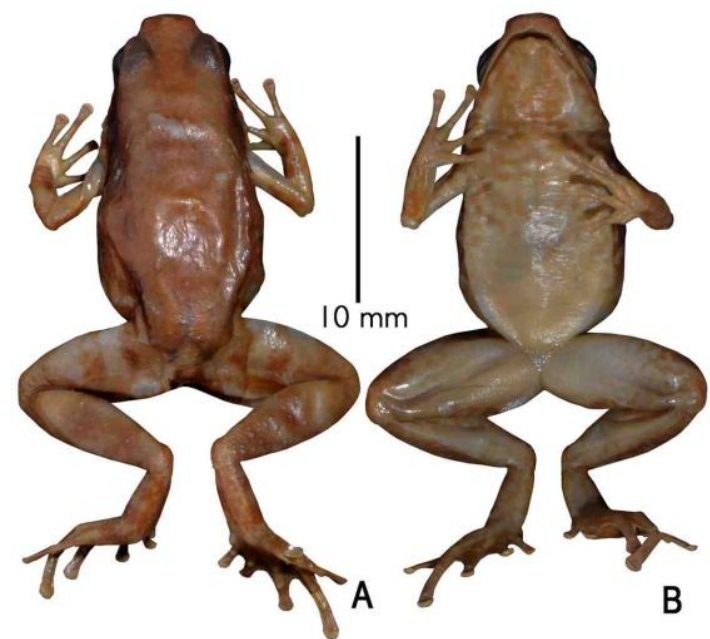

Figure 30. Holotype of Micrixalus nudis (ZSISRS VA/771): A. Dorsal view, B. ventral view.
Comparison. Micrixalus nudis could be confused with M. gadgili, M. sali and M. thampii. However, $M$. nudis differs from $M$. sali by its larger adult size, male, SVL $15.2-16.3 \mathrm{~mm}, N=5$, female, SVL 20.3-20.7 mm, $N=3$ (vs. small, male, SVL 13.8-14.9 mm, $N=6$, female, SVL $16.2 \mathrm{~mm}, N=1$ ), second toe webbing extending up to the base of disc on the outside (vs. basal) and nostril closer to tip of snout than eye, male, EN $1.5 \pm 0.1 \mathrm{~mm}$, NS $1.0 \pm 0.1 \mathrm{~mm}, N=5$, female, EN $1.7 \pm 0.1 \mathrm{~mm}$, NS $1.2 \pm 0.0 \mathrm{~mm}, N=3$ (vs. as close to tip of snout as eye, male, EN $1.1 \pm$ $0.1 \mathrm{~mm}$, NS $1.1 \pm 0.1 \mathrm{~mm}, N=6$, female, EN 1.3 $\mathrm{mm}$, NS $1.3 \mathrm{~mm}, N=1$ ); differs from $M$. thampii by its nostril closer to tip of snout than eye, male, EN $1.5 \pm 0.1 \mathrm{~mm}$, NS $1.0 \pm 0.1 \mathrm{~mm}, N=5$, female, EN $1.7 \pm 0.1 \mathrm{~mm}$, NS $1.2 \pm 0.0 \mathrm{~mm}, N=3$ (vs. as close to tip of snout as eye, male, EN $1.1 \pm$
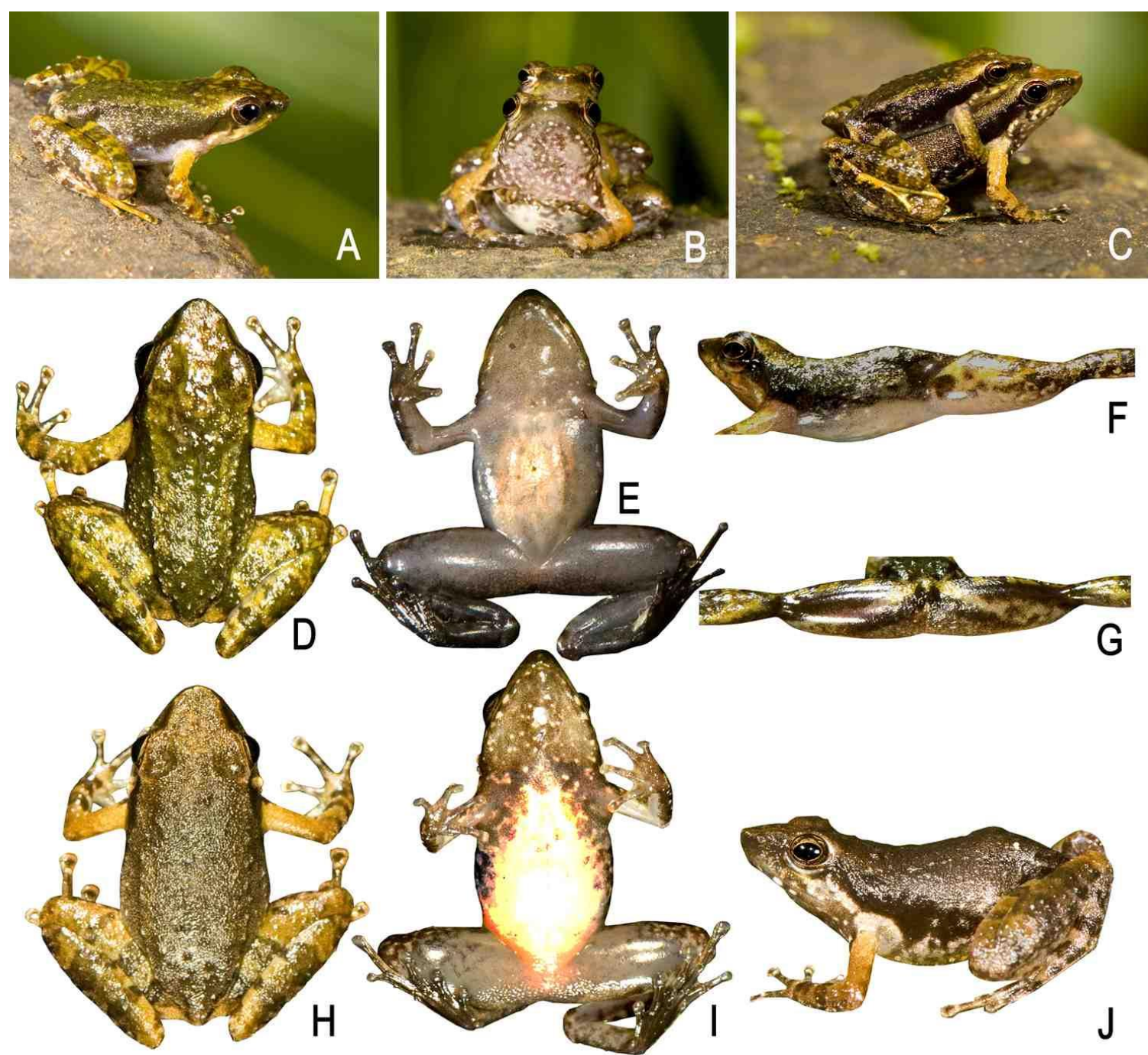

Figure 31. Micrixalus nudis in life: A. dorsolateral view (RS, BNHS 5726, m); B. front view of amplected pair, C. dorsolateral view of amplected pair (RS, BNHS 5727, m, and RS, BNHS 5730, f); D. dorsal view, E. ventral view, F. lateral view of thigh and groin, G. posterior side of thighs (RS, BNHS 5726, m); H. dorsal view, I. ventral view (RS, BNHS 5729, f); J. dorsolateral view (RS, BNHS 5725, m). Photos: SDB. 
$0.2 \mathrm{~mm}$, NS $1.1 \pm 0.1 \mathrm{~mm}, N=6$, female, EN 1.4 $\pm 0.2 \mathrm{~mm}$, NS $1.3 \pm 0.1 \mathrm{~mm}, N=3$ ), third toe webbing extending up to the first subarticular tubercle on the inside (vs. up to the second subarticular tubercle).

For more differences with Micrixalus gadgili see 'Comparison' of that species.

Description of holotype. A general original description was published by Pillai (1978).

Distribution. Micrixalus nudis is known only from the Western Ghats state of Kerala, with its distribution restricted to the north of Palghat gap. The present study found this species in Chethalayam falls in Kurichiat and surrounding regions in Wayanad dist. of Kerala state (Fig. 3, Table 1).

Habitat and natural history. This species was mostly found on damp leaf litter or in shallow waters on the sides of streams covered with forest canopy. The majority of male specimens were found actively calling and collected between 09:00-16:00 h.

\section{Micrixalus sali sp. nov. Sali's Dancing Frog}

(Figs 3, 27C, 32; Tables 1-5)

Holotype. BNHS 5731, an adult male, Ponmudi, Thiruvananthapuram dist., Kerala state, India, collected by SDB, SG and Sali Palode, 30 May 2012.

Paratypes. Kerala: Thiruvananthapuram dist., Ponmudi, BNHS 5732-BNHS 5734, three adult males, collected along with holotype, BNHS 5735-BNHS 5736, two adult males, collected by SDB, 22 November 2002, BNHS 5737, an adult female, collected by SDB and Systematics lab team, 11 September 2011.
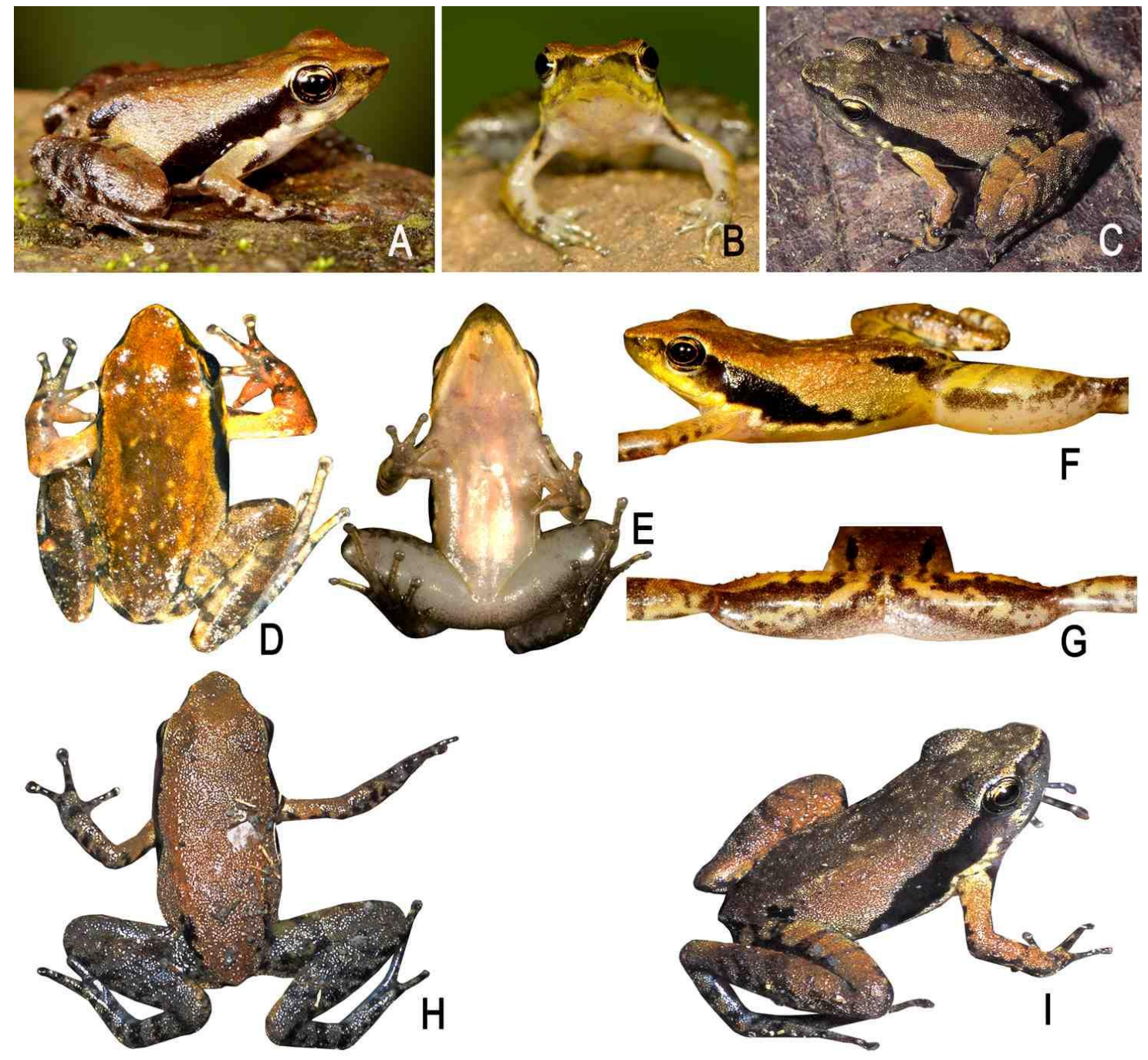

Figure 32. Micrixalus sali sp. nov. in life: A. dorsolateral view, B. front view (HT, BNHS 5731, m); C. dorsolateral view (PT, BNHS 5736, m); D. dorsal view, E. ventral view, F. lateral view of thigh and groin, G. posterior side of thighs (HT, BNHS 5731, m); H. dorsal view, I. dorsolateral view (PT, BNHS 5735, m). Photos: SDB. 
Comparison. Micrixalus sali could be confused with $M$. gadgili, $M$. nudis and $M$. thampii. However, M. sali differs from other members of Micrixalus nudis group by its smaller adult size, male, SVL 13.8-14.9 mm, $N=6$, female, SVL $16.2 \mathrm{~mm}, N=1$ (vs. larger, $M$. gadgili: male, SVL 15.1-16.2 mm, $N=8$, female, SVL 17.0-18.2 mm, $N=2$; M. nudis: male, SVL 15.2-16.3 mm, $N=5$, female, SVL 20.3-20.7 $\mathrm{mm}, N=3$; $M$. thampii: male, SVL 14.4-16.2 mm, $N=6$, female, SVL 18.4-21.1 mm, $N=3$ ) and second toe webbing basal on the outside (vs. well beyond the subarticular tubercle on the outside in M. gadgili; up to the base of disc on the outside in $M$. nudis and $M$. thampii).

For more differences with Micrixalus gadgili and $M$. nudis see 'Comparison' of those species.

Description of holotype (measurements in $\mathrm{mm}$ ). Adult male (SVL 14.8); head small (HW 4.6, HL 5.5), longer than wide, flat above; snout subelliptical in dorsal view, nearly acute in lateral view, its length (SL 2.4) longer than horizontal diameter of eye (EL 1.8); loreal region acute and concave with rounded canthus rostralis; interorbital space flat, wider (IUE 1.7) than upper eyelid (UEW 1.2) and subequal to internarial distance (IN 1.8); distance between back of eye (IBE 4.6) 1.6 times the distance between front of eye (IFE 2.9); nostril oval, as close to eye (EN 1.0 ) as to tip of snout (NS 1.0); tympanum (TYD 0.4 ) $22 \%$ of eye diameter (EL 1.8); tongue moderately large, emarginate, without lingual papilla; supratympanic fold that extends from posterior corner of eye to near the shoulder, well developed. Forelimbs (FAL 3.1) shorter than hand length (HAL 3.9); finger discs moderately wide compared to finger width (fd1 0.4 , fw1 0.2; fd2 0.5, fw2 0.3; fd3 0.5, fw3 0.2; fd4 0.5, fw4 0.2); subarticular tubercles weakly developed, oval, single, all present; round palmar tubercles. Thigh length (TL 7.8) subequal to shank (SHL 7.7), and longer than foot (FOL 6.9); toe discs wide compared to toe width $(\operatorname{td} 10.5, \operatorname{tw} 10.2 ; \operatorname{td} 20.6$, tw2 0.2; td3 0.6, tw3 0.2; td4 0.6, tw4 0.2; td5 0.5, tw5 0.2); webbing reduced: I2-2II $2-3 \mathrm{III} 2^{+}$ $3^{+} \mathrm{IV} 3^{1} / 5_{-}-2 \mathrm{~V}$; subarticular tubercles well developed, oval, all present; inner metatarsal tubercles distinct and moderately short; outer metatarsal tubercles rounded, rather prominent.

Skin of snout, between eyes and upper eyelids shagreened; posterior part of back shagreened; dorsolateral folds that extend from the posterior corner of the eye to the entire body length on both sides, weakly developed; upper and lower parts of flank shagreened and sparsely granular; dorsal parts of forelimb shagreened; thigh, tibia and tarsus with weakly developed granular projections; ventral surfaces of throat, chest and abdomen smooth; posterior parts of thigh shagreened.

Colour in preservation. Dorsum light brown; lateral sides of head (snout and tympanic area) distinctly light grey; a dark brownish-black band that extends from posterior corner of the eye up to the groin, where it ends in to a thin line; posterior parts of flank dark brownish-black; dorsal surfaces of thigh, tibia and feet light greyish-brown with dark brown cross-bands; throat, chest and belly grey with dark grey reticulations. Colour in life. Anterior part of dorsum brownish-orange; a dark brownish-black band that extends from posterior corner of the eye up to the groin, where it ends in to a thin line; iris brown with reddish tinge; flanks light brown with orange tinge; groin yellowish-brown; dorsal surface of limbs brownish-orange with light brown cross-bands; throat light yellowish-red; chest, belly, thighs and shank light grey; foot dark brownish-black.

Variations. See Table 5 for morphometric characters of six adult males and an adult female. For colour variations see Figure 32.

Secondary sexual characters. Male: Single prominent oval-shaped nuptial pad on finger I present, cream-coloured; single gular pouch while calling.

Etymology. The species is named after Mr. Sali Palode, as a token of appreciation for his constant support to SDB during field studies in the Western Ghats over the past two decades. The species name sali is used as a noun in apposition to the generic name and therefore invariable.

Distribution. Micrixalus sali is known only from its type locality Ponmudi (Thiruvananthapuram dist., Kerala state), which is located south of Shencottah gap in the Western Ghats (Fig. 3, Table 1).

Habitat and natural history. The preferred habitat of this species is brooks or damp leaf litter on exposed streambeds, inside wet evergreen forests. The majority of male specimens were found calling and collected between 11:0015:00 h.

\section{Micrixalus thampii Pillai, 1981 \\ Silent Valley Dancing Frog \\ (Figs 3, 27D, 33; Tables 1-5)}

Original name and description. Micrixalus thampii Pillai, 1981. Two new species of Amphibia from Silent Valley, S. India. Bulletin of the Zoological Survey of India 3: 153. Holotype. ZSI-SRS VA/778, an adult female, according to Chanda et al., 2001 "2000”. Type locality. "Silent Valley", Palakkad dist., Kerala state. Current 
status of specific name. Valid name, as Micrixalus thampii Pillai, 1981.

Referred specimens. Kerala: Palakkad dist., Sairandhri, Silent Valley, BNHS 5738, an adult male, and BNHS 5739, an adult female, collected by SDB and team, 6 November 2010,
BNHS 5740-BNHS 5742, three adult males, and BNHS 5743, an adult female, collected by SDB and SG, 19 September 2011; Kuddam, Siruvani, BNHS 5744-BNHS 5745, two adult males, and BNHS 5746, an adult female, collected by SDB and Systematics lab team, 18 October 2011.
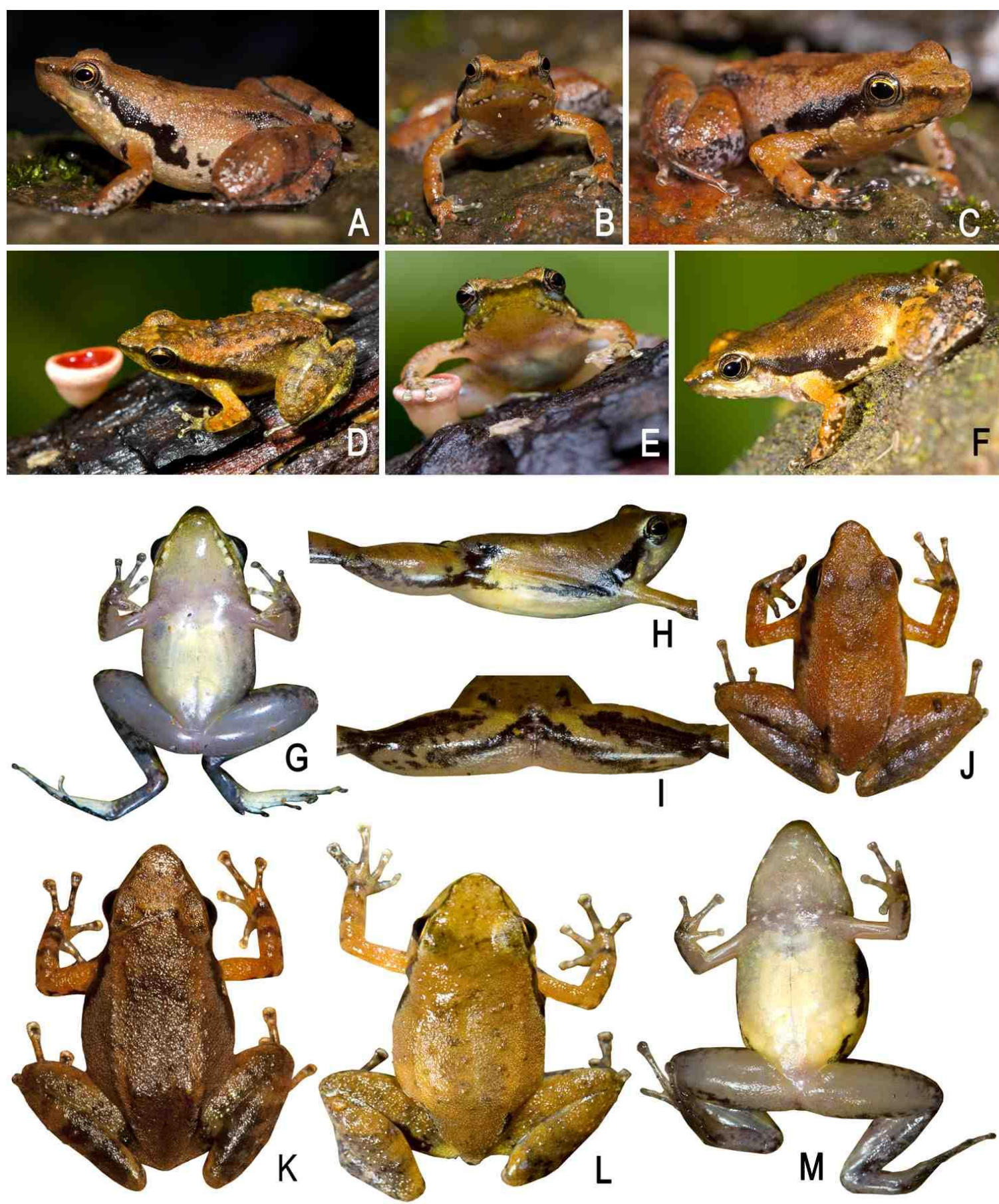

Figure 33. Micrixalus thampii in life: A. dorsolateral view, B. front view (RS, BNHS 5738, m); C. dorsolateral view (RS, BNHS 5739, f); D. dorsolateral view, E. front view (RS, BNHS 5745, m); F. dorsolateral view, G. ventral view, H. lateral view of thigh and groin, I. posterior side of thighs (RS, BNHS 5744, m); J. dorsal view (RS, BNHS 5742, m); K. dorsal view (RS, BNHS 5743, f); L. dorsal view, M. ventral view (RS, BNHS 5746, f). Photos: SDB. 
Other material studied. Kerala: Palakkad dist., Sairandhri, Silent Valley, SDBDU 2010.131, collected by SDB and team, 6 November 2010, SDBDU 2011.963, collected by SDB and SG, 19 September 2011; Singappara, Siruvani, SDBDU 2011.1226, and SDBDU 2011.1271, collected by SDB and Systematics lab team, 18 October 2011.

Comparison. Micrixalus thampii could be confused with Micrixalus gadgili, M. nudis and M. sali. For differences with M. gadgili, M. nudis and $M$. sali see 'Comparison' of those species.

Description of holotype. A general original description was published by Pillai (1981).

Distribution. Micrixalus thampii is known only from the Western Ghats state of Kerala, with its distribution restricted to north of the Palghat gap. The present study found this species in Sairandhri, Silent Valley and Kuddam, Siruvani in Palakkad dist. (Fig. 3, Table 1).

Habitat and natural history. The preferred habitat of this species is banks of shallow streams inside wet evergreen forests. The majority of male specimens were found actively calling and collected between 10:00-16:00 h.

\section{Micrixalus saxicola Group}

Members. Micrixalus kottigeharensis, Micrixalus saxicola and Micrixalus specca sp. nov.

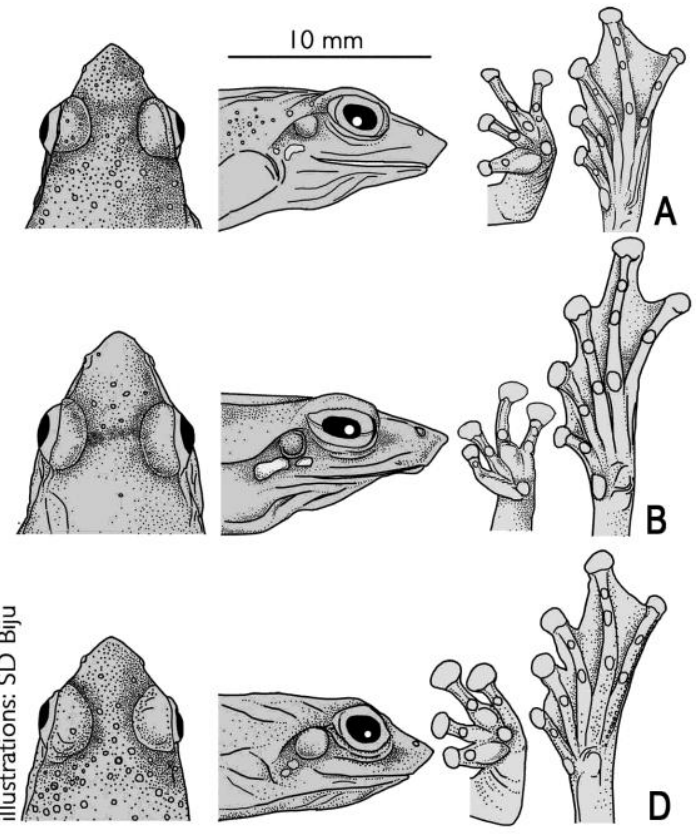

Figure 34. From left to right, dorsal view of head, lateral view of head, ventral view of hand and ventral view of foot of Micrixalus saxicola group: A. M. kottigeharensis (NT, BNHS 5747, m); B. $M$. saxicola (RS, BNHS 5764, f); C. Micrixalus specca sp. nov. (HT, BNHS 5778, m).
This group can be distinguished from other Micrixalus groups by the combination of following morphological characters: small adult size (male, SVL 19.0-24.0 mm; female, SVL 24.0-33.0 mm); absence of dorsolateral folds; tongue with lingual papilla; and fully webbed toes (Fig. 34).

\section{Micrixalus kottigeharensis (Rao, 1937) Kottigehar Dancing Frog \\ (Figs 3, 34A, 35, 36; Tables 1-5)}

Original name and description. Philautus kottigeharensis Rao, 1937. On some new forms of Batrachia from S. India. Proceedings of Indian Academy Science (B), 6: 157. Neotype. By present designation, BNHS 5747, an adult male (SVL 22.1 $\mathrm{mm}$ ), collected by SDB, 17 November 2010. Neotype locality. Kottigehara, Chikmagalur dist., Karnataka state. Current status of specific name. Valid name, as Micrixalus kottigeharensis (Rao, 1937) (Bossuyt and Dubois, 2001). Synonyms. Philautus narainensis Rao, 1937 Syn. nov. (= Micrixalus narainensis [Rao, 1937]) and Philautus swamianus Rao, 1937 Syn. nov. (= Micrixalus narainensis [Rao, 1937]).

Referred specimens. Karnataka: Chikmagalur dist., Kottigehara, BNHS 5748, an adult male, collected along with neotype; Kemmanagundi, BNHS 5749, an adult female, collected by SDB, 29 June 2010; Dakshina Kannada dist., Charmadi Ghats, BNHS 5750, an adult female, collected by SDB and Systematics lab team, 23 October 2011; Hassan dist., Maranhalli, Sakleshpur, BNHS 5751-BNHS 5752, two adult males, and BNHS 5753-BNHS 5754, two adult females, collected by SDB and Systematics lab team, 30 September 2012; Uttara Kannada dist., Kathlekan, BNHS 5755-BNHS 5757, three adult males, and BNHS 5758, an adult female, collected by SDB and team, 22 October 2011; Waddighat, Yana, BNHS 5759, an adult male, and BNHS 5760- BNHS 5761, two adult females, collected by SDB and team, 21 October 2011; Unchalli falls, BNHS 5762, an adult female, collected by KVG and GS, 28 September 2012.

Other material studied. Karnataka: Chikmagalur dist., Kottigehara, SDBDU 2010.124, collected along with neotype, SDBDU 2012.55 and SDBDU 2012.62, collected by SDB and team, 11 June 2012; Kemmanagundi, SDBDU 2003.40268, collected by SDB, 23 August 2003, SDBDU 2010.005, collected by SDB, 29 June 2010; Muthodi, SDBDU 2003.40215, collected by SDB, 2 July 2003; Uttara Kannada dist., Waddighat, Yana, SDBDU 2011.1347, collected by SDB and team, 21 October 2011.

Comments. Rao (1937) described Philautus kottigeharensis from "Kottigehar, 
Kadur" based on a sole specimen (SVL "23.00 mm"), and Bossuyt and Dubois (2001) subsequently transferred this species to Micrixalus. Like several other species that were described by Rao (1937) and the types for which were deposited in Central College Bangalore (CCB), the type of Philautus kottigeharensis is also lost (Dubois 1987 "1986"; SDB personal
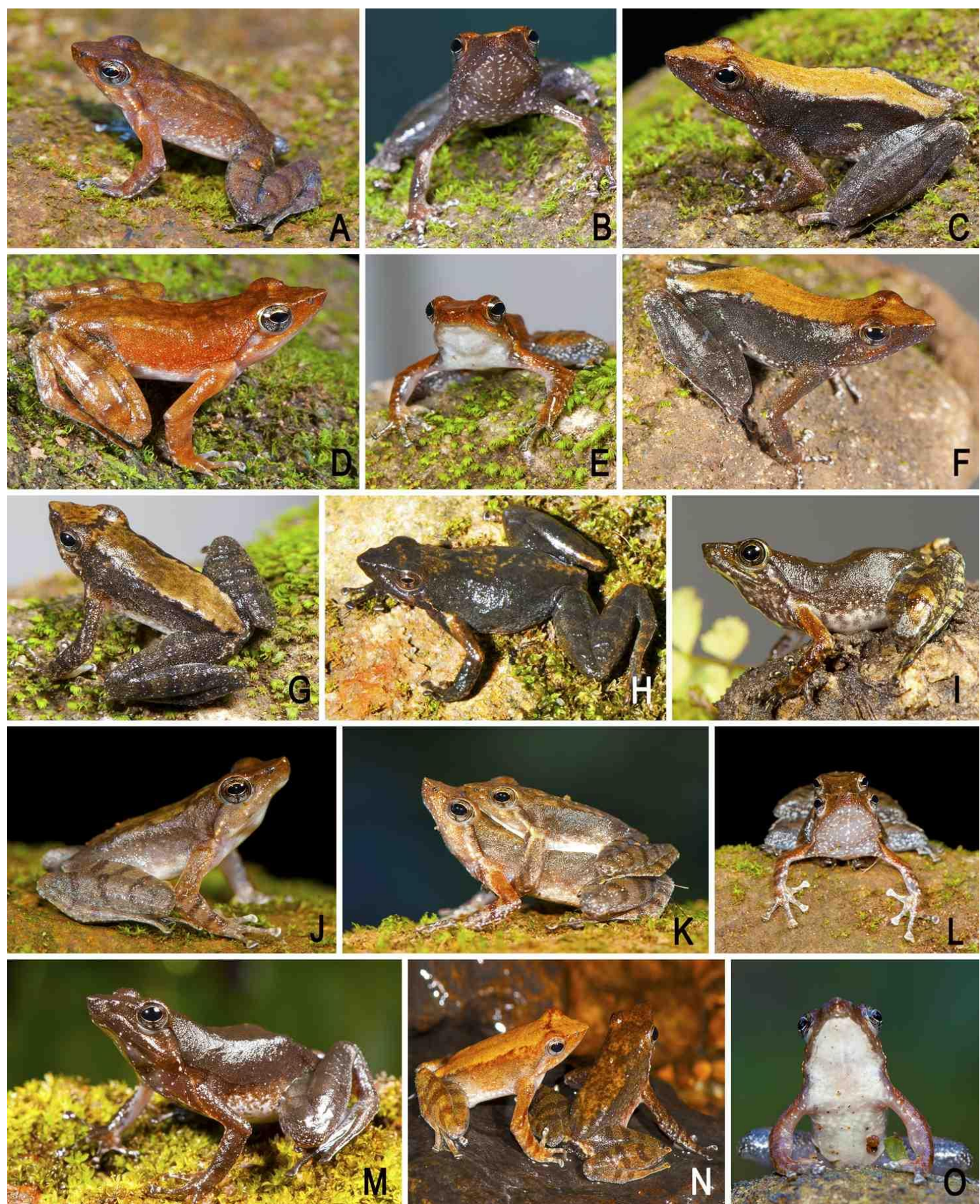

Figure 35. Micrixalus kottigeharensis in life: A. dorsolateral view (NT, BNHS 5747, m); B. front view, C. dorsolateral view (RS, BNHS 5758, f); D. dorsolateral view, E. front view (RS, BNHS 5755, m); F. dorsolateral view (RS, BNHS 5757, m); G. dorsolateral view (from Kathlekan, not preserved); H. dorsolateral view (RS, BNHS 5749, f); I. dorsolateral view (RS, BNHS 5750, f); J. dorsolateral view (RS, BNHS 5754, f); K. dorsolateral view of amplected pair, L. front view of amplected pair (RS, BNHS 5753, f, and RS, BNHS 5751, m); M. dorsolateral view (RS, BNHS 5760, f); N. dorsolateral view (not preserved, on left), and dorsal view (RS, BNHS 5756, m, on right); O. front view (RS, BNHS 5751, m). Photos: SDB. 
observation). We collected several specimens, comparable with Rao's description of Philautus kottigeharensis, from the type locality Kottigehara and its vicinity. However, due to the availability of three names-Micrixalus kottigeharensis (Rao, 1937), Micrixalus narainensis (Rao, 1937) and Micrixalus swamianus (Rao, 1937)—from exactly the same type locality "Kottigehar, Kadur", a species could not be confidently assigned to our recent collections. A critical study of the original descriptions of these three species (Rao 1937) shows that majority of the mentioned characters (M. kottigeharensis: SVL "23.00 mm" [presumably a male with "the sac with tumid lips"], "snout acutely pointed", "tongue with a papilla", "thigh as long as the tibium"; $M$. swamianus: SVL "29.00 mm" [presumably a female], "snout pointed", "conical papilla nearer to the anterior end", "tibia about as long as thigh"; M. narainensis: SVL "29.00 mm" [presumably a female], "snout acutely pointed", tongue "with a conical papilla", "tibia longer than the thigh"), are nearly the same in all the three species, and therefore not helpful in distinguishing them from each other.

We presume that the three taxa were described in the same publication by Rao (1937), based on members of the same population without any diagnostic characters. In our study, we found slight variations in metric and meristic characters among individuals of our new collections. These were mostly observed for some feeble characters (like skin texture, and finger and toe width), which cannot be considered diagnostic for species that were described based on a single specimen each. Our morphological analysis corroborates the molecular evidences, which showed genetic variations that are not sufficient to consider these populations as distinct species.

Therefore, on the basis of evidence provided in this study, we consider Philautus (= Micrixalus) narainensis and Philautus (= Micrixalus) swamianus to be junior subjective synonyms of Philautus (= Micrixalus) kottigeharensis Rao, 1937, which is prioritized by alphabetical appearance of its name in the original description. To stabilize this name, we herein designate a specimen that is most comparable with the original description as the neotype of Philautus (= Micrixalus) kottigeharensis Rao, 1937.

This species was identified as Micrixalus saxicola by Gururaja (2010) and Preininger et al. (2013a, 2013b), and as Micrixalus aff. saxicola by Preininger et al. (2013c).

Comparison. Micrixalus kottigeharensis could be confused with $M$. saxicola and $M$. specca. However, M. kottigeharensis differs from
M. saxicola and $M$. specca by its snout pointed in dorsal view (vs. subovoid in both species) and third finger much longer, male, $\mathrm{F}_{\mathrm{III}} \mathrm{L} 3.7 \pm 0.2 \mathrm{~mm}$, $N=8$, female, $\mathrm{F}_{\mathrm{III}} \mathrm{L} 5.1 \pm 0.5 \mathrm{~mm}, N=8$ (vs. short in both species, $M$. saxicola: male, $\mathrm{F}_{\mathrm{III}} \mathrm{L} 3.3 \pm 0.2$ $\mathrm{mm}, N=9$, female, $\mathrm{F}_{\mathrm{III}} \mathrm{L} 4.3 \pm 0.2 \mathrm{~mm}, N=7 ; M$. specca: male, $\mathrm{F}_{\mathrm{III}} \mathrm{L} 3.1 \pm 0.2 \mathrm{~mm}, N=4$, female, $\left.\mathrm{F}_{\mathrm{III}} \mathrm{L} .9 \pm 0.3 \mathrm{~mm}, N=4\right)$. More specifically differs from $M$. specca by its non-speckled dorsum in life and preservation (vs. prominently speckled) and discs of fingers proportionally smaller in comparison to finger width, male, FD III $1.0 \pm 0.1 \mathrm{~mm}$ vs. $\mathrm{FW}_{\text {III }} 0.7 \pm 0.1 \mathrm{~mm}, N=8$; female, FD III $_{1.2 \pm 0.1 \mathrm{~mm} \text { vs. FW }}$ III $0.4 \pm 0.1 \mathrm{~mm}$, $N=8$ (vs. much enlarged, male, FD III $_{1.2} \pm 0.2$ mm vs. $\mathrm{FW}_{\text {III }} 0.3 \pm 0.0 \mathrm{~mm}, N=4$; female, $\mathrm{FD}_{\text {III }}$ $1.6 \pm 0.1 \mathrm{~mm}$ vs. $\left.\mathrm{FW}_{\text {III }} 0.4 \pm 0.1 \mathrm{~mm}, N=4\right)$.

Description of neotype (all measurements in $\mathrm{mm}$ ). Adult female (SVL 22.1); head small (HW 6.5, HL 7.6), longer than wide, flat above; snout pointed in dorsal view, acute in lateral view, its length (SL 3.5) longer than horizontal diameter of eye (EL 1.9); loreal region vertical with sharp canthus rostralis; interorbital space flat, wider (IUE 2.0) than upper eyelid (UEW 1.5); distance between back of eye (IBE 5.8) 1.6 times the distance between front of eye (IFE 3.7); nostril oval, closer to tip of snout (NS 1.6) than eye (EN 1.8); tympanum (TYD 0.8) $42 \%$ of eye diameter (EL 1.9); tongue moderately large, emarginate, with lingual papilla; supratympanic fold that extends from posterior corner of eye to near the shoulder, weakly developed. Forelimbs (FAL 4.4) shorter than hand length (HAL 5.6); finger discs moderately wide compared to finger width (fd1 0.8, fw1 0.4; fd2 1.0, fw2 0.3; fd3 1.0, fw3 0.3; fd4 0.9, fw4 0.3); subarticular tubercles well developed, oval, single, all present; prepollex weakly developed; round palmar tubercles present. Thigh length (TL 11.4) shorter to shank (SHL 12.7), and longer than foot (FOL 10.6); toe discs wide compared to toe width (td1 0.8, tw1 0.3 ; td2 1.1, tw2 0.3; td3 1.0, tw3 0.4; td4 1.2, tw4 0.3 ; td5 0.9, tw5 0.3); webbing complete: I0-0II00III0-0IV0-0V; subarticular tubercles weakly developed, oval, all present; inner metatarsal tubercles distinct and moderately short; outer metatarsal tubercles absent.

Skin of snout, between eyes and upper eyelids shagreened with scattered granular projections, minute spinular projections throughout the dorsal skin; flanks shagreened with scattered granular projections; thigh, tibia and tarsus shagreened; dermal fringe along toe $\mathrm{V}$ well developed from tip of toe to heel, with glandular projections ending with sharp spinules in males; ventral surface of throat and margins granular; throat, chest and abdomen smooth; posterior parts 
of thigh shagreened.

Colour in preservation. Dorsum dark brown with scattered light grey spots; lateral sides of head (snout and tympanic area) light grey; flanks light brown; forelimbs, dorsal surfaces of thigh, tibia and feet light brown with light grey cross-bands, posterior parts of thigh grey with dark grey reticulations; throat, chest and belly light greyish-brown with light grey spots; hands and posterior sides of thigh light brown, feet dark brown, webbing light grey with minute black spots. Colour in life. Dorsum uniform reddishbrown with scattered yellowish-grey spots; lateral sides of head (snout and tympanic area) light reddish-brown; iris light golden brown with reddish tinge; flanks light reddish-brown; groin light grey with scattered dark grey spots; dorsal surface of limbs greyish-brown with dark brown cross-bands; throat and chest greyish-white; belly grey; thigh and shank grey with light brown spots; foot dark grey.

Variations. See Table 5 for morphometric characters of eight adult males (including neotype) and eight adult females. For colour variations see Figures 35 and 36.
Secondary sexual characters. Male: Single prominent oval-shaped nuptial pad on finger I present, cream-coloured. Female (BNHS 5760): ova yellowish-white with minute black spots (diameter 1.7-2.0 mm, $N=10$ ).

Distribution. Micrixalus kottigeharensis is known only from the Western Ghats state of Karnataka. This species is wide-ranging throughout the state, but its distribution is restricted to the north of Palghat gap and south of Goa gap. The present study found this species in Kemmanagundi, Kottigehara and Muthodi (Chikmagalur dist.), Charmadi Ghats (Dakshina Kannada dist.), Sakleshpur (Hassan dist.), Kathlekan, Unchalli falls and Waddighat (Uttara Kannada dist.) (Fig. 3, Table 1).

Habitat and natural history. The preferred habitat of this species is fast flowing streams and rivulets in primary and secondary forests. Micrixalus kottigeharensis was found to be relatively abundant at all the collection localities. The majority of male specimens were found actively calling and 'foot-flagging'. Collections were made between 08:00-18:00 h.

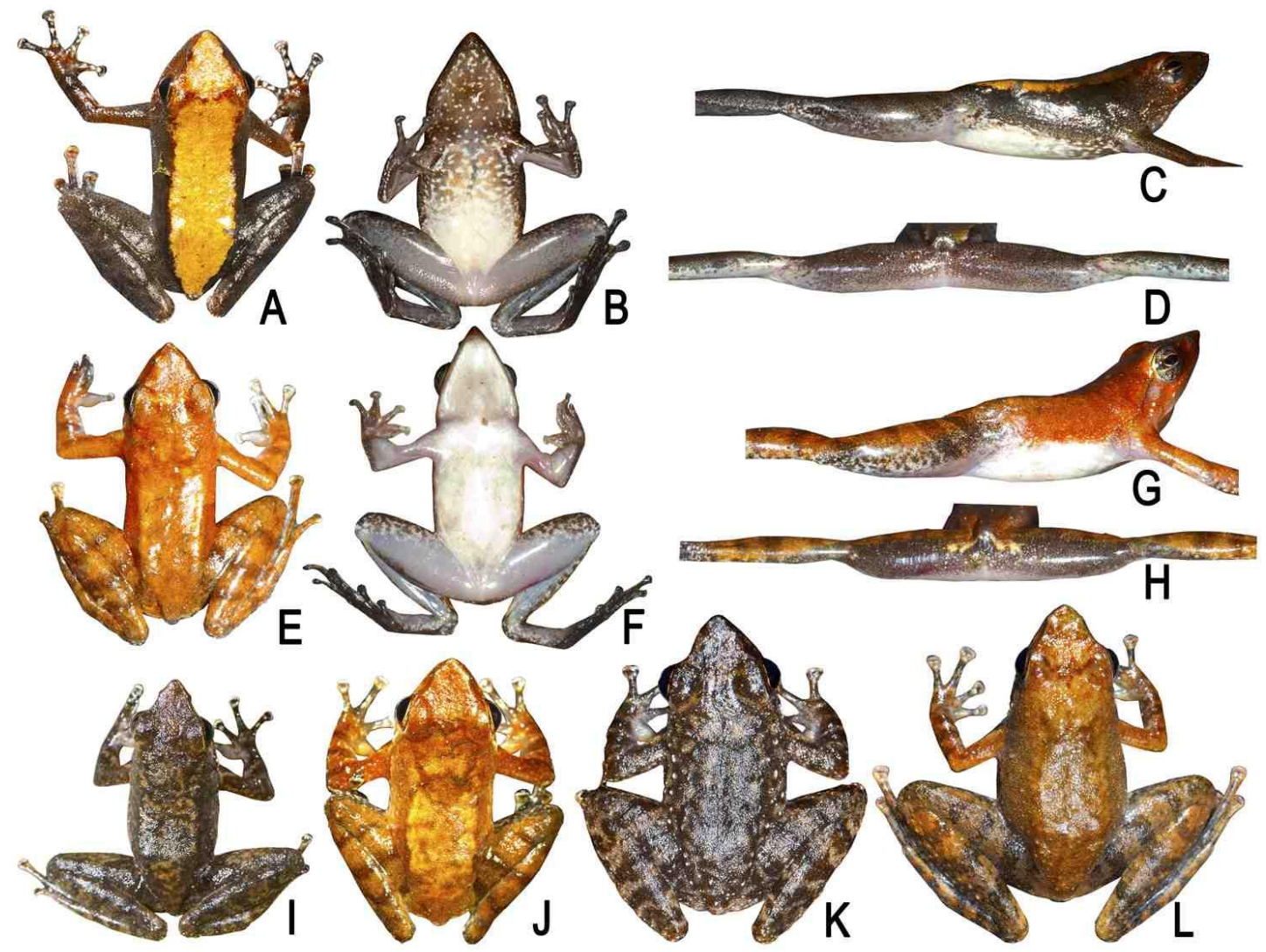

Figure 36. Micrixalus kottigeharensis in life: A. dorsal view, B. ventral view, C. lateral view of thigh and groin, D. posterior side of thighs (RS, BNHS 5758, f); E. dorsal view, F. ventral view, G. lateral view of thigh and groin, H. posterior side of thighs (RS, BNHS 5755, m); I. dorsal view (RS, BNHS 5756, m); J. dorsal view (RS, BNHS 5752, m); K. dorsal view (not preserved); L. dorsal view (RS, BNHS 5762, f). Photos: SDB. 


\author{
Micrixalus saxicola (Jerdon, 1854) \\ Wayanad Dancing Frog \\ (Figs 3, 34B, 37, 38; Tables 1-5)
}

Original name and description. Polypedates? saxicola Jerdon, 1854 “1853". Catalogue of reptiles inhabiting the Peninsula of India, Journal of the Asiatic Society of Bengal 22: 533. Lectotype. BMNH 72.4.17.203, an adult female (SVL $28.8 \mathrm{~mm}$ ), by present designation. Lectotype locality."Malabar". Current status of specific name. Valid name, as Micrixalus saxicola (Jerdon, 1854).

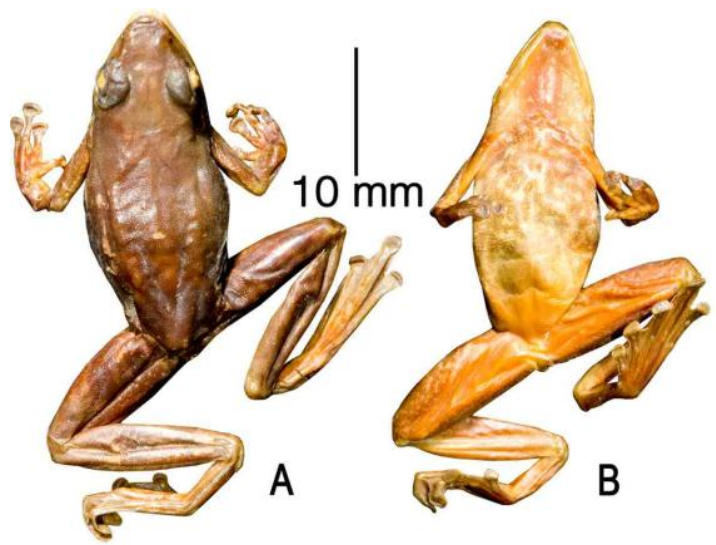

Figure 37. Lectotype of Micrixalus saxicola, NHM 72.4.17.203 (SVL $28.8 \mathrm{~mm}$ ), from "Malabar": A. dorsal view, B. ventral view.

Referred specimens. Kerala: Wayanad dist., Periya, BNHS 5763, an adult male, collected by SDB and Systematics lab team, 20 July 2012, and BNHS 5764, an adult female, collected by SDB, 15 September 2002; Banasura, BNHS 5765, an adult female, collected by SDB, 14 September 2002; Kurichiyarmala, BNHS 5766, an adult male, BNHS 5767, an adult female, collected by SDB and SG, 5 June 2012; Settukunnu, BNHS 5768, an adult female, collected by SDB and Systematics lab team, 15 August 2011; Kannur dist., Aralam, BNHS 5769-BNHS 5770, two adult males, collected by SDB and Systematics lab team, 25 September 2011; Karnataka: Chikmagalur dist., Kottigehara, BNHS 5771, an adult male, collected by SDB, 17 November 2010; Dakshina Kannada dist., Charmadi Ghats, BNHS 5772, an adult female, collected by SDB and Systematic lab team, 23 October 2011; Hassan dist. Maranhalli, BNHS 5773, an adult male, collected by SDB and Systematic lab team, 30 September 2012; Kempholay, BNHS 5774, an adult male, collected by SDB, 16 November 2010; Kodagu dist., Yavakapady, Coorg, BNHS 5775, an adult male, and BNHS 5776, an adult female, collected by SDB and Systematics lab team, 4 October 2012; Uttara Kannada dist., Unchalli falls, BNHS 5777, an adult male, collected by KVG and GS, 28 September 2012.

Other material studied. Kerala: Wayanad dist., Banasura, SDBDU 2002.3021, an adult female, collected by SDB, 14 September 2002; Periya, SDBDU 2012.911, collected by SDB and Systematics lab team, 20 July 2012; Settukunnu, SDBDU 2011.854, collected by SDB and Systematics lab team, 15 August 2011; Suganthagiri, SDBDU 2005.4736, collected by SDB 15 October 2005, and SDBDU 2007.5092, collected by SDB, 14 August 2007; Kannur dist., Aralam, SDBDU 2011.1084, collected by SDB and Systematics lab team, 25 September 2011; Meenmutty, Aralam, SDBDU 2008.427, collected by SDB, 5 June 2008; Karnataka: Hassan dist., Kempholay, SDBDU 2010.010, collected by SDB, 16 November 2010; Sakleshpur, SDBDU 2005.4599 and SDBDU 2005.4661, collected by SDB, 2 October 2005.

Comments. Jerdon (1854 “1853”) described Polypedates? saxicola with a very short description and mentioned its 'type locality' as "found on rocks in shady mountain streams in Malabar and Wynaad". Jerdon's collections were presumably in ZSIC but later Jerdon (1870) himself reported them as lost. Subsequent workers (Dutta, 1997; Chanda et al., 2000) confirmed this, and our study also could not find any specimens of Polypedates? saxicola Jerdon 1853 in ZSIC. However, we examined the 'syntype' series (NHM 72.4.17.203-7, 72.4.17.221-222) currently available in NHM, with a bottle label "N. canara" as the locality. According to Boulenger (1882) and the NHM catalogue, these specimens were 'purchased' from Jerdon and are collections from "Malabar". Therefore we consider these as the syntypes. We also studied new collections from Periya (Wayanad dist.), which is also mentioned in the original description, and found them comparable to the syntype series in NHM. In order to avoid further confusion and for nomenclatural stability, we hereby designate the largest female specimen, NHM 72.4.17.203 (SVL $28.8 \mathrm{~mm}$ ), as lectotype of this species (Fig. 37).

Comparison. Micrixalus saxicola could be confused with M. kottigeharensis and M. specca. However, M. saxicola differs from $M$. specca by its thigh equal to shank length, male, TL $12.2 \pm$ $0.4 \mathrm{~mm}$, SHL $12.2 \pm 0.4 \mathrm{~mm}, N=9$, female, TL $14.7 \pm 0.3 \mathrm{~mm}$, SHL $14.7 \pm 0.4 \mathrm{~mm}, N=7$ (vs. shorter, male, TL $11.3 \pm 1.5 \mathrm{~mm}$, SHL $12.9 \pm 0.5$ $\mathrm{mm}, N=4$, female, TL $14.7 \pm 0.5 \mathrm{~mm}$, SHL 15.7 $\pm 0.6 \mathrm{~mm}, N=4$ ), third finger longer, male, $\mathrm{F}_{\mathrm{III}} \mathrm{L}$ $3.3 \pm 0.2 \mathrm{~mm}, N=9$, female, $\mathrm{F}_{\mathrm{III}} \mathrm{L} 4.3 \pm 0.2 \mathrm{~mm}, N$ $=7$ (vs. short, male, $\mathrm{F}_{\mathrm{III}} \mathrm{L} 3.1 \pm 0.2 \mathrm{~mm}, N=4$, female, $\mathrm{F}_{\mathrm{III}} \mathrm{L} 3.9 \pm 0.3 \mathrm{~mm}, N=4$ ) (Fig. 34). 

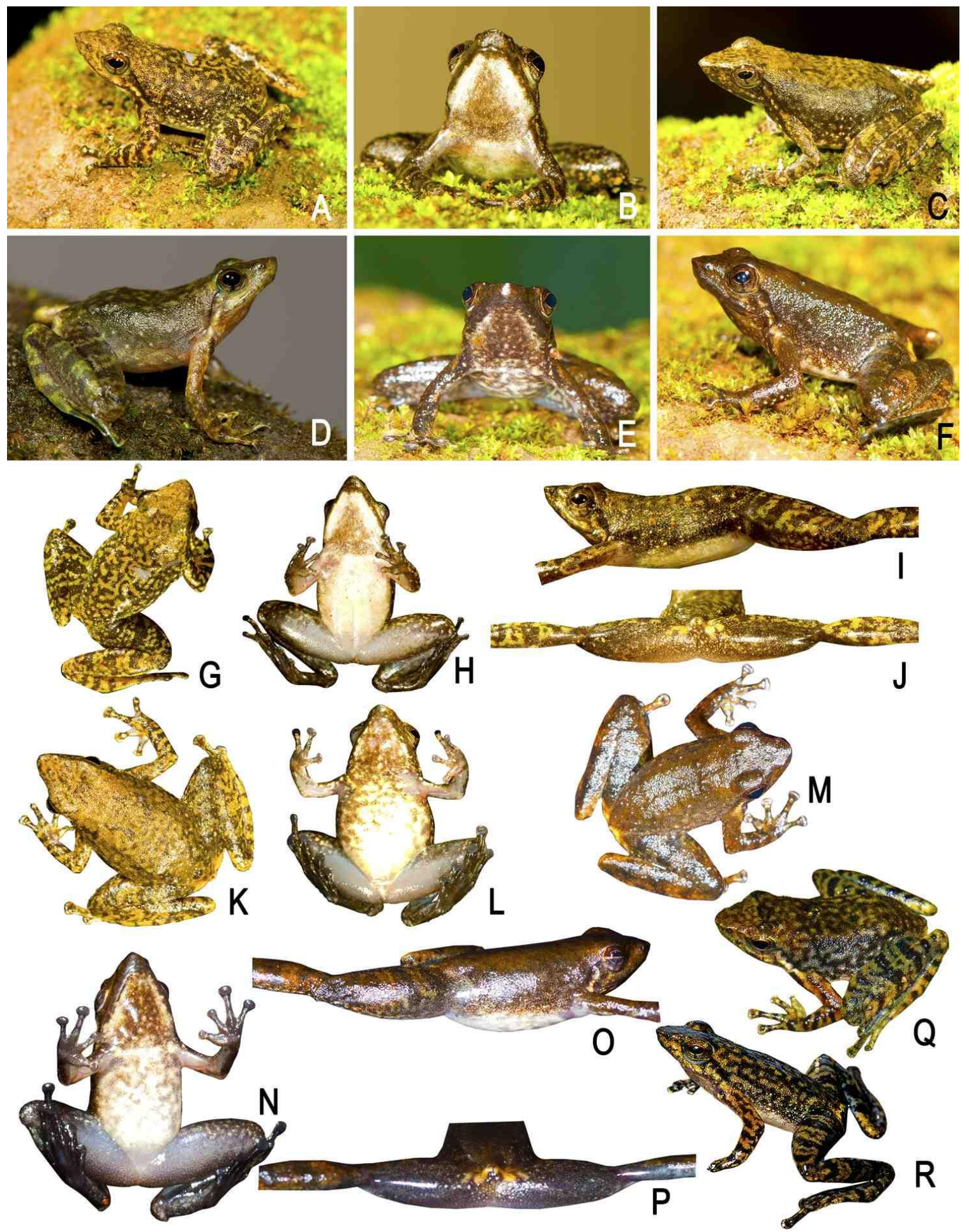

Figure 38. Micrixalus saxicola in life: A. dorsolateral view, B. front view (RS, BNHS 5766, m); C. dorsolateral view (RS, BNHS 5767, f); D. dorsolateral view (RS, BNHS 5772, f); E. front view (RS, BNHS 5775, m); F. dorsolateral view (RS, BNHS 5764, f); G. dorsal view, H. ventral view, I. lateral view of thigh and groin, J. posterior side of thighs (RS, BNHS 5766, m); K. dorsal view, L. ventral view (RS, BNHS 5767, f); M. dorsal view (RS, BNHS 5776, f); N. ventral view, O. lateral view of thigh and groin, P. posterior side of thighs (RS, BNHS 5775, m); Q. dorsolateral view (RS, BNHS 5763, m); R. dorsolateral view (RS, BNHS 5773, m). Photos: SDB. 
For differences with Micrixalus kottigeharensis, see 'Comparison' of that species.

Description of lectotype (all measurements in $\mathrm{mm}$ ). Adult female (SVL 28.8); head small (HW 7.6, HL 9.7), longer than wide, flat above; snout appears subovoid in dorsal view (due to specimen damage an accurate judgment of snout shape cannot be made), its length (SL 4.1) longer than horizontal diameter of eye (EL 3.5); loreal region vertical; interorbital space flat, wider (IUE 2.5) than upper eyelid (UEW 1.9); nostril oval, closer to eye (EN 1.8) than tip of snout (NS 2.1); tympanum (TYD 1.4) $40 \%$ of eye diameter (EL $3.5)$; tongue moderately large, emarginate, with lingual papilla; supratympanic fold that extends from posterior corner of eye to near the shoulder, weakly developed. Forelimbs (FAL 5.2) shorter than hand length (HAL 6.2); finger discs moderately wide compared to finger width (fd1 1.0, fw1 0.4; fd2 1.0, fw2 0.4; fd3 1.1, fw3 0.4; fd4 1.1, fw4 0.5); subarticular tubercles well developed, oval, single, all present; prepollex weakly developed; weakly developed round palmar tubercles present. Thigh length (TL 14.7) subequal to shank (SHL14.8), and longer than foot (FOL 13.3); toe discs wide compared to toe width (td1 1.0, tw1 0.4; td2 1.1, tw2 0.4; td3 1.3, tw3 0.4 ; td4 1.3, tw4 0.4; td5 1.1, tw5 0.4); webbing complete: I0-0II0-0III0-0IV0-0V; subarticular tubercles weakly developed, oval, all present; inner metatarsal tubercles distinct and moderately short; outer metatarsal tubercles weakly developed.

Skin of snout, between eyes and upper eyelids shagreened; flanks shagreened with scattered granular projections; thigh, tibia and tarsus shagreened; ventral surface of throat and margins shagreened; throat, chest and abdomen smooth; posterior parts of thigh shagreened.

Colour in preservation. Dorsum dark brown; lateral sides of head (snout and tympanic area) light grey; flanks light brown; forelimbs, dorsal surfaces of thigh, tibia and feet light greyish-brown with dark grey cross-bands, posterior parts of thigh dark greyish-brown with light grey marbling; throat, chest and belly light greyish-yellow with minute black spots; hands and posterior sides of thigh light brown; feet dark brown; webbing light grey with minute black spots.

Variations. See Table 5 for morphometric characters of nine adult males and seven adult females (including lectotype). For colour variations see Figure 38.

Secondary sexual characters. Female: ova yellowish-white with minute black spots (diameter 1.7-1.9 mm, $N=10$ ). Males (BNHS 5771): Single prominent oval-shaped nuptial pad on finger I present, cream-coloured; dermal fringe along toe $\mathrm{V}$ well developed from tip of toe to heel, with glandular projections ending with sharp spinules in males.

Distribution. Micrixalus saxicola has a wide distribution in Karnataka and adjoining regions in Kerala, but its range is restricted to the north of Palghat gap and south of Goa gap in the Western Ghats. The present study found this species in Banasura, Periya, Kurichiyarmala, Settukunnu and Suganthagiri (Wayanad dist.), Aralam and Meenmutty (Kannur dist.) in Kerala; Kottigehara (Chikmagalur dist.), Charmadi Ghats (Dakshina Kannada dist.), Kempholay, Maranhalli and Sakleshpur (Hassan dist.), Yavakapady, Coorg (Kodagu dist.), and Unchalli falls (Uttara Kannada dist.) in Karnataka (Fig. 3, Table 1).

Habitat and natural history. The preferred habitat of this species is fast flowing streams and rivulets in primary and secondary forests. Micrixalus saxicola was very commonly found at all the collection localities. The majority of male specimens were found actively calling from rocks emerging near the splash zones of streams. 'Footflagging' was observed in males and collections were made between 08:00-18:00 h.

\section{Micrixalus specca sp. nov. Spotted Dancing Frog (Figs 3, 34C, 39; Tables 1-5)}

Holotype. BNHS 5778, an adult male, Charmadi Ghats, Dakshina Kannada dist., Karnataka state, India, collected by SDB and Systematics lab team, 23 October 2011.

Paratypes. Karnataka: Dakshina Kannada dist., Charmadi Ghats, BNHS 5779-BNHS 5781, three adult males, and BNHS 5782-BNHS 5785, four adult females, collected along with holotype.

Comparison. Micrixalus specca could be confused with $M$. kottigeharensis and M. saxicola. For more differences with $M$. kottigeharensis and M. saxicola see 'Comparison' of those species.

Description of holotype (measurements in mm). Adult male (SVL 22.8); head small (HW 6.8, HL 8.6), longer than wide, flat above; snout subovoid in dorsal view, acute in lateral view, its length (SL 3.6) longer than horizontal diameter of eye (EL 2.7); loreal region vertical, sharp canthus rostralis; interorbital space flat, wider (IUE 2.0) than upper eyelid (UEW 1.6) and narrower than internarial distance (IN 2.4); distance between back of eye (IBE 5.9) 1.6 times the distance between front of eye (IFE 3.8); nostril oval, nearly as close to eye (EN 1.7) as to tip of snout (NS 1.6); tympanum (TYD 0.9) 33\% of eye diameter (EL 2.7); tongue moderately large, emarginate, with median lingual papillae; supratympanic fold that extends from posterior corner of eye to near 
the shoulder, weakly developed. Forelimbs (FAL 4.7) shorter than hand length (HAL 5.0); finger discs moderately wide compared to finger width (fd1 1.1, fw1 0.3; fd2 1.1, fw2 0.3; fd3 1.2, fw3 0.3 ; fd4 1.2, fw4 0.3); subarticular tubercles well developed, oval, single, all present. Thigh shorter (TL 11.9) than shank (SHL 13.0), and longer than foot (FOL 11.4); toe discs wide compared to toe width (td1 1.0, tw1 0.3; td2 1.4, tw2 0.3; td3 1.3, tw3 0.3; td4 1.5, tw4 0.2; td5 1.0, tw5 0.2); webbing complete: I0-0II0-0IIIO-0IV0-0V; subarticular tubercles weakly developed, oval, all present; inner metatarsal tubercles distinct and moderately short; outer metatarsal tubercles absent.
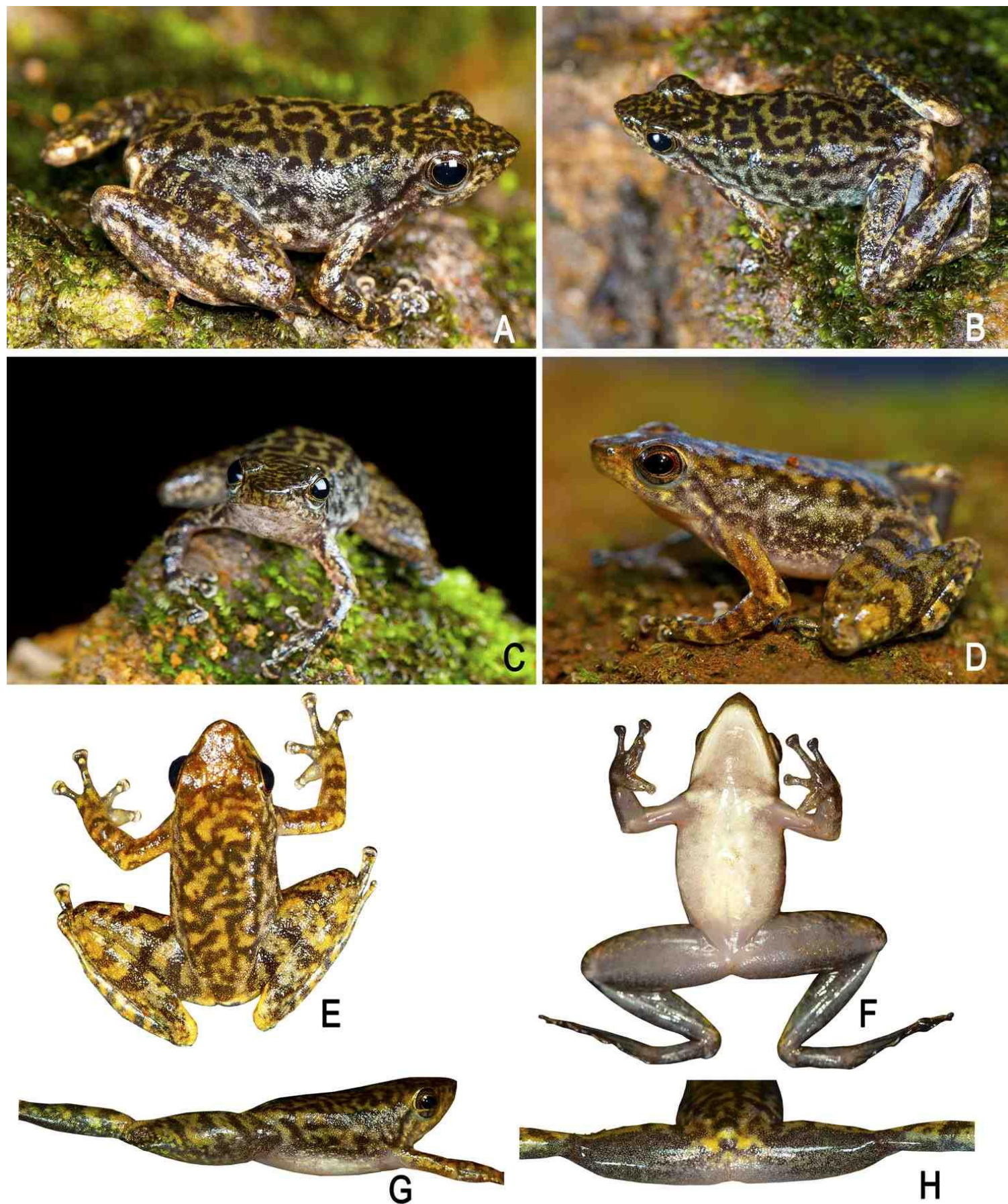

Figure 39. Micrixalus specca sp.nov. in life: A. dorsolateral view (HT, BNHS 5778, m); B. dorsolateral view, C. front view (PT, BNHS 5782, f); D. dorsolateral view (PT, BNHS 5779, m); E. dorsal view, F. ventral view, G. lateral view of thigh and groin, H. posterior side of thigh (PT, BNHS 5781, m). Photos: SDB. 
Skin of snout, between eyes, upper eyelids and posterior part of back shagreened with prominent sharp spinules intermitted by scattered granular projections; flanks shagreened with scattered granular projections; dorsal parts of forelimb, thigh, tibia and tarsus shagreened with glandular projections; dermal fringe along toe $\mathrm{V}$ well developed from tip of toe to heel, with glandular projections ending with sharp spinules in males; ventral surfaces of throat, chest and abdomen smooth; posterior parts of thigh shagreened.

Colour in preservation. Dorsum blackishbrown with grey reticulations; flanks dark brown with grey reticulations extending from the dorsal surface; tympanic area greyish-brown; forelimbs, dorsal surfaces of thigh, tibia and feet blackishbrown with dark brown cross-bands, posterior parts of thigh light brown with dark grey reticulations; throat, chest and belly light grey with minute black spots; margins of shank light brown; feet light brown; webbing blackish-grey. Colour in life. Dorsum and flanks blackish-brown with uniform greyish-yellow reticulations; tympanum and surrounding areas blackish-brown; iris light brown; groin light bluish-brown; dorsal surface of limbs greyish-brown with dark brown cross-bands; throat, chest and belly light greyishwhite; foot blackish-grey.

Variations. See Table 5 for morphometric characters of four adult males and four adult females. For colour variations see Figure 39.

Secondary sexual characters. Male: Single prominent oval-shaped nuptial pad on finger I present, cream-coloured; single gular pouch while calling. Female (BNHS 5782): ova creamy white with black reticulations (diameter $1.1-1.4 \mathrm{~mm}, N=20$ ).
Etymology. The species epithet is a noun in apposition, therefore invariable, derived from the Latin word 'specca' meaning speckled, referring to the prominent reticulations or spots on dorsal surface of this species.

Distribution. Micrixalus specca is known only from its type locality Charmadi Ghats (Dakshina Kannada dist., Karanataka state), which lies north of Palghat gap and south of Goa gap in the Western Ghats (Fig. 3, Table 1).

Habitat and natural history. The preferred habitat of this species is flowing streams covered with forest canopy. The male specimens were found actively calling and 'foot-flagging'. Collections were made between 08:00-16:00 h.

\section{Micrixalus silvaticus group}

Members. Micrixalus frigidus sp. nov., Micrixalus nigraventris sp. nov., Micrixalus phyllophilus and Micrixalus silvaticus.

This group can be distinguished from other Micrixalus groups by the combination of following morphological characters: small adult size (male, SVL 18.0-26.0 mm; female, SVL 23.0-33.0 mm); dorsolateral folds well developed; fourth toe webbing does not extend beyond the second subarticular tubercle on either side; a white streak that starts from the tip of snout, extends over the eyes and tympanum, and ends near the shoulder; lateral sides of head (snout and tympanic area) distinctly blackish-brown; one of the more widely distributed groups that is found on both sides of the Palghat gap in the Western Ghats (but neither south of Shencottah gap, nor north of Goa gap), with narrow and restricted geographical range of individual species (Fig. 40).

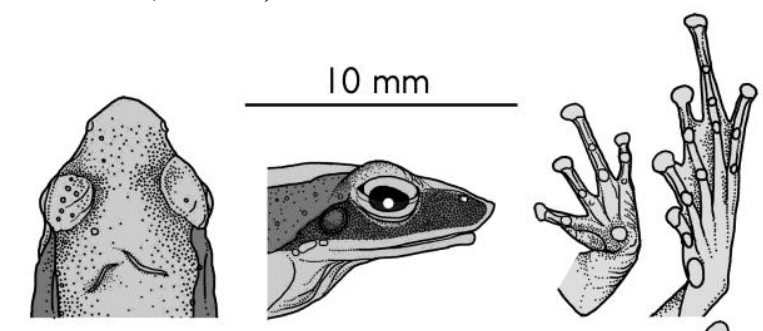

A
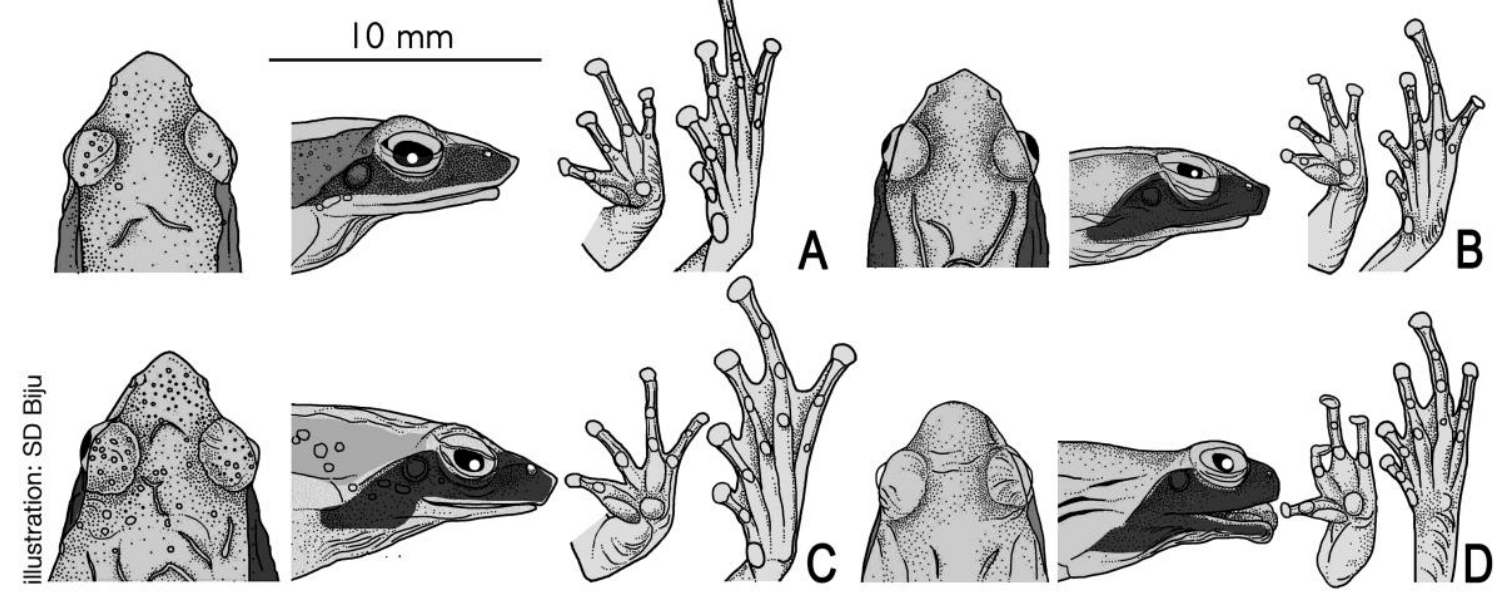

Figure 40. From left to right: dorsal view of head, lateral view of head, ventral view of hand and ventral view of foot of Micrixalus silavticus group: A. Micrixalus frigidus sp. nov. (HT, BNHS 5786, m); B. Micrixalus nigraventris sp. nov. (HT, BNHS 5793, m); C. M. phyllophilus (NT, NHM 1947.2.29.87, m); D. M. silvaticus (LT, NHM 82.2.10.52, f). 


\author{
Micrixalus frigidus sp. nov. \\ Cold Stream Dancing Frog \\ (Figs 3, 40A, 41; Tables 1-5)
}

Holotype. BNHS 5786, an adult male, Eravikulam National Park, Idukki dist., Kerala state, India, collected by SDB, 14 March 2001.

Paratypes. Kerala: Idukki dist., Eravikulam National Park, BNHS 5787, an adult female, collected along with the holotype, BNHS 5788, an adult female, collected by SDB, 22 July 2002; Tamil Nadu: Coimbatore dist., Grass hills, BNHS 5789, an adult male, and BNHS 5790 BNHS 5792, three adult females, collected by SDB, 12 July 2005.

Comparison. Micrixalus frigidus could be confused with $M$. nigraventris, M. phyllophilus and $M$. silvaticus. However, M. frigidus differs from $M$. nigraventris by its larger adult size, male, SVL 24.0-25.9 mm, $N=2$, female, SVL 29.6$32.7 \mathrm{~mm}, N=5$ (vs. small, male, SVL 20.7-20.9 $\mathrm{mm}, N=2$, female, SVL 23.0-26.6 mm, $N=3$ ), snout acute in lateral view (vs. vertical), third toe webbing extending up to the disc on the outside (vs. below the first subarticular tubercle), ventral surface brownish-yellow with prominent light yellow reticulations (vs. dark brownish-black with prominent creamy white irregular patches); differs from $M$. phyllophilus by its snout subelliptical in dorsal view (vs. subovoid), tongue without lingual papilla (vs. with lingual papilla), groin yellow with light grey tinge (vs. red); differs from $M$. silvaticus by its larger adult size, male, SVL 24.0$25.9 \mathrm{~mm}, N=2$, female, SVL 29.6-32.7 mm, $N=$ 5 (vs. small, male, SVL 18.5-19.8 mm, $N=3$, female, SVL 25.4-26.0 mm, $N=3$ ), body slender (vs. robust), snout subelliptical in dorsal view (vs. rounded), acute in lateral view (vs. rounded).

Description of holotype (measurements in mm). Adult male (SVL 24.0); head small (HW 7.7, HL 8.8), longer than wide, flat above; snout subelliptical in dorsal view, acute in lateral view, its length (SL 3.6) longer than horizontal diameter of eye (EL 2.6); loreal region vertical and concave with rounded canthus rostralis; interorbital space flat, wider (IUE 2.7) than upper eyelid (UEW 1.5) and narraower than internarial distance (IN 3.2); distance between back of eye (IBE 6.5) 1.6 times the distance between front of eye (IFE 4.0); nostril oval, closer to tip of snout (NS 1.6) than eye (EN 1.9); tympanum (TYD 1.1) $42 \%$ of eye diameter (EL 2.6); tongue moderately large, emarginate, without lingual papilla; supratympanic fold that extends from posterior corner of eye to near the shoulder, well developed. Forelimbs (FAL 4.4) shorter than hand length (HAL 7.0); finger discs moderately wide compared to finger width (fd1 0.7, fw1 0.3; fd2 0.8, fw2 0.3; fd3 1.1, fw3 0.2; fd4 0.8, fw4 0.3); subarticular tubercles weakly developed, oval, single, all present; prepollex weakly developed; round palmar tubercles; a distinct supernumerary tubercle at the base of each finger. Thigh length (TL 12.3) shorter than shank (SHL 12.8), and longer than foot (FOL 11.9); toe discs wide compared to toe width (td1 0.8, tw1 0.3; td2 1.0, tw2 0.3; td3 1.0, tw3 0.4; td4 1.1, tw4 0.3 ; td5 0.8, tw5 0.3); webbing present: I112/3II1-2III1-3IV3-1V; subarticular tubercles weakly developed, oval, all present; inner metatarsal tubercles distinct and moderately short; outer metatarsal tubercles rounded, rather prominent.

Skin of snout, between eyes shagreened, upper eyelids shagreened to finely granular; posterior part of back shagreened to sparsely granular; dorsolateral folds that extend from the posterior corner of the eye to the entire body length on both sides, well developed; scattered glandular ridge on dorsum; anterior and posterior parts of flanks shagreened and sparsely granular with scattered tubercles; dorsal parts of forelimb shagreened to finely granular; thigh, tibia and tarsus with weakly developed granular projections and glandular ridge; ventral surface of throat, chest and abdomen smooth; posterior parts of thigh sparsely granular.

Colour in preservation. Dorsum light brown; a grey streak starting from the tip of snout, extending over the eyes and tympanum, ending near the shoulder; lateral sides of head (snout and tympanic area) distinctly dark grey; flanks dark grey with black speckles; dorsolateral folds light brown; forelimbs, dorsal surfaces of thigh, tibia and feet light brown with dark brown cross-bands, posterior parts of thigh light grey with dark greyish-brown reticulations; throat, chest and belly greyish-white with dark grey reticulations; ventral parts of thigh light grey with scattered dark grey spots, tibia and feet brownish-black; webbing blackish-grey. Colour in life. Dorsum uniform reddish-brown; a white streak starting from the tip of snout, extending over the eyes and tympanum, ending near the shoulder; lateral sides of head (snout and tympanic area) distinctly blackishbrown; iris light brown with reddish tinge; flanks light yellowish-grey; groin yellow with light grey tinge; dorsal surface of limbs reddish-brown with dark brown cross-bands; throat, chest and belly light greyish-brown with minute black spots; thigh brownish-yellow with prominent light yellow reticulations; shank and foot dark grey with light bluish-grey spots.

Variations. See Table 5 for morphometric characters of two adult males and five adult females. For colour variations see Figure 41. 

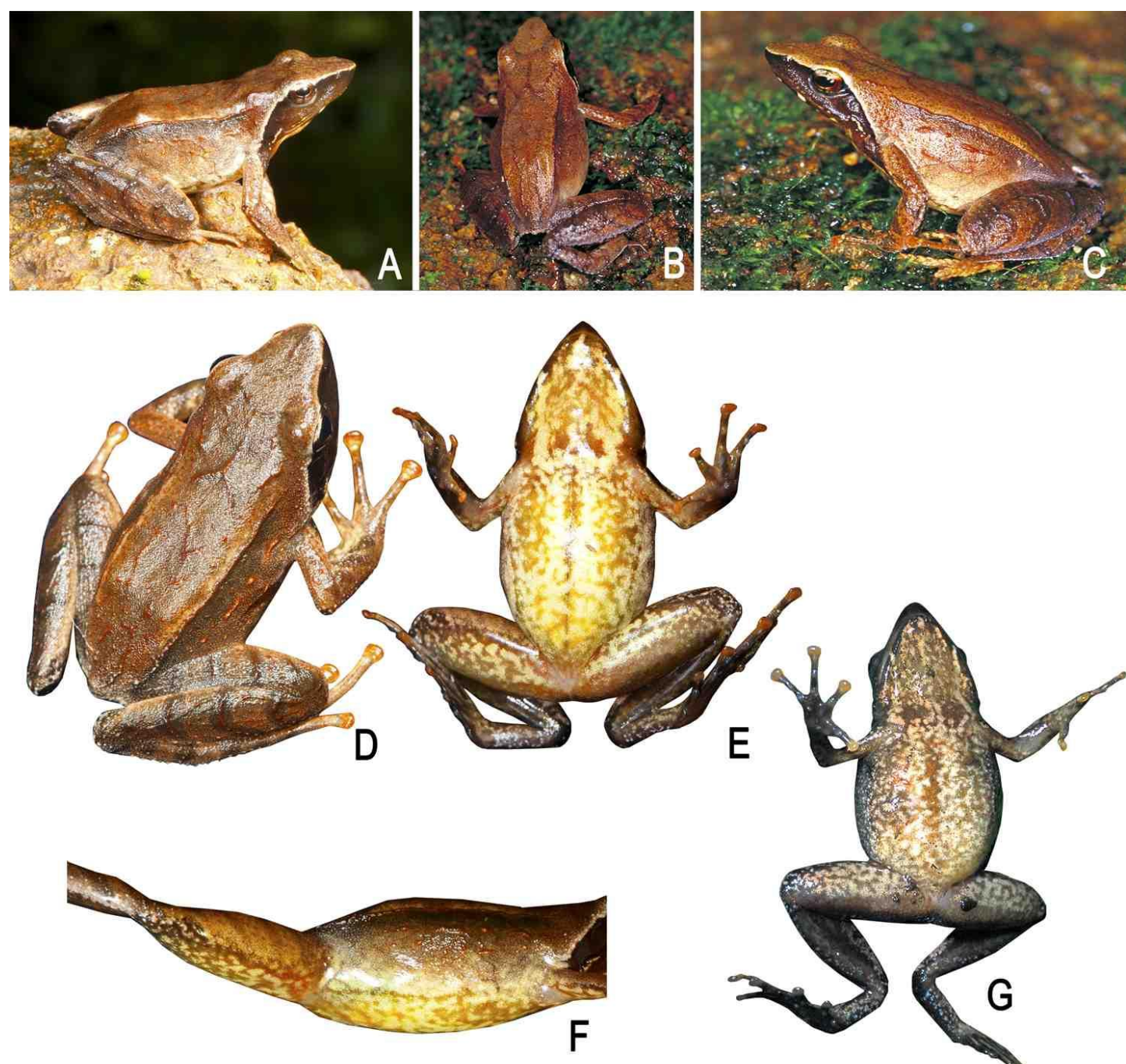

$\mathrm{F}$

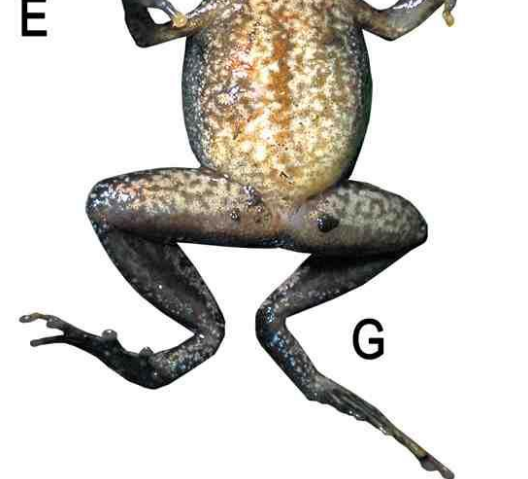

Figure 41. Micrixalus frigidus sp. nov. in life: A. dorsolateral view, B. dorsal view (PT, BNHS 5791, f); C. dorsolateral view, D. dorsal view, E. ventral view, F. lateral view of thigh and groin (PT, BNHS 5788, f); G. dorsal view (PT, BNHS 5792, f). Photos: SDB.

Secondary sexual characters. Male: Single prominent oval-shaped nuptial pad on finger I present, cream-coloured; single gular pouch while calling. Female (BNHS 5788): ova creamy white with minute black spots (diameter $1.0-1.4 \mathrm{~mm}, N=20)$.

Etymology. The species epithet is a noun in apposition, therefore invariable, derived from the Latin word 'frigidus'meaning cold, referring to high altitude cold streams that are the predominant habitat of this species.

Distribution. Micrixalus frigidus is known only from the Western Ghats states of Kerala and Tamil Nadu, with its distribution restricted between the Palghat gap and Shencottah gap. The present study found this species in Eravikulam National Park (Idukki dist.) in Kerala state, and Grass hills (Coimbatore dist.) in Tamil Nadu state (Fig. 3, Table 1).
Habitat and natural history. The preferred habitat of this species is shallow waters on the sides of streams covered with forest canopy. However, BNHS 5791-BNHS 5792 (Grass hills) were collected from a marshy area located away from streams inside a shola forest. Micrixalus frigidus was found in high altitude cold streams above the elevations of $1800 \mathrm{~m}$ asl. The majority of male specimens were found actively calling and collected between 08:00-14:00 h.

\section{Micrixalus nigraventris sp. nov. \\ Black-Bellied Dancing Frog}

(Figs 3, 40B, 42; Tables 1-5)

Holotype. BNHS 5793, an adult male, Kodaikanal, Dindigul dist., Tamil Nadu state, India, collected by SDB, 17 March 2002.

Paratypes. Tamil Nadu: Dindigul dist., Kodaikanal, BNHS 5794, an adult male, and 
BNHS 5795, an adult female, collected along with holotype; Kerala: Idukki dist., Eravikulam National Park, BNHS 5796-BNHS 5797, two adult females, collected by SDB and Systematics lab team, 21 September 2011.

Comparison. Micrixalus nigraventris could be confused with $M$. frigidus, $M$. phyllophilus and $M$. silvaticus. However, $M$. nigraventris differs from $M$. phyllophilus by its smaller size, male, SVL 20.7-20.9 mm, $N=2$, female, SVL 23.0-26.6 mm, $N=3$ (vs. larger, male, SVL 22.5-25.9 mm, $N=7$, female, SVL 28.9-32.5 mm, $N=3$ ), snout subelliptical in dorsal view (vs. subovoid), snout vertical in lateral view (vs. acute), fourth toe webbing below the second subarticular tubercle on either side (vs. beyond the second subarticular tubercle on either side), tongue without lingual papilla (vs. with lingual papilla), groin yellowish-brown with creamy white patches (vs. red), ventral surface brownish-black with prominent creamy white irregular patches (vs. brownish-yellow with prominent light yellow reticulations); differs from $M$. silvaticus by its snout subelliptical in dorsal view (vs. rounded), snout vertical in lateral view (vs. rounded), third toe webbing extending up to the first subarticular tubercle on either side (vs. just beyond the second subarticular tubercle on either side), ventral surface brownish-black with prominent creamy white irregular patches (vs. creamy white with orange reticulations).

For more differences with Micrixalus frigidus see 'Comparison' of that species.

Description of holotype (measurements in $\mathrm{mm}$ ). Adult male (SVL 20.7); head small (HW 6.8, HL 6.4), longer than wide, flat above; snout subelliptical in dorsal view, vertical in lateral view, its length (SL 3.3) longer than horizontal diameter of eye (EL 2.3); loreal region acute and concave with rounded canthus rostralis; interorbital space flat, wider (IUE 2.6) than upper eyelid (UEW 1.6) and narrower than internarial distance (IN 3.0); distance between back of eye (IBE 6.2) 1.7 times the distance between
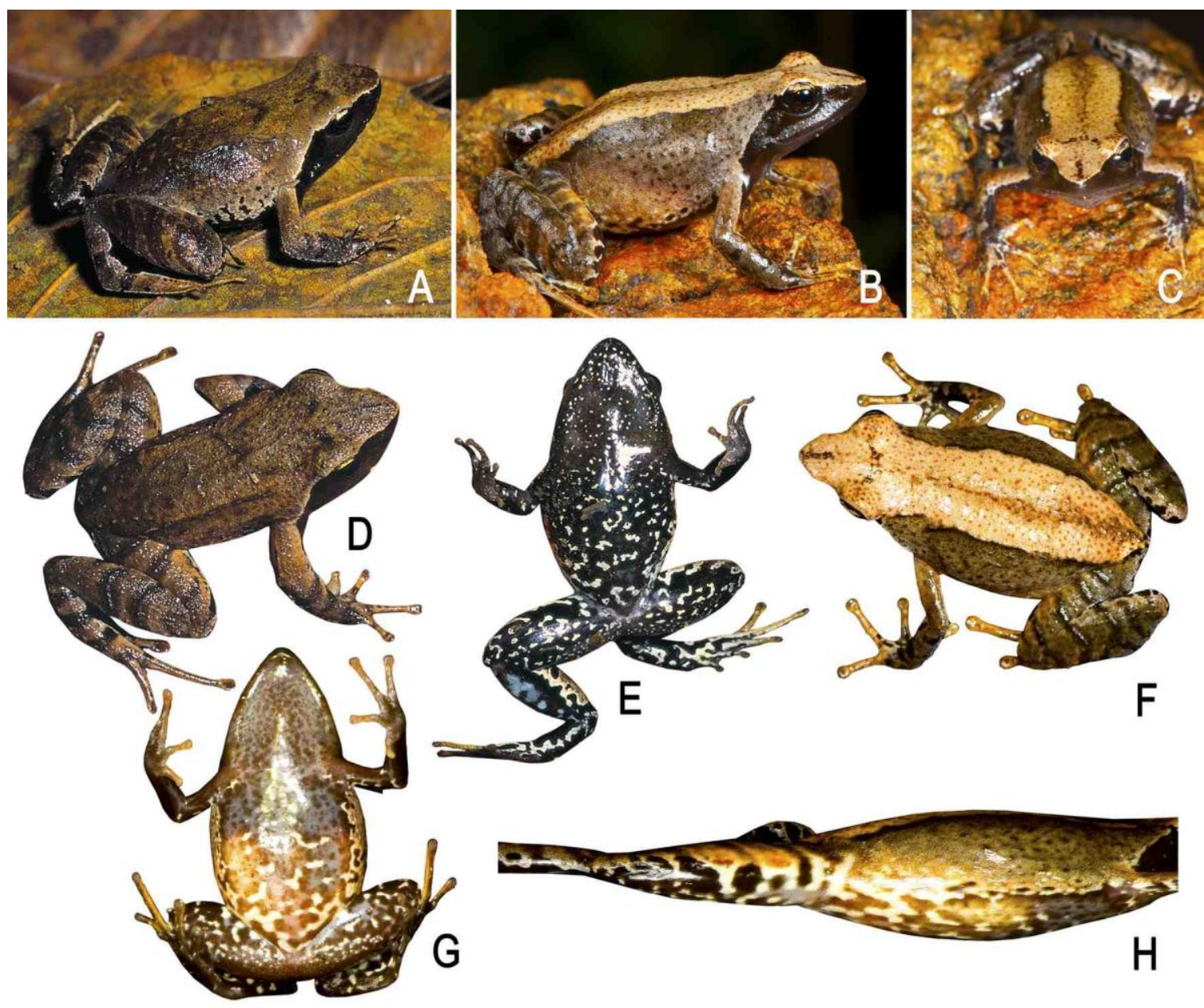

Figure 42. Micrixalus nigraventris sp. nov. in life: A. dorsolateral view (HT, BNHS 5793, m); B. dorsolateral view, C. front view (PT, BNHS 5797, f); D. dorsal view, E. ventral view (PT, BNHS 5794, m); F. dorsal view, G ventral view, H. lateral view of thigh and groin (PT, BNHS 5797, f). Photos: SDB. 
front of eye (IFE 3.6); nostril oval, closer to eye (EN 1.4) than tip of snout (NS 1.6); tympanum (TYD 0.7 ) $30 \%$ of eye diameter (EL 2.3); tongue moderately large, emarginate, without lingual papilla; supratympanic fold that extends from posterior corner of eye to near the shoulder, well developed. Forelimbs (FAL 4.3) shorter than hand length (HAL 5.3); finger discs moderately wide compared to finger width (fd1 0.5 , fw1 0.3 ; fd2 0.6, fw2 0.2; fd3 0.7, fw3 0.3; fd4 0.6, fw4 0.2); subarticular tubercles weakly developed, oval, single, all present; prepollex weakly developed; round palmar tubercles. Thigh length (TL 10.1) equal to shank (SHL 10.1), and longer than foot (FOL 9.5); toe discs wide compared to toe width (td1 0.6, tw1 0.3; td2 0.6, tw2 0.3; td3 0.7, tw3 0.3 ; td4 0.6, tw4 0.2; td5 0.7, tw5 0.2); webbing present: I1-2II1-2III2-3IV3-2V; subarticular tubercles weakly developed, oval, all present; inner metatarsal tubercles distinct and moderately short; outer metatarsal tubercles rounded, rather prominent.

Skin of snout, between eyes and upper eyelids shagreened; posterior part of back shagreened to sparsely granular; dorsolateral folds that extend from the posterior corner of the eye to the entire body length on both sides, well developed; scattered glandular ridge on dorsum; flanks shagreened and sparsely granular; dorsal parts of forelimb shagreened; thigh, tibia and tarsus with weakly developed granular projections and glandular ridge; ventral surface of throat, chest and abdomen smooth; posterior parts of thigh shagreened to sparsely granular.

Colour in preservation. Dorsum light brown; a light grey streak starting from the tip of snout, extending over the eyes and tympanum and ending near the shoulder; lateral sides of head (snout and tympanic area) distinctly dark grey; posterior parts of flank dark brownish-grey with black speckles; forelimbs, dorsal surfaces of thigh, tibia and feet light greyish-brown with dark brown cross-bands, posterior parts of thigh light grey with dark greyish-brown reticulations; throat, chest and belly grey with reticulations. Colour in life. Anterior part of dorsum greyish-brown with dark grey specks, posterior part of dorsum blackish-brown with black patches; a white streak starting from the tip of snout, extending over the eyes and tympanum, and ending near the shoulder; lateral sides of head (snout and tympanic area) distinctly black; iris brown with reddish tinge; flanks light brownish-grey with light grey reticulations; groin yellowish-brown with creamy white patches; dorsal surface of limbs greyishbrown with light brown cross-bands; throat, chest, belly, thigh, shank and foot dark brownish-black with prominent creamy white irregular patches.
Variations. See Table 5 for morphometric characters of two adult males and three adult females. For colour variations see Figure 42.

Secondary sexual characters. Male: Single prominent oval-shaped nuptial pad on finger I present, cream-coloured; single gular pouch while calling. Female (BNHS 5797): ova creamy white with minute black spots (diameter 1.0-1.6 mm, $N=20$ ).

Etymology. The species epithet is a noun in apposition, therefore invariable, derived from two Latin words-'nigra' meaning black and 'ventris' meaning belly-referring to the prominent black ventral surface of this species.

Distribution. Micrixalus nigraventris is known only from the Western Ghats states of Kerala and Tamil Nadu, with its distribution restricted between the Palghat gap and Shencottah gap. The present study found this species in Eravikulam National Park (Idukki dist.) in Kerala state, and Kodaikanal (Dindigul dist.) in Tamil Nadu state (Fig. 3, Table 1).

Habitat and natural history. The preferred habitat of this species is shallow and slow moving streams in shola forests of Eravikulam National Park. Animals from Kodaikanal were collected from moist leaf litter inside a shola forest. Micrixalus nigraventris was found at high altitudes (above $1780 \mathrm{~m}$ asl). The majority of male specimens were found actively calling and collected between 08:00-14:00 h.

\section{Micrixalus phyllophilus (Jerdon, 1854) Nilgiri Dancing Frog \\ (Figs 3, 40C, 43A-B, 44; Tables 1-5)}

Original name and description. Limnodytes ? phyllophila Jerdon, 1854 "1853". Catalogue of reptiles inhabiting the Peninsula of India. Journal of the Asiatic Society of Bengal 22:532. Neotype. BMNH 1947.2.29.87, an adult male, by Dubois (1987 “1986"). Neotype locality. "Nilgherries [= Nilgiri Hills]". Synonym. Micrixalus opisthorhodus (Günther, 1869 “1868”). Current status of specific name. Valid name, as Micrixalus phyllophilus (Jerdon, 1854).

Referred specimens. Tamil Nadu: Nilgiris dist., Avalanche, BNHS 5798, an adult male, and BNHS 5799, an adult female, collected by SDB, 6 October 2001; Longwood Shola, Kotagiri, BNHS 5800, an adult female, collected by SDB, 9 November 2002, BNHS 5801-BNHS 5804, four adult males, and BNHS 5805, an adult female, collected by SDB, 8 June 2005; Naduvattam, BNHS 5806, an adult male, collected by SDB, 8 November 2002.

Other material studied. Tamil Nadu: Nilgiris dist., Avalanche, SDBDU 2001.504, collected by SDB, 6 October 2001; Mukkurthi 
National Park, SDBDUD 2008.4407, collected by SDB, 23 March 2008.

Comparison. Micrixalus phyllophilus could be confused with $M$. frigidus, $M$. nigraventris and $M$. silvaticus. However, $M$. phyllophilus differs from M. silvaticus by its larger adult size, male, SVL $22.5-25.9 \mathrm{~mm}, N=7$, female, SVL 28.9-32.5 mm, $N=3$ (vs. smaller size, male, SVL 18.5-19.8 mm, $N=3$, female, SVL 25.4-26.0 mm, $N=3$ ), snout subovoid in dorsal view (vs. rounded), snout acute in lateral view (vs. rounded), tongue with lingual papilla (vs. without lingual papilla), groin red (vs. greyish-white).

For more differences with Micrixalus frigidus and M. nigraventris, see 'Comparison' of those species.

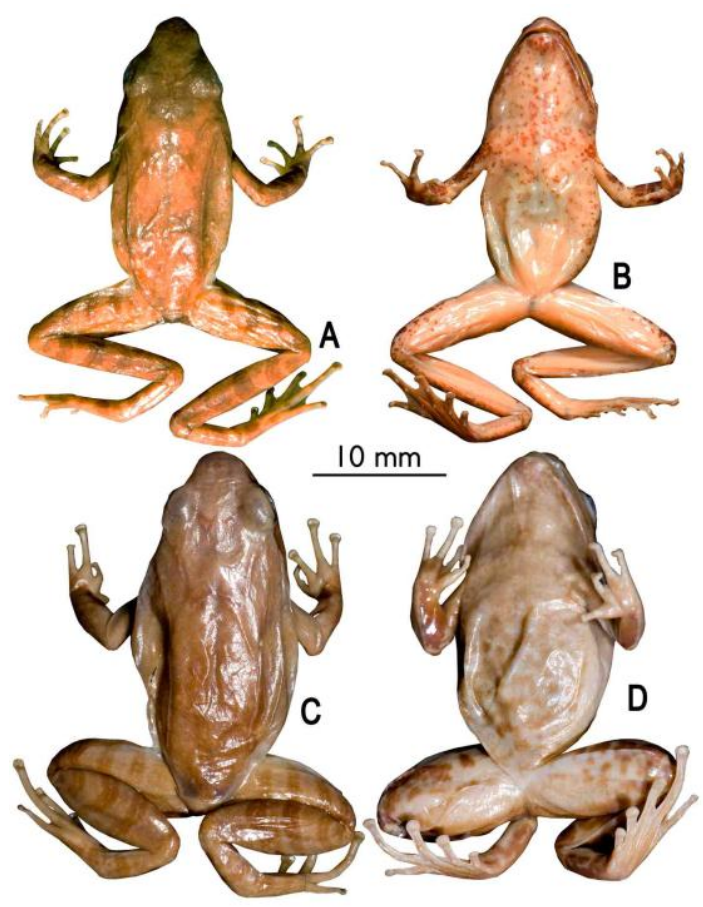

Figure 43. A-B. Neotype of Limnodytes ? phyllophila Jerdon, 1854 "1853" (NHM 1947.2.29.87), from "Nilgherries $[=$ Nilgiri Hills]": A. dorsal view, B. ventral view; C-D. Lectotype of Ixalus silvaticus Boulenger, 1882 (NHM 82.2.10.52), from "Malabar": C. dorsal view, D. ventral view.

Comments. Jerdon (1854 "1853") named this taxon with a brief description and later its name bearing type was reported as lost (Jerdon, 1870). Günther (1869 "1868") described another taxon from "Nilgherries [= Nilgiri Hills]", Ixalus opisthorhodus, which was considered as synonym of Micrixalus phyllophilus (Jerdon, 1854 "1853") by Dubois (1987 "1986"); subsequently Dubois (1987 "1986") designated the holotype of Ixalus opisthorhodus Günther, 1869 "1868”, as neotype of Micrixalus phyllophilus. We studied the original description of this taxon (Jerdon, 1854 “1853") and the holotype of Ixalus opisthorhodus, and follow the synonymy by Dubois (1987 “1986").

Description of neotype (all measurements in $\mathrm{mm}$ ). Adult male (SVL 22.5); head small (HW 7.4, HL 8.3), longer than wide, flat above; snout subovoid in dorsal view, acute in lateral view, its length (SL 3.4) longer than horizontal diameter of eye (EL 2.8); loreal region vertical and concave with rounded canthus rostralis; interorbital space flat, wider (IUE 2.2) than upper eyelid (UEW 1.8); distance between back of eye (IBE 6.3) 1.5 times the distance between front of eye (IFE 4.2); nostril oval, closer to eye (EN 1.0) than tip of snout (NS 1.8); tympanum (TYD 1.0) 36\% of eye diameter (EL 2.8); tongue moderately large, emarginate, with lingual papilla; supratympanic fold that extends from posterior corner of eye to near the shoulder, well developed. Forelimbs (FAL 4.4) shorter than hand length (HAL 5.1); finger discs moderately wide compared to finger width ( $\mathrm{fd} 1$ 0.6, fw1 0.3; fd2 0.8, fw2 0.2; fd3 0.9, fw3 0.3; fd4 0.8, fw4 0.3); subarticular tubercles well developed, oval, single, all present; prepollex weakly developed; round palmar tubercles present. Thigh length (TL 11.0) shorter than shank (SHL 11.3), and longer than foot (FOL 9.6); toe discs wide compared to toe width (td1 0.7, tw1 0.2; td2 1.0, tw2 0.3; td3 1.0, tw3 0.3; td4 1.1, tw4 0.3 ; td5 1.0, tw5 0.3); webbing present: I1-2II1$2 \mathrm{III} 1-2^{3} / 4 \mathrm{IV} 2^{3} / 4-1 \mathrm{~V}$; subarticular tubercles weakly developed, oval, all present; inner metatarsal tubercles distinct and moderately short; outer metatarsal tubercles rounded, rather prominent.

Skin of snout, between eyes and upper eyelids shagreened to sparsely granular; posterior part of back shagreened to granular; dorsolateral folds that extend from the posterior corner of the eye to the entire body length on both sides, discontinuous; scattered glandular ridge on dorsum; flanks shagreened with short tubercles; dorsal parts of forelimb without glandular projections; thigh, tibia and tarsus with weakly developed glandular projections; dorsal parts of forelimb shagreened; thigh, tibia and tarsus with weakly developed granular projections and glandular ridge; toe $\mathrm{V}$ with short granular projections from the base up to the knee; ventral surface of throat, chest and abdomen smooth; posterior parts of thigh shagreened to sparsely granular.

Colour in preservation. Dorsum light brown; a dark grey streak starting from the tip of snout, extending over the eyes and tympanum, and ending near the shoulder; lateral sides of head (snout and tympanic area) distinctly dark grey; 
flanks grey with black speckles; dorsolateral folds reddish-brown; forelimbs, dorsal surfaces of thigh, tibia and feet light brown with dark brown crossbands, posterior parts of thigh grey with dark grey reticulations; throat, chest and belly reddishbrown with greyish-brown reticulations; webbing blackish-grey. Colour in life (BNHS 5801). Dorsum uniform reddish-brown; a white streak starting from the tip of snout, extending over the eyes and tympanum, and ending near the shoulder; lateral sides of head (snout and tympanic area) distinctly reddish-brown; iris light brown with reddish tinge; flanks light yellowish-red; groin red; dorsal surface of limbs reddish-brown with dark brown cross-bands; throat and chest light brown with dark brown spots; belly light yellowish-white with scattered grey reticulations; thighs light red with brown patches, shank and foot red with marginal brown spots; webbing dark brown.

Variations. See Table 5 for morphometric characters of seven adult males and three adult females. For colour variations see Figure 44.

Secondary sexual characters. Male: Single prominent oval-shaped nuptial pad on finger I present, cream-coloured; single gular pouch while calling. Female (BNHS 5799): ova yellowish-white with minute black spots (diameter 1.3-1.7 mm, $N=20$ ).
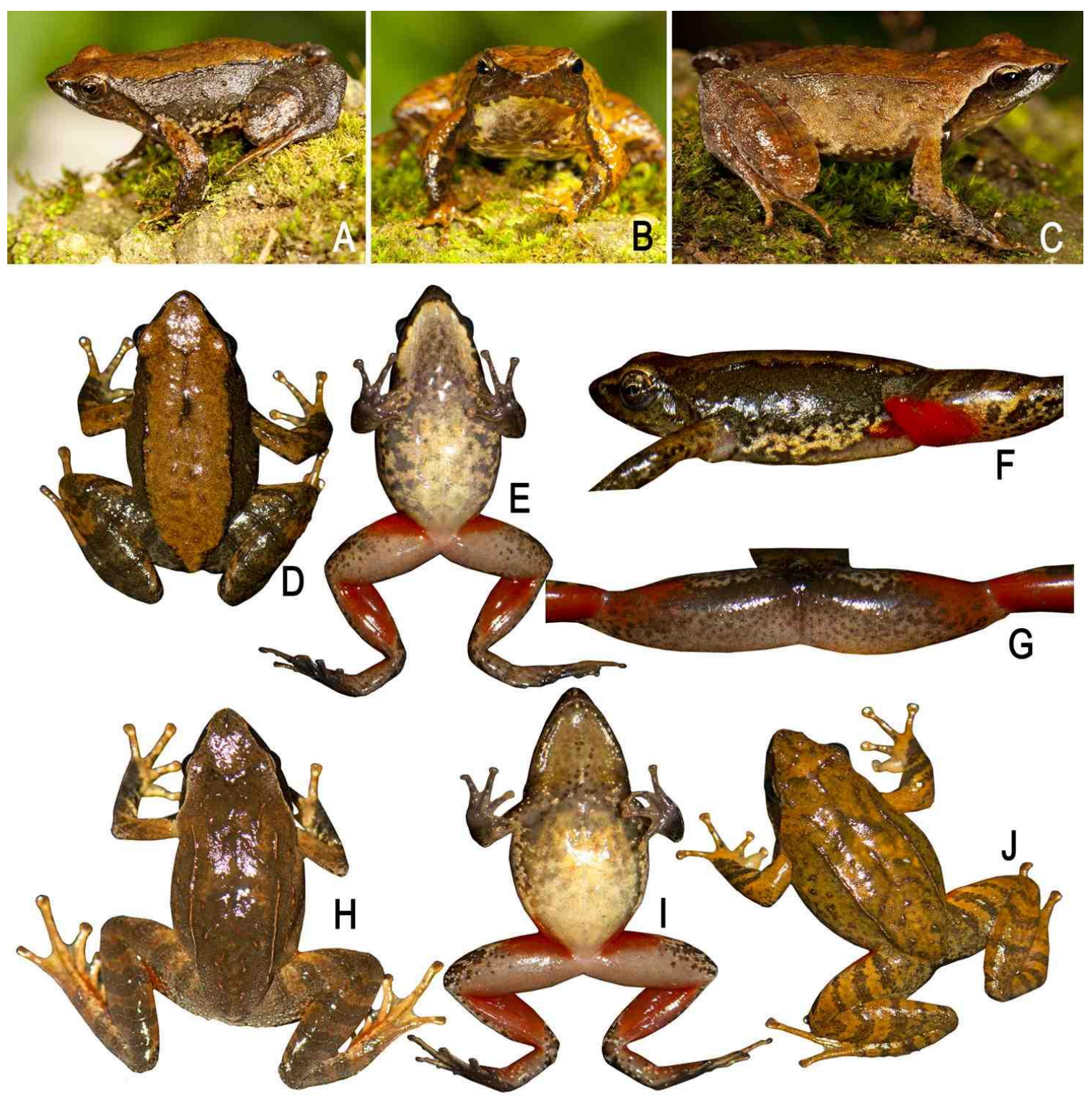

Figure 44. Micrixalus phyllophilus in life: A. dorsolateral view, B. front view (RS, BNHS 5801, m); C. dorsolateral view (RS, BNHS 5802, m); D. dorsal view, E. ventral view, F. lateral view of thigh and groin, G. posterior side of thigh (RS, BNHS 5801, m); H. dorsal view, I. ventral view (RS, BNHS 5805, f); J. dorsal view (RS, BNHS 5802, m). Photos: SDB. 
Distribution. Micrixalus phyllophilus is known only from the high altitudes (above $1800 \mathrm{~m}$ asl) of Nilgiri hills in the Western Ghats. The present study found this species in Avalanche, Longwood Shola and Naduvattam (Nilgiris dist.) in Tamil Nadu state (Fig. 3, Table 1).

Habitat and natural history. The preferred habitat of this species is shallow and slow moving streams located inside shola forests. The majority of male specimens were found actively calling and collected between 10:0016:00 h.

\section{Micrixalus silvaticus (Boulenger, 1882) Forest Dancing Frog}

(Figs 3, 40D, 43C-D, 45; Tables 1-5)

Original name and description. Ixalus silvaticus Boulenger, 1882. Catalogue of the Batrachia Salientia s. Ecaudata in the Collection of the British Museum, ed. 2: 496. Lectotype. NHM 82.2.10.52, an adult female, SVL $26.0 \mathrm{~mm}$, by present designation. Type locality. "Malabar". Current status of specific name. Valid name, as Micrixalus silvaticus (Boulenger, 1882).

Referred specimens. Kerala: Idukki dist., Kadalar estate, BNHS 5807, an adult male, collected by SDB and Systematics lab team, 22 September 2011; "Malabar", NHM82.2.10.59, NHM 82.2.10.58, two adult males, NHM 82.2.10.53 and NHM 82.2.10.55, two adult females, collected by Beddome.

Comparison. Micrixalus silvaticus could be confused with $M$. frigidus, $M$. nigraventris and M. phyllophilus. For differences with M. frigidus, $M$. nigraventris and $M$. phyllophilus see 'Comparison' of those species.

Comments. Boulenger (1882) described this species based on eight specimens, NHM 82.2.10.52-59 (six females and two males), from "Malabar". We examined all the syntypes at NHM and found them to be homogenous in identity, possessing a unique character, i.e. "brown above, with rather indistinct darker markings, the most constant being a broad chevron between the eyes; sides of head blackish brown". In order to avoid any possible doubt or confusion, we hereby designate NHM 82.2.10.52 (an adult female) from "Malabar", with snout-vent size (SVL $26.0 \mathrm{~mm}$ ) almost same as that measured by Boulenger ("snout to vent" $27.0 \mathrm{~mm}$ ), as lectotype of Micrixalus silvaticus (Figs 43C-D).

Description of lectotype (all measurements in mm). Adult female (SVL 26.0); head small (HW 9.0, HL 9.6), longer than wide, flat above; snout rounded in dorsal and lateral view, its length (SL 4.1) longer than horizontal diameter of eye (EL 3.2); loreal region acute with rounded canthus rostralis; interorbital space flat, wider (IUE 2.8) than upper eyelid (UEW 1.9); distance between back of eye (IBE 7.5) 1.9 times the distance between front of eye (IFE 3.9); nostril oval, closer to eye (EN 1.3) than tip of snout (NS 1.9); tympanum (TYD 1.4) $44 \%$ of eye diameter (EL 3.2); tongue moderately large, emarginate, without lingual papilla; supratympanic fold that extends from posterior corner of eye to near the shoulder, well developed. Forelimbs (FAL 5.1) shorter than hand length (HAL 5.9); finger discs moderately wide compared to finger width; subarticular tubercles well developed, oval, single, all present, prepollex weakly developed; round palmar tubercles present. Thigh length (TL 11.5) equal to shank (SHL 11.5), and longer than foot (FOL 10.6); toe discs wide compared to toe width; webbing present: I2-2II $2^{-}-2^{4} / 5 \mathrm{III} 2^{4} / 5-31 / 4 \mathrm{IV} 3^{1 / 4-}$ $2 \mathrm{~V}$; subarticular tubercles weakly developed, oval, all present; inner metatarsal tubercles distinct and moderately short; outer metatarsal tubercles rounded, rather prominent.

Skin of snout, between eyes and upper eyelids shagreened to granular; dorsolateral folds that extend from the posterior corner of the eye to the entire body length on both sides, discontinuous; scattered glandular ridge on dorsum; thigh, tibia and tarsus with weakly developed glandular projections and glandular ridge; ventral surface of throat, chest and abdomen smooth; posterior parts of thigh shagreened to sparsely granular.

Colour in preservation. Dorsum light brown; a greyish-brown streak starting from the tip of snout, extending over the eyes and tympanum, and ending near the shoulder; lateral sides of head (snout and tympanic area) distinctly dark grey; flanks grey; forelimbs, dorsal surfaces of thigh, tibia and feet light brown with dark brown cross-bands, posterior parts of thigh grey with dark grey reticulations; throat, chest and belly light brown with brown reticulations. Colour in life (SDB 2011.1035). Dorsum uniform reddish-brown; a white streak starting from the tip of snout, extending over the eyes and tympanum, and ending near the shoulder; lateral sides of head (snout and tympanic area) distinctly blackishbrown; iris light brown with reddish tinge; flanks light greyish-brown; groin greyish-white; dorsal surface of limbs reddish-brown with dark brown cross-bands; throat and chest light orange; belly creamy white with orange reticulations; thigh, shank and foot light grey.

Variations. See Table 5 for morphometric characters of three adult males and three adult females. For colour variations see Figure 45.

Secondary sexual characters. Male (NHM 82.2.10.59): Single prominent oval-shaped nuptial pad on finger I present, cream-coloured. 

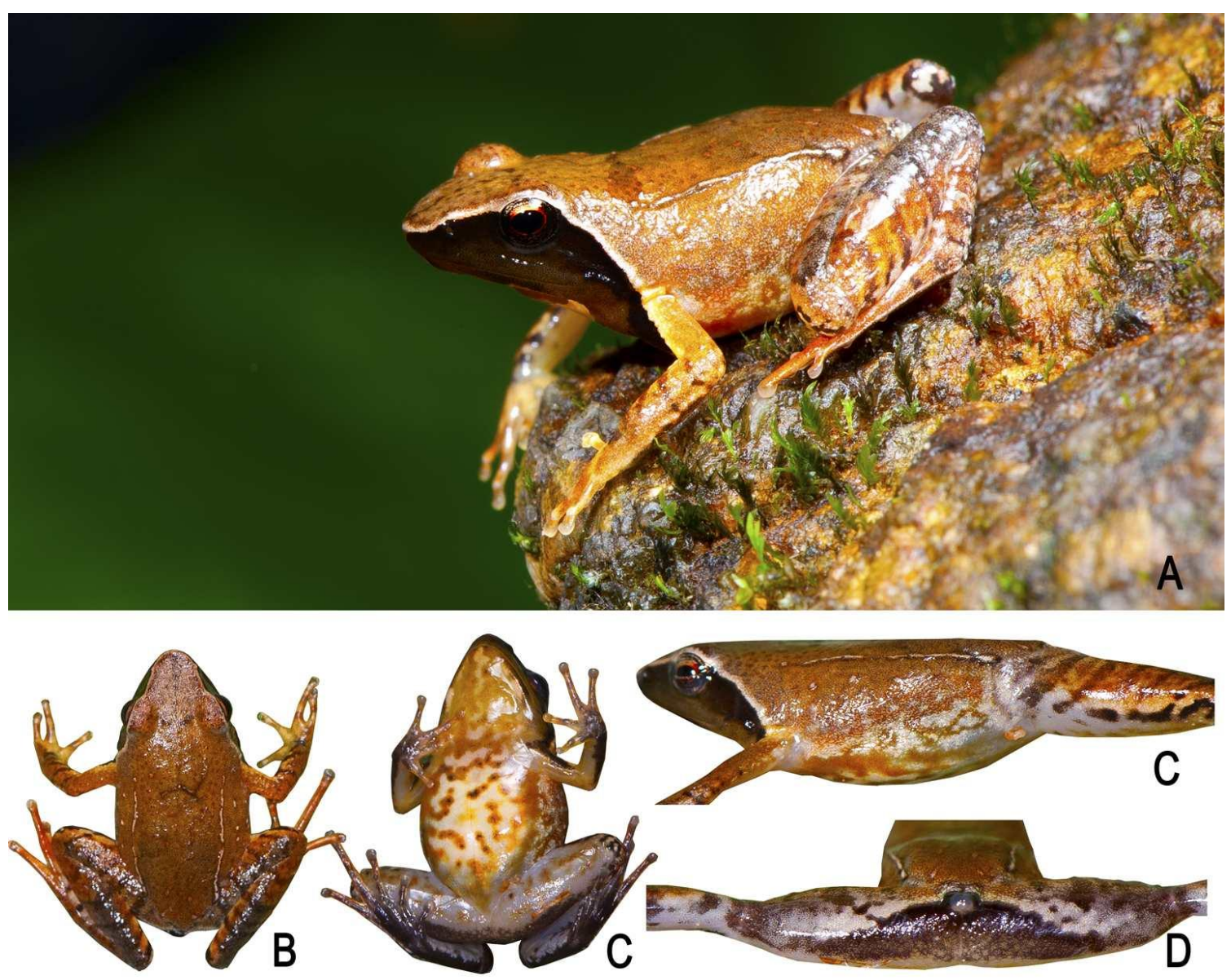

Figure 45. Micrixalus silvaticus in life: A. dorsolateral view, B. dorsal view, C. ventral view, D. lateral view of thigh and groin, E. posterior side of thighs (RS, BNHS 5807, m). Photos: SDB.

Female (NHM 82.2.10.52): ova yellowish- white with minute black spots (diameter $1.3-1.5 \mathrm{~mm}, N$ $=10)$.

Distribution. The present study recorded Micrixalus silvaticus only from one locality, Kadalar estate (Idukki dist., Kerala), which lies south of Palghat gap in the Western Ghats (Fig. 3, Table 1).

Habitat and natural history. The sole specimen of this species was found under leaf litter near a perennial stream inside a plantation located close to shola forest.

\section{DISCUSSION}

Our results conform to the trend of high species diversity reported by recent studies in the Western Ghats (e.g., Abraham et al., 2013; Biju and Bossuyt, 2009; Biju et al., 2009, 2011; Zachariah et al., 2011), thereby highlighting the fact that the amphibian diversity of this region still remains underestimated. Biju (2001) estimated the presence of at least a 100 new anuran species in the Western Ghats. In the following years, 75 amphibian species have already been described from this region (e.g., Abraham et al., 2013; Biju and Bossuyt, 2009; Biju et al., 2009, 2011; Zachariah et al., 2011) (Fig. 1), and we predict that there could possibly be another 100 new species awaiting formal description, before saturation in new discoveries can be expected. Discovering cryptic diversity is not only vital for understanding the patterns and processes of evolution, but also an important step towards prioritizing conservation needs and avoiding the risk of loosing biodiversity even before taxonomic recognition, in other words - nameless extinction.

Ancient lineages like Micrixalidae represent the few remaining relicts of the evolutionary history of ranid anurans (Roelants et al., 2004), and their occurrence only in the Western Ghats further stresses on the need to understand the true diversity within these groups. Apart from containing significant evolutionary information, many of the Western Ghats endemic lineages are known to possess unique ecological and behavioural adaptations (Biju and Bossuyt, 2003; Biju et al., 2011; Bossuyt and Milinkovitch, 2000; 
Roelants et al., 2004). An improved understanding of diversity at the species level can provide better insights into the evolution of such specializations. For example, in the genus Micrixalus, we did not observe foot-flagging behaviour in all species, and it seems that the presence and absence of footflagging is likely to vary based on degree of webbing and habitat preference of species. This could probably suggest that visual communication evolved more specifically in species that prefer noisy torrent environments (Hebets and Papaj, 2005; Hödl and Amézquita, 2001; Preininger et al., 2013b). Further studies with focus on breeding and behavioural aspects of all Micrixalus species will be necessary to address questions on such evolutionary adaptations.

Roelants et al. (2004) discussed the occurrence of low species level diversity in Micrixalus and morphological uniformities in extant members of this genus. However, our barcoding study identified 14 clearly divergent clades in addition to the 10 known Micrixalus species. Detailed morphological examination of these small-sized frogs, believed to be morphologically cryptic, showed the presence of several characters to distinguish each of these species. Therefore, it is evident that due to the absence of careful morphological investigation and comprehensive surveys in the entire Western Ghats, true diversity in this ancient lineage remained unknown. This could be the scenario in several other understudied amphibian lineages in the Western Ghats, for which species richness and endemism remain to be explored. In such precarious circumstances, the DNA barcoding approach holds promise to rapidly inventory species and predict priority locations for effective conservation (Fouquet et al., 2007; Funk et al., 2011; Hebert and Gregory, 2005; Hebert et al., 2003; Janzen et al., 2009; Vences et al., 2005b; Vieites et al., 2009).

Molecular methods have dramatically improved our ability to uncover species and realize the magnitude of cryptic diversity (Fouquet et al., 2007; Funk et al., 2011; Hebert et al., 2003; Vieites et al., 2009). However, use of genetic information for species delimitation is yet to reach its full potential, particularly in diverse tropical and megadiversity regions such as India, where this approach has so far been applied only to selected amphibian groups (Abraham et al., 2013; Biju and Bossuyt, 2003, 2009; Biju et al., 2009, 2011, 2013; Nair et al., 2012). Furthermore, understanding relationships between species in a phylogenetic framework can provide insights into patterns of morphological synapomorphies. Our study found significant patterns of morphological similarity among different species, specifically for characters such as, webbing, dorsolateral folds, colouration of lateral sides of head, which suggested a basis for grouping of species by morphology. A phylogenetic investigation using a combination of mitochondrial and nuclear markers can be useful in substantiating these species grouping.

Integrative taxonomic approach has gained fast acceptance, especially in the field of amphibian systematics (e.g., Padial and De la Riva, 2009; Vieites et al., 2009). Apart from external morphology, several studies have used molecular and acoustic data to understand species diversiy (e.g., Fouquet et al., 2007; Vences et al., 2010). However, the use of internal morphological characters to identify unique features at species or generic level still remains an understudied subject in Indian anuran systematics. Our study provides the first detailed osteological description of a clear and double-stained anuran specimen from India, but due to the lack of osteological information for closely related members, a comparative description could not be provided. Nevertheless, we note the absence of Septomaxilla bone in Micrixalus fuscus. Future research with a greater focus on internal skeletal characters in ancient and endemic anuran lineages of the Western Ghats would make useful contributions to taxonomy and evolutionary studies.

The ultimate goal of biodiversity conservation can be achieved by setting priorities, and the role of systematics is crucial in providing information required for focused conservation efforts (Bickford et al., 2007; McLeod, 2010; Savage, 1995; Vredenburg et al., 2007). Accurate identification of species and knowledge of true diversity are essential to identify regions with high levels of species richness and endemism. In a scenario where new information is available, conservation assessment of individual species and threats in their habitats need to be revisited. Micrixalidae, previously a family of 11 species with taxonomic confusions, ambiguous distinguishing characters and patchy distribution records, and which is now known to be a two-fold more diverse lineage with restricted distribution range of species, is in an urgent need of conservation reassessment. Immediate attention in this regard can go a long way in conserving extant members of this ancient and endemic group of frogs. 


\section{ACKNOWLEDGEMENTS}

This research was supported by grant to SDB from CEPF 'Project 55918/2009' (USA), DU/DST '2009/868' (Government of India) and MoEF '23/3/2007-RE' (Government of India); grant to SDB and YS from DBT 'BT/PR7833/NDB/51/153/2006' (Government of India). The State Forest Departments of Kerala, Tamil Nadu, Karnataka and Maharashtra are greatly appreciated for study permits to SDB and for their support. Franky Bossuyt and Amphibian Evolution Lab (Vrije Universiteit Brussel) supported SDB for initiating this study and conducting part of the lab work during his $\mathrm{PhD}$. SG was supported by fellowship from University of Delhi under the University Teaching Assistantship (UTA) Scheme 2010/56562. Authors would like to thank to M. Meegaskumbura and G. Senevirathne for support in osteological preparation and interpretations; S. Mahony for critical inputs in the intial draft; $M$. Meegaskumbura, M. A. Bee and an anonymous reviewer for valuable comments and suggestions on the manuscript; A. Thomas for lab support; G. Sircar for initial support and involvement; past and present members of the Systematics Lab (R. G. Kamei, A. Thomas, R. Suyesh, G. Sircar) for field support; NCCS Lab-3 members for support to SG and SW during lab work; K. Jayaram, K. V. Sreenivasan, Mallan Kani, Vijayan Kani, Sali Palode, Varad Giri, Sameer Ali, Chandra Sekhar and Tengbat Sangma for valuable field support; B. Clarke (NHM), K. Venkataraman (ZSI) and A. R. Rahmani (BNHS) for providing access to specimens in their care; M. Wilkinson and D. Gower (NHM), and R. V. Khot (BNHS) for providing support to SDB during museum study visits; J. V. Vindum (CAS) for photographs of the type specimen of Micrixalus herrei.

\section{REFERENCES}

Abraham, R. K., Pyron, R. A., Ansil, B. R., Zachariah, A. and Zachariah, A. (2013). Two novel genera and one new species of treefrog (Anura: Rhacophoridae) highlight cryptic diversity in the Western Ghats of India. Zootaxa 3640: 177-189.

AmphibiaWeb (2014). AmphibiaWeb: information on amphibian biology and conservation, University of California, Berkeley, California. Available from: http://www.amphibiaweb.org/ (5 January 2014).

Aravind, N. A. (2002). First report of Micrixalus nudis (Amphibia: Ranidae) from Karnataka, India. Hamadryad 27: 116-117.

Bickford, D., Lohman, D. J., Sodhi, N. S., Ng, P.
K. L., Meier, R., Winker, K., Ingram, K. K. and Das, I. (2007). Cryptic species as a window on diversity and conservation. Trends in Ecology and Evolution 22: 148155.

Biju, S. D. (2001). A synopsis to the frog fauna of the Western Ghats, India. Indian Society for Conservation Biology- Occasional Publication 1: 1-24.

Biju, S. D. and Bossuyt, F. (2003). New frog family from India reveals ancient biogeographic link with the Seychelles. Nature 425: 711-714.

Biju, S. D. and Bossuyt, F. (2009). Systematics and phylogeny of Philautus Gistel, 1848 (Anura, Rhacophoridae) in the Western Ghats of India, with descriptions of 12 new species. Zoological Journal of the Linnean Society 155: 374-444.

Biju, S. D., Dutta, S. and Inger, R. (2004). Micrixalus nudis. In: IUCN 2013. IUCN Red List of Threatened Species. Version 2013.2. Available from: www.iucnredlist.org (5 January 2014).

Biju, S. D., Roelants, K. and Bossuyt, F. (2008). Phylogenetic position of the montane treefrog Polypedates variabilis Jerdon, 1853 (Anura: Rhacophoridae), and description of a related species. Organisms, Diversity and Evolution 8: $267-276$.

Biju, S. D., Van Bocxlaer, I., Giri, V., Loader, S.P. and Bossuyt, F. (2009). Two new endemic genera and a new species of toad (Anura; Bufonidae) from the Western Ghats of India. BMC Evolution Notes 2: 241.

Biju, S. D., Van Bocxlaer, I., Mahony, S., Dinesh, K. P., Radhakrishnan, C., Zachariah, A., Giri, V. and Bossuyt, F. (2011). A taxonomic review of the Night Frog genus Nyctibatrachus Boulenger, 1882 in the Western Ghats, India (Anura: Nyctibatrachidae) with description of twelve new species. Zootaxa 3029: 1-96.

Biju, S. D., Kamei, R. G., Mahony, S., Thomas, A., Garg, S., Sircar, G. and Suyesh, R. (2013). Taxonomic review of the tree frog genus Rhacophorus from the Western Ghats, India (Anura: Rhacophoridae), with description of ontogenetic colour changes and reproductive behaviour. Zootaxa 3636: 257-289.

Bossuyt, F. and Dubois, A. (2001). A review of the frog genus Philautus Gistel, 1848 (Amphibia, Anura, Ranidae, Rhacophorinae). Zeylanica 6: $1-112$.

Bossuyt, F. and Milinkovitch, M. C. (2001). Amphibians as indicators of early tertiary "Out of India" dispersal of vertebrates. Science 292: 93-95. 
Bossuyt, F., Meegaskumbura, M., Beenaerts, N., Gower, D. J., Pethiyagoda, R., Roelants, K., Mannaert, A., Wilkinson, M., Bahir, M. M., Manamendra-Arachchi, K., Ng, P. K. L., Schneider, C. J., Oommen, O. V. and Malinkovitch, M. C. (2004). Local Endemism within the Western Ghats-Sri Lanka biodiversity hotspot. Science 306: 479-481.

Boulenger, G. A. (1882). Catalogue of the Batrachia Salientia s. Caudata in the collections of the British Museum. Second Edition. British Museum (Natural History). Second Edition. Taylor and Francis, London, Xvi + 503 Pp. + XXX pl.

Boulenger, G. A. (1888). Note on the classification of the Ranidae. Proceedings of the Zoological Society of London 56: 204-206.

Briggs, J. C. (2003). The biogeography and tectonic history of India. Journal of Biogeography 30: 381-388.

Chanda, S. K., Das, I. and Dubois, A. (2001 "2000"). Catalogue of amphibian types in the collection of the Zoological Survey of India. Hamadryad 25: 100-128.

Che, J., Chen, H. M., Yang, J. X., Jin, J. Q., Jiang, K., Yuan, Z. Y., Murphy, R. W. and Zhang, Y. P. (2012). Universal COI primers for DNA barcoding amphibians. Molecular Ecology Resources 12: 247-258.

Daniels, R. J. R. (2005). Amphibians of Peninsular India. Universities Press (India), Hyderabad, $268 \mathrm{Pp}$.

Das, I. and Dutta, S. K. (1998). Checklist of the amphibians of India, with English common names. Hamadryad 23: 63-68.

Dinesh, K. P., Radhakrishnan, C., Gururaja, K. V. and Bhatta, G. K. (2009). An annotated checklist of amphibian of India with some insights into the patterns of species discoveries, distribution and endemism. Records of Zoological Survey of India, Occasional Paper, Zoological Survey of India, Kolkata, $302 \mathrm{Pp}$.

Dinesh, K. P., Radhakrishnan, C., Gururaja, K. V. and Zachariya, A. (2010). New locality records of Rhacophorus lateralis Boulenger, 1883 (Amphibia: Anura: Rhacophoridae), in Western Ghats, India. Journal of Threatened Taxa 2: 986-989.

Dubois, A. (1984). Note préliminare sur le groupe de Rana limnocharis Gravenhorst, 1829 (Amphibiens, Anoures). Alytes 3: 143-159.

Dubois, A. (1987 "1986"). Miscellanea taxinomica batrachologica (I). Alytes 5: 7-95.

Dubois, A., Ohler, A. and Biju, S. D. (2001). A new genus and species of Ranidae (Amphibia, Anura) from south-western India. Alytes 19: 53-79.
Duellman, W. E. and Trueb, L. (1986). Biology of Amphibians. McGraw- Hill, New York, 670 Pp.

Dutta, S. K. (1997). Amphibians of India and Sri Lanka, (Checklist and Bibliography). Odyssey Publishing House, Bhubaneswar, $342 \mathrm{Pp}$.

Fouquet, A., Gilles, A., Vences, M., Marty, C., Blance, M. and Gemmel, N. J. (2007). Underestimation of species richness in neotropical frogs revealed by mtDNA analysis. PLOS ONE 2: e1109.

Frank, N. and Ramus, E. (1995). A complete guide to scientific and common names of reptiles and amphibians of the world. N. G. Publishing Inc., Pottsville, Pennsylvania, 337 Pp.

Frost, D. R., Grant, T., Faivovich, J., Bain, R. H., Haas, A., Haddad, C. F. B., Rafael, O. De Sa et al. (2006). The amphibian tree of life. Bulletin of the American Museum of natural History 297: 1-291.

Frost, D. R. (2014). Amphibian Species of the World: an Online Reference, Version 6.0, American Museum of Natural History, New York, USA. Available from: http://research.amnh.org/herpetology/amphibi a/index.html (5 January 2014).

Funk, W. C., Caminer, M. and Ron, S. R. (2011). High levels of cryptic species diversity uncovered in Amazonian frogs. Proceedings of the Royal Society B 279: 1806-1814.

Günther, A. (1869 “1868”). First account of species of tailless batrachians added to the collection of the British Museum. Proceedings of the Zoological Society of London 478-490 + pl. XXXVII-XL.

Gururaja, K. V., Ali, S. and Ramachandra, T. V. (2007). Micrixalus fuscus (Anura: Micrixalidae) in Sharavathi River Basin, Karnataka. Journal of Bombay Natural History Society 104:104-105.

Gururaja, K. V. (2010). Novel reproductive mode in a torrent from Micrixalus saxicola (Jerdon) from the Western Ghats, India. Zootaxa 2642: 45-52.

Gururaja, K. V. (2012). Pictorial guide to frogs and toads of the Western Ghats. Gubbi Labs Publication, $154 \mathrm{Pp}$.

Hebert, P. D., Cywinska, A. and Ball, S. L. (2003). Biological identifications through DNA barcodes. Proceedings of the Royal Society of London. Series B: Biological Sciences 270: 313-321.

Hebert, P. D. and Gregory, T. R. (2005). The promise of DNA barcoding for taxonomy. Systematic biology 54: 852-859. 
Hebets, E. A. and Papaj, D. R. (2005). Complex signal function: developing a framework of testable hypotheses. Behavioral Ecology and Sociobiology 57:197-214.

Hödl, W. and Amézquita, A. (2001). Visual signaling in anuran amphibians. In: M. J. Ryan (Ed.), Anuran communication, Smithsonian Institution Press, Washington DC Pp. 121-141.

Inger, R. F., Shaffer, H. B., Koshy, M. and Bakde, R. (1985 “1984”). A report on a collection of amphibians and reptiles from the Ponmudi, Kerala, South India. Journal of the Bombay Natural History Society 81: 551-570.

IUCN (2013). IUCN Red List of Threatened Species, Version 2013.2. Available from: www.iucnredlist.org (5 January 2014).

Janzen, D. H., Hallwachs, W., Blandin, P., Burns, J. M., Cadiou, J., Chacon, I. et al., (2009). Integration of DNA barcoding into an ongoing inventory of complex tropical biodiversity. Molecular Ecology Resources 9: 1-26.

Jerdon, T. C. (1854 “1853”). Catalogue of reptiles inhabiting the peninsula of India. Journal of the Asiatic Society of Bengal 22: 522-534.

Jerdon, T. C. (1870). Notes on Indian herpetology. Proceedings of the Asiatic Society of Bengal 1870: 66-85.

Krishna, S. N. and Krishna, S. K. (2006). Visual and acoustic communication in an endemic stream frog, Micrixalus saxicolus in the Western Ghats, India. Amphibia-Reptilia 27: 143-147.

Krishnamurthy, S.V. and Sakunthala, K. (1993). Amphibian fauna of Sringeri taluk (Chickamagalure district: Karnataka). Journal of Indian Institute of Science 73: 443-452.

Kuramoto, M., Joshy, S. H., Kurabayashi, A. and Sumida, M. (2007). The genus Fejervarya (Anura: Ranidae) in central Western Ghats, India, with descriptions of four new cryptic species. Current Herpetology 26: 81-105.

Mahony, S, Sengupta, S, Kamei, R. G. and Biju, S. D. (2011). A new low altitude species of Megophrys Kuhl and Van Hasselt (Amphibia: Megophryidae), from Assam, northeast India. Zootaxa 3059: 36-46.

Malhotra, A. and Davis, K. (1991). A report on the herpetological survey of the Srivilliputhur Reserve Forests, Tamil Nadu. Journal of Bombay Natural History Society 88: 157-166.

Martin, P. and Bateson, P. (1986). Measuring Behaviour - An Introductory Guide. Cambridge University Press, New York, 200 Pp.

McLeod, D. S. (2010). Of least concern? Systematics of a cryptic species complex:
Limnonectes kuhlii (Amphibia: Anura: Dicroglossidae). Molecular Phylogenetics and Evolution 56: 991-1000.

Mittermeier, R. A., Gill, P. R., Hoffman, M., Pilgrim, J., Brooks, T., Mittermeier, C. G., Lamoreux, J. and Da Fonseca, G. A. B. (2004). Hotspots Revisited: Earth's Biologically Richest and Most Endangered Terrestrial Ecoregions. Cemex, Conservation International and Agrupación Sierra Madre, Monterrey, Mexico, 431 Pp.

Müller, F. (1887). Fünfter Nachtrag zum Katalog der herpetologischen Sammlung des Basler Museum. Verhandlungen der Naturforschenden Gesellschaft in Basel 8: 249-296.

Myers, G. S. (1942). A new frog of the genus Micrixalus from Travancore. Proceedings of the Biological Society of Washington 55: 7174.

Myers, C. W. and Duellman, W. E. (1982). A New Species of Hyla from Cerro Colorado, and other Tree frog records and geographical notes from Western Panama. American Museum novitates 2752: 1-32.

Nair, A., Gopalan, S. V., George, S., Kumar, K. S., Teacher, A. G. F. and Merilä, J. (2012). High cryptic diversity of endemic Indirana frogs in the Western Ghats biodiversity hotspot. Animal Conservation 15: 489-498.

Padial, J. M. and De la Riva, I. (2009). Integrative taxonomy reveals cryptic Amazonian species of Pristimantis (Anura: Strabomantidae). Zoological Journal of the Linnean Society 155: $97-122$.

Pillai, R. S. (1978). A new frog of the genus Micrixalus Boulenger from Wynad, S. India. Proceedings of the Indian Academy of Sciences, Section B 87: 173-177.

Pillai, R. S. (1981). Two new species of Amphibia from Silent Valley, S. India. Bulletin of the Zoological Survey of India 3: 153-158.

Pillai, R. S. and Pattabiraman, R. (1990). Amphibians from Sabagiri forest, Western Ghats, Kerala, including a new species of Micrixalus. Records of the Zoological Survey of India 86: 383-390.

Preininger, D., Boeckle, M., Sztatecsny, M. and Hödl, W. (2013a). Divergent receiver responses to components of multimodal signals in two foot-flagging frog species. PloS One 8: e55367.

Preininger, D., Boeckle, M., Freudmann, A., Starnberger, I., Sztatecsny, M. and Hödl, W. (2013b). Multimodal signaling in the Small Torrent Frog (Micrixalus saxicola) in a complex acoustic environment. Behavioral Ecology and Sociobiology 67: 1449-1456. 
Preininger, D., Stiegler, M. J., Gururaja, K. V., Vijayakumar, S. P., Torsekar, V. R., Sztatecsny and Hödl, W. (2013c). Getting a kick out of it: multimodal signaling during male-male encounters in the foot-flagging frog Micrixalus aff. saxicola from the Western Ghats of India. Current Science 105: 1735-1740.

Purushotham, C. B. and Tapley, B. (2011). Checklist of Amphibians: Agumbe Rainforest Research Station 16: 2-14.

Rao, C. R. N. (1937). On some new forms of Batrachia from S. India. Proceedings of the Indian Academy of Sciences, Section B 6: 387-427.

Ramesh, B. R., Pascal, J. P. and Nouguier, C., Atlas of Endemics of the Western Ghats (India): Distribution of Tree Species in the Ever- green and Semi-evergreen Forests, Institut Francais de Pondichery, Publications du department d ecologie. 38: 403 Pp.

Reddy, A. H. M., Gururaja, K. V., Ravichandran, M. S. and Krishnamurthy, S. V. (2001). Range extension of Ansonia ornata (Günther, 1875) and Indirana brachitarsus (Günther, 1875). Hamadryad 26: 358-359.

Reddy, A. H. M, Gururaja, K. V. and Krishnamurthy, S. V. (2002). Habitat features of Micrixalus saxicola Jerdon, 1854 in the Western Ghats, India. Amphibia-Reptilia 23: 370-374.

Robin, V. V., Sinha, A. and Ramakrishnan, U. (2010). Ancient geographical gaps and paleoclimate shape the phylogeography of an endemic bird in the sky islands of southern India. PLoS One 5: e13321.

Roelants, K., Jiang, J. and Bossuyt, F. (2004). Endemic ranid (Amphibia: Anura) genera in southern mountain ranges of the Indian subcontinent represent ancient frog lineages: evidence from molecular data. Molecular Phylogenetics and Evolution 31: 730-740.

Sambrook, J., Fritsch, E. F. and Maniatis, T. (1989). Molecular Cloning: A Laboratory Manual. Cold Spring Harbor Laboratory press, Cold Spring Harbor, NY, Pp. 626.

Savage, J. M. and Heyer, W. R. (1967). Variation and distribution in the tree-frog genus Phyllomedusa in Costa Rica, Central America: With 6 figures. Studies on Neotropical Fauna and Environment 2: 111131.

Savage, J. M. (1995). Systematics and the biodiversity crisis. BioScience 673-679.

Simon, C., Frati, F., Beckenbach, A., Crespi, B., Liu, H. and Flook, P. (1994). Evolution, Weighting and Phylogenetic Utility of Mitochondrial Gene Sequences and a
Compilation of Conserved Polymerase Chain Reaction Primers. Annals of the Entomological Society of America 87: 651701.

Smith, M., Poyarkov, N. A. and Hebert, P. D. (2008). DNA barcoding: CO1 DNA barcoding amphibians: take the chance, meet the challenge. Molecular Ecology Resources 8: 235-246.

Swofford, D. L. (2002). PAUP*: Phylogenetic Analysis Using Parsimony (* and other methods), Version 4.0b10. Sinauer, Sunderland.

Tamura, K., Peterson, D., Peterson, N., Stecher, G., Nei, M. and Kumar, S. (2011). MEGA5: Molecular Evolutionary Genetics Analysis using maximum likelihood, evolutionary distance, and maximum parsimony methods. Molecular Biology and Evolution 28: 27312739. http://dx.doi.org/10.1093/molbev/msr121

Taylor, W. R. and Van Dyke, G. C. (1985). Revised procedures for staining and clearing small fishes and other vertebrates for bone and cartilage study. Cybium 9: 107-119.

Van Bocxlaer, I., Biju, S. D., Loader, S. P. and Bossuyt, F. (2009). Toad radiation reveals into-India dispersal as a source of endemism in the Western Ghats-Sri Lanka biodiversity hotspot. BMC Evolutionary Biology 9: 131.

Van Bocxlaer, I., Biju, S. D., Willaert, B., Giri, V., Shouche, Y. S. and Bossuyt, F. (2012). Mountain-associated clade endemism in an ancient frog family (Nyctibatrachidae) on the Indian subcontinent. Molecular Phylogenetics and Evolution 62: 839-847.

Vasudevan, K. (2001). A foot flagging frog from the Western Ghats. Cobra 44: 25-29.

Vences, M., Thomas, M., Van der Meijden, A., Chiari, Y. and Vieites, D. R. (2005a). Comparative performance of the $16 \mathrm{~S}$ rRNA gene in DNA barcoding of amphibians. Frontiers in Zoology 2: 5.

Vences, M., Thomas, M., Bonett, R. M. and Vieites, D. R. (2005b). Deciphering amphibian diversity through DNA barcoding: chances and challenges. Philosophical Transactions of the Royal Society B. Biological Sciences 360: 1859-1868.

Vences, M., Glaw, F., Köhler, J. and Wollenberg, K. C. (2010). Molecular phylogeny, morphology and bioacoustics reveal five additional species of arboreal microhylid frogs of the genus Anodonthyla from Madagascar. Contributions to Zoology 79: 132.

Vieites, D. R., Wollenberg, K. C., Andreone, F., Ko hler, J., Glaw, F. and Vences, M. (2009). 
Vast underestimation of Madagascar's biodiversity evidenced by an integrative amphibian inventory. Proceedings of the National Academy of Sciences 106: 82678272.

Vredenburg, V. T., Bingham, R., Knapp, R., Morgan, J. A. T., Moritz, C. and Wake, D. (2007). Concordant molecular and phenotypic data delineate new taxonomy and conservation priorities for the endangered mountain yellow legged frog. Journal of Zoology 271: 361-374.

Xia, Y. U. N., Gu, H. F., Peng, R. U. I., Chen, Q. I.
N., Zheng, Y. C., Murphy, R. W. and Zeng, X. M. (2012). COI is better than 16S rRNA for DNA barcoding Asiatic salamanders (Amphibia: Caudata: Hynobiidae). Molecular Ecology Resources 12: 48-56.

Zachariah, A., Dinesh, K. P., Kunhikrishnan, E., Das, S., Raju, D. V., Radhakrishnan, C., Palot, M. J. and Kalesh, S. (2011). Nine new species of frogs of the genus Raorchestes (Amphibia: Anura: Rhacophoridae) from southern Western Ghats, India. Biosystematica 5: 2548 .

Table 1. Collection localities of Micrixalus species discussed in the text. Localities are arranged by State. Species described in the present study are shown in bold.

\begin{tabular}{|c|c|c|c|c|}
\hline \multirow[t]{2}{*}{ Locality } & \multirow{2}{*}{$\begin{array}{l}\text { Altitude } \\
\text { (meters) }\end{array}$} & \multicolumn{2}{|c|}{ Coordinates } & \multirow[t]{2}{*}{ Species recorded } \\
\hline & & Latitude $\left({ }^{\circ} \mathrm{N}\right)$ & Longitude $\left({ }^{\circ} \mathrm{E}\right)$ & \\
\hline \multicolumn{5}{|c|}{ INDIA } \\
\hline \multicolumn{5}{|c|}{ Tamil Nadu } \\
\hline \multicolumn{5}{|l|}{ Coimbatore district } \\
\hline Andiparai shola, Valparai & 600 & 10.3669 & 76.967 & M. nelliyampathi \\
\hline Grass hills & 1800 & 10.3166 & 77.0667 & M. frigidus, M. nelliyampathi \\
\hline Puthuthottam, Valparai & 1142 & 10.3438 & 76.9711 & M. nelliyampathi \\
\hline \multicolumn{5}{|l|}{ Dindigul district } \\
\hline Kodaikanal & 1780 & 10.2333 & 77.4833 & M. nigraventris \\
\hline \multicolumn{5}{|l|}{ Kanyakumari district } \\
\hline Glenback estate, Kiriparai & 450 & 08.4188 & 77.4182 & M. herrei \\
\hline \multicolumn{5}{|l|}{ Nilgiris district } \\
\hline Avalanche & 2000 & 11.2667 & 76.5667 & M. phyllophilus \\
\hline Coonoor & 1397 & 11.3328 & 76.8087 & M. spelunca \\
\hline Longwood shola, Kotagiri & 1960 & 11.4353 & 76.8763 & M. phyllophilus \\
\hline Mukkurthi National Park & 2139 & 11.3818 & 76.5485 & M. phyllophilus \\
\hline Naduvattam & 1890 & 11.3833 & 76.5667 & M. phyllophilus \\
\hline \multicolumn{5}{|l|}{ Tirunelveli district } \\
\hline Puthericharium, Shencottah & 140 & 08.9833 & 77.2944 & M. herrei \\
\hline Kakkachi 1 & 1200 & 08.5443 & 77.4278 & M. fuscus, M. kodayari \\
\hline Kakkachi 2 & 1289 & 08.5507 & 77.3916 & M. fuscus \\
\hline Kakkachi 3 & 1294 & 08.5492 & 77.3858 & M. fuscus \\
\hline Kodayar & 1346 & 08.5243 & 77.5069 & M. kodayari \\
\hline \multirow[t]{2}{*}{ Sengaltheri } & 1000 & 08.5371 & 77.4544 & M. fuscus \\
\hline & \multicolumn{4}{|c|}{ Kerala } \\
\hline \multicolumn{5}{|l|}{ Idukki district } \\
\hline Kadalar estate 1, Munnar & 1414 & 10.1324 & 76.9995 & M. adonis \\
\hline Kadalar estate 2, Munnar & 1429 & 10.1311 & 77.0005 & M. silvaticus \\
\hline Letchmi estate, Sevenmallay & 1519 & 10.0668 & 77.0024 & M. adonis \\
\hline Sevenmallay & 1476 & 10.0833 & 77.1333 & M. adonis \\
\hline Thekkady 1 , Periyar TR & 929 & 09.5857 & 77.1621 & M. adonis, M. gadgili \\
\hline Thekkady 2, Periyar TR & 980 & 09.5803 & 77.1593 & M. gadgili \\
\hline Eravikulam National Park 1 & 2105 & 10.1846 & 77.0900 & M. nigraventris \\
\hline Eravikulam National Park 2 & 2150 & 10.3498 & 77.1997 & M. frigidus \\
\hline \multicolumn{5}{|l|}{ Kannur district } \\
\hline Aralam WLS & 461 & 11.9406 & 75.8658 & M. saxicola \\
\hline Meenmutty, Aralam WLS & 358 & 11.9384 & 75.8573 & M. elegans, $M$. saxicola \\
\hline \multicolumn{5}{|l|}{ Kollam district } \\
\hline Kovachal, Shendurney WLS & 816 & 08.8497 & 77.1759 & M. herrei \\
\hline Pandimotta, Shendurney WLS & 1221 & 08.8265 & 77.2122 & M. mallani \\
\hline \multicolumn{5}{|l|}{ Palakkad district } \\
\hline Kesavapara, Nelliyampathy & 923 & 10.5243 & 76.6673 & M. gadgili, M. nelliyampathi \\
\hline Poopara, Parambikulam TR & 955 & 10.3516 & 76.8215 & M. nelliyampathi \\
\hline
\end{tabular}


Sairandhri, Silent Valley

Kuddam, Siruvani

Singappara, Siruvani

Pathanamthitta district

Gavi

Sabarimala

Thiruvananthapuram district

Athirimala

Attayar 1, Agasthyamala hills

Attayar 2, Agasthyamala hills

Chathankod

Chathankod-Bonnacaud

Kallar, Ponmudi

Pandipath, Agasthyamala hills

Ponkalapara

Ponmudi

Wayanad district

Banasura

Chethalayam falls, Kurichiat

Kurichiyarmala 1

Kurichiyarmala 2

Periya

Settukunnu

Suganthagiri

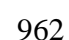

758

880

1143

1108

1425

605

680

116

488

180

1323

1370

1005

1560

870

1210

1167

730

823

1300
11.0949

10.9696

10.9789

09.7491

09.3180

08.7934

08.6341

08.6545

08.6608

08.6737

08.8490

08.6795

08.6247

08.7681

11.6893

11.7603

11.6006

11.5989

11.8336

11.6172

11.6356
76.4505

76.6545

76.6154

77.1427

77.1407

77.3424

77.2093

77.1905

77.1525

77.1575

77.1322

77.1933

77.2425

77.1096

75.8956

76.2520

75.9664

75.9769

75.8570

75.9913

76.1270
M. sairandhri, M. thampii

M. thampii

M. thampii

M. gadgili

M. gadgili, M. mallani

M. fuscus, M. mallani

$M$. herrei

$M$. herrei

$M$. herrei

M. herrei

M. herrei

M. fuscus

M. mallani

M. sali

M. saxicola

M. nudis

M. kurichiyari

M. saxicola

M. saxicola

M. saxicola

M. saxicola

\begin{tabular}{|c|c|c|c|c|}
\hline \multicolumn{5}{|c|}{ Karnataka } \\
\hline \multicolumn{5}{|l|}{ Chikmagalur district } \\
\hline Kemmanagundi & 865 & 13.3000 & 75.4500 & M. candidus, M. kottigeharensis \\
\hline Kottigehara 1 & 798 & 13.2084 & 75.8316 & M. candidus, M. kottigeharensis \\
\hline Kottigehara 2 & 850 & 13.1241 & 75.4954 & M. kottigeharensis \\
\hline Muthodi & 1100 & 13.5650 & 75.6232 & M. kottigeharensis \\
\hline \multicolumn{5}{|l|}{ Dakshina Kannada district } \\
\hline Charmadi Ghats 1 & 489 & 13.0753 & 75.4552 & M. kottigeharensis, M. saxicola \\
\hline Charmadi Ghats 2 & 608 & 13.0798 & 75.4650 & M. elegans \\
\hline Charmadi Ghats 3 & 929 & 13.1184 & 75.5103 & M. specca \\
\hline \multicolumn{5}{|l|}{ Hassan district } \\
\hline Kempholay & 880 & 12.8567 & 75.6955 & M. elegans, M. saxicola \\
\hline Maranhalli, Sakleshpur & 761 & 12.8680 & 75.7032 & $\begin{array}{l}\text { M. elegans, M.kottigeharensis, } \\
\text { M. saxicola }\end{array}$ \\
\hline Sakleshpur & 840 & 13.0833 & 75.7000 & M. elegans, M. saxicola \\
\hline \multicolumn{5}{|l|}{ Kodagu district } \\
\hline Bhagamandala & 921 & 12.4012 & 75.5435 & M. elegans \\
\hline Yavakapady 1 , Coorg & 1187 & 12.2169 & 75.6588 & M. elegans, M. saxicola \\
\hline Yavakapady 2 Coorg & 1146 & 12.2189 & 75.6573 & M. elegans \\
\hline Yavakapady 3, Coorg & 1102 & 12.2201 & 75.6557 & M. elegans \\
\hline \multicolumn{5}{|l|}{ Shimoga district } \\
\hline Niluvase & 686 & 13.7393 & 75.1082 & M. niluvasei \\
\hline \multicolumn{5}{|l|}{ Uttara Kannada district } \\
\hline Kathlekan & 554 & 14.2739 & 74.7469 & M. kottigeharensis \\
\hline Unchalli falls & 444 & 14.4091 & 74.7468 & M. kottigeharensis, M. saxicola \\
\hline Waddighat, Yana & 411 & 14.6112 & 74.5571 & M. kottigeharensis \\
\hline \multicolumn{5}{|c|}{ Maharashtra } \\
\hline $\begin{array}{l}\text { Sindhudurg district } \\
\text { Amboli }\end{array}$ & 781 & 15.9496 & 74.0002 & M. uttaraghati \\
\hline \multicolumn{5}{|c|}{ Colonial locations } \\
\hline "Anamallays" & - & - & - & M. fuscus? \\
\hline & - & - & - & M. fuscus?, M. silvaticus, \\
\hline "Malabar" & & & & M. saxicola \\
\hline "Nilgherries" & - & - & - & M. phyllophilus \\
\hline "Sevagherry" & - & - & - & M. fuscus \\
\hline "Torocata" & - & - & - & M. fuscus? \\
\hline "Travancore" & - & - & - & M. fuscus \\
\hline
\end{tabular}


Table 2. List of $16 \mathrm{~S}$ and COI gene sequences used in the study for intra and interspecific pairwise comparisons and barcoding of Micrixalus species. Species are arranged alphabetically.

\begin{tabular}{|c|c|c|c|c|}
\hline \multirow[b]{2}{*}{ Species } & \multirow[b]{2}{*}{ Collection Locality } & \multirow[b]{2}{*}{ Voucher Number } & \multicolumn{2}{|c|}{ Accession Number } \\
\hline & & & $16 \mathrm{~S}$ & $\mathrm{COI}$ \\
\hline \multirow{5}{*}{ Micrixalus adonis sp. nov. } & Kadalar estate & BNHS 5662 & KJ711257 & KJ711395 \\
\hline & Kadalar estate & BNHS 5663 & KJ711258 & KJ711396 \\
\hline & Letchmi estate & BNHS 5667 & KJ711259 & KJ711397 \\
\hline & Sevenmallay & BNHS 5656 & KJ711260 & KJ711398 \\
\hline & Thekkady & BNHS 5668 & KJ711261 & KJ711399 \\
\hline \multirow[t]{2}{*}{ Micrixalus candidus sp. nov. } & Kemmanagundi & BNHS 5608 & KJ711262 & KJ711400 \\
\hline & Kottigehara & BNHS 5609 & KJ711263 & KJ711401 \\
\hline \multirow[t]{12}{*}{ Micrixalus elegans } & Bhagamandala & BNHS 5617 & KJ711264 & KJ711402 \\
\hline & Charmadi Ghats & SDBDU 2011.1397 & KJ711265 & KJ711403 \\
\hline & Kempholay & BNHS 5612 & KJ711266 & KJ711404 \\
\hline & Kempholay & SDBDU 2010.003 & KJ711267 & KJ711405 \\
\hline & Kempholay & BNHS 5613 & KJ711268 & KJ711406 \\
\hline & Kempholay & BNHS 5808 & KJ711269 & KJ711407 \\
\hline & Maranhalli & BNHS 5616 & KJ711270 & KJ711408 \\
\hline & Maranhalli & BNHS 5614 & KJ711271 & KJ711409 \\
\hline & Meenmutty & SDBDU 2008.412 & KJ711272 & KJ711410 \\
\hline & Yavakapady & BNHS 5620 & KJ711273 & KJ711411 \\
\hline & Yavakapady & BNHS 5618 & KJ711274 & KJ711412 \\
\hline & Yavakapady & BNHS 5619 & KJ711275 & $\mathrm{KJ} 711413$ \\
\hline \multirow{2}{*}{ Micrixalus frigidus sp. nov. } & Eravikulam NP & BNHS 5788 & KJ711276 & KJ711414 \\
\hline & Grass hills & BNHS 5790 & KJ711277 & KJ711415 \\
\hline \multirow[t]{7}{*}{ Micrixalus fuscus } & Kakkachi & SDBDU 2002.2047 & KJ711278 & KJ711416 \\
\hline & Kakkachi & BNHS 5669 & KJ711279 & KJ711417 \\
\hline & Kakkachi & BNHS 5670 & KJ711280 & KJ711418 \\
\hline & Kakkachi & SDBDU 2006.2299 & KJ711281 & - \\
\hline & Pandipath & BNHS 5676 & KJ711282 & KJ711419 \\
\hline & Sengaltheri & SDBDU 2002.874 & KJ711283 & KJ711420 \\
\hline & Sengaltheri & BNHS 5673 & KJ711284 & KJ711421 \\
\hline \multirow[t]{7}{*}{ Micrixalus gadgili } & Kesavapara & SDBDU 2011.1148 & KJ711285 & KJ711422 \\
\hline & Kesavapara & SDBDU 2011.1149 & KJ711286 & KJ711423 \\
\hline & Sabarimala & BNHS 5714 & KJ711287 & KJ711424 \\
\hline & Thekkady & SDBDU 2006.4801 & KJ711288 & KJ711425 \\
\hline & Thekkady & BNHS 5719 & KJ711289 & KJ711426 \\
\hline & Thekkady & SDBDU 2012.1842 & KJ711290 & KJ711427 \\
\hline & Thekkady & SDBDU 2012.1843 & KJ711291 & KJ711428 \\
\hline \multirow[t]{10}{*}{ Micrixalus herrei } & Attayar & SDBDU 2012.2314 & KJ711292 & KJ711429 \\
\hline & Chathankod & SDBDU 2006.4766 & KJ711293 & KJ711430 \\
\hline & Chathankod & SDBDU 2009.106 & KJ711294 & KJ711431 \\
\hline & Chathankod & BNHS 5681 & KJ711295 & KJ711432 \\
\hline & Chathankod & BNHS 5683 & KJ711296 & KJ711433 \\
\hline & Glenback estate & BNHS 5687 & KJ711297 & KJ711434 \\
\hline & Kallar & BNHS 5678 & KJ711298 & KJ711435 \\
\hline & Kallar & BNHS 5677 & KJ711299 & KJ711436 \\
\hline & Kovachal & SDBDU 2011.918 & KJ711300 & KJ711437 \\
\hline & Puthericharium & SDBDU 2002.4054 & KJ711301 & KJ711438 \\
\hline \multirow[t]{2}{*}{ Micrixalus kodayari sp. nov. } & Kakkachi & BNHS 5692 & KJ711302 & KJ711439 \\
\hline & Kodayar & BNHS 5689 & KJ711303 & - \\
\hline \multirow[t]{11}{*}{ Micrixalus kottigeharensis } & Charmadi Ghats & BNHS 5750 & KJ711304 & KJ711440 \\
\hline & Kathlekan & BNHS 5758 & KJ711305 & KJ711441 \\
\hline & Kathlekan & BNHS 5755 & KJ711306 & KJ711442 \\
\hline & Kemmanagundi & SDBDU 2003.40268 & KJ711307 & KJ711443 \\
\hline & Kemmanagundi & SDBDU 2010.005 & KJ711308 & KJ711444 \\
\hline & Kemmanagundi & BNHS 5749 & KJ711309 & - \\
\hline & Kottigehara & BNHS 5747 & KJ711310 & KJ711445 \\
\hline & Kottigehara & SDBDU 2010.124 & KJ711311 & KJ711446 \\
\hline & Kottigehara & SDBDU 2012.55 & KJ711312 & KJ711447 \\
\hline & Kottigehara & SDBDU 2012.62 & KJ711313 & KJ711448 \\
\hline & Maranhalli & BNHS 5754 & KJ711314 & KJ711449 \\
\hline
\end{tabular}




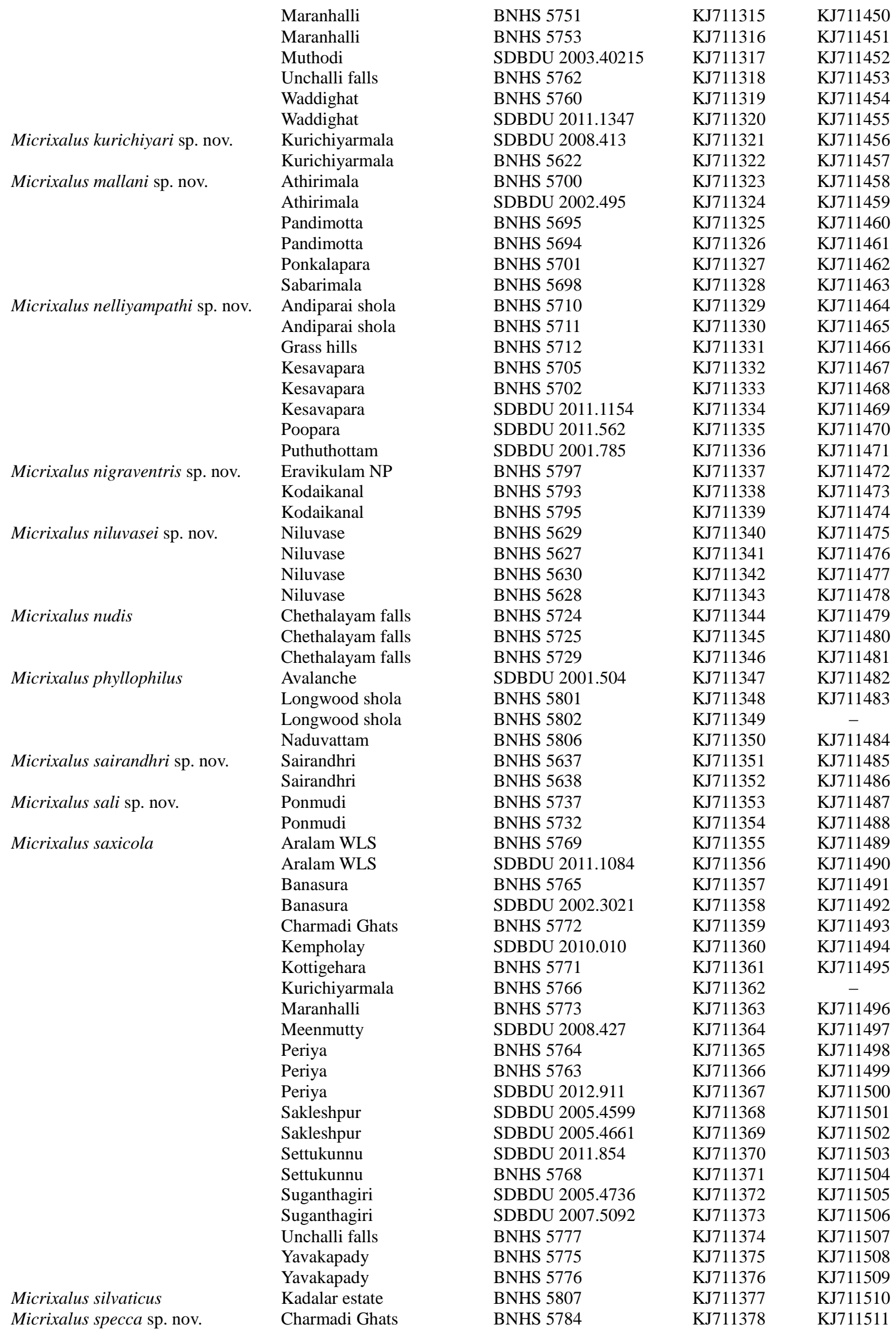




\begin{tabular}{|c|c|c|c|c|}
\hline & Charmadi Ghats & BNHS 5785 & KJ711379 & KJ711512 \\
\hline \multirow{3}{*}{ Micrixalus spelunca sp. nov. } & Coonoor & SDBDU 2005.4731 & KJ711380 & KJ711513 \\
\hline & Coonoor & BNHS 5644 & KJ711381 & KJ711514 \\
\hline & Coonoor & BNHS 5645 & KJ711382 & KJ711515 \\
\hline \multirow[t]{9}{*}{ Micrixalus thampii } & Kuddam & BNHS 5746 & KJ711383 & KJ711516 \\
\hline & Kuddam & SDBDU 2011.1271 & KJ711384 & KJ711517 \\
\hline & Kuddam & BNHS 5744 & KJ711385 & KJ711518 \\
\hline & Sairandhri & BNHS 5739 & KJ711386 & KJ711519 \\
\hline & Sairandhri & BNHS 5738 & KJ711387 & KJ711520 \\
\hline & Sairandhri & SDBDU 2010.131 & KJ711388 & KJ711521 \\
\hline & Sairandhri & BNHS 5743 & KJ711389 & KJ711522 \\
\hline & Sairandhri & SDBDU 2011.963 & KJ711390 & KJ711523 \\
\hline & Singappara & SDBDU 2011.1226 & KJ711391 & - \\
\hline \multirow[t]{2}{*}{ Micrixalus uttaraghati sp. nov. } & Amboli & SDBDU 2007.6084 & KJ711392 & KJ711524 \\
\hline & Amboli & BNHS 5648 & KJ711393 & KJ711525 \\
\hline \multicolumn{5}{|l|}{ Out group } \\
\hline Nyctibatrachus sp. & Nelliyampathy, Kerala & SDBDU 2011.1138 & KJ711394 & KJ711526 \\
\hline
\end{tabular}

Table 3. Uncorrected intraspecific pairwise distances in Micrixalus species for 16S and COI genes. Mean, standard deviation (SD), minimum (Min) and maximum (Max) values are provided over all pairwise comparisons among individuals or populations of a species. $N$ is the number of sequenced individuals. The original pairwise distances are shown in percentage. Species described in the present study are shown in bold.

\begin{tabular}{|c|c|c|c|c|c|c|c|c|c|c|}
\hline \multirow[b]{2}{*}{ Species } & \multicolumn{5}{|c|}{$16 S$} & \multicolumn{5}{|c|}{ COI } \\
\hline & $\mathbf{N}$ & Mean & SD & Min & Max & $\mathbf{N}$ & Mean & SD & Min & Max \\
\hline M. adonis & 5 & 0.7 & 0.5 & 0.0 & 1.7 & 5 & 2.4 & 2.7 & 0.2 & 5.7 \\
\hline M. candidus & 2 & 0.6 & - & - & - & 2 & 2.0 & 2.0 & - & - \\
\hline M. elegans & 12 & 0.4 & 0.3 & 0.0 & 1.1 & 12 & 0.3 & 0.2 & 0.0 & 0.7 \\
\hline M. frigidus & 2 & 0.0 & - & - & - & 2 & 0.0 & - & - & - \\
\hline M. fuscus & 7 & 0.1 & 0.2 & 0.0 & 0.4 & 6 & 0.3 & 0.2 & 0.0 & 6.6 \\
\hline M. gadgili & 7 & 0.8 & 0.7 & 0.0 & 1.9 & 7 & 2.6 & 2.4 & 0.0 & 5.1 \\
\hline M. herrei & 10 & 1.1 & 1.1 & 0.0 & 2.5 & 10 & 0.2 & 0.3 & 0.0 & 0.8 \\
\hline M. kodayari & 2 & 0.0 & - & - & - & 1 & - & - & - & - \\
\hline M. kottigeharensis & 17 & 0.7 & 0.6 & 0.0 & 1.5 & 16 & 5.2 & 3.4 & 0.0 & 8.5 \\
\hline M. kurichiyari & 2 & 0.0 & - & - & - & 2 & 0.5 & - & - & - \\
\hline M. mallani & 6 & 0.7 & 0.6 & 0.0 & 1.7 & 6 & 0.8 & 0.9 & 0.0 & 2.1 \\
\hline M. nelliyampathi & 8 & 0.7 & 0.5 & 0.0 & 1.3 & 8 & 0.6 & 0.4 & 0.0 & 1.1 \\
\hline M. nigraventris & 3 & 0.5 & 0.4 & 0.0 & 0.8 & 3 & 2.4 & 2.1 & 0.0 & 3.6 \\
\hline M. niluvasei & 4 & 0.0 & 0.0 & 0.0 & 0.0 & 4 & 0.1 & 0.1 & 0.0 & 0.2 \\
\hline M. nudis & 3 & 0.0 & 0.0 & 0.0 & 0.0 & 3 & 0.0 & 0.0 & 0.0 & 0.0 \\
\hline M. phyllophilus & 4 & 0.9 & 0.5 & 0.0 & 1.3 & 3 & 3.8 & 0.7 & 0.0 & 4.6 \\
\hline M. sairandhri & 2 & 0.0 & - & - & - & 2 & 0.2 & - & - & - \\
\hline M. sali & 2 & 0.04 & - & - & - & 2 & 0.5 & - & - & - \\
\hline M. saxicola & 22 & 0.8 & 0.6 & 0.0 & 2.3 & 21 & 2.1 & 1.3 & 0.0 & 3.7 \\
\hline M. silvaticus & 1 & - & - & - & - & 1 & - & - & - & - \\
\hline M. specca & 2 & 0.2 & - & - & - & 2 & 0.0 & - & - & - \\
\hline M. spelunca & 3 & 0.0 & 0.0 & 0.0 & 0.0 & 3 & 0.0 & 0.0 & 0.0 & 0.0 \\
\hline M. thampii & 9 & 0.6 & 0.6 & 0.0 & 1.5 & 8 & 1.9 & 2.0 & 0.0 & 4.3 \\
\hline M. uttaraghati & 2 & 0.0 & - & - & - & 2 & 0.0 & - & - & - \\
\hline
\end{tabular}


Table 4. Uncorrected nterspecific pairwise distances between closely related Micrixalus species (based on individual NJ trees). Mean, standard deviation, minimum and maximum values are provided over all pairwise comparisons of individuals sequenced from the two species being compared. $N$ is the number of pairwise comparisons. The original $p$-distances are shown as percentages.

\begin{tabular}{|c|c|c|c|c|c|c|c|c|c|c|c|c|c|}
\hline \multicolumn{7}{|c|}{$16 \mathrm{~S}$} & \multicolumn{7}{|c|}{ COI } \\
\hline Species 1 & Species 2 & $\mathbf{N}$ & Mean & SD & Min & Max & Species 1 & Species 2 & $\mathbf{N}$ & Mean & SD & Min & Max \\
\hline M. adonis & M. herrei & 50 & 4.8 & 0.5 & 4.2 & 5.7 & M. adonis & M. nelliyampathi & 40 & 10.9 & 0.5 & 9.8 & 11.5 \\
\hline M. adonis & M. nellivampathi & 40 & 4.2 & 0.6 & 3.2 & 5.5 & M. adonis & M. herrei & 50 & 14.0 & 0.5 & 12.9 & 14.9 \\
\hline M. adonis & M. fuscus & 35 & 5.0 & 0.1 & 4.6 & 5.2 & M. adonis & M. mallani & 30 & 13.9 & 0.3 & 13.3 & 14.3 \\
\hline M. adonis & M. mallani & 30 & 5.1 & 0.4 & 4.7 & 6.1 & M. adonis & M. fuscus & 30 & 12.5 & 0.3 & 12.1 & 12.9 \\
\hline M. herrei & M. nelliyampathi & 80 & 3.9 & 0.7 & 3.0 & 5.3 & M. adonis & M. kodayari & 5 & 14.4 & 0.2 & 14.2 & 14.6 \\
\hline M. herrei & M. fuscus & 70 & 5.6 & 0.2 & 5.1 & 6.1 & M. nelliyampathi & M. herrei & 80 & 11.6 & 0.5 & 11.0 & 12.8 \\
\hline M. herrei & M. mallani & 60 & 4.8 & 0.6 & 4.2 & 6.0 & M. nelliyampathi & M. mallani & 48 & 11.5 & 0.4 & 10.6 & 12.3 \\
\hline M. nelliyampathi & M. fuscus & 56 & 4.2 & 0.3 & 3.1 & 4.6 & M. nelliyampathi & M. fuscus & 48 & 9.7 & 0.1 & 9.5 & 10.0 \\
\hline M. nelliyampathi & M. mallani & 48 & 4.1 & 0.2 & 3.8 & 4.4 & M. nelliyampathi & M. kodayari & 8 & 15.1 & 0.1 & 14.9 & 15.2 \\
\hline M. fuscus & M. mallani & 42 & 5.4 & 0.2 & 4.9 & 5.6 & M. herrei & M. mallani & 60 & 9.6 & 0.6 & 8.2 & 10.5 \\
\hline M. candidus & M. niluvasei & 8 & 7.7 & 0.1 & 7.6 & 7.8 & M. herrei & M. fuscus & 60 & 12.6 & 0.1 & 12.4 & 13.0 \\
\hline M. candidus & M. kurichiyari & 4 & 5.8 & 0.1 & 5.7 & 5.9 & M. herrei & M. kodayari & 10 & 15.3 & 0.1 & 15.2 & 15.4 \\
\hline M. candidus & M. uttaraghati & 4 & 7.6 & 0.01 & 7.59 & 7.6 & M. mallani & M. fuscus & 36 & 12.7 & 0.4 & 11.8 & 13.3 \\
\hline M. niluvasei & M. kurichiyari & 8 & 7.8 & 0.0 & - & - & M. mallani & M. kodayari & 6 & 15.0 & 0.1 & 14.9 & 15.1 \\
\hline M. niluvasei & M. uttaraghati & 8 & 8.2 & 0.0 & - & - & M. fuscus & M. kodayari & 6 & 12.5 & 0.1 & 12.4 & 12.7 \\
\hline M. kurichiyari & M. uttaraghati & 4 & 7.6 & 0.0 & - & - & M. silvaticus & M. frigidus & 2 & 11.8 & - & - & - \\
\hline M. sali & M. gadgili & 14 & 4.2 & 0.3 & 3.6 & 4.8 & M. silvaticus & M. nigraventris & 3 & 14.4 & 0.1 & 14.3 & 14.4 \\
\hline M. sali & M. silvaticus & 2 & 8.8 & 0.02 & 8.78 & 8.80 & M. silvaticus & M. phyllophilus & 3 & 17.5 & 0.1 & 17.4 & 17.6 \\
\hline M. sali & M. frigidus & 4 & 8.9 & 0.1 & 8.8 & 9.0 & M. frigidus & M. nigraventris & 6 & 15.1 & 0.2 & 14.9 & 15.2 \\
\hline M. sali & M. nigraventris & 6 & 9.2 & 0.4 & 8.6 & 9.6 & M. frigidus & M. phyllophilus & 6 & 15.2 & 0.2 & 15.1 & 15.4 \\
\hline M. sali & M. kodayari & 4 & 8.6 & 0.01 & 8.57 & 8.59 & M. nigraventris & M. phyllophilus & 9 & 14.6 & 0.4 & 13.9 & 15.2 \\
\hline M. sali & M. phyllophilus & 8 & 7.8 & 0.2 & 7.6 & 8.2 & M. sali & M. gadgili & 14 & 7.0 & 0.3 & 6.5 & 7.7 \\
\hline M. gadgili & M. silvaticus & 7 & 10.2 & 0.2 & 10.1 & 10.5 & M. sali & M. candidus & 4 & 17.6 & 0.1 & 17.6 & 17.7 \\
\hline M. gadgili & M. frigidus & 14 & 9.7 & 0.2 & 9.3 & 9.9 & M. sali & M. kurichiyari & 4 & 16.1 & 0.1 & 15.9 & 16.2 \\
\hline M. gadgili & M. nigraventris & 21 & 10.7 & 0.3 & 10.1 & 11.2 & M. sali & M. uttaraghati & 4 & 16.2 & 0.2 & 16.1 & 16.4 \\
\hline M. gadgili & M. kodayari & 14 & 9.7 & 0.1 & 9.7 & 9.9 & M. sali & M. sairandhri & 4 & 16.8 & 0.2 & 16.5 & 17.1 \\
\hline M. gadgili & M. phyllophilus & 28 & 8.1 & 0.3 & 7.6 & 8.7 & M. gadgili & M. candidus & 14 & 18.9 & 0.6 & 18.0 & 19.5 \\
\hline M. silvaticus & M. frigidus & 2 & 5.0 & 0.0 & - & - & M. gadgili & M. kurichiyari & 14 & 17.6 & 0.1 & 17.3 & 17.7 \\
\hline M. silvaticus & M. nigraventris & 3 & 9.0 & 0.3 & 8.6 & 9.1 & M. gadgili & M. uttaraghati & 14 & 15.9 & 0.7 & 14.9 & 16.4 \\
\hline M. silvaticus & M. kodayari & 2 & 9.5 & 0.0 & - & - & M. gadgili & M. sairandhri & 14 & 16.3 & 0.1 & 16.2 & 16.5 \\
\hline M. silvaticus & M. phyllophilus & 5 & 9.0 & 0.3 & 8.8 & 9.3 & M. candidus & M. kurichiyari & 4 & 10.7 & 0.2 & 10.5 & 11.0 \\
\hline M. frigidus & M. nigraventris & 6 & 7.2 & 0.3 & 6.9 & 7.4 & M. candidus & M. uttaraghati & 4 & 17.5 & 0.2 & 17.4 & 17.7 \\
\hline M. frigidus & M. kodayari & 4 & 8.8 & 0.0 & - & - & M. candidus & M. sairandhri & 4 & 17.9 & 0.2 & 17.7 & 18.2 \\
\hline M. frigidus & M. phyllophilus & 8 & 8.2 & 0.2 & 8.0 & 8.4 & M. kurichiyari & M. uttaraghati & 4 & 16.3 & 0.1 & 16.2 & 16.4 \\
\hline M. nigraventris & M. kodayari & 6 & 9.2 & 0.2 & 9.0 & 9.3 & M. kurichiyari & M. sairandhri & 4 & 17.3 & 0.1 & 17.2 & 17.3 \\
\hline
\end{tabular}




\begin{tabular}{|c|c|c|c|c|c|c|c|c|c|c|c|c|c|}
\hline M. nigraventris & M. phyllophilus & 12 & 7.8 & 0.2 & 7.4 & 8.0 & M. uttaraghati & M. sairandhri & 4 & 14.0 & 0.1 & 13.9 & 14.1 \\
\hline M. kodayari & M. phyllophilus & 8 & 6.8 & 0.2 & 6.5 & 7.0 & M. elegans & M. thampii & 96 & 9.0 & 0.2 & 8.7 & 9.3 \\
\hline M. saxicola & M. kottigeharensis & 374 & 4.3 & 0.4 & 3.4 & 5.7 & M. elegans & M. nudis & 36 & 9.3 & 0.2 & 9.2 & 9.5 \\
\hline M. saxicola & M. specca & 44 & 4.6 & 0.3 & 4.0 & 5.1 & M. elegans & M. spelunca & 36 & 13.8 & 0.1 & 13.6 & 13.9 \\
\hline M. kottigeharensis & M. specca & 34 & 5.0 & 0.5 & 4.0 & 5.5 & M. elegans & M. niluvasei & 48 & 17.0 & 0.1 & 16.9 & 17.3 \\
\hline M. sairandhri & M. spelunca & 6 & 11.3 & 0.0 & - & - & M. thampii & M. nudis & 24 & 6.4 & 0.5 & 6.1 & 7.4 \\
\hline M. elegans & M. nudis & 36 & 2.7 & 0.2 & 2.3 & 3.1 & M. thampii & M. spelunca & 24 & 12.6 & 0.2 & 12.3 & 12.9 \\
\hline M. elegans & M. thampii & 108 & 3.1 & 0.1 & 2.9 & 3.4 & M. thampii & M. niluvasei & 32 & 16.5 & 0.2 & 16.2 & 16.9 \\
\hline \multirow[t]{6}{*}{ M. nudis } & M. thampii & 27 & 2.1 & 0.1 & 2.1 & 2.3 & M. nudis & M. spelunca & 9 & 13.1 & 0.0 & - & - \\
\hline & & & & & & & M. nudis & M. niluvasei & 12 & 16.3 & 0.1 & 16.2 & 16.4 \\
\hline & & & & & & & M. spelunca & M. niluvasei & 12 & 16.0 & 0.1 & 15.9 & 16.0 \\
\hline & & & & & & & M. saxicola & M. specca & 42 & 14.0 & 0.4 & 13.3 & 14.9 \\
\hline & & & & & & & M. saxicola & M. kottigeharensis & 336 & 12.2 & 0.7 & 11.0 & 13.6 \\
\hline & & & & & & & M. specca & M. kottigeharensis & 32 & 14.1 & 0.3 & 13.4 & 14.6 \\
\hline
\end{tabular}

Table 5. Morphometric measurements (in mm) of the specimens used in this study. Status of specimens is given after the Museum number. Abbreviations are defined in the materials and methods. Species are arranged by 'Taxonomic groups'.

\begin{tabular}{|c|c|c|c|c|c|c|c|c|c|c|c|c|c|c|c|c|c|c|c|}
\hline Species & Sex & Locality & Museum Number & SVL & HW & HL & TYD & SL & IUE & UEW & MN & EN & NS & EL & FAL & HAL & TL & SHL & FOL \\
\hline \multicolumn{20}{|c|}{ Micrixalus elegans GROUP } \\
\hline \multicolumn{20}{|c|}{ Micrixalus candidus sp. nov. } \\
\hline & M & Kemmanagundi & BNHS 5608 (HT) & 20.2 & 6.2 & 7.1 & 0.6 & 3.1 & 1.5 & 1.0 & 5.2 & 1.4 & 1.1 & 2.5 & 3.7 & 5.0 & 9.7 & 9.7 & 8.2 \\
\hline & M & Kottigehara & BNHS 5609 (PT) & 16.6 & 5.5 & 6.2 & 0.6 & 2.5 & 1.3 & 1.1 & 5.4 & 1.4 & 0.9 & 2.1 & 3.6 & 4.4 & 9.7 & 9.3 & 8.0 \\
\hline & M & Kottigehara & BNHS $5610(\mathrm{PT})$ & 13.0 & 4.7 & 4.9 & 0.5 & 2.1 & 1.4 & 0.9 & 3.5 & 0.9 & 0.8 & 1.8 & 2.4 & 3.7 & 8.4 & 7.7 & 7.5 \\
\hline & M & Kottigehara & BNHS 5611 (PT) & 11.6 & 5.3 & 6.1 & 0.5 & 2.4 & 1.6 & 1.1 & 4.8 & 1.2 & 0.9 & 1.5 & 3.3 & 3.3 & 7.9 & 7.6 & 7.4 \\
\hline & & & Average & 15.4 & 5.4 & 6.1 & 0.6 & 2.5 & 1.5 & 1.0 & 4.7 & 1.2 & 0.9 & 2.0 & 3.3 & 4.1 & 8.9 & 8.6 & 7.8 \\
\hline & & & Standard deviation & 3.9 & 0.6 & 0.9 & 0.1 & 0.4 & 0.1 & 0.1 & 0.9 & 0.2 & 0.1 & 0.4 & 0.6 & 0.8 & 0.9 & 1.1 & 0.4 \\
\hline \multicolumn{20}{|c|}{ Micrixalus elegans } \\
\hline & M & Kempholay & BNHS 5612 (RS) & 15.5 & 5.0 & 5.2 & 0.7 & 2.4 & 1.8 & 0.8 & 4.0 & 1.1 & 0.9 & 1.7 & 3.0 & 3.8 & 7.6 & 7.6 & 7.1 \\
\hline & M & Kempholay & BNHS 5613 (RS) & 15.5 & 5.2 & 5.5 & 0.7 & 2.6 & 1.8 & 1.2 & 4.0 & 1.1 & 1.1 & 2.0 & 3.5 & 4.0 & 8.5 & 8.5 & 7.2 \\
\hline & M & Maranhalli & BNHS 5614 (RS) & 14.7 & 4.9 & 5.0 & 0.6 & 2.1 & 1.8 & 0.9 & 3.9 & 0.9 & 0.8 & 1.9 & 2.9 & 3.5 & 8.1 & 8.1 & 7.0 \\
\hline & M & Maranhalli & BNHS 5615 (RS) & 14.7 & 5.0 & 5.4 & 0.7 & 2.4 & 1.7 & 1.1 & 3.9 & 0.9 & 1.0 & 1.7 & 2.9 & 4.1 & 8.1 & 8.2 & 7.2 \\
\hline & M & Yavakapady & BNHS 5618 (RS) & 13.0 & 4.3 & 4.9 & 0.5 & 2.0 & 1.5 & 1.0 & 4.0 & 1.2 & 1.2 & 1.9 & 2.4 & 3.5 & 7.2 & 7.2 & 6.2 \\
\hline
\end{tabular}




\begin{tabular}{|c|c|c|c|c|c|c|c|c|c|c|c|c|c|c|c|c|c|c|c|}
\hline & & Average & 14.7 & 4.9 & 5.2 & 0.6 & 2.3 & 1.7 & 1.0 & 4.0 & 1.0 & 1.0 & 1.8 & 2.9 & 3.8 & 7.9 & 7.9 & 6.9 & $\bar{F}$ \\
\hline & & Standard deviation & 1.0 & 0.3 & 0.3 & 0.1 & 0.2 & 0.1 & 0.2 & 0.1 & 0.1 & 0.2 & 0.1 & 0.4 & 0.3 & 0.5 & 0.5 & 0.4 & \\
\hline $\mathrm{F}$ & Kempholay & BNHS 5808 (NT) & 21.0 & 6.4 & 7.0 & 0.8 & 3.5 & 2.7 & 1.2 & 5.7 & 1.6 & 1.6 & 2.4 & 4.2 & 5.6 & 10.6 & 10.5 & 8.0 & \\
\hline $\mathrm{F}$ & Maranhalli & BNHS 5616 (RS) & 19.0 & 5.2 & 5.8 & 0.8 & 3.0 & 2.4 & 1.1 & 5.0 & 1.3 & 1.3 & 2.0 & 3.3 & 5.0 & 10.1 & 9.9 & 8.6 & \\
\hline $\mathrm{F}$ & Bhagamandala & BNHS 5617 (RS) & 20.7 & 6.4 & 6.7 & 0.8 & 3.4 & 2.4 & 1.5 & 5.0 & 1.3 & 1.3 & 2,5 & 3.6 & 5.1 & 10.4 & 10.0 & 8.0 & \\
\hline $\mathrm{F}$ & Yavakapady & BNHS 5619 (RS) & 17.7 & 6.0 & 6.5 & 0.8 & 2.9 & 2.2 & 1.1 & 4.3 & 1.2 & 1.2 & 1.9 & 3.2 & 4.9 & 9.2 & 10.0 & 8.6 & \\
\hline $\mathrm{F}$ & Yavakapady & BNHS 5620 (RS) & 20.3 & 6.1 & 6.6 & 0.9 & 3.2 & 2.0 & 1.3 & 5.1 & 1.3 & 1.3 & 2.1 & 3.9 & 5.3 & 11.0 & 10.9 & 9.4 & \\
\hline & & Average & 19.7 & 6.0 & 6.5 & 0.8 & 3.2 & 2.3 & 1.2 & 5.0 & 1.3 & 1.3 & 2.1 & 3.6 & 5.2 & 10.3 & 10.3 & 8.5 & \\
\hline & & Standard deviation & 1.4 & 0.5 & 0.4 & 0.0 & 0.3 & 0.3 & 0.2 & 0.5 & 0.2 & 0.2 & 0.2 & 0.4 & 0.3 & 0.7 & 0.4 & 0.6 & \\
\hline kuric & yari sp. nov. & & & & & & & & & & & & & & & & & & \\
\hline M & Kurichiyarmala & BNHS 5621 (HT) & 18.6 & 6.1 & 7.3 & 1.0 & 3.2 & 2.3 & 1.5 & 5.4 & 1.5 & 1.5 & 2.6 & 4.0 & 5.0 & 9.1 & 9.8 & 9.2 & \\
\hline M & Kurichiyarmala & BNHS $5622(\mathrm{PT})$ & 19.7 & 6.0 & 7.1 & 1.0 & 3.1 & 2.2 & 1.4 & 5.7 & 1.3 & 1.4 & 2.5 & 3.9 & 5.1 & 9.2 & 9.7 & 9.5 & \\
\hline M & Kurichiyarmala & BNHS 5623 (PT) & 18.7 & 6.0 & 7.5 & 1.0 & 3.4 & 2.2 & 1.3 & 5.3 & 1.5 & 1.5 & 2.5 & 4.0 & 5.0 & 9.3 & 9.9 & 9.5 & \\
\hline M & Kurichiyarmala & BNHS $5624(\mathrm{PT})$ & 18.8 & 6.0 & 7.2 & 0.9 & 3.1 & 2.0 & 1.4 & 5.3 & 1.5 & 1.4 & 2.1 & 3.8 & 5.0 & 9.1 & 9.6 & 8.9 & \\
\hline M & Kurichiyarmala & BNHS 5625 (PT) & 17.4 & 6.0 & 7.1 & 0.9 & 3.0 & 2.0 & 1.3 & 5.4 & 1.4 & 1.4 & 2.3 & 3.7 & 5.0 & 9.1 & 9.7 & 9.1 & \\
\hline M & Kurichiyarmala & BNHS 5626 (PT) & 18.4 & 6.1 & 7.3 & 1.0 & 3.1 & 2.2 & 1.4 & 5.5 & 1.4 & 1.4 & 2.5 & 3.6 & 5.0 & 9.2 & 9.6 & 9.5 & \\
\hline & & Average & 18.6 & 6.0 & 7.3 & 1.0 & 3.2 & 2.2 & 1.4 & 5.4 & 1.4 & 1.4 & 2.4 & 3.8 & 5.0 & 9.2 & 9.7 & 9.3 & $\begin{array}{l}7 \\
2 \\
2\end{array}$ \\
\hline & & Standard deviation & 0.7 & 0.1 & 0.2 & 0.1 & 0.1 & 0.1 & 0.1 & 0.2 & 0.1 & 0.1 & 0.2 & 0.2 & 0.0 & 0.1 & 0.1 & 0.3 & $\stackrel{2}{2}$ \\
\hline niluv & $i$ sp.nov. & & & & & & & & & & & & & & & & & & \\
\hline M & Niluvase & BNHS 5627 (HT) & 15.5 & 4.9 & 5.3 & 0.4 & 1.8 & 1.8 & 1.2 & 4.4 & 0.9 & 0.5 & 1.2 & 2.9 & 3.6 & 8.8 & 8.7 & 6.9 & \\
\hline M & Niluvase & BNHS $5628(\mathrm{PT})$ & 16.2 & 5.4 & 6.1 & 0.6 & 2.4 & 1.9 & 1.1 & 4.9 & 1.0 & 0.4 & 1.8 & 3.0 & 4.0 & 8.7 & 8.9 & 7.1 & \\
\hline & & Average & 15.9 & 5.2 & 5.7 & 0.5 & 2.1 & 1.9 & 1.2 & 4.7 & 1.0 & 0.5 & 1.5 & 3.0 & 3.8 & 8.8 & 8.8 & 7.0 & \\
\hline & & Standard deviation & 0.4 & 0.3 & 0.4 & 0.1 & 0.3 & 0.0 & 0.0 & 0.3 & 0.1 & 0.1 & 0.3 & 0.1 & 0.2 & 0.1 & 0.1 & 0.1 & \\
\hline F & Niluvase & BNHS 5629 (PT) & 21.5 & 6.6 & 7.2 & 0.8 & 3.4 & 2.4 & 1.4 & 5.3 & 1.9 & 1.1 & 2.3 & 4.1 & 5.1 & 10.4 & 10.5 & 9.3 & \\
\hline F & Niluvase & BNHS $5630(\mathrm{PT})$ & 19.9 & 5.8 & 6.7 & 0.9 & 3.0 & 1.9 & 1.2 & 5.3 & 1.7 & 1.0 & 1.9 & 3.9 & 4.8 & 10.1 & 10.1 & 8.5 & \\
\hline $\mathrm{F}$ & Niluvase & BNHS 5631 (PT) & 19.8 & 6.3 & 6.6 & 0.7 & 2.7 & 1.9 & 1.1 & 4.9 & 1.8 & 1.1 & 2.1 & 3.7 & 4.6 & 10.0 & 9.9 & 8.7 & \\
\hline $\mathrm{F}$ & Niluvase & BNHS $5632(\mathrm{PT})$ & 20.7 & 6.0 & 7.0 & 1.0 & 2.8 & 1.8 & 1.2 & 5.6 & 1.6 & 1.1 & 1.9 & 4.0 & 5.0 & 10.6 & 10.6 & 9.4 & \\
\hline & & Average & 20.5 & 6.2 & 6.9 & 0.9 & 3.0 & 2.0 & 1.2 & 5.3 & 1.8 & 1.1 & 2.1 & 3.9 & 4.9 & 10.3 & 10.3 & 9.0 & \\
\hline & & Standard deviation & 0.8 & 0.4 & 0.3 & 0.1 & 0.3 & 0.3 & 0.1 & 0.3 & 0.1 & 0.1 & 0.2 & 0.2 & 0.2 & 0.3 & 0.3 & 0.4 & \\
\hline saira & hri sp.nov. & & & & & & & & & & & & & & & & & & \\
\hline M & Sairandhri & BNHS 5633 (HT) & 17.8 & 5.5 & 6.8 & 0.6 & 2.9 & 1.6 & 1.5 & 5.5 & 1.5 & 1.4 & 2.4 & 3.8 & 4.9 & 10.3 & 9.8 & 8.7 & \\
\hline M & Sairandhri & BNHS 5634 (PT) & 17.9 & 5.9 & 6.6 & 0.7 & 3.0 & 1.4 & 1.4 & 4.9 & 1.1 & 1.3 & 2.3 & 3.8 & 4.9 & 10.3 & 9.4 & 9.1 & \\
\hline M & Sairandhri & BNHS 5635 (PT) & 17.1 & 5.8 & 6.5 & 0.8 & 2.5 & 1.5 & 1.6 & 4.9 & 1.1 & 1.3 & 2.2 & 3.5 & 4.7 & 9.6 & 9.1 & 8.9 & \\
\hline
\end{tabular}




\section{Sairandhri \\ M Sairandhri \\ M Sairandhri}

F Sairandhri

Micrixalus spelunca sp.nov.

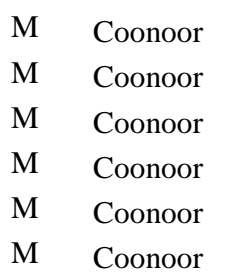

F Coonoor

Micrixalus uttaraghati sp. nov.

$$
\begin{array}{ll}
\text { M } & \text { Amboli } \\
\text { M } & \text { Amboli } \\
\text { M } & \text { Amboli } \\
\text { M } & \text { Amboli } \\
\text { M } & \text { Amboli } \\
\text { M } & \text { Amboli } \\
\text { M } & \text { Amboli }
\end{array}
$$

\begin{tabular}{|c|c|c|c|c|c|c|c|c|c|c|c|c|c|c|c|c|}
\hline BNHS $5636(\mathrm{PT})$ & 18.7 & 5.9 & 6.8 & 0.6 & 3.0 & 1.6 & 1.6 & 5.1 & 1.5 & 1.3 & 2.4 & 3.7 & 4.9 & 10.7 & 9.7 & 9.1 \\
\hline BNHS 5637 (PT) & 17.4 & 5.6 & 6.3 & 0.6 & 2.9 & 1.6 & 1.6 & 4.8 & 1.2 & 1.4 & 1.9 & 3.4 & 4.7 & 10.0 & 9.2 & 8.9 \\
\hline BNHS 5638 (PT) & 17.8 & 5.5 & 6.6 & 0.7 & 2.7 & 1.5 & 1.5 & 5.0 & 1.1 & 1.1 & 2.1 & 3.6 & 4.9 & 9.9 & 9.0 & 8.6 \\
\hline Average & $\mathbf{1 7 . 8}$ & 5.7 & 6.6 & 0.7 & 2.8 & 1.5 & 1.5 & 5.0 & 1.3 & 1.3 & 2.2 & 3.6 & 4.8 & 10.1 & 9.4 & 8.9 \\
\hline Standard deviation & 0.5 & 0.2 & 0.2 & 0.1 & 0.2 & 0.1 & 0.1 & 0.2 & 0.2 & 0.1 & 0.2 & 0.1 & 0.1 & 0.3 & 0.3 & 0.2 \\
\hline BNHS 5639 (PT) & 22.9 & 7.1 & 7.2 & 0.8 & 3.5 & 2.1 & 2.0 & 5.4 & 1.5 & 1.6 & 2.4 & 4.4 & 5.9 & 12.3 & 11.5 & 10.7 \\
\hline BNHS 5640 (HT) & 17.2 & 5.9 & 5.9 & 0.6 & 2.6 & 2.3 & 1.3 & 4.8 & 1.4 & 1.1 & 2.1 & 3.5 & 4.5 & 9.5 & 8.5 & 8.5 \\
\hline BNHS 5641 (PT) & 17.7 & 5.8 & 5.9 & 0.6 & 2.6 & 2.1 & 1.1 & 4.8 & 1.1 & 1.0 & 2.1 & 3.2 & 4.8 & 9.5 & 8.3 & 8.3 \\
\hline BNHS 5642 (PT) & 15.5 & 5.6 & 5.5 & 0.5 & 2.6 & 1.9 & 1.1 & 4.5 & 1.2 & 1.0 & 1.7 & 2.8 & 4.2 & 9.1 & 8.1 & 8.1 \\
\hline BNHS 5643 (PT) & 15.8 & 5.4 & 5.4 & 0.5 & 1.1 & 2.0 & 1.0 & 4.2 & 1.2 & 1.1 & 1.7 & 3.2 & 4.3 & 9.9 & 8.7 & 8.6 \\
\hline BNHS 5645 (PT) & 16.8 & 5.5 & 5.4 & 0.5 & 2.5 & 1.9 & 1.3 & 4.3 & 1.4 & 1.1 & 2.2 & 3.0 & 4.5 & 9.1 & 8.3 & 8.3 \\
\hline BNHS 5646 (PT) & 16.7 & 5.5 & 5.7 & 0.6 & 2.3 & 2.0 & 1.2 & 4.6 & 1.1 & 1.2 & 1.0 & 3.5 & 4.4 & 9.0 & 8.7 & 8.8 \\
\hline Average & 16.6 & 5.6 & 5.6 & 0.6 & 2.3 & 2.0 & 1.2 & 4.5 & 1.2 & 1.1 & 1.8 & 3.2 & 4.5 & 9.4 & 8.4 & 8.4 \\
\hline Standard deviation & 0.8 & 0.2 & 0.2 & 0.1 & 0.6 & 0.2 & 0.1 & 0.3 & 0.1 & 0.1 & 0.4 & 0.3 & 0.2 & 0.3 & 0.2 & 0.3 \\
\hline BNHS $5644(\mathrm{PT})$ & 21.8 & 6.3 & 6.4 & 0.6 & 3.4 & 2.0 & 1.4 & 5.5 & 1.4 & 1.1 & 1.1 & 4.4 & 5.2 & 10.5 & 9.1 & 9.1 \\
\hline BNHS 5647 (HT) & 17.4 & 5.8 & 6.2 & 0.8 & 2.6 & 2.1 & 1.2 & 4.9 & 1.1 & 1.5 & 1.8 & 2.7 & 4.7 & 10.2 & 9.7 & 8.0 \\
\hline BNHS 5648 (PT) & 16.6 & 5.1 & 5.8 & 0.7 & 2.6 & 1.8 & 1.2 & 4.8 & 0.9 & 1.5 & 2.9 & 2.8 & 4.6 & 10.2 & 8.4 & 7.9 \\
\hline BNHS 5649 (PT) & 15.4 & 5.6 & 5.3 & 0.7 & 2.6 & 1.8 & 1.1 & 3.8 & 0.9 & 1.3 & 1.8 & 3.3 & 4.4 & 10.0 & 8.4 & 7,7 \\
\hline BNHS 5650 (PT) & 14.6 & 5.3 & 5.7 & 0.6 & 2.6 & 2.0 & 1.1 & 4.5 & 0.8 & 1.3 & 1.9 & 3.0 & 4.4 & 9.4 & 8.0 & 7.5 \\
\hline BNHS 5651 (PT) & 15.8 & 5.5 & 6.0 & 0.6 & 2.4 & 1.9 & 1.0 & 4.5 & 0.9 & 1.3 & 1.8 & 3.0 & 4.3 & 9.0 & 8.2 & 7.8 \\
\hline BNHS 5652 (PT) & 15.3 & 5.1 & 5.7 & 0.7 & 2.5 & 1.9 & 1.2 & 4.0 & 0.9 & 1.3 & 1.8 & 2.9 & 4.0 & 8.0 & 7.5 & 7.3 \\
\hline BNHS 5653 (PT) & 14.6 & 5.3 & 5.2 & 0.6 & 2.5 & 2.0 & 1.3 & 4.3 & 0.8 & 1.2 & 1.7 & 3.1 & 4.3 & 8.1 & 7.6 & 7.4 \\
\hline Average & 15.7 & 5.4 & 5.7 & 0.7 & 2.5 & 1.9 & 1.2 & 4.4 & 0.9 & 1.3 & 2.0 & 3.0 & 4.4 & 9.3 & 8.3 & 7.7 \\
\hline Standard deviation & 1.0 & 0.3 & 0.4 & 0.1 & 0.1 & 0.1 & 0.1 & 0.4 & 0.1 & 0.1 & 0.4 & 0.2 & 0.2 & 0.9 & 0.7 & 0.3 \\
\hline BNHS $5654(\mathrm{PT})$ & 20.1 & 6.2 & 6.8 & 0.7 & 3.2 & 2.2 & 1.4 & 5.5 & 1.1 & 1.6 & 1.9 & 3.4 & 5.2 & 10.3 & 9.8 & 8.8 \\
\hline BNHS 5655 (HT) & 22.6 & 6.7 & 8.0 & 1.0 & 3.8 & 2.3 & 1.8 & 6.5 & 1.4 & 1.7 & 2.8 & 4.7 & 5.8 & 11.5 & 12.3 & 10.2 \\
\hline BNHS 5656 (PT) & 21.1 & 6.2 & 7.9 & 1.1 & 3.1 & 1.8 & 1.5 & 6.0 & 1.4 & 1.2 & 2.7 & 4.6 & 5.6 & 11.2 & 12.3 & 10.1 \\
\hline BNHS 5657 (PT) & 23.5 & 6.8 & 8.2 & 1.1 & 3.4 & 2.1 & 2.0 & 6.3 & 1.6 & 1.6 & 2.6 & 4.8 & 5.8 & 12.1 & 13.1 & 10.7 \\
\hline BNHS 5658 (PT) & 22.5 & 6.8 & 8.1 & 1.2 & 3.4 & 2.3 & 2.0 & 6.6 & 1.5 & 1.5 & 2.7 & 4.2 & 5.9 & 11.3 & 12.5 & 10.3 \\
\hline
\end{tabular}

$$
\text { F Amboli }
$$

\section{Micrixalus fuscus GROUP}

Micrixalus adonis sp. nov.

$$
\begin{array}{ll}
\text { M } & \text { Sevenmallay } \\
\text { M } & \text { Sevenmallay } \\
\text { M } & \text { Kadalar estate } \\
\text { M } & \text { Kadalar estate }
\end{array}
$$




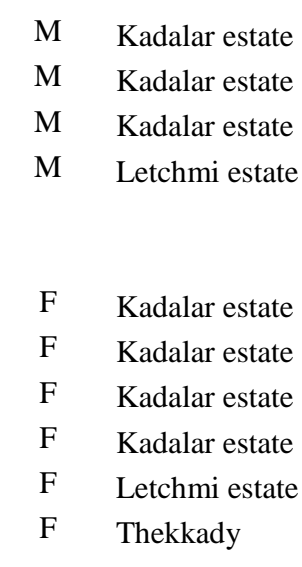

Micrixalus fuscus

$$
\begin{array}{ll}
\text { M } & \text { Kakkachi } \\
\text { M } & \text { Kakkachi } \\
\text { M } & \text { Kakkachi } \\
& \\
& \\
\text { F } & \text { "Travancore" } \\
\text { F } & \text { "Travancore" } \\
\text { F } & \text { Kakkachi } \\
\text { F } & \text { Kakkachi } \\
\text { F } & \text { Sengaltheri } \\
\text { F } & \text { Sengaltheri } \\
\text { F } & \text { Athirimala } \\
\text { F } & \text { Pandipath }
\end{array}
$$

\begin{tabular}{|c|c|c|c|c|c|c|c|c|c|c|c|c|c|c|c|c|}
\hline BNHS 5659 (PT) & 22.6 & 6.8 & 8.1 & 1.3 & 3.2 & 2.0 & 2.0 & 6.7 & 1.6 & 1.4 & 3.2 & 4.7 & 5.8 & 11.8 & 12.9 & 10.3 \\
\hline BNHS 5660 (PT) & 21.9 & 6.6 & 8.0 & 1.1 & 3.1 & 2.1 & 1.2 & 6.5 & 1.4 & 1.4 & 2.6 & 4.5 & 5.6 & 10.7 & 11.9 & 9.9 \\
\hline BNHS 5661 (PT) & 24.1 & 6.9 & 8.6 & 1.3 & 3.8 & 2.0 & 1.9 & 6.8 & 1.4 & 1.5 & 2.7 & 4.9 & 6.0 & 11.4 & 12.1 & 10.6 \\
\hline BNHS $5666(\mathrm{PT})$ & 22.6 & 6.9 & 8.1 & 1.0 & 3.5 & 2.1 & 1.4 & 6.0 & 1.4 & 1.6 & 2.6 & 4.9 & 5.5 & 10.9 & 12.2 & 10.1 \\
\hline Average & 22.6 & 6.7 & 8.1 & 1.1 & 3.4 & 2.1 & 1.7 & 6.4 & 1.5 & 1.5 & 2.7 & 4.7 & 5.8 & 11.4 & 12.4 & 10.3 \\
\hline Standard deviation & 0.9 & 0.2 & 0.2 & 0.1 & 0.3 & 0.2 & 0.3 & 0.3 & 0.1 & 0.2 & 0.2 & 0.2 & 0.2 & 0.5 & 0.4 & 0.3 \\
\hline BNHS $5662(\mathrm{PT})$ & 28.6 & 8.1 & 8.6 & 1.1 & 4.4 & 2.7 & 2.1 & 7.3 & 1.8 & 1.7 & 3.0 & 5.7 & 7.1 & 13.8 & 15.7 & 11.6 \\
\hline BNHS 5663 (PT) & 30.1 & 8.7 & 9.3 & 1.4 & 4.5 & 2.4 & 2.6 & 8.2 & 1.9 & 1.7 & 3.4 & 5.2 & 7.3 & 13.1 & 15 & 12.1 \\
\hline BNHS 5664 (PT) & 26.5 & 7.9 & 9.1 & 1.3 & 4.3 & 2.3 & 2.0 & 7.0 & 1.8 & 1.7 & 2.9 & 5.4 & 6.9 & 13.0 & 14.5 & 11.7 \\
\hline BNHS 5665 (PT) & 27.6 & 7.9 & 8.8 & 1.2 & 4.3 & 2.3 & 2.3 & 7.8 & 1.7 & 1.6 & 3.3 & 5.2 & 6.7 & 13.1 & 14.6 & 11.7 \\
\hline BNHS 5667 (PT) & 28.1 & 8.6 & 9.5 & 1.3 & 4.2 & 2.4 & 2.1 & 7.1 & 1.9 & 1.8 & 3.1 & 5.2 & 7.6 & 13.0 & 14.8 & 12.1 \\
\hline BNHS 5668 (PT) & 27.6 & 7.8 & 9.2 & 1.1 & 4.2 & 2.6 & 2.0 & 8.0 & 1.8 & 1.7 & 3.1 & 5.1 & 6.8 & 13.1 & 15.7 & 11.1 \\
\hline Average & 28.1 & 8.2 & 9.1 & 1.2 & 4.3 & 2.5 & 2.2 & 7.6 & 1.8 & 1.7 & 3.1 & 5.3 & 7.1 & 13.2 & 15.1 & 11.7 \\
\hline Standard deviation & 1.2 & 0.4 & 0.3 & 0.1 & 0.1 & 0.2 & 0.2 & 0.5 & 0.1 & 0.1 & 0.2 & 0.2 & 0.3 & 0.3 & 0.5 & 0.4 \\
\hline $\begin{array}{l}\text { BNHS } 5669(\mathrm{RS}) \\
\text { SDBDU } 2006.2296\end{array}$ & 28.2 & 8.2 & 9.1 & 1.1 & 4.2 & 2.4 & 1.7 & 7.2 & 1.7 & 1.7 & 3.5 & 5.2 & 7.1 & 14.5 & 14.9 & 12.1 \\
\hline (RS) & 27.9 & 8.1 & 9.1 & 0.9 & 4.1 & 2.3 & 1.8 & 7.2 & 1.6 & 1.6 & 3.6 & 5.1 & 7.1 & 14.4 & 14.9 & 12.3 \\
\hline BNHS 5670 (RS) & 28.8 & 8.3 & 9.2 & 1.1 & 4.3 & 2.5 & 1.9 & 7.3 & 1.6 & 1.8 & 3.2 & 5.1 & 7.3 & 14.7 & 15.1 & 12.4 \\
\hline Average & 28.3 & 8.2 & 9.1 & 1.0 & 4.2 & 2.4 & 1.8 & 7.2 & 1.6 & 1.7 & 3.4 & 5.1 & 7.1 & 14.5 & 15.0 & 12.3 \\
\hline Standard deviation & 0.5 & 0.1 & 0.1 & 0.1 & 0.1 & 0.1 & 0.1 & 0.1 & 0.1 & 0.1 & 0.2 & 0.1 & 0.2 & 0.2 & 0.1 & 0.2 \\
\hline NHM 74.4.29.258 (LT) & 32.1 & 8.3 & 10.5 & 1.2 & 5.1 & 2.7 & 2.5 & 8.8 & 2.1 & 2.2 & 3.5 & 5.2 & 7.9 & 14.9 & 16.0 & 13.6 \\
\hline NHM 74.4.29.259 (PL) & 30.6 & 8.7 & 10.3 & 1.1 & 4.9 & 2.5 & 2.0 & 8.5 & 2 & 2.1 & 3.3 & 5.0 & 7.4 & 14.8 & 15.9 & 13.2 \\
\hline BNHS 5671 (RS) & 32.7 & 8.4 & 10.4 & 1.1 & 5.0 & 2.4 & 2.0 & 8.9 & 2.3 & 2.1 & 3.6 & 4.9 & 7.8 & 15.5 & 16.1 & 13.6 \\
\hline BNHS 5672 (RS) & 33.1 & 9.2 & 10.4 & 1.3 & 5.3 & 3.1 & 2.1 & 8.1 & 2.5 & 2.5 & 3.6 & 5.5 & 7.9 & 16.1 & 16.2 & 13.9 \\
\hline BNHS 5673 (RS) & 30.1 & 8.6 & 9.9 & 1.1 & 4.8 & 2.6 & 1.6 & 8.1 & 2.1 & 2.0 & 3.0 & 5.0 & 7.5 & 14.2 & 15.8 & 13.6 \\
\hline BNHS 5674 (RS) & 31.1 & 8.2 & 9.7 & 1.0 & 4.8 & 2.9 & 2.0 & 8.4 & 2.0 & 2.0 & 3.2 & 5.2 & 7.4 & 14.8 & 16.0 & 16.5 \\
\hline BNHS 5675 (RS) & 32.1 & 8.8 & 11.1 & 1.2 & 5.1 & 2.8 & 1.9 & 8.9 & 2.4 & 2.4 & 3.2 & 5.8 & 7.7 & 15.2 & 15.3 & 13.0 \\
\hline BNHS $5676(\mathrm{RS})$ & 30.9 & 8.8 & 10.0 & 1.2 & 4.7 & 2.6 & 1.9 & 8.4 & 2.1 & 2.2 & 3.1 & 5.1 & 8.1 & 14.4 & 15.8 & 13.3 \\
\hline Average & 31.6 & 8.6 & 10.2 & 1.2 & 4.9 & 2.7 & 2.0 & 8.5 & 2.2 & 2.2 & 3.3 & 5.2 & 7.7 & 15.0 & 15.9 & 13.8 \\
\hline Standard deviation & 1.1 & 0.3 & 0.3 & 0.1 & 0.2 & 0.2 & 0.3 & 0.3 & 0.2 & 0.2 & 0.2 & 0.3 & 0.3 & 0.6 & 0.3 & 1.1 \\
\hline BNHS 5677 (TT) & 17.7 & 6.0 & 6.0 & 0.9 & 2.8 & 1.7 & 1.3 & 4.9 & 1.2 & 1.1 & 2.3 & 3.6 & 4.8 & 10.4 & 10.5 & 8.9 \\
\hline
\end{tabular}

Micrixalus herrei

$$
\text { M Kallar }
$$




$\begin{array}{ll}\text { M } & \text { Kallar } \\ \text { M } & \text { Chathankod } \\ \text { M } & \text { Chathankod } \\ \text { M } & \text { Chathankod } \\ \text { M } & \text { Chathankod } \\ \text { M } & \text { Ponmudi } \\ \text { M } & \text { Kovachal } \\ \text { M } & \text { Kiriparai }\end{array}$

Micrixalus kodayari sp. nov.

$$
\begin{array}{ll}
\text { M } & \text { Kodayar } \\
\text { M } & \text { Kodayar } \\
& \\
\text { F } & \text { Kodayar } \\
\text { F } & \text { Kakkachi } \\
\text { F } & \text { Kakkachi }
\end{array}
$$

Micrixalus mallani sp. nov.

$$
\begin{array}{ll}
\text { M } & \text { Pandimotta } \\
\text { M } & \text { Sabarimala } \\
\text { M } & \text { Sabarimala } \\
\text { M } & \text { Sabarimala }
\end{array}
$$

F Pandimotta

$\begin{array}{ccccccc}\text { BNHS 5678 (RS) } & 18.3 & 5.9 & 6.0 & 0.9 & 2.8 & 1.9 \\ \text { BNHS 5679(RS) } & 19.4 & 6.3 & 6.3 & 1.0 & 2.8 & 2.0 \\ \text { BNHS 5681 (RS) } & 18.8 & 5.9 & 6.0 & 0.7 & 2.8 & 1.4 \\ \text { BNHS 5682(RS) } & 18.3 & 6.0 & 6.1 & 0.9 & 2.7 & 1.7 \\ \text { BNHS 5684 (RS) } & 18.8 & 6.2 & 6.2 & 0.9 & 2.7 & 1.8 \\ \text { BNHS 5685(RS) } & 16.7 & 5.9 & 6.0 & 0.7 & 2.7 & 1.5 \\ \text { BNHS 5686(RS) } & 19.1 & 6.2 & 6.1 & 1.0 & 2.9 & 1.6 \\ \text { BNHS 5687 (RS) } & 17.3 & 5.9 & 6.0 & 0.8 & 2.4 & 1.6 \\ \text { Average } & \mathbf{1 8 . 3} & \mathbf{6 . 0} & \mathbf{6 . 1} & \mathbf{0 . 9} & \mathbf{2 . 7} & \mathbf{1 . 7} \\ \text { Standard deviation } & \mathbf{0 . 9} & \mathbf{0 . 2} & \mathbf{0 . 1} & \mathbf{0 . 1} & \mathbf{0 . 1} & \mathbf{0 . 2} \\ \text { BNHS 5680(RS) } & 24.8 & 8.4 & 8.6 & 0.9 & 3.8 & 2.1 \\ \text { BNHS 5683(RS) } & 26.6 & 8.3 & 8.5 & 1.4 & 3.9 & 2.6 \\ \text { BNHS 5688 (RS) } & 26.1 & 8.5 & 8.4 & 1.1 & 3.7 & 2.0 \\ \text { Average } & \mathbf{2 5 . 8} & \mathbf{8 . 4} & \mathbf{8 . 5} & \mathbf{1 . 1} & \mathbf{3 . 8} & \mathbf{2 . 2} \\ \text { Standard deviation } & \mathbf{0 . 9} & \mathbf{0 . 1} & \mathbf{0 . 1} & \mathbf{0 . 3} & \mathbf{0 . 1} & \mathbf{0 . 3}\end{array}$

$\begin{array}{rccccccc}\text { BNHS 5690(PT) } & 18.7 & 6.6 & 7.8 & 0.9 & 3.2 & 1.7 & 1.4 \\ \text { BNHS 5691 (PT) } & 17.7 & 5.8 & 6.4 & 0.8 & 2.5 & 1.6 & 1.3 \\ \text { Average } & \mathbf{1 8 . 2} & \mathbf{6 . 2} & \mathbf{7 . 1} & \mathbf{0 . 9} & \mathbf{2 . 9} & \mathbf{1 . 7} & \mathbf{1} \\ \text { Standard deviation } & \mathbf{0 . 7} & \mathbf{0 . 6} & \mathbf{1 . 0} & \mathbf{0 . 1} & \mathbf{0 . 5} & \mathbf{0 . 1} & \mathbf{0 . 1} \\ \text { BNHS 5689(HT) } & 24.6 & 8.0 & 8.8 & 0.9 & 3.6 & 2.0 & 1.9 \\ \text { BNHS 5692(PT) } & 25.6 & 8.2 & 8.7 & 1.1 & 3.8 & 2.2 & 2.0 \\ \text { BNHS 5693 (PT) } & 25.1 & 8.1 & 8.7 & 1.1 & 3.9 & 2.2 & 2.1 \\ \text { Average } & \mathbf{2 5 . 1} & \mathbf{8 . 1} & \mathbf{8 . 7} & \mathbf{1 . 0} & \mathbf{3 . 8} & \mathbf{2 . 1} & \mathbf{2} \\ \text { Standard deviation } & \mathbf{0 . 5} & \mathbf{0 . 1} & \mathbf{0 . 1} & \mathbf{0 . 1} & \mathbf{0 . 2} & \mathbf{0 . 1} & \mathbf{0 . 1}\end{array}$

$\begin{array}{cccccccc}\text { BNHS 5694 (HT) } & 19.5 & 6.1 & 7.2 & 0.9 & 3.1 & 1.7 & 1.2 \\ \text { BNHS 5696(PT) } & 22.4 & 6.4 & 7.4 & 1.1 & 3.3 & 2.1 & 1.7 \\ \text { BNHS 5697 (PT) } & 21.5 & 6.1 & 7.1 & 1.0 & 3.2 & 2.2 & 1.3 \\ \text { BNHS 5698 (PT) } & 20.8 & 6.1 & 7.1 & 1.0 & 3.2 & 1.9 & 1.4 \\ \text { Average } & \mathbf{2 1 . 1} & \mathbf{6 . 2} & \mathbf{7 . 2} & \mathbf{1 . 0} & \mathbf{3 . 2} & \mathbf{2 . 0} & \mathbf{1} \\ \text { Standard deviation } & \mathbf{1 . 2} & \mathbf{0 . 2} & \mathbf{0 . 1} & \mathbf{0 . 1} & \mathbf{0 . 1} & \mathbf{0 . 2} & \mathbf{0 . 2} \\ \text { BNHS 5695(PT) } & 27.7 & 8.1 & 9.5 & 1.2 & 4.2 & 2.4 & 1.6\end{array}$

$\begin{array}{ccccccccc}5.0 & 1.1 & 0.9 & 2.4 & 3.6 & 4.9 & 9.2 & 9.1 & 8.9 \\ 5.3 & 1.3 & 1.1 & 2.8 & 3.8 & 5.3 & 10.2 & 10.3 & 9.5 \\ 5.6 & 1.0 & 0.8 & 2.6 & 3.7 & 5.1 & 10.5 & 10.4 & 8.7 \\ 5.0 & 1.3 & 1.1 & 2.4 & 3.7 & 4.9 & 9.6 & 10.1 & 9.0 \\ 5.5 & 1.5 & 1.1 & 2.4 & 3.7 & 4.8 & 9.9 & 10.0 & 9.0 \\ 5.3 & 1.5 & 1.2 & 2.4 & 3.5 & 4.4 & 10.3 & 10.2 & 8.8 \\ 5.3 & 1.7 & 1.2 & 2.8 & 3.9 & 5.1 & 10.2 & 10.2 & 9.4 \\ 4.8 & 1.4 & 1.1 & 2.2 & 3.4 & 4.6 & 10.1 & 10.1 & 8.7 \\ \mathbf{5 . 2} & \mathbf{1 . 3} & \mathbf{1 . 1} & \mathbf{2 . 5} & \mathbf{3 . 7} & \mathbf{4 . 9} & \mathbf{1 0 . 0} & \mathbf{1 0 . 1} & \mathbf{9 . 0} \\ \mathbf{0 . 3} & \mathbf{0 . 2} & \mathbf{0 . 1} & \mathbf{0 . 2} & \mathbf{0 . 2} & \mathbf{0 . 3} & \mathbf{0 . 4} & \mathbf{0 . 4} & \mathbf{0 . 3} \\ 7.0 & 1.6 & 1.4 & 2.3 & 4.4 & 5.8 & 12.8 & 12.9 & 11.6 \\ 6.7 & 1.7 & 1.6 & 3.0 & 5.0 & 6.4 & 14.0 & 14.1 & 12.5 \\ 6.7 & 1.8 & 1.5 & 2.7 & 4.9 & 6.6 & 13.5 & 13.6 & 12.2 \\ \mathbf{6 . 8} & \mathbf{1 . 7} & \mathbf{1 . 5} & \mathbf{2 . 7} & \mathbf{4 . 8} & \mathbf{6 . 3} & \mathbf{1 3 . 4} & \mathbf{1 3 . 5} & \mathbf{1 2 . 1} \\ \mathbf{0 . 2} & \mathbf{0 . 1} & \mathbf{0 . 1} & \mathbf{0 . 4} & \mathbf{0 . 3} & \mathbf{0 . 4} & \mathbf{0 . 6} & \mathbf{0 . 6} & \mathbf{0 . 5}\end{array}$

$\begin{array}{lllllllll}6.2 & 1.4 & 1.4 & 2.4 & 4.3 & 5.5 & 10.9 & 10.9 & 9.5\end{array}$

$\begin{array}{lllllllll}5.3 & 1.4 & 1.4 & 2.3 & 3.6 & 4.6 & 9.5 & 9.6 & 7.6\end{array}$

$\begin{array}{lllllllll}5.8 & 1.4 & 1.4 & 2.4 & 4.0 & 5.1 & 10.2 & 10.3 & 8.6\end{array}$

$\begin{array}{llllllllll}0.6 & 0.0 & 0.0 & 0.1 & 0.5 & 0.6 & 1.0 & 0.9 & 1.3\end{array}$

$\begin{array}{llllllllll}6.8 & 1.6 & 1.7 & 2.3 & 4.9 & 6.1 & 12.9 & 12.9 & 11.2\end{array}$

$\begin{array}{lllllllll}7.0 & 1.8 & 1.6 & 2.7 & 5.0 & 6.5 & 13.1 & 13.2 & 11.4\end{array}$

$\begin{array}{lllllllll}6.9 & 1.8 & 1.7 & 2.9 & 5.1 & 6.4 & 13.0 & 13.0 & 11.5\end{array}$

$\begin{array}{lllllllll}6.9 & 1.7 & 1.7 & 2.6 & 5.0 & 6.3 & 13.0 & 13.0 & 11.4\end{array}$

$\begin{array}{lllllllll}0.1 & 0.1 & 0.1 & 0.3 & 0.1 & 0.2 & 0.1 & 0.2 & 0.2\end{array}$

$\begin{array}{lllllllll}5.4 & 1.1 & 1.3 & 2.3 & 3.8 & 5.1 & 10.5 & 10.1 & 9.2\end{array}$

$\begin{array}{lllllllll}5.6 & 1.6 & 1.4 & 2.6 & 4.0 & 5.5 & 10.7 & 10.8 & 9.3\end{array}$

$\begin{array}{lllllllll}5.4 & 1.4 & 1.3 & 2.4 & 4.2 & 5.7 & 10.5 & 10.5 & 9.3\end{array}$

$\begin{array}{lllllllll}5.1 & 1.2 & 1.2 & 2.3 & 4.1 & 5.7 & 10.3 & 10.4 & 9.6\end{array}$

$\begin{array}{lllllllll}5.4 & 1.3 & 1.3 & 2.4 & 4.0 & 5.5 & 10.5 & 10.5 & 9.4\end{array}$

$\begin{array}{ccccccccc}0.2 & 0.2 & 0.1 & 0.1 & 0.2 & 0.3 & 0.2 & 0.3 & 0.2\end{array}$

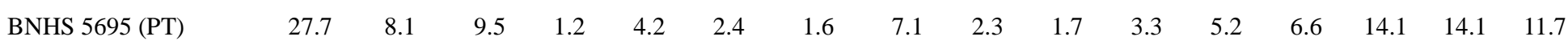




$\begin{array}{ll}\text { F } & \text { Athirimala } \\ \text { F } & \text { Athirimala } \\ \text { F } & \text { Ponkalappara }\end{array}$

Micrixalus nelliyampathi sp.nov.

M Kesavapara

M Kesavapara

M Poopara

M Andiparai

M Andiparai

M Andiparai

F Kesavapara

F Kesavapara

F Andiparai

F Grass hills

F Grass hills

\section{Micrixalus nudis GROUP}

Micrixalus gadgili

$$
\begin{array}{ll}
\text { M } & \text { Sabarimala } \\
\text { M } & \text { Gavi } \\
\text { M } & \text { Thekkady } \\
\text { M } & \text { Thekkady } \\
\text { M } & \text { Thekkady } \\
\text { M } & \text { Kesavapara } \\
\text { M } & \text { Kesavapara } \\
\text { M } & \text { Kesavapara }
\end{array}
$$

\begin{tabular}{|c|c|c|c|c|c|c|c|c|c|c|c|c|c|c|c|c|}
\hline BNHS 5699 (PT) & 25.4 & 7.9 & 8.2 & 1.1 & 4.1 & 2.1 & 1.6 & 6.6 & 2.0 & 1.8 & 3.0 & 5.2 & 6.2 & 13.2 & 13.3 & 11.9 \\
\hline BNHS 5700 (PT) & 27.3 & 7.9 & 9.1 & 1.1 & 4.1 & 2.5 & 1.4 & 7.2 & 2.2 & 2.2 & 2.9 & 5.3 & 6.1 & 14.3 & 14.2 & 11.1 \\
\hline BNHS 5701 (PT) & 25.1 & 7.6 & 9.1 & 1.1 & 4.3 & 2.2 & 1.9 & 6.8 & 1.9 & 1.5 & 2.7 & 4.7 & 6.1 & 13.1 & 13.2 & 10.8 \\
\hline Average & 26.4 & 7.9 & 9.0 & 1.1 & 4.2 & 2.3 & 1.6 & 6.9 & 2.1 & 1.8 & 3.0 & 5.1 & 6.3 & 13.7 & 13.7 & 11.4 \\
\hline Standard deviation & 1.3 & 0.2 & 0.6 & 0.0 & 0.1 & 0.2 & 0.2 & 0.3 & 0.2 & 0.3 & 0.3 & 0.3 & 0.2 & 0.6 & 0.5 & 0.5 \\
\hline BNHS $5702(\mathrm{HT})$ & 23.7 & 7.2 & 8.4 & 0.8 & 4.1 & 2.1 & 1.8 & 6.3 & 1.3 & 1.7 & 3.0 & 5.1 & 6.2 & 11.9 & 12.1 & 11.8 \\
\hline BNHS 5703 (PT) & 21.5 & 6.2 & 8.2 & 1.1 & 3.7 & 2.3 & 1.7 & 5.9 & 1.2 & 1.5 & 2.8 & 4.0 & 5.5 & 9.9 & 11.3 & 9.8 \\
\hline BNHS 5704 (PT) & 21.4 & 6.1 & 8.1 & 0.9 & 3.4 & 2.1 & 1.2 & 5.9 & 1.1 & 1.5 & 2.6 & 3.9 & 5.6 & 9.8 & 11.2 & 9.8 \\
\hline BNHS 5707 (PT) & 21.3 & 6.3 & 8.0 & 1.2 & 3.6 & 2.3 & 1.2 & 6.1 & 1.4 & 1.7 & 2.5 & 4.2 & 5.8 & 10.0 & 11.9 & 10.0 \\
\hline BNHS 5708 (PT) & 21.7 & 6.5 & 8.0 & 1.0 & 3.5 & 1.9 & 1.3 & 6.1 & 1.4 & 1.7 & 2.6 & 4.1 & 5.9 & 10.1 & 11.9 & 10.0 \\
\hline BNHS 5709 (PT) & 23.4 & 7.1 & 8.4 & 1.0 & 4.1 & 2.2 & 1.8 & 6.3 & 1.2 & 1.9 & 2.0 & 5.0 & 6.0 & 11.6 & 12.6 & 11.6 \\
\hline BNHS 5711 (PT) & 22.2 & 6.9 & 8.4 & 1.1 & 3.8 & 2.1 & 1.6 & 6.1 & 1.5 & 1.4 & 2,8 & 5.0 & 6.0 & 11.3 & 12.8 & 11.3 \\
\hline Average & 22.2 & 6.6 & 8.2 & 1.0 & 3.7 & 2.1 & 1.5 & 6.1 & 1.3 & 1.6 & 2.6 & 4.5 & 5.9 & 10.7 & 12.0 & 10.6 \\
\hline Standard deviation & 1.0 & 0.4 & 0.2 & 0.1 & 0.3 & 0.1 & 0.3 & 0.2 & 0.1 & 0.2 & 0.3 & 0.5 & 0.2 & 0.9 & 0.6 & 0.9 \\
\hline BNHS 5705 (PT) & 28.5 & 8.5 & 9.9 & 1.2 & 4.5 & 3.4 & 2.1 & 7.4 & 1.9 & 2.3 & 3.2 & 5.1 & 6.8 & 13.1 & 14.8 & 13.1 \\
\hline BNHS 5706 (PT) & 27.1 & 7.9 & 9.1 & 1.1 & 4.4 & 3.1 & 2.0 & 7.3 & 1.6 & 2.6 & 3.0 & 4.8 & 7.4 & 12.1 & 14.9 & 12.1 \\
\hline BNHS 5710 (PT) & 29.5 & 8.2 & 10.0 & 1.3 & 4.8 & 3.4 & 2.1 & 8.1 & 2.0 & 2.6 & 3.1 & 5.5 & 7.1 & 13.3 & 15.1 & 13.2 \\
\hline BNHS 5712 (PT) & 29.1 & 8.4 & 11.2 & 1.2 & 4.7 & 3.3 & 2.1 & 7.8 & 2.1 & 2.5 & 3.1 & 5.4 & 7.6 & 13.0 & 15.0 & 12.9 \\
\hline BNHS 5713 (PT) & 25.6 & 7.5 & 8.7 & 1.5 & 4.1 & 2.9 & 1.9 & 7.0 & 2.0 & 2.6 & 2.8 & 4.7 & 7.2 & 12.2 & 14.1 & 12.1 \\
\hline Average & 28.0 & 8.1 & 9.8 & 1.3 & 4.5 & 3.2 & 2.0 & 7.5 & 1.9 & 2.5 & 3.0 & 5.1 & 7.2 & 12.7 & 14.8 & 12.7 \\
\hline Standard deviation & 1.6 & 0.4 & 1.0 & 0.2 & 0.3 & 0.2 & 0.1 & 0.4 & 0.2 & 0.1 & 0.2 & 0.4 & 0.3 & 0.6 & 0.4 & 0.5 \\
\hline BNHS 5714 (RS) & 16.1 & 5.1 & 5.3 & 0.5 & 2.3 & 1.7 & 1.3 & 4.8 & 0.8 & 1.2 & 1.8 & 3.5 & 3.6 & 8.2 & 8.4 & 7.7 \\
\hline BNHS 5715 (RS) & 15.7 & 4.9 & 5.1 & 0.4 & 2.4 & 1.5 & 1.2 & 4.2 & 0.7 & 1.1 & 1.7 & 3.1 & 3.5 & 8.2 & 8.5 & 7.4 \\
\hline BNHS 5717 (RS) & 16.2 & 4.8 & 5.5 & 0.5 & 2.6 & 1.7 & 1.2 & 4.6 & 0.9 & 1.4 & 1.9 & 3.2 & 3.5 & 7.8 & 8.0 & 7.1 \\
\hline BNHS 5718 (RS) & 15.5 & 4.8 & 5.1 & 0.6 & 2.5 & 1.6 & 1.1 & 4.1 & 0.8 & 1.4 & 1.9 & 3.1 & 3.6 & 7.8 & 7.9 & 7.4 \\
\hline BNHS 5719 (RS) & 15.1 & 4.8 & 5.1 & 0.6 & 2.4 & 1.3 & 1.3 & 4.1 & 0.8 & 1.3 & 2.0 & 3.1 & 3.7 & 8.3 & 8.6 & 7.4 \\
\hline BNHS 5720 (RS) & 15.1 & 4.8 & 5.4 & 0.5 & 2.2 & 1.7 & 1.3 & 4.5 & 0.9 & 1.3 & 1.8 & 3.2 & 3.8 & 7.8 & 7.9 & 7.1 \\
\hline BNHS 5721 (RS) & 15.9 & 4.9 & 5.5 & 0.5 & 2.4 & 1.6 & 1.1 & 4.4 & 0.8 & 1.2 & 1.6 & 3.1 & 4.3 & 8.1 & 8.2 & 7.8 \\
\hline BNHS 5722 (RS) & 15.9 & 4.8 & 5.1 & 0.6 & 2.2 & 1.7 & 1.3 & 4.2 & 0.9 & 1.3 & 1.8 & 3.1 & 3.9 & 8.3 & 7.9 & 7.3 \\
\hline Average & 15.7 & 4.9 & 5.3 & 0.5 & 2.4 & 1.6 & 1.2 & 4.4 & 0.8 & 1.3 & 1.8 & 3.2 & 3.7 & 8.1 & 8.2 & 7.4 \\
\hline
\end{tabular}


F "Pamba, Sabarigiri"

F Gavi

Micrixalus nudis

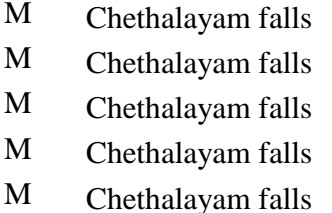

F Chethalayam falls

F Chethalayam falls

F Chethalayam falls

Micrixalus sali sp. nov.

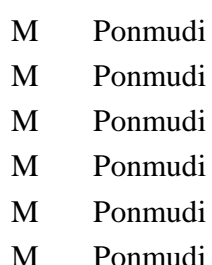

F Ponmudi

Micrixalus thampii

$\begin{array}{ll}\text { M } & \text { Sairandhri } \\ \text { M } & \text { Sairandhri } \\ \text { M } & \text { Sairandhri } \\ \text { M } & \text { Sairandhri } \\ \text { M } & \text { Kuddam }\end{array}$

ZSI-SRS VA/780 (HT)

BNHS 5716 (RS)

Average

Standard deviation

BNHS 5723 (RS)

BNHS 5725 (RS)

BNHS 5726 (RS)

BNHS 5727 (RS)

BNHS 5728 (RS)

Average

Standard deviation $\quad 0.4$

BNHS 5724 (RS) $\quad 20.3$

BNHS 5729 (RS) $\quad 20.5$

BNHS 5730 (RS)

Average $\quad 20.5$

Standard deviation $\quad 0.2$

$\begin{array}{ccccccc}\text { BNHS 5731(HT) } & 14.8 & 4.6 & 5.5 & 0.4 & 2.4 & 1.7 \\ \text { BNHS 5735(PT) } & 14.8 & 4.7 & 5.4 & 0.5 & 2.4 & 1.7 \\ \text { BNHS 5736(PT) } & 13.8 & 4.5 & 5.5 & 0.5 & 2.4 & 1.4 \\ \text { BNHS 5732(PT) } & 14.5 & 4.7 & 5.2 & 0.5 & 2.4 & 1.7 \\ \text { BNHS 5733(PT) } & 14.9 & 4.6 & 5.0 & 0.5 & 2.5 & 1.7 \\ \text { BNHS 5734(PT) } & 14.7 & 4.6 & 5.1 & 0.5 & 2.8 & 1.7 \\ \text { Average } & \mathbf{1 4 . 6} & \mathbf{4 . 6} & \mathbf{5 . 3} & \mathbf{0 . 5} & \mathbf{2 . 5} & \mathbf{1 . 7} \\ \text { Standard deviation } & \mathbf{0 . 4} & \mathbf{0 . 1} & \mathbf{0 . 2} & \mathbf{0 . 0} & \mathbf{0 . 2} & \mathbf{0 . 1} \\ \text { BNHS 5737 (RS) } & 16.2 & 5.1 & 5.6 & 0.8 & 2.5 & 1.9\end{array}$

BNHS 5737 (RS)

16.2

BNHS 5738 (RS)

BNHS 5740 (RS)

BNHS 5741 (RS)

BNHS 5742 (RS)

BNHS 5744 (RS)

$\begin{array}{llllllllllllllll}16.2 & 5.4 & 6.1 & 0.9 & 2.7 & 1.7 & 1.5 & 4.7 & 1.3 & 1.3 & 1.8 & 3.5 & 3.9 & 8.8 & 8.9 & 7.9 \\ 14.7 & 5.4 & 6.0 & 0.8 & 2.8 & 1.2 & 1.2 & 4.2 & 1.2 & 1.2 & 1.8 & 3.1 & 3.9 & 8.7 & 8.8 & 8.3 \\ 14.4 & 5.1 & 5.6 & 0.7 & 2.4 & 1.5 & 1.2 & 4.3 & 1.1 & 1.1 & 1.7 & 2.7 & 3.6 & 7.9 & 8.5 & 7.4 \\ 16.1 & 5.3 & 6.0 & 0.7 & 2.9 & 1.7 & 1.3 & 4.8 & 1.3 & 1.2 & 1.9 & 3.3 & 3.9 & 9.9 & 9.1 & 7.9 \\ 15.0 & 5.0 & 5.5 & 0.6 & 2.5 & 1.6 & 1.2 & 4.5 & 0.9 & 0.9 & 2.2 & 2.8 & 3.5 & 7.8 & 8.3 & 7.2\end{array}$

$\Xi$ 


\section{Kuddam \\ F Sairandhri \\ F Sairandhri \\ F Kuddam}

\section{Micrixalus saxicola GROUP}

Micrixalus kottigeharensis

$\begin{array}{ll}\text { M } & \text { Kottigehara } \\ \text { M } & \text { Kottigehara } \\ \text { M } & \text { Maranhalli } \\ \text { M } & \text { Maranhalli } \\ \text { M } & \text { Kathlekan } \\ \text { M } & \text { Kathlekan } \\ \text { M } & \text { Kathlekan } \\ \text { M } & \text { Waddighat }\end{array}$

F Kemmanagundi

Charmadi Ghats

Maranhalli

Maranhalli

Kathlekan

Waddighat

Waddighat

Unchalli falls

Micrixalus saxicola

M Periya

M Kurichiyarmala

$\begin{array}{rcccccc}\text { BNHS 5745 (RS) } & 15.3 & 4.9 & 5.6 & 0.7 & 2.5 & 1.6 \\ \text { Average } & \mathbf{1 5 . 3} & \mathbf{5 . 2} & \mathbf{5 . 8} & \mathbf{0 . 7} & \mathbf{2 . 6} & \mathbf{1 . 6} \\ \text { Standard deviation } & \mathbf{0 . 7} & \mathbf{0 . 2} & \mathbf{0 . 3} & \mathbf{0 . 1} & \mathbf{0 . 2} & \mathbf{0 . 2} \\ \text { BNHS 5739 (RS) } & 21.1 & 7.4 & 7.2 & 0.9 & 3.3 & 2.2 \\ \text { BNHS 5743 (RS) } & 19.5 & 6.0 & 6.2 & 0.9 & 3.0 & 2.1 \\ \text { BNHS 5746 (RS) } & 18.4 & 6.2 & 6.7 & 0.8 & 2.8 & 2.0 \\ \text { Average } & \mathbf{1 9 . 7} & \mathbf{6 . 5} & \mathbf{6 . 7} & \mathbf{0 . 9} & \mathbf{2 . 9} & \mathbf{2 . 1} \\ \text { Standard deviation } & \mathbf{1 . 4} & \mathbf{0 . 8} & \mathbf{0 . 5} & \mathbf{0 . 1} & \mathbf{0 . 1} & \mathbf{0 . 1}\end{array}$

1.2
$\mathbf{1 . 3}$
$\mathbf{0 . 1}$
1.4
1.5
1.6
$\mathbf{1 . 5}$
$\mathbf{0 . 1}$

4.5

4.5

0.2

4.2

4.6

4.7

0.6

\begin{tabular}{|c|c|c|c|c|c|c|c|c|c|c|c|c|c|c|c|c|}
\hline BNHS 5747 (NT) & 22.1 & 6.5 & 7.6 & 0.8 & 3.5 & 2.0 & 1.5 & 5.7 & 1.8 & 1.6 & 1.9 & 4.4 & 5.6 & 11.4 & 12.7 & 10.6 \\
\hline BNHS 5748 (RS) & 22.5 & 6.7 & 8.2 & 0.6 & 3.7 & 1.1 & 1.7 & 6.8 & 1.7 & 1.5 & 2.4 & 4.5 & 5.9 & 12.7 & 13.4 & 10.8 \\
\hline BNHS 5751 (RS) & 22.1 & 6.5 & 7.7 & 0.7 & 3.3 & 2.1 & 1.7 & 6.1 & 1.6 & 1.6 & 2.1 & 4.7 & 5.9 & 12.7 & 12.3 & 12.2 \\
\hline BNHS 5752 (RS) & 23.9 & 7.2 & 8.6 & 0.5 & 3.6 & 2.1 & 1.9 & 6.8 & 1.7 & 1.7 & 2.7 & 4.3 & 6.0 & 11.6 & 12.8 & 10.6 \\
\hline BNHS 5755 (RS) & 22.5 & 6.4 & 8.1 & 0.7 & 3.4 & 1.9 & 1.5 & 6.6 & 1.6 & 1.6 & 2.2 & 4.9 & 5.5 & 12.2 & 11.9 & 11.2 \\
\hline BNHS 5756 (RS) & 23.8 & 6.4 & 8.5 & 0.6 & 3.9 & 2.4 & 1.4 & 6.4 & 1.6 & 1.5 & 2.4 & 5.0 & 6.0 & 13 & 12.3 & 11.2 \\
\hline BNHS 5757 (RS) & 22.9 & 6.5 & 8.8 & 0.7 & 3.9 & 1.9 & 1.4 & 6.7 & 1.5 & 1.6 & 2.3 & 4.6 & 6.0 & 12.9 & 12.4 & 11.2 \\
\hline BNHS 5759 (RS) & 23.3 & 6.7 & 8.6 & 0.6 & 2.9 & 1.6 & 1.7 & 6.1 & 1.6 & 1.6 & 2.6 & 4.8 & 6.0 & 12.4 & 13.0 & 10.9 \\
\hline Average & 22.9 & 6.6 & 8.3 & 0.7 & 3.5 & 1.9 & 1.6 & 6.4 & 1.6 & 1.6 & 2.3 & 4.7 & 5.9 & 12.4 & 12.6 & 11.1 \\
\hline Standard deviation & 0.7 & 0.3 & 0.4 & 0.1 & 0.3 & 0.4 & 0.2 & 0.4 & 0.1 & 0.1 & 0.3 & 0.2 & 0.2 & 0.6 & 0.5 & 0.5 \\
\hline BNHS $5749(\mathrm{RS})$ & 28.7 & 8.1 & 10.2 & 1.0 & 4.4 & 2.7 & 1.8 & 8.3 & 2.3 & 2.2 & 3.0 & 5.7 & 7.3 & 14.5 & 14.7 & 12.9 \\
\hline BNHS 5750 (RS) & 28.1 & 7.8 & 9.2 & 1.3 & 4.0 & 2.3 & 1.9 & 7.5 & 1.9 & 1.8 & 2.5 & 5.5 & 6.9 & 15.4 & 15.8 & 13.2 \\
\hline BNHS 5753 (RS) & 30.4 & 8.6 & 11.0 & 1.0 & 4.8 & 2.9 & 1.8 & 8.8 & 2.1 & 2.1 & 2.8 & 6.1 & 6.7 & 15.1 & 15.4 & 13.7 \\
\hline BNHS 5754 (RS) & 28.6 & 8.5 & 9.1 & 1.0 & 4.2 & 2.6 & 1.8 & 6.9 & 2.2 & 1.6 & 2.1 & 5.7 & 6.7 & 15.6 & 15.0 & 13.6 \\
\hline BNHS 5758 (RS) & 28.4 & 8.2 & 10.1 & 7.8 & 4.8 & 2.6 & 1.8 & 8.2 & 2.0 & 1.6 & 2.5 & 5.4 & 6.8 & 14.5 & 15.5 & 12.8 \\
\hline BNHS 5760 (RS) & 32.6 & 9.1 & 9.6 & 1.5 & 4.8 & 2.9 & 1.8 & 8.6 & 2.7 & 2.5 & 3.0 & 5.6 & 8.8 & 16.3 & 16.8 & 14.6 \\
\hline BNHS 5761 (RS) & 27.6 & 8.3 & 10.0 & 1.1 & 4.5 & 2.7 & 1.7 & 8.2 & 1.7 & 1.7 & 2.6 & 5.7 & 7.2 & 16.0 & 15.6 & 13.4 \\
\hline BNHS 5762 (RS) & 28.1 & 8.9 & 10 & 1.1 & 3.9 & 2.7 & 1.9 & 7.7 & 1.9 & 1.6 & 1.5 & 5.3 & 7.0 & 14.8 & 15.0 & 13.3 \\
\hline Average & 29.1 & 8.4 & 9.9 & 2.0 & 4.4 & 2.7 & 1.8 & 8.0 & 2.1 & 1.9 & 2.5 & 5.6 & 7.2 & 15.3 & 15.5 & 13.4 \\
\hline Standard deviation & 1.7 & 0.4 & 0.6 & 2.4 & 0.4 & 0.2 & 0.1 & 0.6 & 0.3 & 0.3 & 0.5 & 0.2 & 0.7 & 0.7 & 0.6 & 0.6 \\
\hline BNHS 5763 (RS) & 20.0 & 6.1 & 7.3 & 0.8 & 3.3 & 2.1 & 1.5 & 5.1 & 1.4 & 1.3 & 2.4 & 4.1 & 5.0 & 12.2 & 12.1 & 9.7 \\
\hline 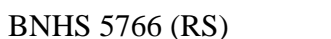 & & 6.0 & 7.8 & 1.0 & 3.4 & 1.9 & 1.5 & 6.1 & 1.6 & 1.7 & 2.2 & 4.0 & 5.0 & 12.4 & 12.5 & 10.3 \\
\hline
\end{tabular}

$\begin{array}{ll}1.0 & 1.0 \\ \mathbf{1 . 1} & \mathbf{1 . 1} \\ \mathbf{0 . 2} & \mathbf{0 . 1} \\ 1.5 & 1.4 \\ 1.2 & 1.2 \\ 1.4 & 1.4 \\ \mathbf{1 . 4} & \mathbf{1 . 3} \\ \mathbf{0 . 2} & \mathbf{0 . 1}\end{array}$

$\begin{array}{cccccc}1.9 & 2.8 & 3.6 & 7.9 & 7.9 & 7.1 \\ \mathbf{1 . 9} & \mathbf{3 . 0} & \mathbf{3 . 7} & \mathbf{8 . 5} & \mathbf{8 . 6} & \mathbf{7 . 6} \\ \mathbf{0 . 2} & \mathbf{0 . 3} & \mathbf{0 . 2} & \mathbf{0 . 8} & \mathbf{0 . 4} & \mathbf{0 . 5} \\ 2.0 & 4.3 & 5.5 & 10.7 & 11.1 & 9.9 \\ 2.0 & 3.6 & 4.7 & 10.0 & 10.0 & 9.2 \\ 1.8 & 3.7 & 4.5 & 9.8 & 9.7 & 8.8 \\ \mathbf{1 . 9} & \mathbf{3 . 9} & \mathbf{4 . 9} & \mathbf{1 0 . 2} & \mathbf{1 0 . 3} & \mathbf{9 . 3} \\ \mathbf{0 . 1} & \mathbf{0 . 4} & \mathbf{0 . 5} & \mathbf{0 . 5} & \mathbf{0 . 7} & \mathbf{0 . 6}\end{array}$

BNHS 5766 (RS)
21.5
6. 


$\begin{array}{ll}\text { M } & \text { Aralam } \\ \text { M } & \text { Aralam } \\ \text { M } & \text { Kottigehara } \\ \text { M } & \text { Maranhalli } \\ \text { M } & \text { Kempholay } \\ \text { M } & \text { Yavakapady } \\ \text { M } & \text { Unchalli falls } \\ & \\ & \\ \text { F } & \\ \text { F } & \text { "Malabar" } \\ \text { F } & \text { Banasura } \\ \text { F } & \text { Kurichiyarmala } \\ \text { F } & \text { Settukunnu } \\ \text { F } & \text { Charmadi Ghats } \\ \text { F } & \text { Yavakapady } \\ & \end{array}$

Micrixalus specca sp. nov.

M Charmadi Ghats

M Charmadi Ghats

M Charmadi Ghats

M Charmadi Ghats

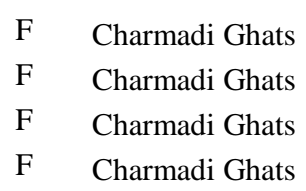

Micrixalus silvaticus GROUP

\begin{tabular}{|c|c|c|c|c|c|c|c|c|c|c|c|c|c|c|c|c|}
\hline BNHS 5770 (RS) & 20.5 & 6.4 & 6.7 & 0.9 & 4.4 & 1.9 & 1.5 & 5.4 & 1.6 & 1.6 & 2.8 & 4.3 & 4.8 & 12.6 & 12.5 & 10.3 \\
\hline BNHS 5769 (RS) & 20.8 & 6.2 & 7.4 & 1.1 & 3.2 & 1.9 & 1.7 & 6.4 & 1.6 & 1.4 & 2.6 & 4.0 & 5.5 & 12.6 & 12.5 & 10.1 \\
\hline BNHS 5771 (RS) & 20.0 & 6.2 & 7.8 & 0.9 & 3.3 & 1.9 & 1.5 & 5.9 & 1.5 & 1.4 & 2.3 & 4.4 & 5.2 & 12.5 & 12.5 & 10.5 \\
\hline BNHS 5773 (RS) & 20.1 & 6.1 & 7.5 & 0.8 & 3.2 & 1.9 & 1.5 & 7.1 & 1.5 & 1.2 & 2.1 & 4.1 & 5.4 & 11.5 & 11.5 & 10.0 \\
\hline BNHS 5774 (RS) & 20.0 & 6.0 & 7.5 & 0.9 & 2.9 & 1.8 & 1.3 & 6.0 & 1.2 & 1.2 & 2.4 & 3.8 & 4.8 & 11.7 & 11.6 & 9.7 \\
\hline BNHS 5775 (RS) & 20.6 & 6.7 & 7.8 & 1.0 & 3.2 & 2.7 & 1.4 & 7.9 & 1.4 & 1.4 & 2.4 & 4.1 & 5.7 & 12.2 & 12.1 & 10.3 \\
\hline BNHS 5777 (RS) & 21.6 & 6.5 & 7.2 & 1.0 & 3.6 & 2.2 & 1.6 & 5.5 & 1.3 & 1.5 & 2.2 & 4.0 & 5.2 & 12.5 & 12.4 & 9.9 \\
\hline Average & 20.6 & 6.2 & 7.4 & 0.9 & 3.4 & 2.0 & 1.5 & 6.2 & 1.5 & 1.4 & 2.4 & 4.1 & 5.2 & 12.2 & 12.2 & 10.1 \\
\hline Standard deviation & 0.6 & 0.2 & 0.4 & 0.1 & 0.4 & 0.3 & 0.1 & 0.9 & 0.1 & 0.2 & 0.2 & 0.2 & 0.3 & 0.4 & 0.4 & 0.3 \\
\hline BMNH 72.4.17.203 & & & & & & & & & & & & & & & & \\
\hline (LT) & 28.8 & 7.6 & 9.7 & 1.4 & 4.1 & 2.5 & 1.9 & 7.1 & 1.8 & 2.1 & 3.5 & 5.2 & 6.2 & 14.7 & 14.8 & 13.3 \\
\hline SDB 2002.3023 (RS) & 26.1 & 7.5 & 9.6 & 1.2 & 4.1 & 2.2 & 1.6 & 7.6 & 1.6 & 2.0 & 3.0 & 5.6 & 6.4 & 15.1 & 15.1 & 12.7 \\
\hline SDB 2002.3015 (RS) & 26.6 & 7.4 & 8.6 & 1.2 & 4.2 & 2.4 & 1.9 & 7.3 & 2.1 & 1.8 & 2.4 & 4.9 & 6.9 & 14.3 & 14.2 & 12.4 \\
\hline SDB $2012.2331(\mathrm{RS})$ & 28.3 & 7.5 & 9.7 & 1.1 & 4.1 & 2.3 & 1.1 & 7.5 & 2.2 & 1.8 & 3.2 & 4.9 & 6.5 & 14.8 & 14.9 & 13.1 \\
\hline SDB 2011.857 (RS) & 25.8 & 7.2 & 8.3 & 1.1 & 4.0 & 2.3 & 1.6 & 7.0 & 1.9 & 1.8 & 2.6 & 5.1 & 6.3 & 15.0 & 15.1 & 12.1 \\
\hline SDB $2011.1383(\mathrm{RS})$ & 25.2 & 6.7 & 8.8 & 1.2 & 3.9 & 2.0 & 2.0 & 6.7 & 1.6 & 1.4 & 3.0 & 4.8 & 6.2 & 14.2 & 14.3 & 12.4 \\
\hline SDB $2012.2238(\mathrm{RS})$ & 26.0 & 7.5 & 8.5 & 1.3 & 4.2 & 2.3 & 1.6 & 6.6 & 1.8 & 1.7 & 2.2 & 4.7 & 6.9 & 14.7 & 14.8 & 12.9 \\
\hline Average & 26.7 & 7.3 & 9.0 & 1.2 & 4.1 & 2.3 & 1.7 & 7.1 & 1.9 & 1.8 & 2.8 & 5.0 & 6.5 & 14.7 & 14.7 & 12.7 \\
\hline Standard deviation & 1.3 & 0.3 & 0.6 & 0.1 & 0.1 & 0.2 & 0.3 & 0.4 & 0.2 & 0.2 & 0.5 & 0.3 & 0.3 & 0.3 & 0.4 & 0.4 \\
\hline BNHS $5778(\mathrm{HT})$ & 22.8 & 6.8 & 8.6 & 0.9 & 3.6 & 2.0 & 1.6 & 6.7 & 1.7 & 1.6 & 2.7 & 4.7 & 5.0 & 11.9 & 13.0 & 11.4 \\
\hline BNHS 5779 (PT) & 23.1 & 6.4 & 8.6 & 0.7 & 3.8 & 2.1 & 1.4 & 6.6 & 1.8 & 1.8 & 2.7 & 4.2 & 5.4 & 12.1 & 13.2 & 11.1 \\
\hline BNHS $5780(\mathrm{PT})$ & 23.2 & 7.0 & 8.9 & 1.0 & 3.8 & 2.2 & 1.4 & 5.9 & 1.7 & 1.7 & 2.5 & 4.7 & 5.5 & 12.0 & 13.2 & 10.9 \\
\hline BNHS 5781 (PT) & 19.8 & 6.1 & 7.6 & 0.8 & 3.3 & 1.6 & 1.5 & 5.8 & 1.3 & 1.4 & 2.4 & 4.5 & 4.7 & 9.0 & 12.1 & 9.2 \\
\hline Average & 22.2 & 6.6 & 8.4 & 0.9 & 3.6 & 2.0 & 1.5 & 6.3 & 1.6 & 1.6 & 2.6 & 4.5 & 5.2 & 11.3 & 12.9 & 10.7 \\
\hline Standard deviation & 1.6 & 0.4 & 0.6 & 0.1 & 0.2 & 0.3 & 0.1 & 0.5 & 0.2 & 0.2 & 0.2 & 0.2 & 0.4 & 1.5 & 0.5 & 1.0 \\
\hline BNHS $5782(\mathrm{PT})$ & 27.6 & 7.6 & 9.0 & 1.0 & 4.0 & 2.1 & 1.8 & 6.9 & 1.7 & 1.7 & 2.7 & 5.4 & 6.1 & 15.0 & 15.9 & 13.4 \\
\hline BNHS 5783 (PT) & 25.8 & 8.0 & 8.3 & 1.3 & 3.7 & 3.4 & 1.8 & 6.8 & 1.9 & 1.8 & 2.3 & 5.3 & 5.7 & 14.2 & 14.9 & 12.0 \\
\hline BNHS 5784 (PT) & 29.2 & 7.8 & 9.5 & 1.1 & 4.2 & 2.3 & 1.9 & 7.7 & 1.9 & 1.9 & 2.8 & 5.1 & 6.0 & 14.3 & 15.6 & 13.0 \\
\hline BNHS 5785 (PT) & 24.6 & 8.3 & 8.6 & 1.0 & 3.4 & 2.0 & 1.4 & 7.7 & 1.7 & 1.4 & 2.7 & 5.2 & 6.6 & 15.3 & 16.2 & 13.7 \\
\hline Average & 26.8 & 7.9 & 8.9 & 1.1 & 3.8 & 2.5 & 1.7 & 7.3 & 1.8 & 1.7 & 2.6 & 5.3 & 6.1 & 14.7 & 15.7 & 13.0 \\
\hline Standard deviation & 2.0 & 0.3 & 0.5 & 0.1 & 0.4 & 0.6 & 0.2 & 0.5 & 0.1 & 0.2 & 0.2 & 0.1 & 0.4 & 0.5 & 0.6 & 0.7 \\
\hline
\end{tabular}


Micrixalus frigidus sp. nov.

$\begin{array}{ll}\text { M } & \text { Eravikulam NP } \\ \text { M } & \text { Grass hills } \\ & \\ & \\ \text { F } & \text { Eravikulam NP } \\ \text { F } & \text { Eravikulam NP } \\ \text { F } & \text { Grass hills } \\ \text { F } & \text { Grass hills } \\ \text { F } & \text { Grass hills }\end{array}$

Micrixalus nigraventris sp. nov.

$$
\begin{array}{ll}
\text { M } & \text { Kodaikanal } \\
\text { M } & \text { Kodaikanal } \\
& \\
\text { F } & \text { Kodaikanal } \\
\text { F } & \text { Eravikulam NP } \\
\text { F } & \text { Eravikulam NP }
\end{array}
$$

\begin{tabular}{|c|c|c|c|c|c|c|c|c|c|c|c|c|c|c|c|c|c|}
\hline BNHS $5786(\mathrm{HT})$ & 24.0 & 7.7 & 8.8 & 1.1 & 3.6 & 2.7 & 1.5 & 7.0 & 1.9 & 1.6 & 2.6 & 4.4 & 7.0 & 12.3 & 12.8 & 11.9 & $\bar{N}$ \\
\hline BNHS 5789 (PT) & 25.9 & 8.2 & 10.5 & 1.2 & 4.3 & 3.2 & 2.0 & 8.1 & 2.1 & 2.1 & 2.7 & 5.0 & 7.6 & 12.9 & 13.0 & 11.5 & \\
\hline Average & 25.0 & 8.0 & 9.7 & 1.2 & 4.0 & 3.0 & 1.8 & 7.6 & 2.0 & 1.9 & 2.7 & 4.7 & 7.3 & 12.6 & 12.9 & 11.7 & \\
\hline Standard deviation & 1.3 & 0.4 & 1.2 & 0.1 & 0.5 & 0.4 & 0.4 & 0.8 & 0.1 & 0.4 & 0.1 & 0.4 & 0.4 & 0.4 & 0.1 & 0.3 & \\
\hline BNHS 5787 (PT) & 31.1 & 9.3 & 11.3 & 1.4 & 4.7 & 2.9 & 2.2 & 9.4 & 2.2 & 1.8 & 3.2 & 5.4 & 7.8 & 14.7 & 14.7 & 13.3 & \\
\hline BNHS $5788(\mathrm{PT})$ & 29.6 & 8.3 & 10.3 & 1.1 & 4.3 & 3.1 & 2.1 & 7.8 & 1.9 & 1.9 & 2.8 & 5.5 & 7.9 & 13.8 & 13.7 & 11.8 & \\
\hline BNHS $5790(\mathrm{PT})$ & 31.8 & 8.8 & 11.1 & 1.3 & 4.6 & 3.5 & 1.9 & 9.1 & 2.0 & 1.9 & 3.2 & 5.8 & 8.8 & 14.8 & 14.9 & 13.3 & \\
\hline BNHS $5791(\mathrm{PT})$ & 30.1 & 8.7 & 10.8 & 1.1 & 4.7 & 3.4 & 2.1 & 8.4 & 2.0 & 2.0 & 2.9 & 5.6 & 8.4 & 14.5 & 14.5 & 13.2 & \\
\hline BNHS $5792(\mathrm{PT})$ & 32.7 & 9.3 & 11.4 & 1.5 & 4.8 & 3.7 & 1.7 & 9.4 & 2.4 & 2.2 & 3.1 & 5.7 & 8.9 & 14.9 & 15.0 & 13.9 & \\
\hline Average & 31.0 & 8.9 & 11.0 & 1.3 & 4.6 & 3.3 & 2.0 & 8.8 & 2.1 & 2.0 & 3.0 & 5.6 & 8.4 & 14.5 & 14.6 & 13.1 & \\
\hline Standard deviation & 1.3 & 0.4 & 0.4 & 0.2 & 0.2 & 0.3 & 0.2 & 0.7 & 0.2 & 0.2 & 0.2 & 0.2 & 0.5 & 0.4 & 0.5 & 0.8 & \\
\hline BNHS $5793(\mathrm{HT})$ & 20.7 & 6.8 & 6.4 & 0.7 & 3.3 & 2.6 & 1.6 & 4.7 & 1.4 & 1.6 & 2.3 & 4.3 & 5.3 & 10.1 & 10.1 & 9.5 & \\
\hline BNHS 5794 (PT) & 20.9 & 7.1 & 6.7 & 0.7 & 3.5 & 2.6 & 1.7 & 5.4 & 1.5 & 1.5 & 2.4 & 4.6 & 5.1 & 10.1 & 10.1 & 9.4 & \\
\hline Average & 20.8 & 7.0 & 6.6 & 0.7 & 3.4 & 2.6 & 1.7 & 5.1 & 1.5 & 1.6 & 2.4 & 4.5 & 5.2 & 10.1 & 10.1 & 9.5 & \\
\hline Standard deviation & 20.8 & 7.0 & 6.6 & 0.7 & 3.4 & 2.6 & 1.7 & 5.1 & 1.5 & 1.6 & 2.4 & 4.5 & 5.2 & 10.1 & 10.1 & 9.5 & \\
\hline BNHS 5795 (PT) & 23.3 & 8.3 & 9.1 & 1.2 & 3.7 & 3.0 & 1.9 & 7.3 & 1.8 & 1.3 & 2.6 & 5.5 & 6.3 & 12.0 & 12.0 & 10.8 & $\frac{1}{7}$ \\
\hline BNHS 5796 (PT) & 23.0 & 7.4 & 9.3 & 7.4 & 4.3 & 2.4 & 1.6 & 7.3 & 2.0 & 1.6 & 1.8 & 4.7 & 6.7 & 12.1 & 12.6 & 12.1 & 2 \\
\hline BNHS 5797 (PT) & 26.6 & 8.7 & 9.5 & 1.2 & 3.9 & 3.0 & 1.8 & 7.5 & 1.9 & 1.6 & 2.6 & 5.3 & 7.4 & 12.3 & 12.2 & 12.2 & \\
\hline Average & 24.3 & 8.1 & 9.3 & 3.3 & 4.0 & 2.8 & 1.8 & 7.4 & 1.9 & 1.5 & 2.3 & 5.2 & 6.8 & 12.1 & 12.3 & 11.7 & \\
\hline Standard deviation & 2.0 & 0.7 & 0.2 & 3.6 & 0.3 & 0.3 & 0.2 & 0.1 & 0.1 & 0.2 & 0.5 & 0.4 & 0.6 & 0.2 & 0.3 & 0.8 & \\
\hline
\end{tabular}

Micrixalus phyllophilus

$$
\begin{array}{ll}
\text { M } & \text { "Nilgherries" } \\
\text { M } & \text { Avalache } \\
\text { M } & \text { Longwood shola } \\
\text { M } & \text { Longwood shola } \\
\text { M } & \text { Longwood shola } \\
\text { M } & \text { Longwood shola } \\
\text { M } & \text { Naduvattam }
\end{array}
$$

NHM 1947.2.29.87

(NT)

BNHS 5798 (RS)

BNHS 5801 (RS)

BNHS 5802 (RS)

BNHS 5803 (RS)

BNHS 5804 (RS)

BNHS 5806 (RS)

$$
\begin{aligned}
& 22.5 \\
& 24.8 \\
& 25.8 \\
& 24.8 \\
& 25.9 \\
& 25.3 \\
& 24 .
\end{aligned}
$$

Average

$\begin{array}{llllll}225 & 7.4 & 83 & 1.0 & 3.4 & 2.2\end{array}$

$\begin{array}{llllll}24.8 & 8.1 & 9.3 & 1.2 & 3.9 & 2.9\end{array}$

25.8

25.8

25.9

25.3

24.2

Standard deviation $\begin{array}{llllll}8.1 & 9.3 & 1.2 & 3.9 & 2.9 & 1.7\end{array}$

$\begin{array}{llllll}8.4 & 9.9 & 1.3 & 4.0 & 2.8 & 1.7\end{array}$

$\begin{array}{llllll}8.0 & 9.2 & 1.0 & 3.9 & 2.5 & 1.7\end{array}$

$\begin{array}{llllll}8.3 & 9.7 & 1.0 & 3.9 & 2.9 & 1.7\end{array}$

$\begin{array}{llllll}8.3 & 9.1 & 1.1 & 3.6 & 2.8 & 1.7\end{array}$

$\begin{array}{lllll}8.2 & 9.5 & 1.1 & 3.5 & 2.6\end{array}$

$\begin{array}{llll}9.5 & 1.1 & 3.5 & 2.6 \\ \mathbf{9 . 3} & \mathbf{1 . 1} & \mathbf{3 . 7} & \mathbf{2 . 7}\end{array}$

$\begin{array}{llll}0.5 & 0.1 & 0.2 & 0.3\end{array}$

$\begin{array}{cccccccccc}1.8 & 7.4 & 1.0 & 1.8 & 2.8 & 4.4 & 5.1 & 11.0 & 11.3 & 9.6 \\ 1.7 & 7.2 & 1.4 & 1.8 & 2.6 & 5.2 & 6.5 & 12.2 & 12.9 & 12.0 \\ 1.7 & 8.0 & 1.6 & 1.8 & 2.8 & 5.0 & 7.0 & 12.9 & 13.3 & 11.8 \\ 1.7 & 6.9 & 1.9 & 1.6 & 2.5 & 5.0 & 6.6 & 12.6 & 12.9 & 11.9 \\ 1.7 & 8.1 & 1.9 & 1.8 & 2.7 & 5.3 & 6.9 & 12.8 & 12.9 & 12.1 \\ 1.7 & 7.6 & 1.2 & 1.9 & 2.8 & 5.2 & 7.1 & 12.9 & 12.8 & 12.4 \\ 1.7 & 7.6 & 1.3 & 1.7 & 2.4 & 4.9 & 6.6 & 12.9 & 12.8 & 11.6 \\ \mathbf{1 . 7} & \mathbf{7 . 5} & \mathbf{1 . 5} & \mathbf{1 . 8} & \mathbf{2 . 7} & \mathbf{5 . 0} & \mathbf{6 . 5} & \mathbf{1 2 . 5} & \mathbf{1 2 . 7} & \mathbf{1 1 . 6} \\ \mathbf{0 . 0} & \mathbf{0 . 4} & \mathbf{0 . 3} & \mathbf{0 . 1} & \mathbf{0 . 2} & \mathbf{0 . 3} & \mathbf{0 . 7} & \mathbf{0 . 7} & \mathbf{0 . 6} & \mathbf{0 . 9}\end{array}$




\begin{tabular}{|c|c|c|c|c|c|c|c|c|c|c|c|c|c|c|c|c|c|c|}
\hline $\mathrm{F}$ & Avalanche & BNHS 5799 (RS) & 32.5 & 9.8 & 10.9 & 1.2 & 4.8 & 3.3 & 2.4 & 8.8 & 2.1 & 2.5 & 3.0 & 5.5 & 8.2 & 14.7 & 15.3 & 15.0 \\
\hline $\mathrm{F}$ & Longwood shola & BNHS 5800 (RS) & 30.0 & 9.8 & 10.9 & 1.0 & 4.2 & 3.0 & 1.7 & 8.0 & 1.9 & 2.3 & 2.9 & 6.6 & 7.8 & 14.8 & 15.3 & 14.4 \\
\hline $\mathrm{F}$ & Longwood shola & BNHS 5805 (RS) & 28.9 & 9.5 & 11.3 & 9.0 & 4.1 & 2.9 & 1.8 & 8.1 & 1.5 & 2.3 & 3.1 & 6.0 & 7.8 & 14.5 & 14.5 & 13.2 \\
\hline & & Average & 30.5 & 9.7 & 11.0 & 3.7 & 4.4 & 3.1 & 2.0 & 8.3 & 1.8 & 2.4 & 3.0 & 6.0 & 7.9 & 14.7 & 15.0 & 14.2 \\
\hline & & Standard deviation & 1.8 & 0.2 & 0.2 & 4.6 & 0.4 & 0.2 & 0.4 & 0.4 & 0.3 & 0.1 & 0.1 & 0.6 & 0.2 & 0.2 & 0.5 & 0.9 \\
\hline \multicolumn{19}{|c|}{ Micrixalus silvaticus } \\
\hline M & "Malabar" & NHM 82.2.10.59 (PL) & 18.5 & 6.0 & 7.0 & 0.7 & 3.3 & 2.1 & 1.2 & 5.5 & 1.4 & 1.1 & 2.5 & 3.5 & 4.4 & 9.7 & 9.5 & 8.1 \\
\hline M & "Malabar" & NHM 82.2.10.58 (PL) & 19.8 & 6.2 & 7.2 & 0.8 & 4.0 & 2.2 & 1.4 & 5.7 & 1.4 & 1.4 & 2.3 & 3.6 & 5.0 & 10.1 & 10.3 & 8.4 \\
\hline M & Kadalar & BNHS 5807 (RS) & 19.8 & 6.1 & 7.1 & 0.7 & 4.1 & 2.3 & 1.4 & 5.6 & 1.3 & 1.4 & 2.5 & 3.8 & 5.2 & 10.2 & 10.2 & 8.5 \\
\hline & & Average & 19.4 & 6.1 & 7.1 & 0.7 & 3.8 & 2.2 & 1.3 & 5.6 & 1.4 & 1.3 & 2.4 & 3.6 & 4.9 & 10.0 & 10.0 & 8.3 \\
\hline & & Standard deviation & 0.8 & 0.1 & 0.1 & 0.1 & 0.4 & 0.1 & 0.1 & 0.1 & 0.1 & 0.2 & 0.1 & 0.2 & 0.4 & 0.3 & 0.4 & 0.2 \\
\hline $\mathrm{F}$ & "Malabar" & NHM 82.2.10.52 (LT) & 26.0 & 9.0 & 9.6 & 1.4 & 4.1 & 2.8 & 1.9 & 7.3 & 1.3 & 1.9 & 3.2 & 5.1 & 5.9 & 11.5 & 11.5 & 10.6 \\
\hline $\mathrm{F}$ & "Malabar" & NHM 82.2.10.53 (PL) & 25.6 & 8.2 & 9.2 & 1.3 & 4.0 & 2.5 & 1.6 & 7.1 & 1.3 & 1.7 & 3.1 & 4.7 & 5.8 & 11.4 & 11.5 & 10.6 \\
\hline $\mathrm{F}$ & "Malabar" & NHM 82.2.10.55 (PL) & 25.4 & 7.9 & 9.1 & 1.2 & 4.0 & 2.5 & 1.7 & 7.1 & 1.3 & 1.6 & 3.1 & 5.0 & 5.9 & 11.2 & 11.3 & 10.5 \\
\hline & & Average & 25.7 & 8.4 & 9.3 & 1.3 & 4.0 & 2.6 & 1.7 & 7.2 & 1.3 & 1.7 & 3.1 & 4.9 & 5.9 & 11.4 & 11.4 & 10.6 \\
\hline & & Standard deviation & 0.3 & 0.6 & 0.3 & 0.1 & 0.1 & 0.2 & 0.2 & 0.1 & $\mathbf{0 . 0}$ & 0.2 & 0.1 & 0.2 & 0.1 & 0.2 & 0.1 & 0.1 \\
\hline
\end{tabular}

